Henrique Batalha Filho

Padrões e processos de diversificação em aves da Amazônia e da Mata Atlântica

Patterns and processes of diversification in birds from the Amazon and the Atlantic Forest

São Paulo 
Henrique Batalha Filho

Padrões e processos de diversificação em aves da Amazônia e da Mata Atlântica

Patterns and processes of diversification in birds from the Amazon and the Atlantic Forest

Tese apresentada ao Instituto de Biociências da Universidade de São Paulo, para a obtenção de Título de Doutor em Ciências Biológicas, na Área de Biologia - Genética.

Orientadora: Cristina Yumi Miyaki

São Paulo 


\section{Ficha Catalográfica}

Batalha Filho, Henrique

Padrões e processos de

diversificação em aves da Amazônia e da

Mata Atlântica

166 páginas

Tese (Doutorado) - Instituto de Biociências da Universidade de São Paulo. Departamento de Genética e Biologia Evolutiva.

1. Filogeografia 2. Filogenia 3. Passeriformes 4. Região Neotropical I. Universidade de São Paulo. Instituto de Biociências. Departamento de Genética e Biologia Evolutiva.

\section{Comissão Julgadora:}

Prof.(a) Dr.(a)

Prof.(a) Dr.(a)

$$
\text { Prof.(a) Dr.(a) }
$$

Prof.(a) Dr.(a)

Prof.(a) Dr.(a) Cristina Yumi Miyaki

Orientadora 
"Nothing in biology makes sense except in the light of evolution" Theodosius Dobzhansky, 1973 


\section{Agradecimentos}

À Cristina Miyaki pela oportunidade, dedicação, ensinamentos e orientação sempre a postos, e pela confiança depositada.

Ao Jon Fjeldså e ao Per Ericson pela oportunidade e ensinamentos durante o estágio no Zoological Museum University of Copenhagen e no Swedish Museum of Natural History, e aos pesquisadores e pós-docs destes museus Pierre-Henri Fabre, Knud Jønsson, Martin Irestedt e Jan Ohlson pela ajuda e ensinamentos.

Aos colegas do LGEMA Adriana Marques, Ana Carolina, Ana Cristina, André Freddi, Bruno Lima, Carolina Bianchi, Cibele Biondo, Claydson Assis, Danilo Rufo, Fábio Amaral, Flávia Presti, Gustavo Cabanne, Marcos Maldonado, Rafaella Monteiro, Ricardo Campos e Tiago Ribeiro pelo ótimo convívio, ajuda, comentários e inúmeros momentos de descontração.

Às pessoas que me ajudaram e me ensinaram muito sobre aves nas coletas de campo: Ana Cristina, Claydson Assis, Fábio Amaral, Luciano Lima, Marcos Maldonado e Tiago Ribeiro.

Às coleções e curadores que cederam amostras utilizadas nesta tese: Fabrício Santos e Sibele Vilaça (UFMG); Alexandre Aleixo e Fabíola Poletto (MPEG); Luis Fábio Silveira (MZUSP); Mário Con-Haft, Camila Ribas e Ingrid Tôrres (INPA); Marcos Raposo e Claydson Assis (MNRJ); Claiton Ferreira (UFRGS); Carla Fontana (PUC-RS); Larissa Lacerda e Rômulo Ribon (MZUFV); Ulf Johansson (NRM); Jon Fjeldså e Niels Krabbe (ZMUC). E aos inúmeros coletores das amostras utilizadas nesta tese.

Ao Santiago Claramunt por sequenciar as amostras de Synallaxis do LSU.

Ao Gustavo Cabanne pela parceria na filogeografia de Basileuterus leucoblepharus.

À Renata Stopiglia pela ajuda e discussões sobre sistemática dos Synallaxis.

Ao John Bates pelos comentários sobre a tese.

Aos professores do Instituto de Biociências (IB) pelos ensinamentos durante as disciplinas.

Aos funcionários do IB pelo auxílio com as questões burocráticas da pós-graduação.

À FAPESP e CAPES pela concessão da bolsa de doutorado, e à FAPESP, CNPq e CAPES pelo financiamento deste estudo. Este trabalho foi desenvolvido no âmbito do Núcleo de Pesquisa em Biodiversidade e Computação da Universidade de São Paulo (BioComp), com apoio da Pró-Reitoria de Pesquisa da USP.

Ao IBAMA e ICMBio pelas licenças de coleta.

À minha esposa Edenise pelo amor e apoio incondicionais, e paciência para que eu pudesse concluir esta tese.

Aos meus pais Henrique e Leila e minha irmã Samira pelo carinho, incentivo e ensinamentos desde os tempos de criança.

Àqueles que eu tenha omitido nestes agradecimentos, mas contribuíram direta ou indiretamente para execução desta tese. 


\section{Índice}

pág.

Resumo - iv

Abstract - -

Introdução geral - 1

Capítulo 1. Phylogeography of an Atlantic forest passerine reveals demographic

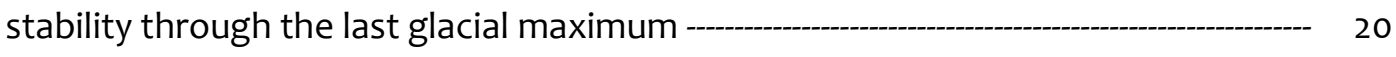

Capítulo 2. Vicariância pleistocênica e expansão depois do último máximo glacial em Myrmotherula gularis (Passeriformes: Thamnophilidae) na Mata Atlântica ------ 32

Capítulo 3. Molecular systematics and evolution of the Synallaxis ruficapilla complex (Aves: Furnariidae) in the Atlantic Forest --- 56

Capítulo 4. Filogeografia e história demográfica do complexo Synallaxis ruficapilla/S. whitneyi (Passeriformes, Furnariidae) revelam diversidade críptica e contato secundário na Mata Atlântica

Capítulo 5. Filogeografia multilocos de Thamnomanes caesius (Passeriformes, Thamnophilidae) revela diversificação Plio-Pleistocênica na Amazônia --.-_-_ 116

Capítulo 6. Connections between the Atlantic and the Amazonian forest

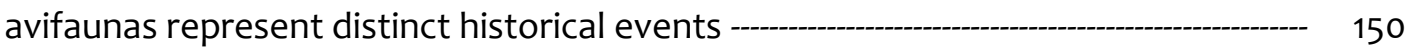

Discussão geral e conclusões - 


\section{Resumo}

Nesta Tese foram descritos padrões de diversificação de pássaros que ocorrem na Amazônia e na Mata Atlântica, os quais permitiram fazer inferências sobre os processos que podem ter influenciado a evolução das biotas residentes nestes biomas. Nós produzimos sequências de genes mitocondriais e nucleares para fazer inferências sobre a biogeografia histórica destes biomas. A Tese foi dividida em seis capítulos. Nos capítulos 1 a 4 os táxons Basileuterus leucoblepharus, Myrmotherula gularis e o complexo Synallaxis ruficapilla foram estudados para se entender a diversificação da Mata Atlântica. Estes estudos revelaram que os ciclos glaciais do fim do Pleistoceno tiveram importante papel na diversificação destes táxons. Ainda, atividades tectônicas ocorridas durante o Quaternário possivelmente contribuíram para a diversificação do complexo S. ruficapilla. No capítulo 5 o complexo Thamnomanes caesius/T. schistogynus foi analisado visando inferir a história evolutiva da Amazônia. Os resultados deste estudo mostraram que tanto a origem recente dos rios amazônicos (do Plioceno ao Pleistoceno) quanto os ciclos glaciais possivelmente foram responsáveis pela diversificação deste grupo. No capítulo 6 o grupo Suboscines foi estudado para compreender a dinâmica das conexões históricas entre as florestas Amazônica e Atlântica. Os resultados mostraram que os contatos históricos entre estes dois biomas correspondem a duas conexões espaçotemporais distintas: uma mais antiga durante o Mioceno através da porção sul da diagonal seca da América do sul, e uma mais recente durante o Plioceno e o Pleistoceno através da Caatinga e Cerrado no Nordeste do Brasil. Os dados desta Tese permitiram testar o papel de algumas hipóteses concorrentes na diversificação da Amazônia e da Mata Atlântica. A hipótese dos rios parece ter contribuído para a diversificação da Amazônia. A hipótese dos refúgios florestais possivelmente teve um papel crucial da diversificação da biota da Mata Atlântica. A hipótese dos refúgios também não pode ser rejeitada como um das forças que deu origem à biota da Amazônia que observamos atualmente. Eventos tectônicos e mudanças climáticas contribuíram para conexões históricas entre a Amazônia e Mata Atlântica. 


\section{Abstract}

This PhD Dissertation describes patterns of diversification of species of passerines that occur in the Amazon and the Atlantic Forest and that allowed making inferences on the processes that may have influenced the evolution of the organisms that live in these forests. We generated sequences of mitochondrial and nuclear genes to study the historical biogeography of these biomes. This work includes six chapters. In chapters 1 to 4 we analyzed Basileuterus leucoblepharus, Myrmotherula gularis, and the Synallaxis ruficapilla complex in order to depict the diversification within the Atlantic Forest. These studies revealed that late Pleistocene glacial cycles played an important role on the diversification of these taxa. Furthermore, tectonic activities in the Quaternary may have contributed for the diversification of the S. ruficapilla complex. In chapter 5 we analyzed the Thamnomanes caesius/T. schistogynus complex in order to infer about the diversification in the Amazon. The results of this study showed that both the recent origin of Amazonian rivers (Pliocene to Pleistocene) as glacial cycles could be responsible for the diversification of these organisms. In chapter 6 we analyzed the New World suboscines in order to depict the historical connection dynamics between the Amazon and the Atlantic Forest. Our results pointed to two distinct spatiotemporal pathways connecting these forests in the past: (1) older connections during the Miocene through southern South America dry diagonal; (2) younger connections during the Pliocene to Pleistocene through Cerrado and Caatinga in northeastern Brazil. The results of this PhD Dissertation allowed us to test the role of concurrent hypotheses of diversification in the Amazon and the Atlantic Forest. The riverine hypothesis seems to have contributed to the evolution of the Amazonian biota. The refuge hypothesis seems to be the main force of diversification of organisms from the Atlantic Forest. Moreover, we could not reject the refuge hypothesis as a force of diversification of organisms that occur in the Amazon forest. Tectonic events and climate changes played important roles in the historical connection between the Amazon and the Atlantic Forest. 
Introdução geral 


\section{Introdução geral}

\subsection{Biogeografia histórica: uma abordagem filogeográfica}

A biogeografia é uma ciência que procura entender como os organismos estão distribuídos geograficamente, tanto no passado como no presente, e quais padrões e processos ocorridos na Terra, tanto no passado quanto no presente, estão relacionados à biodiversidade que observamos atualmente (Brown \& Lomolino, 2006). Há algum tempo os biogeógrafos reconhecem duas escolas clássicas dentro da biogeografia: a biogeografia ecológica e a biogeografia histórica. A biogeografia ecológica tem como foco entender como os processos ecológicos que aconteceram há um relativo curto intervalo de tempo atuaram nos padrões de distribuição dos seres vivos; enquanto a biogeografia histórica concentra-se em entender como os processos que ocorreram no passado (ao longo de milhares a milhões de anos) influenciaram os padrões que observamos atualmente (Crisci et al., 2003). O objetivo central da biogeografia histórica vem sendo elaborar e desenvolver hipóteses sobre como a distribuição dos organismos se modificou sobre a Terra ao mesmo tempo em que a diversificação evolutiva das linhagens ocorria (Brown \& Lomolino, 2006).

O advento das análises por meio do acesso ao DNA na década de 1970 proporcionou uma revolução no modo pelo qual os biogeógrafos poderiam olhar para trás no tempo. Em 1987 John Avise e seus colaboradores cunharam o termo filogeografia, que pode classificada como uma subárea da biogeografia (Crisci et al., 2003). A filogeografia tem como objetivo central entender os princípios e processos que governam a distribuição geográfica das linhagens intra-específicas ou de espécies relacionadas, baseada na distribuição espacial de genealogias gênicas (Avise, 2000). Os estudos filogeográficos procuram interpretar a extensão e o modo pelo qual os processos históricos na demografia da população levaram às mudanças evolutivas na distribuição geográfica contemporânea das genealogias gênicas das espécies (Avise et al., 1987; Avise, 2000). O marcador molecular inicialmente escolhido para os estudos filogeográficos de animais foi o DNA mitocondrial, pois possui algumas características que o tornam bastante adequado para esse tipo de estudo, tais como: ser herdado maternalmente, ser haplóide, não apresentar 
recombinação significante, evoluir rapidamente e ser de fácil extração (Avise et al., 1987). Nas plantas a molécula geralmente utilizada em estudos filogeográficos é o DNA plastidial (Avise, 2008).

A filogeografia também tem sua essência na genética de populações, principalmente no campo da teoria da coalescência. A formulação desta teoria foi proposta por John Kingman na década de 80. Kingman propôs um teorema que permite estimar a probabilidade de que alelos presentes em uma genealogia coalesçam ao longo das gerações do presente para o passado (Felsenstein, 2004). Deste modo a coalescência pode ser definida como o processo pelo qual uma amostra de alelos atuais encontra um ancestral comum no passado. Felsenstein (2004) brilhantemente descreveu uma analogia para a teoria coalescente. Nesta analogia ele descreve o processo como uma caixa (população) contendo $k$ besouros (alelos amostrados), e estes besouros seriam hiperativos, indiscriminados, vorazes e insaciáveis. Então estes besouros estariam caminhando nesta caixa de maneira aleatória, e ocasionalmente dois destes besouros podem se colidir, e quando isto acontece um deles come o outro (evento coalescente). Assim, como os besouros são insaciáveis, eles continuam a caminhar aleatoriamente até colidirem com o próximo besouro e então comê-lo ou ser comido. Com isso o número de besouros tende a cair gradualmente de $k$ para $k-1, k-2$, e assim sucessivamente conforme os besouros vão se encontrando, até que então reste somente um único besouro na caixa (coalescência até o ancestral comum). Desta forma é possível formular que o número de pares de besouros que podem se colidir é $k(k-1) / 2$.

A teoria da coalescência têm permitido aos filogeógrafos inúmeras possibilidades de inferência sobre os processos históricos, uma vez que sua formulação é baseada voltando no tempo. Diversos incrementos metodológicos associados a esta teoria vêm sendo desenvolvidos nos últimos anos (Hickerson et al. 2010), e abordagens Bayesianas da coalescência têm possibilitado realizar estimativas robustas de tamanho efetivo populacional e de sua variação ao longo do tempo, de taxas de crescimento populacional, de fluxo gênico, de tempo até o ancestral comum mais recente, e de tempo de divergência (Kuhner, 2009). 
Entretanto, o processo coalescente é estocástico e em diversificações recentes cada genealogia gênica pode gerar uma árvore distinta, fazendo com que a árvore de genes não reflita a árvore de espécies ou populações, ou seja, a análise de um único loco pode não refletir a história do organismo, mas somente do loco analisado (Edwards \& Beerli, 2000). Com o intuito de diminuir o ruído desta estocasticidade, nos últimos anos vem se desenvolvendo a filogeografia multilocos (revisado por Brito \& Edwards, 2009). Essa abordagem utiliza vários marcadores dispersos ao longo do genoma nuclear e baseia-se em abordagens coalescentes complexas (Khuner, 2009). Embora diferentes locos possam recuperar diferentes genealogias, eles devem compartilhar uma história demográfica em comum, e desta maneira as análises multilocos podem proporcionar uma maneira mais robusta de se reconstruir a história demográfica das populações. Entretanto, também existem alguns problemas associados ao DNA nuclear que podem atrapalhar as estimativas, tais como altas taxas de recombinação intragênica, existência de genes parálogos, baixa taxa de mutação em comparação com o DNA mitocondrial, dificuldade na obtenção da fase gamética e sorteamento incompleto de linhagens (incomplete lineage sorting) por retenção de polimorfismo ancestral (Avise, 2008; Brito \& Edwards, 2009). Contudo, apesar destes problemas, a filogeografia multilocos parece ser bastante robusta na reconstrução da história evolutiva das espécies, uma vez que permite recuperar grande riqueza de informações históricas, demográficas e é particularmente informativa quando considerada no âmbito dos modelos genealógicos, e recentemente vem surgindo inúmeros algoritmos que visam acomodar estes problemas associados às estimativas multilocos (Brito \& Edwards, 2009).

Nos últimos anos abordagens que também vêm crescendo são as inferências filogeográficas baseadas em modelos estatísticos (Knowles \& Maddison, 2002; Hickerson et al., 2010) e Aproximate Bayesian Computation (ABC; Beaumont et al., 2002), que são simulações coalescentes que visam testar cenários demográficos históricos (hipóteses) que teriam acontecido com o táxon estudado. Nesta abordagem vários cenários demográficos são testados com o intuito de aceitar as hipóteses que apresentem maiores probabilidades em relação a outros cenários. 
Desta maneira, as probabilidades de todos os cenários simulados são avaliadas com base em estatísticas sumárias com o objetivo de se detectar qual o cenário que mais se aproxima dos dados estimados (Knowles, 2001).

\subsection{Amazônia e Mata Atlântica: extensão e biodiversidade}

As florestas da Amazônia ( $A M)$ e da Mata Atlântica (MA) estão entre os ecossistemas com os maiores índices de biodiversidade do mundo (Galindo-Leal \& Câmara, 2005; Hubbell et al., 2008), e estão separadas pela diagonal seca da América do Sul, que é formada pelos biomas Chaco, Cerrado e Caatinga (Fig. 1; Ab'Saber, 1977).

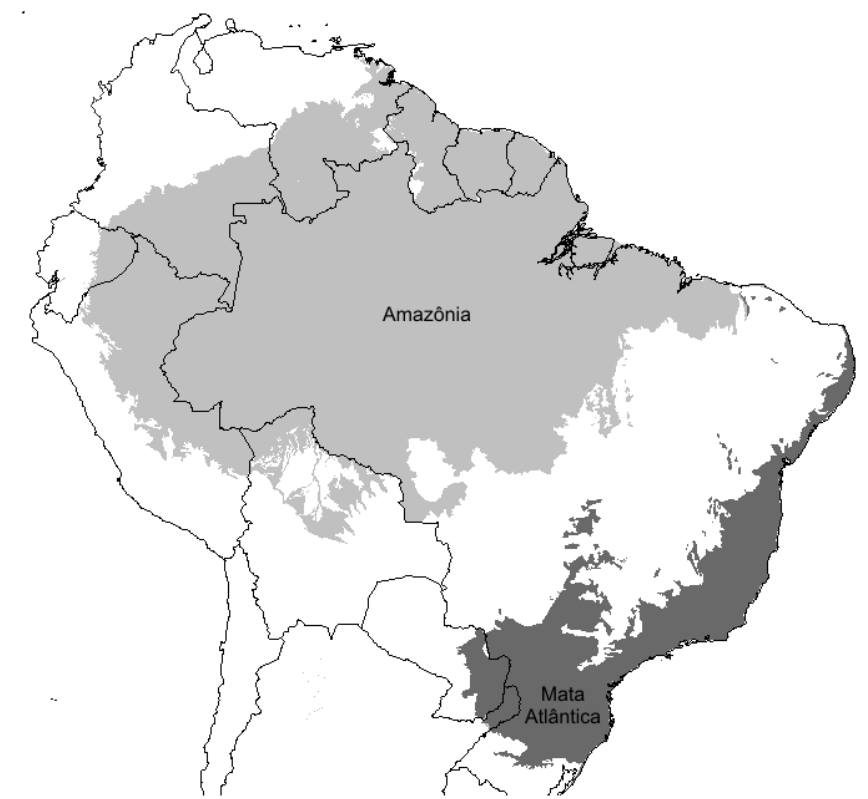

Figura 1. Distribuição geográfica da Amazônia (cinza claro) e da Mata Atlântica (cinza escuro).

A AM é conhecida mundialmente por sua grande biodiversidade, tanto aquática e terrestre, e contém cerca de 40\% dos remanescentes florestais do planeta (Hubbell et al., 2008). Números exatos para quantificar sua biodiversidade ainda não existem, e as estimativas sobre quantas espécies existem no bioma ainda estão aumentando. Contudo suspeita-se que a AM abrigue nada menos do que 7500 espécies de lepidópteros (possivelmente cerca de 40\% das espécies de borboletas do mundo), 1500 espécies de aves (cerca de um terço das aves do planeta) e cerca de 11200 espécies de árvores (Hubbell et al., 2008; Hoorn \& Wesselingh, 2010). A drenagem da bacia Amazônia cobre mais de 8 milhões de $\mathrm{km}^{2}$ e tem a maior floresta 
tropical da Terra. O Rio Amazonas possui uma extensão de $6400 \mathrm{~km}$ e estende-se desde a sua origem na Cordilheira dos Andes até a sua foz no Oceano Atlântico, sendo considerado o maior rio do mundo em extensão. A bacia Amazônia inclui uma variedade de paisagens, como os enigmáticos Tepuis ao norte, as florestas de encosta no sopé dos Andes a oeste, e as florestas de várzea e terra firme na parte central da bacia (Hoorn \& Wesselingh, 2010).

Por sua vez, a MA é um dos 25 hotspots de biodiversidade reconhecidos no mundo por abrigar altos índices de biodiversidade e estar entre os biomas mais degradados do mundo (Myers et al., 2000). Estimativas recentes mostram que a MA está reduzida em 11,4\% a 16\% de sua extensão original (Ribeiro et al., 2009). A biota da MA é extremamente rica e provavelmente abriga entre 1 a $8 \%$ de toda biodiversidade do planeta (Silva \& Casteleti, 2003). Esse alto índice de diversidade possivelmente está associado à heterogeneidade de habitats presentes na MA. Essa diversidade pode ser explicada pelas variações latitudinais, longitudinais e de altitude presentes no bioma: sendo que sua latitude se estende entre $1^{\circ}$ ao $30^{\circ}$ grau no continente sul americano, sua longitude vai de $35^{\circ}$ a $60^{\circ}$ graus, e a altitude varia desde o nível do mar até 2700 metros (Silva \& Casteleti, 2003). A combinação destes fatores proporciona uma grande possibilidade para existência de vários macro e micro-habitats ao longo do bioma.

\subsection{Hipóteses sobre a diversificação da biota Neotropical}

Uma das questões que surge sobre a biogeografia histórica da região neotropical é como e quando surgiu tamanha biodiversidade (Antonelli \& Sanmartín, 2011), em especial na AM e MA? À primeira vista essa grande diversidade parece estar relacionada com a heterogeneidade de habitats destas florestas, entretanto determinar quais fatores históricos atuaram nessa diversificação e a quantidade destes padrões históricos não é uma tarefa trivial.

Para alguns autores, boa parte da diversificação na região neotropical teria ocorrido em um período bastante recente, o Quaternário, com destaque para o Pleistoceno (Whitmore \& Prance, 1987). Isso porque durante o Pleistoceno o planeta passou por muitos ciclos glaciais e interglaciais, durante os quais as geleiras 
continentais avançaram e recuaram (Sant'Anna Neto \& Nery, 2005), o que teria provocado fragmentação nas distribuições geográficas de uma série de organismos. Nos trópicos pode não ter acontecido um avanço destas geleiras, mas uma diminuição da umidade e da temperatura que, consequentemente, pode ter causado a fragmentação das florestas. A hipótese mais discutida sobre a diversificação nos neotrópicos durante o Quaternário é a teoria dos refúgios florestais (Haffer, 1969; Vanzolini \& Williams, 1970; Brown \& Ab’Sáber, 1979). Segundo a teoria, os refúgios são ilhas de florestas densas úmidas isoladas por vegetação aberta. Essas florestas úmidas se retrairiam durante os períodos de máximo glacial (formando os refúgios) e se expandiriam durante os períodos mais quentes (ciclos interglaciais), enquanto as áreas de vegetação aberta se comportavam de maneira contrária. Assim, espécies dependentes de ambientes florestais devem ter acompanhado esses ciclos de retração e expansão das florestas durante o Pleistoceno, fazendo com que populações associadas a diferentes refúgios se diversificassem de maneira alopátrica caso o tempo de isolamento tenha sido suficiente para acumular diferenças entre elas.

Entretanto, devido às criticas à hipótese dos refúgios florestais (Colinvaux et al., 2000; Bush \& Oliveira, 2006), o possível envolvimento de rios, de gradientes ecológicos e de eventos tectônicos surge (ou ressurge) como hipóteses alternativas para explicar a origem da diversificação dos organismos neotropicais:

i) a hipótese de rios como barreira ao fluxo gênico para animais terrestres, que inicialmente foi proposta pelo naturalista Alfred Russell Wallace (1852), advoga que o surgimento de um rio foi a barreira primária para os eventos vicariantes que levaram a especiação (Patton et al., 1994; Patton et al., 2000);

ii) a hipótese de gradientes ecológicos (Smith et al., 1997; Smith et al., 2001), que sugere que a diversificação pode ocorrer em parapatria, ou seja, a diferenciação entre espécies ou linhagens pode ocorrer devido a diferentes pressões seletivas atuantes em ambientes diferentes e adjacentes;

iii) a hipótese de diversificação por tectonismo (Cracraft, 1985; Silva \& Straube, 1996), que prediz que o evento de especiação ocorreu como consequência de uma atividade tectônica que levou a vicariância entre duas populações de uma espécie, 
como, por exemplo, o soerguimento de uma montanha ou o surgimento de um vale.

Um dos principais objetivos dos estudos sobre diversificação da biota neotropical é entender quais destes processos mencionados acima estiveram envolvidos na diversificação evolutiva dos organismos. Os estudos biogeográficos que utilizam sequências de DNA permitem que sejam feitas inferências temporais do processo de diversificação dos organismos, como por exemplo, estimativas dos tempos de divergência entre as espécies; e inferências demográficas com base na teoria da coalescência. Com base nestas estimativas algumas predições das hipóteses mencionadas acima podem ser feitas, e desta forma permitindo testá-las e consequentemente aceitá-las ou refutá-las (Moritz et al., 2000), embora muitas vezes algumas delas apresentem certas ambiguidades que impossibilitam distinguilas. Contudo, é bastante desafiador construir predições genéticas para as hipóteses de diversificação nos neotrópicos, uma vez que o conhecimento de quando os eventos vicariantes e a evolução da paisagem ocorreram é incerto para maioria das regiões (Brumfield, 2012). A tabela 1 descreve predições genéticas de três das principais hipóteses de diversificação da biota neotropical com base em Moritz et al. (2000). No entanto, na presente Tese, algumas das predições foram readequadas de acordo com nosso melhor entendimento.

Tabela 1. Descrição das predições genéticas das principais hipóteses de diversificação para as florestas tropicais com base em Moritz et al. (2000).

\begin{tabular}{|c|c|}
\hline Hipótese & Predições \\
\hline Refúgios & $\begin{array}{l}1 \text { - estrutura genética com a presença de linhagens que se divergiram em } \\
\text { alopatria, e que agora podem estar em contato secundário; } 2 \text { - datação dos } \\
\text { eventos vicariantes concordante com máximos glaciais (não se restringido } \\
\text { somente ao último máximo glacial, mas podendo também coincidir com } \\
\text { glaciações anteriores a este período); } 3 \text { - sinal de expansão demográfica em } \\
\text { cada linhagem que divergiu em alopatria. }\end{array}$ \\
\hline Rios & $\begin{array}{l}1 \text { - estrutura genética com presença de clados delimitados pelo rio; } 2 \text { - } \\
\text { datação do evento de separação congruente com a origem do rio; } 3 \text { - } \\
\text { ausência de sinais de expansão demográfica, ou seja, estabilidade } \\
\text { populacional. }\end{array}$ \\
\hline Gradiente ecológico & $\begin{array}{l}1 \text { - estrutura genética com presença de clados concordantes com uma } \\
\text { variante ecológica, como por exemplo, ao longo de uma transição entre dois } \\
\text { biomas; } 2 \text { - presença de uma zona de contato (por exemplo, um ecótone) } \\
\text { onde existe uma mistura entre as linhagens; } 3 \text { - ausência de sinais de } \\
\text { expansão demográfica, ou seja, estabilidade populacional. }\end{array}$ \\
\hline
\end{tabular}




\subsection{Estado da arte da diversificação da Amazônia}

Durante muitos anos a hipótese dos refúgios (Haffer, 1969; Vanzolini \& Williams, 1970) foi atribuída como o mecanismo principal que deu origem à biodiversidade Amazônica. Entretanto, dados paleoecológicos revelaram a presença de florestas durante o último máximo glacial na AM (Colinvaux et al., 2000; Bush \& Oliveira, 2006), o que sucumbiu a teoria dos refúgios como força evolutiva na bacia Amazônica.

Recentemente uma nova perspectiva sobre a origem da biodiversidade Amazônica tem emergido (Antonelli \& Sanmartín, 2011; Hoorn et al., 2010). Segundo esta teoria o soerguimento dos Andes em conjunto com as incursões marinhas durante o Mioceno superior influenciaram na formação da drenagem atual da bacia Amazônica, bem como do sistema fluvial do norte da América do Sul (Hoorn et al., 2010). Ainda, o soerguimento dos Andes desencadeou uma mudança climática no continente, pois esta cordilheira atua como um "paredão" que retém toda umidade que vem do Oceano Atlântico e, com isso, a AM se torna uma das florestas mais úmidas do mundo. Entretanto, ainda existem controvérsias em relação a esta hipótese (Rull, 2011b), pois vários grupos se diversificaram durante o Quaternário (Rull, 2008) e uma diversificação contínua ao longo do tempo seria atribuída como a hipótese mais plausível para a origem da biota neotropical (Rull, 2011a).

Ainda mais recentemente alguns estudos têm mostrado que a hipótese dos rios como barreira ao fluxo gênico para animais terrestres (Wallace, 1852) foi responsável por eventos de especiação recentes na AM (Fernandes et al., 2012; Patel et al., 2011; Ribas et al., 2012). Estes estudos mostraram a presença de linhagens ou espécies limitadas pelos grandes rios Amazônicos, sendo estes rios as barreiras primárias que levaram a separação entre estes táxons. As datações concordam com a hipótese do estabelecimento recente da drenagem moderna da bacia Amazônica nos últimos 3 milhões de anos (Ribas et al., 2012).

Deste modo mais estudos sobre a evolução da biota Amazônica são necessários, principalmente aqueles que testam hipóteses concorrentes sobre a evolução do bioma. Assim com o acúmulo destes estudos será possível traçar um 
panorama sobre quais eventos históricos deram origem a enorme biodiversidade que observamos atualmente.

\subsection{Estado da arte da diversificação da Mata Atlântica}

A história evolutiva da MA parece ter sido bastante influenciada pelos períodos de máximo glacial ocorridos no Pleistoceno. Registros paleopalinológicos mostram que o último máximo glacial na MA ocorreu entre 18 e 48 mil anos A.P., com a expansão de áreas abertas (grasslands) pelo sudeste brasileiro (Behling \& Pillar, 2007). Essas áreas abertas se estenderam por cerca de $750 \mathrm{~km}$, do sul ao sudeste do Brasil da latitude $28^{\circ} / 27^{\circ} \mathrm{S}$ até $20^{\circ} \mathrm{S}$ (Behling \& Lichte, 1997; Behling, 2002). A expansão das áreas florestadas modernas ocorreu somente no Holoceno (Behling, 2002; Behling \& Pillar, 2007).

Carnaval \& Moritz (2008) realizaram um estudo com modelagem paleoclimática do último máximo glacial ocorrido na MA ( 21 mil anos atrás) e revelaram a existência de hipotéticos refúgios florestais pleistocênicos no corredor central da MA (Bahia) e em Pernambuco. Os autores ainda mostraram a possível existência de uma região florestada instável em São Paulo durante o final do Pleistoceno. Estas possíveis zonas de estabilidade e instabilidade florestal durante o último máximo glacial (refúgios) mostram bastante concordância com alguns estudos filogeográficos (Cabanne et al., 2007, 2008; Carnaval et al., 2009; d'Horta et al., 2011; Maldonado-Coelho, 2012; Martins et al., 2009; Ribeiro et al., 2010).

Contudo, a despeito da grande biodiversidade da MA poucos estudos filogeográficos detalhados foram realizados até o momento, e ainda são pouco conclusivos sobre a riqueza de padrões de diversificação que ocorreram neste bioma. Porém estes estudos apontam para a existência de descontinuidades filogeográficas recorrentes para diferentes grupos de organismos (ver Fig. 1a no Capítulo 1). Entretanto, essas quebras filogeográficas recorrentes são congruentes no espaço, porém não totalmente congruentes no tempo. Alguns estudos reportam que os ciclos glaciais pleistocênicos possivelmente teriam atuado como o efeito vicariante que originou as linhagens observadas (Cabanne et al., 2007, 2008; d'Horta et al., 2011; Carnaval et al., 2009; Martins et al., 2009; Ribeiro et al., 2010), porém em 
outros estudos, além da teoria dos refúgios, a hipótese de diversificação por tectonismo foi invocada para explicar os resultados (Amaro et al., 2012; BatalhaFilho et al., 2010; Thomé et al., 2010). Ainda, alguns estudos reportaram eventos vicariantes com datação anterior ao Quaternário, no Plioceno (Amaro et al., 2012; Grazziotin et al., 2006; Thomé et al., 2010).

Ainda conhecemos muito pouco sobre a história evolutiva da MA e a existência de uma grande biodiversidade remete à possibilidade de existência de uma gama de processos que geraram essa diversidade. Nesse sentido, torna-se necessário maior acúmulo de estudos filogeográficos de organismos que habitam esse bioma com o intuito de fornecer dados que irão contribuir para 0 entendimento da complexa história evolutiva da MA.

\subsection{Contatos históricos entre Amazônia e Mata Atlântica}

Acredita-se que a $\mathrm{AM}$ e a MA foram conectadas várias vezes através da diagonal seca da América do Sul durante períodos climáticos mais úmidos que o atual nesta região (Auler et al., 2004; Auler \& Smart 2001; Behling et al., 2000; Costa, 2003; Oliveira et al., 1999; Por, 1992; Wang et al., 2004). Estudos paleopalinológicos e de espeleotemas têm mostrado que durante o final do Pleistoceno (últimos 900 mil de anos) estes dois biomas foram conectados por matas de galerias que se estenderam através do domínio atual dos biomas Cerrado e Caatinga (Auler et al., 2004; Auler \& Smart 2001; Behling et al., 2000; Oliveira et al., 1999; Wang et al., 2004). Além disso, em um estudo filogeográfico comparando pequenos mamíferos não voadores da AM e MA, Costa (2003) encontrou linhagens de ambos biomas distribuídas no domínio atual do Cerrado, e em alguns casos as populações do norte da MA foram mais próximas da AM do que do sul MA.

Porém algumas questões referentes ao tempo e espaço destas conexões ainda permanecem enigmáticas, como por exemplo: quantas vezes estas conexões aconteceram? Somente as mudanças climáticas do Quaternário tiveram influência nestas conexões? Quando estas conexões aconteceram? Diante destas questões abordagens filogenéticas e filogeográficas de organismos com distribuição disjunta 
entre $A M$ e MA poderão auxiliar na compreensão dos padrões e processos inerentes a estas conexões.

\subsection{Os modelos do estudo}

Na presente Tese foram analisados os padrões biogeográficos de espécies de pássaros florestais endêmicos da AM e MA. As aves figuram entre os grupos de vertebrados terrestres com maior riqueza de espécies no mundo, e a ordem Passeriformes (grupo das espécies analisadas nesta Tese) é a que apresenta maior numero de espécies. A América do Sul é a porção do planeta com maior riqueza de espécies de aves, abrigando 2645 espécies (Sick, 1997). A AM possui um terço de todas das aves do planeta ( 1500 espécies; Hubbell et al., 2008; Hoorn \& Wesselingh, 2010). A MA também está entre os biomas mais ricos em espécies endêmicas de aves, tornando essa área de extremo interesse conservacionista (Bibby et al., 1992; Myers et al., 2000), com 620 espécies, sendo 181 endêmicas (Myers et al., 2000).

As aves possuem várias características que as tornam bons modelos para estudos sobre biogeografia histórica, tais como: ocupam uma ampla diversidade de habitats, possuem uma grande diversidade comportamental e de hábitos alimentares e muitas espécies florestais podem ser bastante sensíveis a mudanças no habitat. Dessa maneira, espécies de aves florestais endêmicas da AM e da MA são bons modelos para estudos de diversificação destes biomas, pois possuem dependência florestal e provavelmente flutuaram demograficamente de maneira contígua com as florestas e assim podem refletir suas histórias evolutivas. Além disso, muitas espécies estão associadas a micro-habitats diferentes no bioma e possivelmente possuem histórias evolutivas relacionadas às suas dependências ecológicas.

As espécies de pássaros aqui analisadas para buscar entender a diversificação na MA foram: Basileuterus leucoblepharus, Myrmotherula gularis e o complexo de espécies Synallaxis ruficapilla/whitneyi/infuscata. Para a análise dos padrões de diversificação da AM nós analisamos o complexo Thamnomanes caesius/T. schistogynus. Este último estudo, além de uma análise multiespécies do 
grupo Suboscines utilizando-se sequências disponíveis no GenBank, também permitiu inferir a dinâmica das conexões históricas entre a AM e a MA. Mais detalhes sobre cada táxon e das respectivas análises são abordados nos capítulos desta Tese.

\section{Objetivos}

A presente Tese teve por objetivos analisar a sistemática molecular, a estrutura filogeográfica e a demografia histórica de pássaros florestais endêmicos da $A M$ e da MA, bem como entender o padrão de diversificação desses taxa nesses biomas e fornecer dados que possam contribuir para o entendimento da história evolutiva da biota residente nestas florestas. Além disso, nós analisamos a dinâmica de conexões históricas entre a AM e a MA com intuito de fornecer uma perspectiva espaço-temporal sobre os contatos históricos entre estes dois biomas. Os objetivos específicos são apresentados em cada capítulo desta tese.

\section{Referências}

Ab'Saber AN. 1977. Os domínios morfoclimáticos da América do Sul. Primeira aproximação. Geomorfologia 53:1-23.

Amaro RC, Rodrigues MT, Yonenaga-Yassuda Y, Carnaval AC. 2012. Demographic processes in the montane Atlantic rainforest: Molecular and cytogenetic evidence from the endemic frog Proceratophrys boiei. Mol. Phylogenet. Evol. 62: $880-888$.

Antonelli A, Sanmartín I. 2011. Why are there so many plant species in the Neotropics? Taxon 60: 403-414.

Auler AS, Smart PL. 2001. Late Quaternary paleoclimate in semiarid northeastern Brazil from u-series dating of travertine and water-table speleothems. Quat. Res. 55: 159-167.

Auler AS, Wang A, Edwards RL, Cheng H, Cristalli PS, Smart ML, Richards DA. 2004. Quaternary ecological and geomorphic changes associated with rainfall events in presently semi-arid northeastern Brazil. J. Quat. Sci. 19: 693-701. 
Avise JC, Arnold J, Ball RM, Bermingham E, Lamb T, Neigel JE, Reeb CA, Saunders NC. 1987. Intraspecific phylogeography: The mitochondrial DNA bridge between population genetics and systematics. Annu. Rev. Ecol. Evol. Syst. 18: 489-522.

Avise JC. 2000. Phylogeography: the History and Formation of Species. Cambridge: Harvard University Press.

Avise JC. 2008. Phylogeography: retrospect and prospect. J. Biogeogr. 36: 3-15.

Batalha-Filho H, Waldschmidt AM, Campos LAO, Tavares MG, Fernandes-Salomão TM. 2010. Phylogeography and historical demography of the Neotropical stingless bee Melipona quadrifasciata (Hymenoptera, Apidae): incongruence between morphology and mitochondrial DNA. Apidologie 41: 534-547.

Beaumont MA, Zhang W, Balding DJ. 2002. Approximate Bayesian computation in population genetics. Genetics 162: 2025-2035.

Behling H. 2002. South and southeast Brazilian grasslands during Late Quaternary times: a synthesis. Palaeogeogr. Palaeoclimatol. Palaeoecol. 177: 19-27.

Behling H, Arz HW, Patzold J, Wefer G. 2000. Late Quaternary vegetational and climate dynamics in northeastern Brazil, inferences from marine core GeoB3104-1. Quat. Sci. Rev. 19: 981-994.

Behling H, Lichte M. 1997. Evidence of dry and cold climatic conditions at glacial times in tropical southeastern Brazil. Quatern. Res. 48: 348-358.

Behling H, Pillar VDP. 2007. Late Quaternary vegetation, biodiversity and fire dynamics on the southern Brazilian highland and their implication for conservation and management of modern Araucaria forest and grassland ecosystems. Philos. Trans. R. Soc. B 362: 243-251.

Bibby CJ, Collar NJ, Crosby MJ, Heath MF, Imboden C, Johnson TH, Long AJ, Stattersfield AJ, Thirgood SJ. 1992. Putting Biodiversity on the Map: Priority Areas for Global Conservation. Cambridge: ICBP.

Brito PH, Edwards SV. 2009. Multilocus phylogeography and phylogenetics using sequence-based markers. Genetica 135: 439-455.

Brown JH, Lomolino MV. 2006. Biogeografia. $2^{\text {a }}$ ed. Trad: Iulo Feliciano Afonso. Ribeirão Preto: FUNPEC Editora. 
Brown KS, Ab'Saber AN. 1979. Ice - ages forest refuges and evolution in the Neotropics: correlation of paleoclimatological, geomorphological, and pedological data with modern biological endemism. Paleoclimas 5: 1-30.

Brumfield RT. 2012. Inferring the origins of lowland neotropical birds. Auk 129: $367-376$.

Bush MB, de Oliveira PE. 2006. The rise and fall of the refugial hypothesis of Amazonian speciation: a paleoecological perspective. Biot. Neotrop. 6: 1-17.

Cabanne GS, Santos FR, Miyaki CY. 2007. Phylogeography of Xiphorhynchus fuscus (Passeriformes, Dendrocolaptidae): vicariance and recent demographic expansion in southern Atlantic forest. Biol. J. Linn. Soc. 91: 73-84.

Cabanne GS, d'Horta FM, Sari EHR, Santos FR, Miyaki CY. 2008. Nuclear and mitochondrial phylogeography of the Atlantic forest endemic Xiphorhynchus fuscus (Aves: Dendrocolaptidae): biogeography and systematic implications. Mol. Phylogenet. Evol. 49: 760-773.

Carnaval AC, Moritz C. 2008. Historical climate modeling predicts patterns of current biodiversity in the Brazilian Atlantic forest. J. Biogeogr. 35: 1187-1201.

Carnaval AC, Hickerson MJ, Haddad CFB, Rodrigues MT, Moritz C. 2009. Stability predicts genetic diversity in the Brazilian Atlantic forest hotspot. Science 323: 785-789.

Colinvaux PA, de Oliveira PE, Bush MB. 2000. Amazonian and Neotropical plant communities on glacial time scales: The failure of the aridity and refuge hypothesis. Quaternary Sci. Rev. 19: 141-169.

Costa LP. 2003. The historical bridge between the Amazon and the Atlantic forests of Brazil: a study of molecular phylogeography with small mammals. J. Biogeogr. 30: 71-86.

Cracraft J. 1985. Historical biogeography and patterns of differentiation within the South American avifauna: areas of endemism. Ornithol. Monogr. 36: 49-84.

Crisci JV, Katinas L, Posadas P. 2003. Historical Biogeography: an Introduction. Cambridge: Harvard University Press. 
d'Horta F, Cabanne GS, Meyer D, Miyaki CY. 2011. The genetic effects of Late Quaternary climatic changes over a tropical latitudinal gradient: diversification of an Atlantic Forest passerine. Mol. Ecol. 20: 1932-1935.

Edwards SV, Beerli P. 2000. Perspective: gene divergence, population divergence, and the variance in coalescence time in phylogeographic studies. Evolution 54: $1839-1854$.

Felsenstein J. 2004. Inferring Phylogenies. Sunderland: Sinauer Associates.

Fernandes AM, Wink M. Aleixo A. 2012. Phylogeography of the chestnut-tailed antbird (Myrmeciza hemimelaena) clarifies the role of rivers in Amazonian biogeography. J. Biogeogr. 39: 1524-1535.

Galindo-Leal C, Câmara IG. 2005. Status do hotspot Mata Atlântica: uma síntese. In: Galindo-Leal C, Câmara IG (Eds). Mata Atlântica: Biodiversidade, Ameaças e Perspectivas. Belo Horizonte: Conservação Internacional, 3-11 pp.

Grazziotin FG, Monzel M, Echeverrigaray S, Bonatto SL. 2006. Phylogeography of the Bothrops jararaca complex (Serpentes: Viperidae): past fragmentation and island colonization in the Brazilian Atlantic Forest. Mol. Ecol. 15: 3969-3982.

Haffer J. 1969. Speciation in Amazonian forest birds. Science 165: 131-137.

Hickerson MJ, Carstens BC, Cavender-Bares J, Crandall KA, Graham CH, Johnson JB, Rissler L, Victoriano PF, Yoder AD. 2010. Phylogeography's past, present, and future: 10 years after Avise, 2000. Mol. Phylogenet. Evol. 54: 291-301.

Hoorn C, Wesselingh FP. 2010. Introduction: Amazonia, landscape and species evolution. In: Hoorn C, Wesselingh FP (Eds). Amazonia: Landscape and Species Evolution: a Look into the Past. London: Blackwell, pp 1-6.

Hoorn C, Wesselingh FP, ter Steege H, Bermudez MA, Mora A, Sevink J, Sanmartín I, Sanchez-Meseguer A, Anderson CL, Figueiredo, Jaramillo C, Riff D, Negri FR, Hooghiemstra H, Lundberg J, Stadler T, Särkinen T, Antonelli A. 2010. Amazonia through time: Andean uplift, climate change, landscape evolution, and biodiversity. Science 330: 927-931.

Hubbell SP, He F, Condit R, Borda-de-Água L, Kellner J, ter Steege H. 2008. How many tree species are there in the Amazon and how many of them will go extinct? Proc. Natl. Acad. Sci. USA 105: 11498-11504. 
Knowles LL. 2001. Did the Pleistocene glaciations promote divergence? Tests of explicit refugial models in montane grasshopprers. Mol. Ecol. 10: 691-702.

Knowles LL, Maddison WP. 2002. Statistical phylogeography. Mol. Ecol. 11: 26232635 .

Kuhner MK. 2009. Coalescent genealogy samplers: windows into population history. Trends Ecol. Evol. 24: 86-93.

Maldonado-Coelho M. 2012. Climatic oscillations shape the phylogeographical structure of Atlantic Forest fire-eye antbirds (Aves: Thamnophilidae). Biol. J. Linn. Soc. 105: 900-924.

Martins FM, Templeton AR, Pavan ACO, Kohlbach BC, Morgante JS. 2009. Phylogeography of the common vampire bat (Desmodus rotundus): marked population structure, Neotropical Pleistocene vicariance and incongruence between nuclear and mtDNA markers. BMC Evol. Biol. 9: 294.

Moritz C, Patton JL, Schneider CJ, Smith TB. 2000. Diversification of rainforest faunas: An integrated molecular approach. Annu. Rev. Ecol. Syst. 31: 533-563.

Myers N, Mittermeier RA, Mittermeier CG, da Fonseca GAB, Kent J. 2000. Biodiversity hotspots for conservation priorities. Nature 403: 853-858.

Oliveira PE, Barreto AMF, Suguio K. 1999. Late Pleistocene/Holocene climatic and vegetational history of the Brazilian caatinga: the fossil dunes of the middle São Francisco River. Palaeogeogr. Palaeoclimatol. Palaeoecol. 152: 319-337.

Patel S, Weckstein JD, Patané JSL, Bates JM, Aleixo A. 2011. Temporal and spatial diversification of Pteroglossus araçaris (Aves: Ramphastidae) in the neotropics: constant rate of diversification does not support an increase in radiation during the Pleistocene. Mol. Phylogenet. Evol. 58:105-115.

Patton JL, Dasilva MNF, Malcolm JR. 1994. Gene genealogy and differentiation among arboreal spiny rats (Rodentia, Echimyidae) of the Amazon basin - a test of the riverine barrier hypothesis. Evolution 48: 1314-1323.

Patton JL, Da Silva MNF, Malcolm JR. 2000. Mammals of the rio Jurua and the evolutionary and ecological diversification of Amazonia. Bull. Am. Mus. Nat. Hist. 244: 1-306. 
Por FD. 1992. Sooretama: the Atlantic Rain Forest of Brazil. The Haugue: SPB Academic Publishing.

Ribas CC, Aleixo A, Nogueira ACR, Miyaki CY, Cracraft J. 2012. A palaeobiogeographic model for biotic diversification within Amazonia over the past three million years. Proc. Roy. Soc. London B 279, 681-689.

Ribeiro CA, Metzger JP, Martensen AC, Ponzoni FJ, Hirota MM. 2009. The Brazilian Atlantic Forest: How much is left, and how is the remaining forest distributed? Implications for conservation. Biol. Cons. 142: 1141-1153.

Ribeiro RA, Lemos-Filho JP, Ramos ACS, Lovato MB. 2010. Phylogeography of the endangered rosewood Dalbergia nigra (Fabaceae): insights into the evolutionary history and conservation of the Brazilian Atlantic Forest. Heredity 106: 46-57.

Rull V. 2008. Speciation timing and neotropical biodiversity: the Tertiary-Quaternary debate in the light of molecular phylogenetic evidence. Mol. Ecol. 17: 2722-2729.

Rull V. 2011a. Neotropical biodiversity: timing and potential drivers. Trends Ecol. Evol. 26: 508-513.

Rull V. 2011b. Origins of biodiversity. Science 331: 398-399.

Sant'Anna Neto JL, Nery JT. 2005. Variabilidade e mudanças climáticas no Brasil e seus impactos. In: Souza GRG, Suguio K, Oliveira MAS, Oliveira PL (Eds). Quaternário do Brasil. Ribeirão Preto: Holos Editora, 28-50 pp.

Sick H. 1997. Ornitologia Brasileira. Rio de Janeiro: Nova Fronteira.

Silva JMC, Casteleti CHM. 2005. Estado da biodiversidade da Mata Atlântica brasileira. In: Galindo-Leal C, Câmara IG (Eds). Mata Atlântica: Biodiversidade, Ameaças e Perspectivas. Belo Horizonte: Conservação Internacional, 43-59 pp.

Silva JMC, Straube FC. 1996. Systematics and biogeography of scaled woodcreepers (Aves: Dendrocolaptidae). Stud. Neotrop. Fauna E. 31: 3-10.

Smith TB, Wayne RK, Girman DJ, Bruford MW. 1997. A role for ecotones in generating rainforest biodiversity. Science 276: 1855-1857.

Smith TB, Schneider CJ, Holder K. 2001 Refugial isolation versus ecological gradients. Genetica 112: 383-398. 
Thomé MTC, Zamudio KR, Giovanelli JGR, Haddad CFB, Baldissera Jr FA, Alexandrino JMB. 2010. Phylogeography of endemic toads and post-Pliocene persistence of the Brazilian Atlantic Forest. Mol. Phylogenet. Evol. 55: 1018-1031.

Vanzolini PE, Williams EE. 1970. South American anoles: the geographic differentiation and evolution of the Anolis chrysolepis species group (Sauria: Iguanidae). Arquiv. Zool. (S. Paulo) 19: 1-298.

Wallace AR. 1852. On the monkeys of the Amazon. Proc. Zool. Soc. London 20: 107110.

Wang XF, Auler AS, Edwards RL, Cheng H, Cristalli PS, Smart PL, Richards DA, Shen CC. 2004. Wet periods in northeastern Brazil over the past 210 kyr linked to distant climate anomalies. Nature 432: 740-743.

Whitmore TC, Prance GT. 1987. Biogeography and Quaternary History in Tropical America. Oxford: Oxford University Press. 


\section{Capítulo 1}

\section{Phylogeography of an Atlantic forest passerine reveals demographic stability through the last glacial maximum}

Artigo aceito para publicação no periódico Molecular Phylogenetics and Evolution de autoria de Henrique Batalha-Filho, Gustavo Sebástian Cabanne e Cristina Yumi Miyaki com previsão para publicação em 2012 sob DOI:

http://dx.doi.org/10.1016/j.ympev.2012.08.010. 


\title{
Phylogeography of an Atlantic forest passerine reveals demographic stability through the last glacial maximum
}

\author{
Henrique Batalha-Filho $^{\text {a,* }}$, Gustavo Sebastián Cabanne ${ }^{\text {b,c }}$, Cristina Yumi Miyaki ${ }^{\text {a }}$

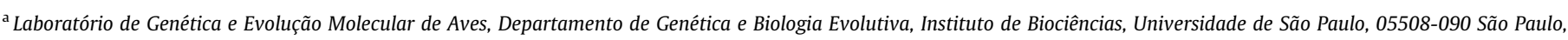 \\ SP, Brazil \\ ${ }^{\mathrm{b}}$ CONICET, Av. Rivadavia 1917, Ciudad de Buenos Aires C1033AAJ, Argentina \\ 'División de Ornitología, Museo Argentino de Ciencias Naturales “B. Rivadavia”, Ángel Gallardo 470, Ciudad de Buenos Aires C1405DJR, Argentina
}

\section{A R T I C L E I N F O}

\section{Article history:}

Received 19 September 2011

Revised 17 July 2012

Accepted 14 August 2012

Available online $\mathrm{xxxx}$

\section{Keywords:}

Neotropical region

Demographic history

Coalescent simulations

Basileuterus leucoblepharus

Parulidae

\begin{abstract}
A B S T R A C T
In this study we analyzed the phylogeographic pattern and historical demography of an endemic Atlantic forest (AF) bird, Basileuterus leucoblepharus, and test the influence of the last glacial maximum (LGM) on its population effective size using coalescent simulations. We address two main questions: (i) Does $B$. leucoblepharus present population genetic structure congruent with the patterns observed for other AF organisms? (ii) How did the LGM affect the effective population size of B. leucoblepharus? We sequenced $914 \mathrm{bp}$ of the mitochondrial gene cytochrome $\mathrm{b}$ and $512 \mathrm{bp}$ of the nuclear intron 5 of beta-fibrinogen of 62 individuals from 15 localities along the AF. Both molecular markers revealed no genetic structure in $B$. leucoblepharus. Neutrality tests based on both loci showed significant demographic expansion. The extended Bayesian skyline plot showed that the species seems to have experienced demographic expansion starting around 300,000 years ago, during the late Pleistocene. This date does not coincide with the LGM and the dynamics of population size showed stability during the LGM. To further test the effect of the LGM on this species, we simulated seven demographic scenarios to explore whether populations suffered specific bottlenecks. The scenarios most congruent with our data were population stability during the LGM with bottlenecks older than this period. This is the first example of an AF organism that does not show phylogeographic breaks caused by vicariant events associated to climate change and geotectonic activities in the Quaternary. Differential ecological, environmental tolerances and habitat requirements are possibly influencing the different evolutionary histories of these organisms. Our results show that the history of organism diversification in this megadiverse Neotropical forest is complex.
\end{abstract}

Crown Copyright $\odot 2012$ Published by Elsevier Inc. All rights reserved.

\section{Introduction}

The Atlantic forest (AF) is among the top five biodiversity hotspots in the world and these areas hold more than $60 \%$ of all terrestrial species on the planet (Myers et al., 2000; Galindo-Leal and Câmara, 2005). It is distributed along the coastal regions of eastern Brazil to eastern Paraguay and northeastern Argentina (GalindoLeal and Câmara, 2005) (Fig. 1). Also, the AF now holds only between $11.4 \%$ and $16 \%$ of its original forest cover (Ribeiro et al., 2009).

The high species diversity in the AF may be a consequence of various evolutionary processes. Some of them possibly occurred in the Quaternary, especially in the late Pleistocene (Whitmore

\footnotetext{
* Corresponding author. Address: Laboratório de Genética e Evolução Molecular de Aves, Departamento de Genética e Biologia Evolutiva, Instituto de Biociências, Universidade de São Paulo, Rua do Matão 277, Cidade Universitária, 05508-090 São Paulo, SP, Brazil. Fax: +55 1130917553.

E-mail addresses: rickbio@hotmail.com, henrique.batalha@usp.br (H. BatalhaFilho).
}

and Prance, 1987). During this period the planet went through many glacial and interglacial cycles, when continental glaciers advanced and retreated and forests suffered cycles of reduction, fragmentation and expansion (Sant'Anna Neto and Nery, 2005). Palynological data analyses show that the last glacial maximum in the AF occurred between 18 and 48 thousand years ago, with open areas (grasslands) in southeastern Brazil that extended $750 \mathrm{~km}$ northward, from latitude $28^{\circ} / 27^{\circ} \mathrm{S}$ to at least $20^{\circ} \mathrm{S}$ (Behling and Lichte, 1997; Behling, 2002). The final expansion of forested areas to its current distribution occurred only at the end of the Holocene (Behling, 2002; Behling and Pillar, 2007).

One of the most discussed hypotheses on the origin of the Neotropical biodiversity during the Pleistocene is the theory of forest refugia (Haffer, 1969; Vanzolini and Williams, 1970; Brown and Ab'Saber, 1979). According to this theory, refugia are islands of humid forest isolated by open vegetation, such us grasslands or dry forest. These rainforests would shrink during glacial maxima (forming refugia) and expand during warmer periods (interglacial cycles), while areas of open vegetation would behave the other

1055-7903/\$ - see front matter Crown Copyright @ 2012 Published by Elsevier Inc. All rights reserved. http://dx.doi.org/10.1016/j.ympev.2012.08.010 
(b)

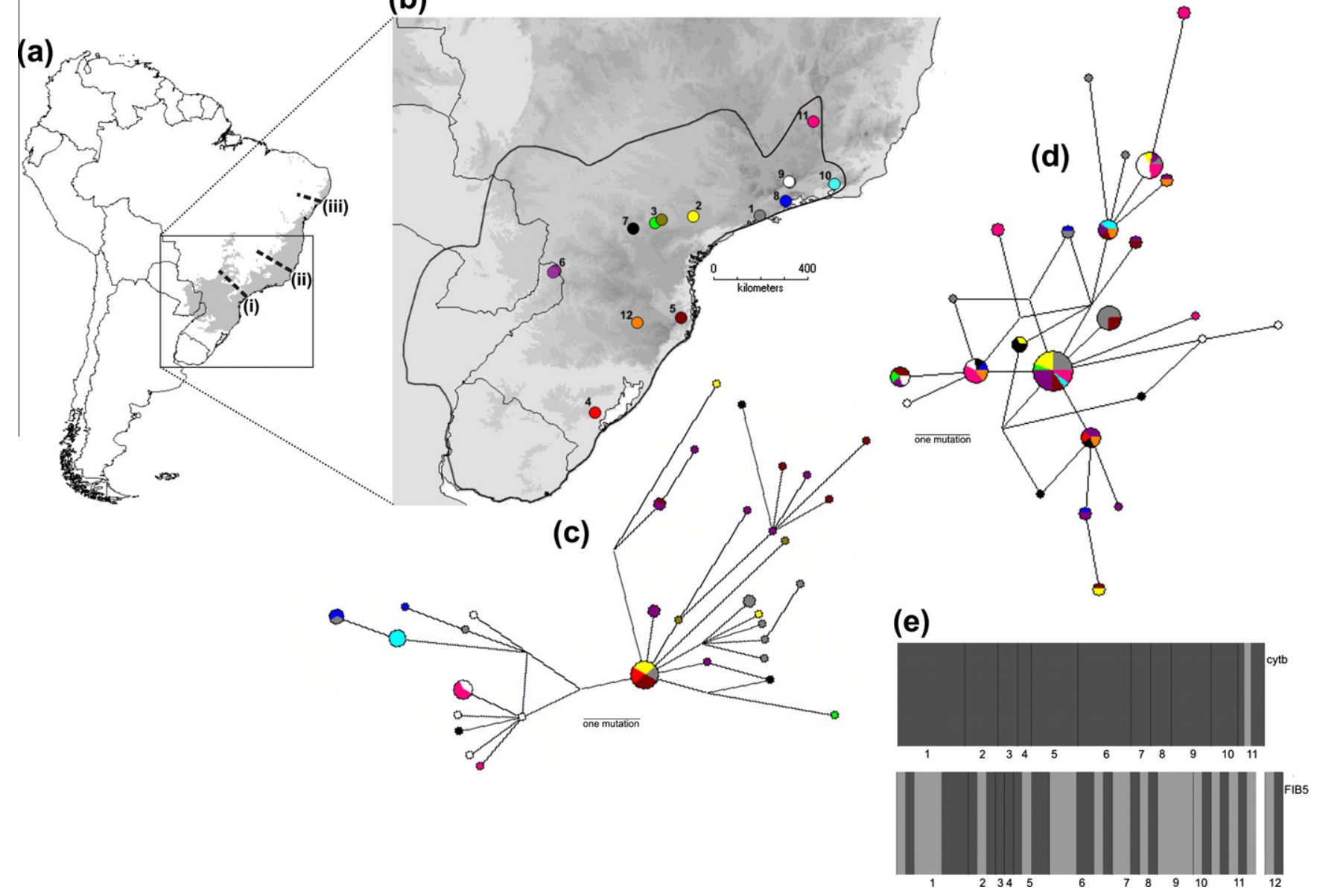

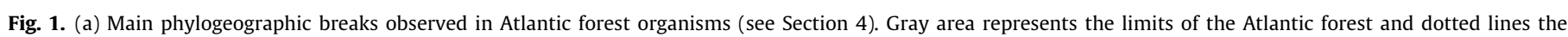

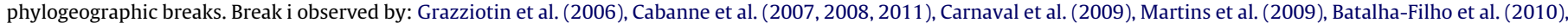

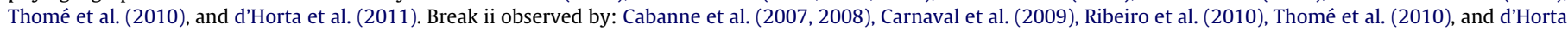

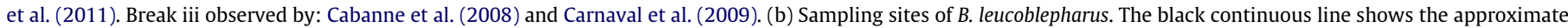

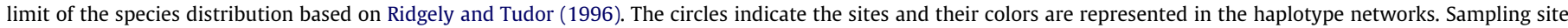

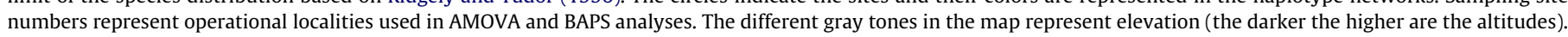

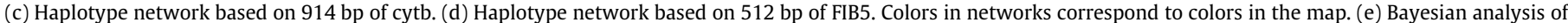

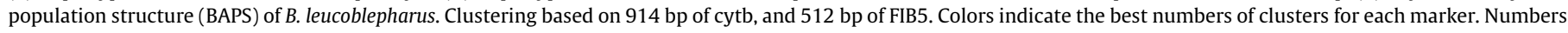
represents the operational localities according to the map.

way round. Thus, the geographic distribution of species that inhabit rainforests should have accompanied these cycles of contraction and expansion of forests during the Pleistocene. If these populations were isolated for enough time to accumulate differences between them, even if they subsequently got in contact again after the expansion of forests, no gene flow would occur. However, geological and palaeoclimatic studies questioned the existence of Pleistocene refugia (Colinvaux et al., 2000; Bush and de Oliveira, 2006).

Another possible driver of diversification is rivers as barriers to gene flow for terrestrial animals. This hypothesis was initially proposed by Alfred Russell Wallace (1852), and recent studies showed that rivers played an important role for diversification in Amazonia (Ribas et al., 2012), but not in the AF (Maldonado-Coelho, 2012). Another hypothesis is the ecological gradient theory (Smith et al., 1997,2001 ) that suggests that diversification can occur in parapatry, i.e., species or lineage differentiation may occur due to differential selective pressures acting on different and adjacent habitats. This hypothesis was evaluated and supported by Cabanne et al. (2011) in the intra-specific diversification of a bird that inhabits the AF and gallery forest of Caatinga, Cerrado, and Chaco. Finally, geotectonic activity during the Quaternary (including movement of geological faults in Brazil; Saadi et al., 2002) may have originated gene flow barriers that triggered diversification of some AF organisms (Batalha-Filho et al., 2010; Thomé et al., 2010).

Recent phylogeographic and paleoclimatic modeling studies do not reject the Pleistocene refuge theory as possible explanation of intra-specific diversification of Neotropical species (Cabanne et al., 2007, 2008; Carnaval and Moritz, 2008; Solomon et al., 2008; Carnaval et al., 2009; d'Horta et al., 2011; Martins, 2011; MaldonadoCoelho, 2012). Phylogeographic studies focused on organisms that occur in the AF are still scarce (Grazziotin et al., 2006; Cabanne et al., 2007, 2008; Carnaval et al., 2009; Fitzpatrick et al., 2009; Batalha-Filho et al., 2010; Thomé et al., 2010; Cabanne et al., 2011; d'Horta et al., 2011) compared to its high species diversity. These phylogeographic studies revealed three main phylogeographic breaks shared among taxa (Fig. 1a), but there is no clear temporal congruence between estimated dates of divergence of these populations or lineages (see Section 4 for more details).

In the present study we performed a phylogeographic analysis to study the historical demography of the white-rimmed warbler, Basileuterus leucoblepharus, an endemic bird of the AF (Passeriformes, Parulidae). We based the study on nuclear and mitochondrial 
DNA sequences for testing the effect of the last glacial maximum on its demographic history.

This species is distributed from the states of Minas Gerais and Rio de Janeiro to Rio Grande do Sul in Brazil to Paraguay, Uruguay and the northeastern and eastern Argentina (Fig. 1b; Ridgely and Tudor, 1996; Sick, 1997). It can be fairly common and easily identified by its characteristic song. It occurs from uplands in its northern distribution (e.g. between 800 and $2200 \mathrm{~m}$ in latitude $22^{\circ}$ ) to sea level in the southern part of its distribution. B. leucoblepharus lives inside moist and shaded forests (Sick, 1997), but also occurs in secondary and mixed forests in agroecosystems (i.e. Eucalyptus sp. and Araucaria angustifolia plantations), as well as gallery forests within the humid Chaco, and Argentinean and Uruguayan Pampas (Stotz et al., 1996).

In this study we addressed two main questions: (i) Does B. leucoblepharus present population genetic structure concordant with patterns observed for other AF organisms (Fig. 1a), such as birds (Cabanne et al., 2007, 2008, 2011; d'Horta et al., 2011; Maldonado-Coelho, 2012), other vertebrates (Grazziotin et al., 2006; Carnaval et al., 2009; Fitzpatrick et al., 2009; Martins et al., 2009; Thomé et al., 2010), invertebrates (Batalha-Filho et al., 2010) and plants (Ribeiro et al., 2010)?; and (ii) How did the last maximum glacial affect the effective population size of $B$. leucoblepharus?

\section{Material and methods}

\subsection{Sampling and molecular analyses methods}

Samples (muscle and blood) of 62 specimens from 15 localities in Brazil and Argentina were collected between 2000 and 2009 (Table 1, Fig. 1b). Samples are deposited in three collections in Brazil: Laboratório de Genética e Evolução Molecular de Aves (Instituto de Biociências, Universidade de São Paulo); Laboratório de Biodiversidade e Evolução Molecular (Instituto de Ciências Biomédicas, Universidade Federal de Minas Gerais); and Departamento de Genética (Universidade Federal do Rio Grande do Sul). Specimens' vouchers of all muscle samples are deposited at Museu de Zoologia da Universidade de São Paulo (MZUSP). The identification codes of samples, specimens' vouchers and GenBank accession numbers are presented in Table 1.

Total DNA was extracted following Bruford et al. (1992). The mitochondrial gene cytochrome $b$ (cytb) was amplified with primers L-14841 and H-16065 (Lougheed et al., 2000) and the nuclear beta-fibrinogen intron 5 (FIB5) with primers FIB5 and FIB6 (Marini and Hackett, 2002). PCR $(25 \mu \mathrm{L})$ contained template DNA (50 ng), $1 \mathrm{X}$ of Taq buffer (GE Healthcare), dNTPs $(0.32 \mu \mathrm{M}), 0.5 \mu \mathrm{M}$ of each primer and $0.5 \mathrm{U}$ of Taq polymerase (GE Healthcare). PCR conditions were: an initial denaturation step at $94{ }^{\circ} \mathrm{C}$ for $3 \mathrm{~min}$ and $30 \mathrm{~s}$; followed by 35 cycles at $94{ }^{\circ} \mathrm{C}$ for $35 \mathrm{~s}, 56{ }^{\circ} \mathrm{C}$ (cytb) or $51-$ $56{ }^{\circ} \mathrm{C}$ (FIB5) for $40 \mathrm{~s}$ and $72{ }^{\circ} \mathrm{C}$ for $1 \mathrm{~min}$; plus a final extension step at $72{ }^{\circ} \mathrm{C}$ for $9 \mathrm{~min}$.

Amplicons were purified using polyethylene glycol 20\% (PEG) precipitation (Sambrook et al., 1989). This DNA was then directly sequenced in both directions with the same amplification primers using Big Dye terminator 3.0 cycle sequencing kit (Applied Biosystems) following the manufacturer's protocol. Sequences were analyzed in an automated sequencer ABI PRISM 3100 (Applied Biosystems).

\subsection{Sequence editing, haplotype reconstruction and recombination} test

The electropherograms were edited and assembled in contigs using the software package Phred, Phrap, Consed (Ewing et al., 1998; Ewing and Green, 1998; Gordon et al., 1998). Sequences were aligned using the CLUSTAL W method (Higgins et al., 1994) in MEGA4 (Tamura et al., 2007). All alignments were inspected and corrected visually.

Initially, we codified double peaks present in both strands in the FIB5 sequence electropherograms as ambiguous sites according to the IUPAC code. We did not find any indel heterozygote. The gametic phase of heterozygote individuals was resolved using the algorithm PHASE (Stephens et al., 2001) with the default settings in DnaSP 5 (Librado and Rozas, 2009) and 0.7 as the minimum probability. Individuals with lower probabilities were removed from further analyses. We used PHI test in SPLITSTREE4 (Bruen et al., 2006; Huson and Bryant, 2006) to check for recombination in the FIB5 sequences. This test was used due to its power to distinguish recombination events from homoplasies (Bruen et al., 2006).

\subsection{Population structure tests}

Median-joining networks (Bandelt et al., 1999) were obtained using NETWORK 4.5.1.0 (www.fluxus-engineering.com) in order to study the relationships between haplotypes and their geographic distribution. To check the level of population genetic structure among localities we performed an analysis of molecular variance (AMOVA, Excoffier et al., 1992) with two hierarchical levels for each gene separately using ARLEQUIN 3.11 (Excoffier et al., 2005). We also calculated an AMOVA with three hierarchical levels for the cytb. For the third level of this analysis, we separated in two groups those localities south and north of the phylogeographic break i (Fig. 1a). In order to verify if there is correlation between geographic and genetic (pair wise $\Phi_{S T}$ ) distances we used Mantel test (Sokal and Rolf, 1995) using ARLEQUIN 3.11. Significances of these analyses were obtained with 1000 permutations.

In addition, we used BAPS 5.3 (Bayesian Analysis of Population Structure; Corander and Marttinen, 2006; Corander et al., 2008) to access the number of populations without prior information of the sampling location for mitochondrial and nuclear datasets. Due to the difference in ploidy, BAPS analysis was performed for each gene separately. Firstly, we ran the analysis assuming mixture model to determine the most probable number of populations $(k)$ given the data. After that the resulting mixture clustering was used for an admixture analysis with 500 reference individuals and repeated the admixture analysis 500 times per individual. The analyses were repeated five times to check for convergence between different runs.

\subsection{Demographic analyses}

The nucleotide diversity per site $(\pi)$ and number of haplotypes ( $l$ ) were calculated in DnaSP 5. In order to test if there is any evidence of demographic expansion, the neutrality test indexes Tajima's $D$ (Tajima, 1989) and Fu's $F_{S}(\mathrm{Fu}, 1997)$ and the population size change test $R_{2}$ (Ramos-Onsins and Rozas, 2002) were calculated for each gene using DnaSP 5 . The significances of these tests were obtained based on 1000 coalescent simulations. In order to identify the putative direction of the demographic expansion (north to south, or vice versa) we plotted the nucleotide diversity per site $(\pi)$ of each locality against its latitude in degrees, and we performed a linear regression. It is expected that higher values of $\pi$ is associated with a larger and more stable historical population size (Spellman and Klicka, 2006). Thus, localities with higher values of $\pi$ could be associated to past refugia.

In addition, to analyze population size dynamics through time for both loci combined, we used the Extended Bayesian Skyline Plot method (EBSP; Heled and Drummond, 2008) implemented in BEAST 1.6.1 (Drummond and Rambaut, 2007). Two independent EBSP runs were obtained using the following parameters: an initial 
Table 1

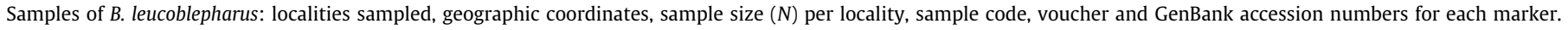

\begin{tabular}{|c|c|c|c|c|c|c|}
\hline Locality & Coordinates & $N$ & Sample code & Voucher $^{d}$ & GenBank cytb & GenBank FIB5 \\
\hline 1. Nova Lima - MG, BRA & $19^{\circ} 58^{\prime} \mathrm{S} ; 43^{\circ} 49^{\prime} \mathrm{W}$ & 8 & 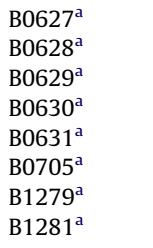 & $\begin{array}{l}- \\
- \\
- \\
- \\
- \\
- \\
- \\
-\end{array}$ & $\begin{array}{l}- \\
- \\
\text { JX488543 } \\
\text { JX488544 } \\
\text { JX488545 } \\
\text { JX488546 } \\
- \\
-\end{array}$ & $\begin{array}{l}\text { JX488594 } \\
\text { JX488595 } \\
\text { JX488596 } \\
\text { JX488597 } \\
\text { JX488598 } \\
- \\
\text { JX488599 } \\
\text { JX488600 }\end{array}$ \\
\hline 2. Itamonte - MG, BRA & $22^{\circ} 21^{\prime} \mathrm{S} ; 44^{\circ} 46^{\prime} \mathrm{W}$ & 2 & $\begin{array}{l}12017^{\mathrm{b}} \\
12020^{\mathrm{b}}\end{array}$ & $\begin{array}{l}\text { MZUSP82630 } \\
\text { MZUSP82629 }\end{array}$ & $\begin{array}{l}\text { JX488535 } \\
\text { JX488536 }\end{array}$ & $\begin{array}{l}\text { JX488586 } \\
\text { JX488587 }\end{array}$ \\
\hline 3. Resende - RJ, BRA & $22^{\circ} 23^{\prime} \mathrm{S} ; 44^{\circ} 45^{\prime} \mathrm{W}$ & 4 & $\begin{array}{l}12014^{\mathrm{b}} \\
12015^{\mathrm{b}} \\
12023^{\mathrm{b}} \\
12024^{\mathrm{b}}\end{array}$ & $\begin{array}{l}\text { MZUSP82617 } \\
\text { MZUSP82627 } \\
\text { MZUSP82628 } \\
\text { MZUSP82616 }\end{array}$ & $\begin{array}{l}\text { JX488533 } \\
\text { JX488534 } \\
\text { JX488537 } \\
\text { JX488538 }\end{array}$ & $\begin{array}{l}\text { JX488584 } \\
\text { JX488585 } \\
\text { JX488588 } \\
\text { JX488589 }\end{array}$ \\
\hline 4. Parque Nacional Serra dos Órgãos - RJ, BRA & $22^{\circ} 26^{\prime} \mathrm{S} ; 43^{\circ} 00^{\prime} \mathrm{W}$ & 4 & $\begin{array}{l}13000^{\mathrm{b}} \\
13006^{\mathrm{b}} \\
13008^{\mathrm{b}} \\
13019^{\mathrm{b}}\end{array}$ & $\begin{array}{l}\text { MZUSP82588 } \\
\text { MZUSP82589 } \\
\text { MZUSP82587 } \\
\text { MZUSP82586 }\end{array}$ & $\begin{array}{l}\text { JX488539 } \\
\text { JX488540 } \\
\text { JX488541 } \\
\text { JX488542 }\end{array}$ & $\begin{array}{l}\text { JX488590 } \\
\text { JX488591 } \\
\text { JX488592 } \\
\text { JX488593 }\end{array}$ \\
\hline 5. Parque Estadual Morro Grande - SP, BRA & $23^{\circ} 41^{\prime} \mathrm{S} ; 45^{\circ} 51^{\prime} \mathrm{W}$ & 10 & $\begin{array}{l}779^{\mathrm{b}} \\
820^{\mathrm{b}} \\
825^{\mathrm{b}} \\
828^{\mathrm{b}} \\
830^{\mathrm{b}} \\
834^{\mathrm{b}} \\
835^{\mathrm{b}} \\
852^{\mathrm{b}} \\
853^{\mathrm{b}} \\
854^{\mathrm{b}}\end{array}$ & $\begin{array}{l}- \\
- \\
- \\
- \\
- \\
- \\
- \\
- \\
- \\
-\end{array}$ & $\begin{array}{l}\text { JX488492 } \\
\text { JX488493 } \\
\text { JX488494 } \\
\text { JX488495 } \\
\text { JX488499 } \\
\text { JX488497 } \\
\text { JX488498 } \\
\text { JX488496 } \\
\text { JX488500 } \\
\text { JX488501 }\end{array}$ & $\begin{array}{l}\text { JX488547 } \\
\text { JX488548 } \\
\text { JX488549 } \\
\text { JX488550 } \\
\text { JX488554 } \\
\text { JX488552 } \\
\text { JX488553 } \\
\text { JX488551 } \\
\text { JX488555 } \\
\text { JX488556 }\end{array}$ \\
\hline 6. Buri - SP, BRA & $23^{\circ} 42^{\prime} \mathrm{S} ; 48^{\circ} 34^{\prime} \mathrm{W}$ & 5 & $\begin{array}{l}1240^{\mathrm{b}} \\
1251^{\mathrm{b}} \\
1254^{\mathrm{b}} \\
2962^{\mathrm{b}} \\
2966^{\mathrm{b}}\end{array}$ & $\begin{array}{l}\text { MZUSP76135 } \\
\text { MZUSP75604 } \\
- \\
- \\
-\end{array}$ & $\begin{array}{l}\text { JX488502 } \\
\text { JX488503 } \\
\text { JX488504 } \\
\text { JX488505 } \\
\text { JX488506 }\end{array}$ & $\begin{array}{l}\text { JX488557 } \\
\text { JX488558 } \\
\text { JX488559 } \\
\text { JX488570 } \\
\text { JX488571 }\end{array}$ \\
\hline 7. Cunha - SP, BRA & $23^{\circ} 07^{\prime} \mathrm{S} ; 44^{\circ} 56^{\prime} \mathrm{W}$ & 3 & $\begin{array}{l}12003^{\mathrm{b}} \\
12006^{\mathrm{b}} \\
12007^{\mathrm{b}}\end{array}$ & $\begin{array}{l}\text { MZUSP } 81387 \\
\text { MZUSP82632 } \\
\text { MZUSP82631 }\end{array}$ & $\begin{array}{l}\text { JX488530 } \\
\text { JX488531 } \\
\text { JX488532 }\end{array}$ & $\begin{array}{l}\text { JX488581 } \\
\text { JX488582 } \\
\text { JX488583 }\end{array}$ \\
\hline 8. Ortigueira - PR, BRA & $24^{\circ} 12^{\prime} \mathrm{S} ; 50^{\circ} 55^{\prime} \mathrm{W}$ & 3 & $\begin{array}{l}11407^{\mathrm{b}} \\
11408^{\mathrm{b}} \\
11412^{\mathrm{b}}\end{array}$ & $\begin{array}{l}\text { MZUSP75679 } \\
- \\
-\end{array}$ & $\begin{array}{l}\text { JX488527 } \\
\text { JX488528 } \\
\text { JX488529 }\end{array}$ & $\begin{array}{l}\text { JX488578 } \\
\text { JX488579 } \\
\text { JX488580 }\end{array}$ \\
\hline 9. Pinhalão - PR, BRA & $23^{\circ} 58^{\prime} \mathrm{S} ; 50^{\circ} 03^{\prime} \mathrm{W}$ & 1 & $1296^{\mathrm{b}}$ & MZUSP75641 & JX488507 & JX488560 \\
\hline 10. Wenceslau Braz - PR, BRA & $23^{\circ} 51^{\prime} \mathrm{S} ; 49^{\circ} 48^{\prime} \mathrm{W}$ & 2 & $\begin{array}{l}1384^{\mathrm{b}} \\
1388^{\mathrm{b}}\end{array}$ & $\begin{array}{l}- \\
-\end{array}$ & $\begin{array}{l}\text { JX488508 } \\
\text { JX488509 }\end{array}$ & $\begin{array}{l}- \\
\text { JX488561 }\end{array}$ \\
\hline 11. Campo Belo do Sul - SC, BRA & $27^{\circ} 53 \mathrm{~S} ; 50^{\circ} 45^{\prime} \mathrm{W}$ & 3 & $\begin{array}{l}\text { DA29326 } \\
\text { DA29328 } \\
\text { DA29522 }\end{array}$ & $\begin{array}{l}- \\
- \\
-\end{array}$ & $\begin{array}{l}- \\
- \\
-\end{array}$ & $\begin{array}{l}\text { JX488601 } \\
\text { JX488602 } \\
\text { JX488603 }\end{array}$ \\
\hline 12. Rancho Queimado - SC, BRA & $27^{\circ} 40^{\prime} \mathrm{S} ; 49^{\circ} 01^{\prime} \mathrm{W}$ & 7 & $\begin{array}{l}2150^{\mathrm{b}} \\
2153^{\mathrm{b}} \\
2160^{\mathrm{b}} \\
2161^{\mathrm{b}} \\
2164^{\mathrm{b}} \\
2165^{\mathrm{b}} \\
2196^{\mathrm{b}}\end{array}$ & $\begin{array}{l}- \\
- \\
- \\
- \\
- \\
- \\
\text { MZUSP82783 }\end{array}$ & $\begin{array}{l}\text { JX488512 } \\
\text { JX488513 } \\
\text { JX488514 } \\
\text { JX488515 } \\
\text { JX488516 } \\
\text { JX488517 } \\
\text { JX488518 }\end{array}$ & $\begin{array}{l}\text { JX488565 } \\
- \\
\text { JX488566 } \\
\text { JX488567 } \\
\text { JX488568 } \\
\text { JX488569 } \\
-\end{array}$ \\
\hline 13. Arroio do Padre - RS, BRA & $31^{\circ} 22^{\prime} \mathrm{S} ; 52^{\circ} 23^{\prime} \mathrm{W}$ & 2 & $\begin{array}{l}2135^{\mathrm{b}} \\
2138^{\mathrm{b}}\end{array}$ & - & $\begin{array}{l}\text { JX488510 } \\
\text { JX488511 }\end{array}$ & $\begin{array}{l}\text { JX488563 } \\
\text { JX488564 }\end{array}$ \\
\hline 14. Parque Uruguaí, Uruzú, Misiones, ARG & $25^{\circ} 51^{\prime} \mathrm{S} ; 55^{\circ} 10^{\prime} \mathrm{W}$ & 1 & $1409^{\mathrm{b}}$ & - & JX488519 & JX488562 \\
\hline 15. Paraje Maria Soledad, Misiones, ARG & $25^{\circ} 51^{\prime} \mathrm{S} ; 53^{\circ} 59^{\prime} \mathrm{W}$ & 7 & $\begin{array}{l}10345^{\mathrm{b}} \\
10358^{\mathrm{b}} \\
10364^{\mathrm{b}} \\
10371^{\mathrm{b}} \\
10383^{\mathrm{b}} \\
10385^{\mathrm{b}} \\
10387^{\mathrm{b}}\end{array}$ & $\begin{array}{l}- \\
- \\
- \\
- \\
- \\
-\end{array}$ & $\begin{array}{l}\text { JX488520 } \\
\text { JX488521 } \\
\text { JX488522 } \\
\text { JX488523 } \\
\text { JX488524 } \\
\text { JX488525 } \\
\text { JX488526 }\end{array}$ & $\begin{array}{l}\text { JX488572 } \\
\text { JX488573 } \\
- \\
\text { JX488574 } \\
\text { JX488575 } \\
\text { JX488576 } \\
\text { JX488577 }\end{array}$ \\
\hline
\end{tabular}

BRA - Brasil; ARG - Argentina.

Tissue collections:

${ }^{a}$ Laboratório de Biodiversidade e Evolução Molecular, Instituto de Ciências Biomédicas, Universidade Federal de Minas Gerais.

b Laboratório de Genética e Evolução Molecular de Aves (LGEMA), Instituto de Biociências, Universidade de São Paulo.

c Departamento de Genética, Universidade Federal do Rio Grande do Sul.

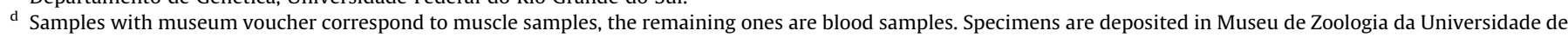
São Paulo (MZUSP). 
UPGMA tree, linear model, 50 million steps, parameters sampled every 10,000 steps and a burn-in of $10 \%$. The hLRT test did not reject the molecular clock hypothesis for both loci. The best fit substitution model for each partition (loci) was determined by Modeltest 3.7 (Posada and Krandall, 1998). We used 1.05\% (s.d. $0.05 \%$ ) per lineage per million years as the mutation rate for cytb (Weir and Schluter, 2008) under a normal prior distribution. Based on the probabilities obtained, BEAST estimated the mutation rate for FIB5 under a default lognormal prior distribution. To check the convergence of parameters between runs and analysis performance (ESS values > 200) we used TRACER 1.5 (http://beast.bio. ed.ac.uk/Tracer).

\subsection{Coalescent simulations}

In order to evaluate the demographic history we simulated scenarios in BAYESSC, a modified version of SERIAL SIMCOAL (Anderson et al., 2005; Chan et al., 2006), and evaluated the goodness of fit of the observed data to the simulations. The general procedure followed Richards et al. (2007). We also followed the methodology suggested by Voight et al. (2005) that considers several summary statistics and results on a single posterior probability for each model. This procedure has been widely applied in recent studies (i.e.: Belle et al., 2006; Fabre et al., 2009; Ghirotto et al., 2010; Cabanne et al., 2011; Fischer et al., 2011; Brace et al., 2012).
The rationale of this procedure consists in testing models by simulating genealogies under specific demographic scenarios and then evaluating the fit of the empirical data to the simulated data (Knowles, 2009). If the empirical (observed) data fits well to the simulated data, this given demographic scenario would receive a high posterior probability and therefore, be supported. Alternatively, if the observed data does not fit well into the distribution of the simulated data, the posterior probability would be low and the specific scenario would not be supported.

The models that were tested differed in the timing and number of bottlenecks (Fig. 2, models A to E). Also, as genetic signals of expansion may be found in a demographically stable island system (see Nielsen and Beaumont, 2009; Peter et al., 2010), we also simulated two island models that originated before the Pleistocene (Fig. 2, models $F$ and $G$ ). This date was estimated based on the divergence of $B$. leucoblepharus and its sister species B. flaveolus (Lovette et al., 2010). For the island models we grouped sampling localities by geographic proximity into five populations as follows: pop 1 - localities $1-4$; pop 2 - locality 5; pop 3 - localities 6-10; pop 4 - localities 11-13; pop 5 - localities 14 and 15. Grouping by geographic proximity was the simplest way to recreate a plausible island model. Other configurations of island models could have been evaluated, but they would be more complex. Complex models should be avoided in this kind of procedure because they would get a higher posterior probability but without being plausi-
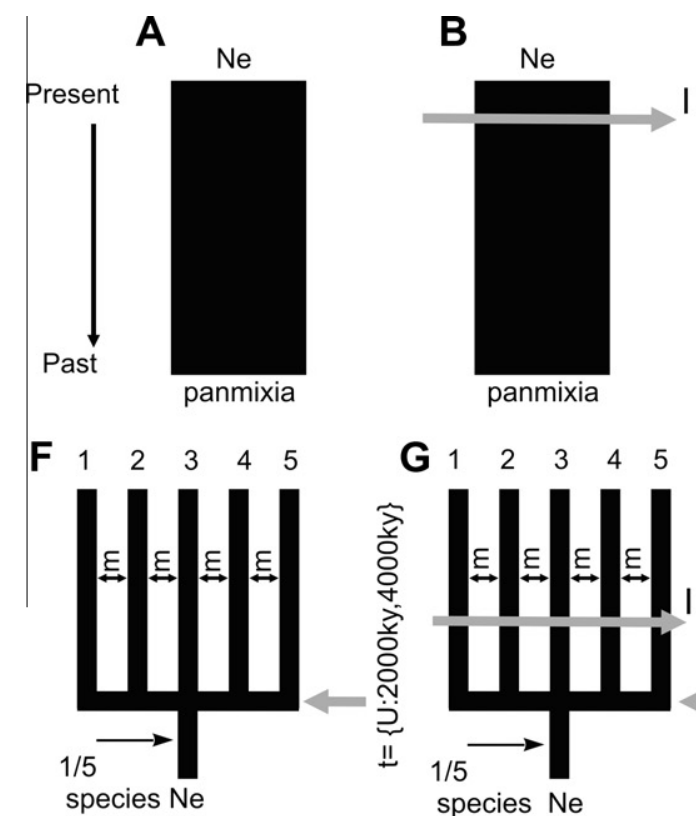

Migration parameters panmixia: random mating $m=\{U: 0,0.01\}$

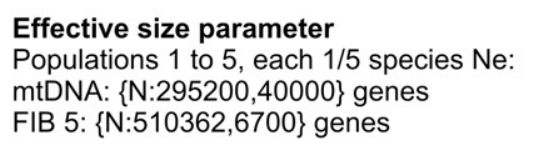

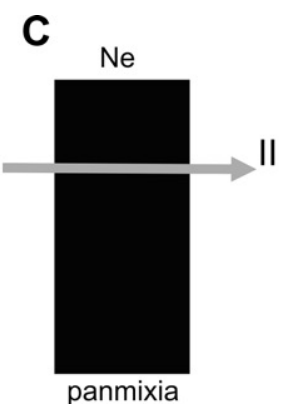

D
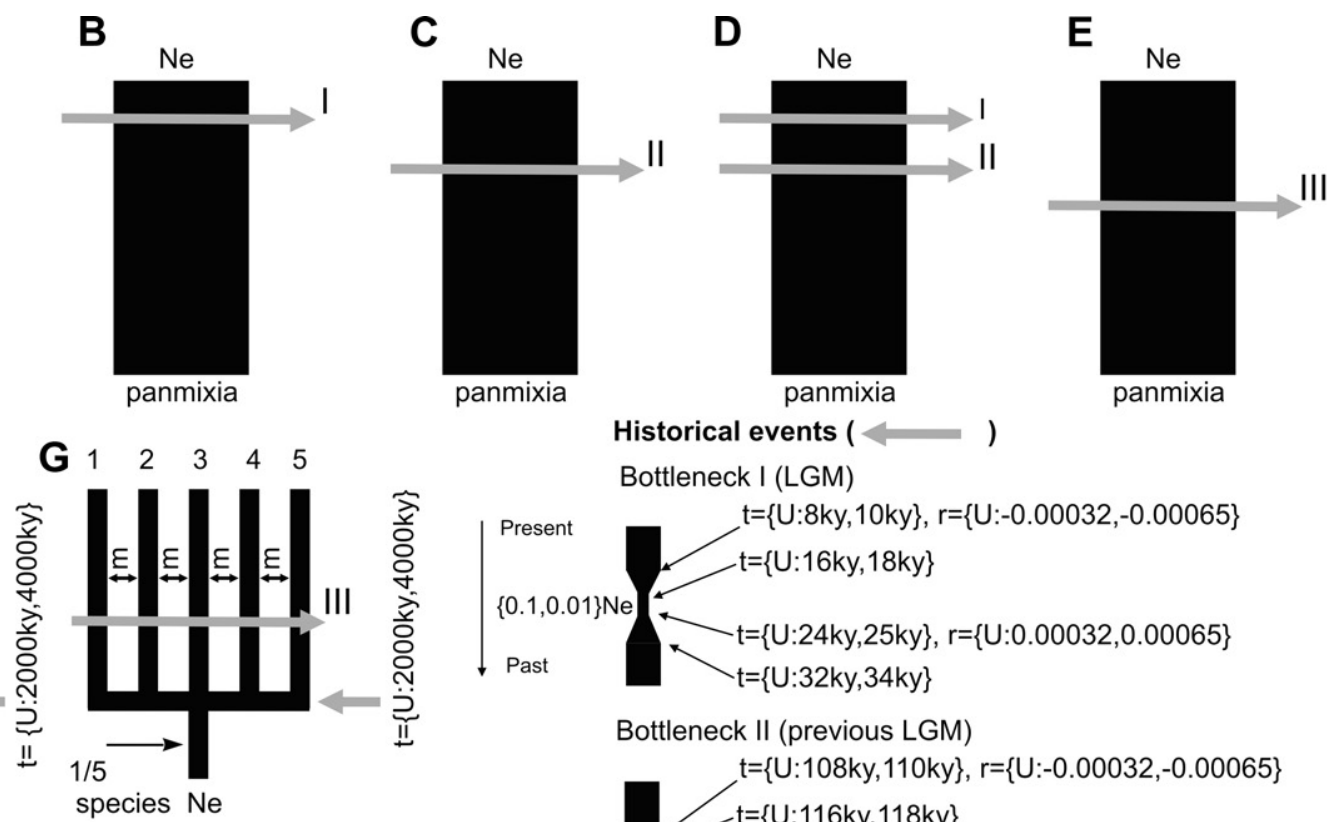

Bottleneck II (previous LGM)

$\{0.1,0.01\} \mathrm{Ne}$

Bottleneck III (Upper Pleistocene)

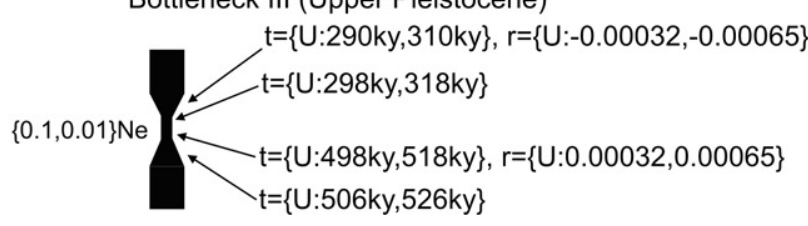

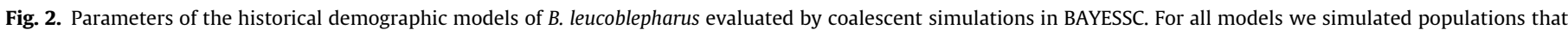

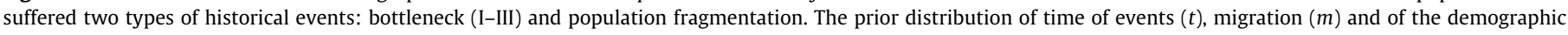

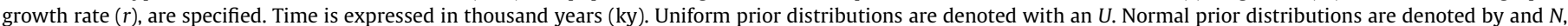

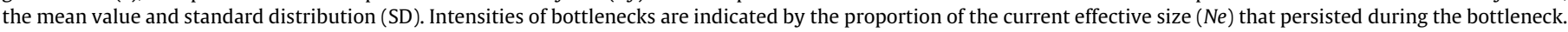
Time is expressed in kilo-years (ky). LGM: last glacial maximum. 
Table 2

Summary statistics for cytochrome b (cytb) and beta-fibrinogen intron 5 (FIB5) of $B$. leucoblepharus.

\begin{tabular}{lllllll}
\hline Locus & $N$ & $\pi$ & $l$ & $D$ & $F_{s}$ & $R_{2}$ \\
\hline cytb & 55 & 0.00562 & 34 & $-1.7072^{*}$ & $-27.1696^{* * *}$ & $0.0494^{* *}$ \\
FIB5 & 86 & 0.00536 & 25 & $-1.3053^{\text {ns }}$ & $-14.1737^{* * *}$ & $0.0554^{*}$ \\
\hline
\end{tabular}

$N$ : sample size; $\pi$ : nucleotide diversity per site; $l$ : number of haplotypes; $D$ : Tajima's test; $F_{s}$ : Fu's test; $R_{2}$ : Ramos-Onsins and Rozas' test; ${ }^{\text {ns }}$ not-significant.

* $0.10>p>0.05$.

** $p<0.05$.

*** $p<0.01$.

ble (Nielsen and Beaumont, 2009). Specifically, Nielsen and Beaumont (2009) suggested to use simple models as a baseline against which to compare more complex models.

We simulated bottlenecks that reduced the population effective size $(\mathrm{Ne})$ to $1-10 \%$ of the current size. We estimated $\mathrm{Ne}$ from theta $(\Theta=2 \mu \mathrm{Ne}$ ) that was obtained assuming the F84 model of sequence evolution (Felsenstein and Churchill, 1996), and empirical base frequencies and transition/transversion ratios with a Markov chain Monte Carlo (default settings) in LAMARC 2.1.2b (Kuhner, 2006). We assumed that $\mathrm{Ne}$ from each present population and from ancestral populations in models $F$ and G (Fig. 2) was $1 / 5$ of the species' $N e$. Effective number of genes was introduced in BAYESSC infiles as presenting a normal distribution with a mean equal to the maximum likelihood estimation of $\mathrm{Ne}$ and standard deviation estimated from $\Theta$ confidence interval. For mtDNA we used a mutation rate as a uniform interval $1.05 \times 10^{-8}-9.14 \times 10^{-7}$ changes/site/generation (Weir and Schluter, 2008). The transition bias was 0.85 , the mutation rate gamma distribution was 0.84 and the number of mutation categories was six. For FIB5, the mutation rate was obtained from the EBSP analysis in BEAST; the uniform rate interval was $3.86 \times 10^{-9}-6.99 \times 10^{-10}$ changes/site/ generation. The transition bias was 0.7 , the mutation rate gamma distribution was 0.77 and the number of mutation categories was six. We assumed a generation time of 1 year as Cabanne et al. (2008).

For each model we ran 1000 simulations per marker (mtDNA and FIB5). Then, for each simulated data we estimated three sum- mary statistics [nucleotide diversity - $\pi$, Tajima's $D$ (Tajima, 1989), and number of haplotypes $-h$ ] to obtain null distributions against which we tested the observed data (Hickerson et al., 2006). For evaluating the goodness of fit of the observed data to the simulated one, we followed Voight et al. (2005) and used the two-tailed empirical likelihood $p i$ of each summary statistics $i$;

$p i=1-[2 \times(|0.5-p|)]$

being $p$ the proportion of simulated values equal or higher than the observed summary statistic. When the observed statistic fell outside the simulated distribution we attributed $p i=0.00001$, as in Cabanne et al. (2011). Then, we combined the three pi values by

$C_{o b s}=-2 \sum_{i=1}^{k} \ln p_{i}$

and obtained its significance. The significance was assessed by comparing $C_{o b s}$ against a null distribution of $C$ obtained following Voight et al. (2005) and Fabre et al. (2009). For each simulated dataset, each summary statistic was compared with the other values representing the empirical distribution of the statistic from simulation. Specifically, we treated the value of each summary statistic as the observed value and calculated with Eq. (1) its $p_{\text {sim }}$-value relative to the remaining 999 simulated data. Then, the null distribution of $C$ was obtained by combining with Eq. (2) $p_{s i m}$-values across summary statistics and the significance of $C_{o b s}$ was obtained as in step 1 (Eq. (1)). This procedure generated two-tailed combined $p$-values associated to each marker. Finally, the overall $P$-value for the model was obtained by combining $p$-values of both markers by the parametric Fisher's method in METAP (Whitlock, 2005), which is authored by Ge (available at http://compute1.lsrc.duke.edu/softwares/MetaP/metap.php). We rejected models when $P \leqslant 0.05$.

\section{Results}

\subsection{Diversity and genetic structure}

We obtained 914 bp of cytb $(N=55)$ and 512 bp of FIB5 $(N=114$ sampled chromosomes). No indels were observed in cytb, but FIB5

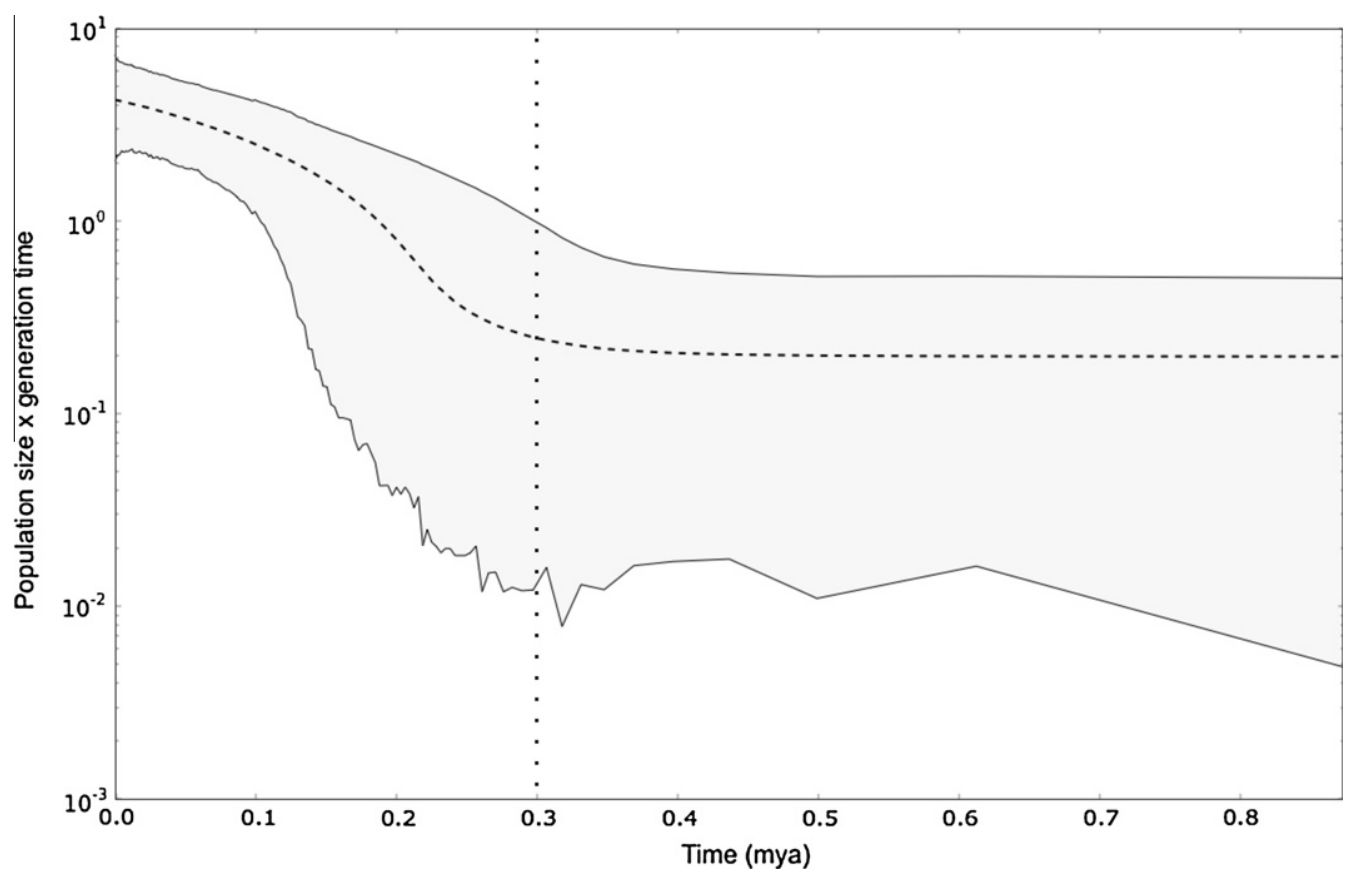

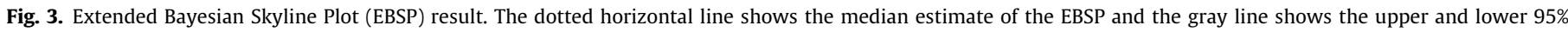

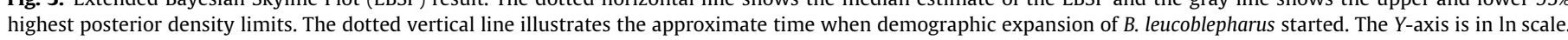



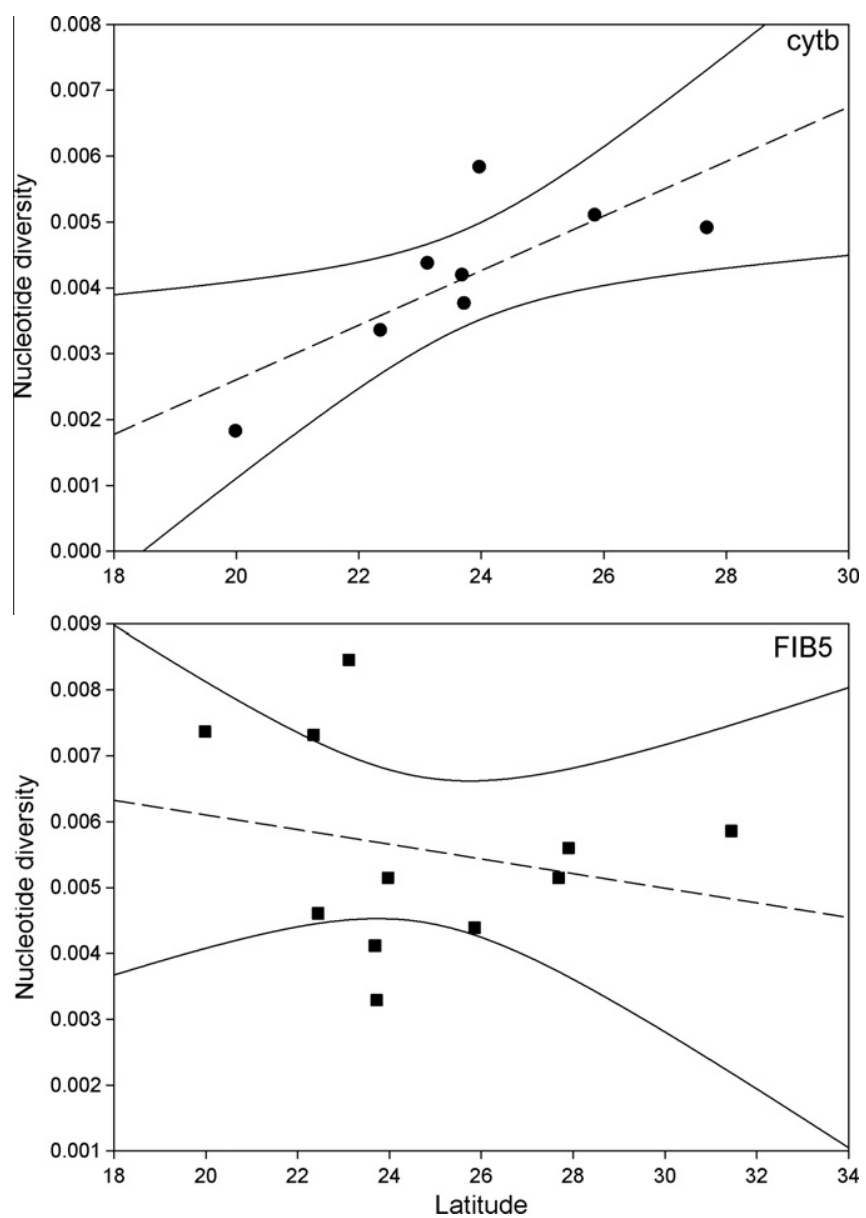

Fig. 4. Correlation between nucleotide diversity $(\pi)$ of mitochondrial (cytb) and nuclear (FIB5) genes, and degrees of latitude of localities. Dashed lines represent the fitted linear model and the solid lines represent 95\% of confidence intervals calculated for the regression line.

had an indel of $6 \mathrm{bp}$ in ten samples from various localities. There were 40 polymorphic sites in cytb and 41 in FIB5 after excluding indels and ambiguous sites. No unexpected stop codons or ambiguous peaks in the electropherograms were found in cytb sequences, suggesting that they were of mitochondrial origin. The haplotype reconstruction by PHASE resolved a total of 43 samples ( 86 sampled chromosomes) with $p>0.7$, and the remaining 11 specimens with low PHASE probability were removed from further analyses. The PHI test $(p=0.09)$ excluded the hypothesis of recombination in FIB5. The summary statistics for both loci are shown in Table 2.
We used different strategies to identify population genetic structure. Haplotype networks based on each of the two marker sequences showed absence of genetic structure. The most common and internal haplotypes were found in geographically distant locations (Fig. 1). AMOVA indicated that the highest percentage of genetic variation was observed within localities, 69.8\% $(p<0.00001)$ for cytb and $92.3 \%$ ( $p=0.02053$ ) for FIB5, indicating that the genetic structure among localities is low (mtDNA) or absent (FIB5). When we applied the three hierarchical level AMOVA we did not find strong genetic structure between the hypothetical groups (variation among groups $=18.23 \%$; variation among localities within groups $=17.53 \%$; variation within localities $=64.23 \%$ ). Mantel test indicated no correlation between genetic and geographic distances $\left[r_{c y t b}=0.2567(p=0.107) ; r_{F I B 5}=0.1108(p=0.201)\right]$, also suggesting absence of isolation by distance between localities. BAPS analysis indicated presence of two and three populations for mitochondrial and nuclear genes, respectively (Fig. 1e). Notwithstanding, these clusters were not spatially coherent for either markers and therefore confirmed absence of population structure.

\subsection{Historical demography}

All neutrality test values were significant (except Tajima's $D$ for FIB5), indicating sign of demographic expansion in both loci (Table 2). According to Ramos-Onsins and Rozas (2002), $F_{s}$ and $R_{2}$ tests are more robust in detecting events of demographic expansion, and $F_{S}$ is more suitable for larger samples while $R_{2}$, for smaller samples.

The EBSP indicated that $B$. leucoblepharus experienced a demographic expansion starting about 300,000 years ago (Fig. 3), possibly associated to climate changes during the late Pleistocene. The demographic expansion event dated here is older than the last glacial maximum (LGM), when paleopalinological records indicate that open areas (grasslands) were present in the AF between 48,000 and 18,000 years ago (Behling and Lichte, 1997; Behling, 2002). Thus, we performed coalescent simulations to test the effect of the LGM on the effective population size of B. leucoblepharus.

The relationship between $\pi$ and latitude indicated a possible demographic expansion from south to north for cytb $\left(R^{2}=31.36 \%, p=0.029\right)$, but for FIB5 there is no correlation between latitude and $\pi\left(R^{2}=5.21 \%, p=0.4998\right)$ (Fig. 4).

\subsection{Coalescent simulations}

We simulated mtDNA and FIB5 sequences under seven different demographic scenarios to explore whether populations suffered specific bottlenecks, as expected according to the history of the AF, or alternatively, followed a panmictic or finite island model. The simulated models are (Fig. 2): (A) a panmictic stable population;

Table 3

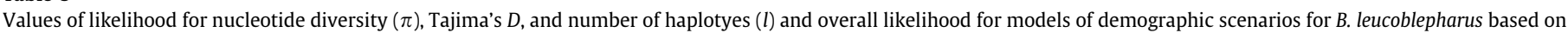
mtDNA and FIB5 datasets.

\begin{tabular}{|c|c|c|c|c|c|c|c|c|c|c|}
\hline \multicolumn{2}{|c|}{ Demographic model } & \multicolumn{4}{|l|}{ mtDNA } & \multicolumn{4}{|l|}{ FIB5 } & \multirow{2}{*}{$\begin{array}{l}\text { Overall } P \text { - } \\
\text { value }\end{array}$} \\
\hline & & $p \pi$ & $p D$ & $p l$ & $\begin{array}{l}\text { Combined } p \text { - } \\
\text { values }\end{array}$ & $p \pi$ & $p D$ & $p l$ & $\begin{array}{l}\text { Combined } p \text { - } \\
\text { values }\end{array}$ & \\
\hline A & Panmixia, stability & 0.00001 & 0.016 & 0.87 & 0.00001 & 0.006 & 0.088 & 0.868 & 0.076 & 0.00001146 \\
\hline B & Panmixia, bottleneck LGM & 0.364 & 0.136 & 0.00001 & 0.00001 & 0.45 & 0.074 & 0.132 & 0.254 & 0.00003526 \\
\hline $\mathrm{C}$ & Panmixia, bottleneck 120 ky ago & 0.304 & 0.294 & 0.342 & 0.61 & 0.384 & 0.264 & 0.26 & 0.584 & $0.7239^{*}$ \\
\hline $\mathrm{D}$ & Panmixia, bottlenecks LGM and 120 ky ago & 0.68 & 0.236 & 0.00001 & 0.006 & 0.594 & 0.18 & 0.054 & 0.32 & 0.0139 \\
\hline $\mathrm{E}$ & Panmixia, bottleneck $300-500$ ky ago ${ }^{* *}$ & 0.614 & 0.6918 & 0.755 & 0.3483 & 0.42 & 0.4225 & 0.3159 & 0.8305 & $0.6481^{*}$ \\
\hline $\mathrm{F}$ & $\begin{array}{l}\text { Stable finite island, origin } 2-4 \text { m.y.a. ago, gene } \\
\text { flow } 0-0.01\end{array}$ & 0.004 & 0.024 & 0.284 & 0.010 & 0.07 & 0.114 & 0.418 & 0.212 & 0.0152 \\
\hline G & Model F, bottleneck 300-500 ky ago & 0.928 & 0.994 & 0.258 & 0.474 & 0.00001 & 0.106 & 0.052 & 0.00001 & 0.00006284 \\
\hline
\end{tabular}

* Scenarios not rejected.

** Date in accordance with observed results from EBSP analysis. 
(B) a panmictic population that suffered a bottleneck during the LGM; (C) a panmictic population that suffered a bottleneck during the glaciation previous to the LGM; (D) a panmictic population that suffered bottlenecks during the last two glacial maxima; (E) a panmictic population that suffered a bottleneck during the upper Pleistocene (300,000-500,000 years ago), according to the results of EBSP (Fig. 3); (F) a stable finite island system connected by gene flow and that originated before the Pleistocene (2-4 m.y.a. ago); (G) model $\mathrm{F}$ but including a bottleneck at the upper Pleistocene.

We initially estimated the effective number of genes to be used in simulations. Species' Ne for mtDNA was $1,476,000$ (SE 200,000) genes and for FIB5 2,551,810 (SE 33,700) genes. We used one fifth of the total species' $\mathrm{Ne}$ as the effective size of each of the five populations used in simulated models: 295,200 genes for mtDNA and 510,362 for FIB5.

Five models were rejected (overall $P<0.05$; Table 3 ), namely, a single panmictic and stable population (model A), a bottleneck during the LGM (B), two consecutive bottlenecks during the last two glaciations (D), and island systems (F and $G$ ). The last result shows that our data does not support the possibility that the observed expansion signal could be explained by an island model.

There were two models that were not rejected. The simplest scenario suggests that the observed data could have been produced after a bottleneck that occurred at the maximum glaciation before the last one (model C, 120,000 years ago). The other scenario suggests a bottleneck at mid Pleistocene (model E, 300,000500,000 years ago).

\section{Discussion}

\subsection{Phylogeographic structure and demography of B. leucoblepharus}

The results of the haplotype networks, AMOVA, and comparison between genetic and geographic distances based on both mitochondrial and nuclear loci indicate absence of a strong population genetic structure in Basileuterus leucoblepharus (Fig. 1). Nevertheless, BAPS analysis indicated the presence of clusters for both loci, but these groups did not present any geographic structure (Fig. 1e). However, Bayesian approaches implemented in BAPS and Structure (Pritchard et al., 2000) are very sensitive to low levels of genetic differentiation (i.e. $F_{S T}$ around 0.03-0.05; Latch et al., 2006), thus, when $F_{S T}$ values are very low the number of incorrect assignments is high (Latch et al., 2006). In sum, even though AMOVA also indicated that $30 \%$ of the genetic variation of cytb is allocated between localities, no clear geographic structure was observed. Yet, the three hierarchical level AMOVA showed that just $18 \%$ of variation is allocated between the hypothetical groups. Thus, our data indicated absence of genetic structure in B. leucoblepharus.

Interestingly, the phylogeographic pattern we found in $B$. leucoblepharus is not congruent with previous phylogeographic studies of other AF organisms (Fig. 1a) that show recurrent geographic discontinuities possibly caused by vicariant events associated to climate changes or geotectonic activities in the Quaternary (Grazziotin et al., 2006; Cabanne et al., 2007, 2008; Carnaval et al., 2009; Martins et al., 2009; Batalha-Filho et al., 2010; Ribeiro et al., 2010; Thomé et al., 2010; d'Horta et al., 2011).

The absence of a strong differentiation among localities and the significant signal of demographic expansion (Table 2 and Fig. 4) suggest that $B$. leucoblepharus suffered a bottleneck followed by demographic expansion. This expansion occurred approximately in mid Pleistocene, as suggested by the EBSP, and is likely related to climate changes that occurred locally in that period. This date estimate is not congruent with the end of the LGM, when the glaciers started to retreat between 20,000 and 14,000 years ago (Sant'Anna Neto and Nery, 2005; Anderson et al., 2007). Therefore, our results suggest that $B$. leucoblepharus maintained its population size relatively stable during the LGM in the AF, contrarily to what would be expected according to the Pleistocene forest refuge model.

The particular pattern exhibited by B. leucoblepharus, in comparison to other organisms from the AF (Grazziotin et al., 2006; Cabanne et al., 2007, 2008; Carnaval et al., 2009; Martins et al., 2009; Batalha-Filho et al., 2010; Ribeiro et al., 2010; Thomé et al., 2010; d'Horta et al., 2011; Cabanne et al., 2011; Maldonado-Coelho, 2012), might be associated to different habitat requirements presented by these species. In addition, the phylogeographic barriers observed for some endemic taxa from AF (Fig. 1a) may have acted as selective ecological filters (see Toon et al., 2010), i.e., only species with higher tolerance to habitat fragmentation were able to maintain gene flow or disperse across these barriers. $B$. leucoblepharus is relatively tolerant to habitat fragmentation (Stotz et al., 1996), and thus, barriers that affected several other AF forest birds (references as above) were probably not strong enough to preclude gene flow in B. leucoblepharus. This would explain the absence of phylogeographic structure in this species.

According to Moritz et al. (2000), the location, size and existence of forest refugia during the glacial maximum are dependent on the ecological and environmental tolerances of each species. Thus, $B$. leucoblepharus seems to have been able to maintain a stable population through the late Pleistocene, even during peaks of glaciations when forests fragmented and the climate was temperate (Behling, 2002). Contrarily to other AF birds that present a strong population genetic structure and historical demography affected by late Pleistocene glaciations, such as Sclerurus scansor (d'Horta et al., 2011) and Xiphorhynchus fuscus (Cabanne et al., 2007, 2008), the current southeastern distribution limit of $B$. leucoblepharus reaches temperate regions with discontinuous forest; namely the riparian forest from humid Chaco and pampas grasslands in eastern Argentina and Uruguay. Also, in the core of the AF B. leucoblepharus is found in montane forests where winters are temperate to cool (personal observation by HBF, Stotz et al., 1996), and in forest fragments within the Cerrado (Stotz et al., 1996). Thus, B. leucoblepharus seems to have been more tolerant to the climatic changes of the late Pleistocene than S. scansor and X. fuscus.

We rejected the presence of a bottleneck and demographic expansion at the LGM, and apparently the ecological flexibility of $B$. leucoblepharus might have been determinant for this response. However, it is not clear why this bird seems not to have been affected by the last glaciation, but affected by the previous glaciation, as suggested by the observed data (Fig. 3) and the simulations (Fig. 2). The two last glaciation maxima seem to have been similar in duration and intensity of cooling (Petit et al., 1999; Anderson et al., 2007), therefore, the effect on forests and their organisms should have been similar. Knowledge on the detailed paleogeographic and paleo-vegetation histories of the AF during the mid Pleistocene is almost inexistent. At the global scale this period coincides with the Mid-Brunhes event, a transition period from relative cool interglacial and small amplitude of glacial/interglacial temperature variation to warmer interglacials with larger amplitude of temperature variation (Anderson et al., 2007). However, the conditions in the AF and how organisms were affected during this period are unknown. Anyway, even though simulations did not favor a single date for bottlenecks, they suggest that there was a strong one. More phylogeographic studies are needed to identify the nature of the demographic expansion suffered by $B$. leucoblepharus.

\subsection{Phylogeographic patterns in the Atlantic forest: a new pattern revealed by Basileuterus leucoblepharus?}

In general, phylogeography studies of AF organisms show three main recurrent breaks (Fig. 1a): (i) one break in the state of São 
Paulo, close to the valleys of the rivers Paraíba do Sul, Tietê and Ribeira do Iguape (snake, birds, frogs, bats, and toad; Grazziotin et al., 2006; Cabanne et al., 2007, 2008, 2011; Carnaval et al., 2009; Martins et al., 2009; Batalha-Filho et al., 2010; Thomé et al., 2010; d'Horta et al., 2011); (ii) one break in the state of Minas Gerais, close to the valleys of the rivers Jequitinhonha and Doce (bird and frogs; Cabanne et al., 2007, 2008; Carnaval et al., 2009; d'Horta et al., 2011); and (iii) a break in northeastern Brazil, close to the mouth of the São Francisco river (bird and frogs; Cabanne et al., 2008; Carnaval et al., 2009).

Regarding phylogeographic breaks $\mathrm{i}$ and ii, the dates of the origins of the river valleys are older than the estimated intraspecific divergence dates, and therefore the geologic origin of the valleys could not have been the primary cause of lineage divergence. Phylogeographic studies of AF birds (Cabanne et al., 2007, 2008; d'Horta et al., 2011), bats (Pavan et al., 2011) and frogs (Carnaval et al., 2009) could not reject that lineage divergences were associated with habitat fragmentation due to the glacial cycles in the Pleistocene. These studies were also congruent with a model of Pleistocene forest refugia in the AF based on paleoclimatic modeling of the LGM (Carnaval and Moritz, 2008). However, it is interesting to note that a snake (Grazziotin et al., 2006) also presents a phylogeographic break in this same region (break i, Fig. 1a). Even though these barriers show congruence in space, the estimated dates were not congruent (e.g. for break i: 3.87 m.y.a. for the snake and 0.39 m.y.a. for a bird). Moreover, two other studies with bees (Batalha-Filho et al., 2010) and toads (Thomé et al., 2010) suggest that some of these phylogeographic breaks also coincide with putative barriers associated to neotectonic activities.

The ecological niche modeling of the AF during the LGM by Carnaval and Moritz (2008) indicated that the forested areas in the southern portion of this biome were more fragmented than forests at the northern portion. Some recent studies have confirmed this hypothesis (Cabanne et al., 2007, 2008; Carnaval et al., 2009; Martins et al., 2009; d'Horta et al., 2011; Martins, 2011). However, our results were not congruent with the Carnaval and Moritz (2008) hypothesis because we did not find a strong genetic structure, a bottleneck followed by a strong signal of demographic expansion at the LGM, and a tendency of expansion from north to south (Figs. 1 and 3). Moreover, the comparison of nucleotide diversity of the mtDNA versus latitude showed that the south holds higher levels of genetic diversity (Fig. 4). This result disagrees with the latitudinal gradient hypothesis, which states that higher diversity levels should be found in lower latitudes (Miller et al., 2010; d'Horta et al., 2011). Furthermore, our simulations rejected the scenarios where the effects of LGM were tested (Table 3). Thomé et al. (2010) observed toad lineages that survived in the southern portion of the AF, and this is also not congruent with the Carnaval and Moritz (2008) hypothesis.

Both traditional and model-based phylogeographic approaches allowed us to infer about the evolutionary history of $B$. leucoblepharus and the diversification dynamics within the AF. To our knowledge, the present work revealed the first example of an AF organism (B. leucoblepharus) without a strong population genetic structure and whose population size did not change during the LGM. Thus, our results show that more AF organisms should be investigated to help in the reconstruction of the evolutionary history of this biome. As more taxa are studied, new scenarios shall be revealed. Costa (2003) suggested that speciation in the Neotropics could not be explained by any single model of vicariance or climatic change. Thus, it is possible that no general pattern for organisms' diversification in the AF will arise, but a complex range of scenarios shall be described.

\section{Acknowledgments}

We thank Pablo Tubaro, Fabrício R. Santos, Sibelle T. Vilaça, Luis F. Silveira, and Claiton M. Ferreira for access to tissues and skins under their care. We thank Fábio S.R. Amaral and Claydson P. Assis for immensely help in field work. We thank Fernando M. d'Horta, Rodrigo O. Pessoa, Renato G. Lima, and Guilherme R. Brito for collecting some samples used in this study. We thank Diogo Meyer for insightful discussions on coalescent simulations and Virginie Fabre for helping us to estimate the C-statistics. We thank an anonymous reviewer and the Editor Richard E. Taschian for their comments. This study is part of the PhD dissertation of HBF. Fundação de Amparo à Pesquisa do Estado de São Paulo, Coordenação de Aperfeiçoamento de Pessoal de Nível Superior, Conselho Nacional de Desenvolvimento Científico e Tecnológico, and Consejo Nacional de Investigaciones Científicas y Técnicas (Argentina) provided funds. Instituto Brasileiro do Meio Ambiente e dos Recursos Naturais Renováveis, Instituto Chico Mendes de Conservação da Biodiversidade, and Ministério de Ecologia de la Província de Misiones (Argentina) provided permits to collect samples. BEAST analysis was carried out by using the resources of the Computational Biology Service Unit from Cornell University which is partially funded by Microsoft Corporation. This work was developed in the Research Center on Biodiversity and Computing, of the Universidade de São Paulo (BioComp).

\section{References}

Anderson, C.N.K., Ramakrishnan, U., Chan, Y.L., Hadly, E.A., 2005. Serial SimCoal: a population genetics model for data from multiple populations and points in time. Bioinformatics 21, 1733-1734.

Anderson, D.E., Goudie, A.S., Parker, A.G., 2007. Global Environments through the Quaternary. Oxford University Press, Oxford.

Bandelt, H.J., Forster, P., Röhl, A., 1999. Median-joining networks for inferring intraspecific phylogenies. Mol. Biol. Evol. 16, 37-48.

Batalha-Filho, H., Waldschmidt, A.M., Campos, L.A.O., Tavares, M.G., FernandesSalomão, T.M., 2010. Phylogeography and historical demography of the Neotropical stingless bee Melipona quadrifasciata (Hymenoptera, Apidae): incongruence between morphology and mitochondrial DNA. Apidologie 41, 534-547.

Behling, H., 2002. South and southeast Brazilian grasslands during Late Quaternary times: a synthesis. Palaeogeogr. Palaeoclimatol. Palaeoecol. 177, 19-27.

Behling, H., Lichte, M., 1997. Evidence of dry and cold climatic conditions at glacial times in tropical southeastern Brazil. Quatern. Res. 48, 348-358.

Behling, H., Pillar, V.D.P., 2007. Late Quaternary vegetation, biodiversity and fire dynamics on the southern Brazilian highland and their implication for conservation and management of modern Araucaria forest and grassland ecosystems. Philos. Trans. R. Soc. B 362, 243-251.

Belle, E.M., Ramakrishnan, U., Mountain, J.L., Barbujani, G., 2006. Serial coalescent simulations suggest a weak genealogical relationship between Etruscans and modern Tuscans. Proc. Natl. Acad. Sci. USA 103, 8012-8017.

Brace, S., Barnes, I., Powell, A., Pearson, R., Woolaver, L.G., Thomas, M.G., Turvey, S.T., 2012. Population history of the Hispaniolan hutia Plagiodontia aedium (Rodentia: Capromyidae): testing the model of ancient differentiation on a geotectonically complex Caribbean island. Mol. Ecol. 21, 2239-2253.

Brown, K.S., Ab'Saber, A.N., 1979. Ice-ages forest refuges and evolution in the Neotropics: correlation of paleoclimatological, geomorphological, and pedological data with modern biological endemism. Paleoclimas 5, 1-30.

Bruen, T.C., Philippe, H., Bryant, D., 2006. A simple and robust statistical test for detecting the presence of recombination. Genetics 172, 2665-2681.

Bruford, M.W., Hanotte, O., Brookfield, J.F.Y., Burke, T., 1992. Single-locus and multilocus DNA fingerprinting. In: Hoelzel, A.R. (Ed.), Molecular Genetic Analysis of Populations-A Practical Approach. IRL Press, New York, pp. 287336.

Bush, M.B., de Oliveira, P.E., 2006. The rise and fall of the refugial hypothesis of Amazonian speciation: a paleoecological perspective. Biot. Neotrop. 6, 1-17.

Cabanne, G.S., Santos, F.R., Miyaki, C.Y., 2007. Phylogeography of Xiphorhynchus fuscus (Passeriformes, Dendrocolaptidae): vicariance and recent demographic expansion in southern Atlantic forest. Biol. J. Linn. Soc. 91, 73-84.

Cabanne, G.S., d'Horta, F.M., Sari, E.H.R., Santos, F.R., Miyaki, C.Y., 2008. Nuclear and mitochondrial phylogeography of the Atlantic forest endemic Xiphorhynchus fuscus (Aves: Dendrocolaptidae): biogeography and systematic implications. Mol. Phylogenet. Evol. 49, 760-773.

Cabanne, G.S., D'Horta, F.M., Meyer, D., Silva, J.M.C., Miyaki, C.Y., 2011. Evolution of Dendrocolaptes platyrostris (Aves: Furnariidae) between the South American open vegetation corridor and the Atlantic forest. Biol. J. Linn. Soc. 103, 801-820. 
Carnaval, A.C., Moritz, C., 2008. Historical climate modeling predicts patterns of current biodiversity in the Brazilian Atlantic forest. J. Biogeogr. 35, 1187-1201.

Carnaval, A.C., Hickerson, M.J., Haddad, C.F.B., Rodrigues, M.T., Moritz, C., 2009. Stability predicts genetic diversity in the Brazilian Atlantic forest hotspot. Science 323, 785-789.

Chan, Y.L., Anderson, C.N.K., Hadly, E.A., 2006. Bayesian estimation of the timing and severity of a population bottleneck from ancient DNA. PLoS Genet. 2, 451-460.

Colinvaux, P.A., de Oliveira, P.E., Bush, M.B., 2000. Amazonian and Neotropical plant communities on glacial time scales: the failure of the aridity and refuge hypothesis. Quaternary Sci. Rev. 19, 141-169.

Corander, J., Marttinen, P., 2006. Bayesian identification of admixture events using multilocus molecular markers. Mol. Ecol. 15, 2833-2843.

Corander, J., Marttinen, P., Siren, J., Tang, J., 2008. Enhanced Bayesian modelling in BAPS software for learning genetic structures of populations. BMC Bioinformatics 9, 539 .

Costa, L.P., 2003. The historical bridge between the Amazon and the Atlantic forest of Brazil: a study of molecular phylogeography with small mammals. J. Biogeogr. 30, 71-86.

d'Horta, F., Cabanne, G.S., Meyer, D., Miyaki, C.Y., 2011. The genetic effects of Late Quaternary climatic changes over a tropical latitudinal gradient: diversification of an Atlantic forest passerine. Mol. Ecol. 20, 1932-1935.

Drummond, A.J., Rambaut, A., 2007. BEAST: Bayesian evolutionary analysis by sampling trees. BMC Evol. Biol. 7, 214.

Ewing, B., Green, P., 1998. Base-calling of automated sequencer traces using phred. II. Error probabilities. Genome Res. 8, 186-194.

Ewing, B., Hillier, L., Wendl, M.C., Green, P., 1998. Base-calling of automated sequencer traces using phred. I. Accuracy assessment. Genome Res. 8, 175-185.

Excoffier, L., Smouse, P.E., Quattro, J.M., 1992. Analyses of molecular variance inferred from metric distances among DNA haplotypes: application to human mitochondrial DNA restriction data. Genetics 131, 479-491.

Excoffier, L., Laval, G., Schneider, S., 2005. Arlequin ver. 3.0: an integrated software package for population genetics data analysis. Evol. Bioinform. 1, 47-50 (online).

Fabre, V., Condemi, S., Degioanni, A., 2009. Genetic evidence of geographical groups among Neanderthals. PLoS One 4, e5151.

Felsenstein, J., Churchill, G.A., 1996. A hidden Markov model approach to variation among sites in rate of evolution. Mol. Biol. Evol. 13, 93-104.

Fischer, A., Prüfer, K., Good, J.M., Halbwax, M., Wiebe, V., André, C., Atencia, R., Mugisha, L., Ptak, S.E., Pääbo, S., 2011. Bonobos fall within the genomic variation of chimpanzees. PLoS One 6, e21605.

Fitzpatrick, S.W., Brasileiro, C.A., Haddad, C.F., Zamudio, K.R., 2009. Geographical variation in genetic structure of an Atlantic coastal forest frog reveals regional differences in habitat stability. Mol. Ecol. 18, 2877-2896.

Fu, Y.X., 1997. Statistical tests of neutrality of mutations against population growth, hitchhiking and background selection. Genetics 147, 915-925.

Galindo-Leal, C., Câmara, I.G., 2005. Status do hotspot Mata Atlântica: uma síntese. In: Galindo-Leal, C., Câmara, I.G. (Eds.), Mata Atlântica: Biodiversidade, Ameaças e Perspectivas. Conservação Internacional, Belo Horizonte, pp. 3-11.

Ghirotto, S., Mona, S., Benazzo, A., Paparazzo, F., Caramelli, D., Barbujani, G., 2010. Inferring genealogical processes from patterns of bronze-age and modern DNA variation in Sardinia. Mol. Biol. Evol. 27, 875-886.

Gordon, D., Abajian, C., Green, P., 1998. Consed: a graphical tool for sequence finishing. Genome Res. 8, 195-202.

Grazziotin, F.G., Monzel, M., Echeverrigaray, S., Bonatto, S.L., 2006. Phylogeography of the Bothrops jararaca complex (Serpentes: Viperidae): past fragmentation and island colonization in the Brazilian Atlantic forest. Mol. Ecol. 15, 39693982.

Haffer, J., 1969. Speciation in Amazonian forest birds. Science 165, 131-137.

Heled, J., Drummond, A.J., 2008. Bayesian inference of population size history from multiple loci. BMC Evol. Biol. 8, 289.

Hickerson, M.J., Dolman, G., Moritz, C., 2006. Comparative phylogeographic summary statistics for testing simultaneous vicariance. Mol. Ecol. 15, 209-223.

Higgins, D., Thompson, J., Gibson, T., Thompson, J.D., Higgins, D.G., Gibson, T.J., 1994. CLUSTAL W: improving the sensitivity of progressive multiple sequence alignment through sequence weighting, position-specific gap penalties and weight matrix choice. Nucleic Acids Res. 22, 4673-4680.

Huson, D.H., Bryant, D., 2006. Application of phylogenetic networks in evolutionary studies. Mol. Biol. Evol. 23, 254-267.

Knowles, L.L., 2009. Statistical phylogeography. Annu. Rev. Ecol. Syst. 40, 593-612.

Kuhner, M.K., 2006. LAMARC 2.0: maximum likelihood and Bayesian estimation of population parameters. Bioinformatics 22, 768-770.

Latch, E.K., Dharmarajan, G., Glaubitz, J.C., Rhodes Jr., O.E., 2006. Relative performance of Bayesian clustering software for inferring population substructure and individual assignment at low levels of population differentiation. Conserv. Genet. 7, 295-302.

Librado, P., Rozas, J., 2009. DnaSP v5: a software for comprehensive analysis of DNA polymorphism data. Bioinformatics 25, 1451-1452.

Lougheed, S.C., Freeland, J.R., Handford, P., Boag, P.T., 2000. A molecular phylogeny of warbling-finches (Poospiza): paraphyly in a Neotropical emberizid genus. Mol. Phylogenet. Evol. 17, 367-378.

Lovette, I.J., Perez-Eman, J.L., Sullivan, J.P., Banks, R.C., Fiorentino, I., CordobaCordoba, S., Echeverry-Galvis, M., Barker, F.K., Burns, K.J., Klicka, J., Lanyon, S.M., Bermingham, E., 2010. A comprehensive multilocus phylogeny for the woodwarblers and a revised classification of the Parulidae (Aves). Mol. Phylogenet. Evol. 57, 753-770.
Maldonado-Coelho, M., 2012. Climatic oscillations shape the phylogeographical structure of Atlantic forest fire-eye antbirds (Aves: Thamnophilidae). Biol. J. Linn. Soc. 105, 900-924.

Marini, M.A., Hackett, S.J., 2002. A multifaceted approach to the characterization of an intergeneric hybrid manakin (Pipridae) from Brazil. Auk 119, 1114-1120.

Martins, F.M., 2011. The Brazilian Atlantic forest historical biogeography and the Carnaval-Moritz model of Pleistocene refugia: what do the phylogeographical studies tell us? Biol. J. Linn. Soc. 104, 499-509.

Martins, F.M., Templeton, A.R., Pavan, A.C.O., Kohlbach, B.C., Morgante, J.S., 2009 Phylogeography of the common vampire bat (Desmodus rotundus): marked population structure, Neotropical Pleistocene vicariance and incongruence between nuclear and mtDNA markers. BMC Evol. Biol. 9, 294.

Miller, M.J., Bermingham, E., Klicka, J., Escalante, P., Winker, K., 2010. Neotropical birds show a humped distribution of within-population genetic diversity along a latitudinal transect. Ecol. Lett. 13, 576-586.

Moritz, C., Patton, J.L., Schneider, C.J., Smith, T.B., 2000. Diversification of rainforest faunas: an integrated molecular approach. Annu. Rev. Ecol. Syst. 31, 533-563.

Myers, N., Mittermeier, R.A., Mittermeier, C.G., da Fonseca, G.A.B., Kent, J., 2000 Biodiversity hotspots for conservation priorities. Nature 403, 853-858.

Nielsen, R., Beaumont, M.A., 2009. Statistical inferences in phylogeography. Mol. Ecol. 18, 1034-1047.

Pavan, A.C., Martins, F.M., Santos, F.R., Ditchfield, A., Redondo, R.A.F., 2011. Patterns of diversification in two species of short-tailed bats (Carollia Gray, 1838): the effects of historical fragmentation of Brazilian rainforests. Biol. J. Linn. Soc. 102, 527-539.

Peter, B.M., Wegmann, D., Excoffier, L., 2010. Distinguishing between population bottleneck and population subdivision by a Bayesian model choice procedure. Mol. Ecol. 19, 4648-4660.

Petit, J.R., Jouzel, J., Raynaud, D., Barkov, N.I., Barnola, J.M., Basile, I., Bender, M. Chappellaz, J., Davis, M., Delaygue, G., Delmotte, M., Kotlyakov, V.M., Legrand, M., Lipenkov, V.Y., Lorius, C., Pepin, L., Ritz, C., Saltzman, E., Stievenard, M., 1999 Climate and atmospheric history of the past 420,000 years from the Vostok ice core, Antarctica. Nature 399, 429-436.

Posada, D., Krandall, K.A., 1998. MODELTEST: testing the model of DNA substitution. Bioinformatics 14, 817-818.

Pritchard, J.K., Stephens, M., Donnelly, P., 2000. Inference of population structure using multilocus genotype data. Genetics 155, 945-959.

Ramos-Onsins, S., Rozas, J., 2002. Statistical properties of new neutrality test against population growth. Mol. Biol. Evol. 19, 2092-2100.

Ribas, C.C., Aleixo, A., Nogueira, A.C.R., Miyaki, C.Y., Cracraft, J., 2012. A palaeobiogeographic model for biotic diversification within Amazonia over the past three million years. Proc. R. Soc. B 279, 681-689.

Ribeiro, C.A., Metzger, J.P., Martensen, A.C., Ponzoni, F.J., Hirota, M.M., 2009. The Brazilian Atlantic forest: how much is left, and how is the remaining forest distributed? Implications for conservation. Biol. Conserv. 142, 1141-1153.

Ribeiro, R.A., Lemos-Filho, J.P., Ramos, A.C.S., Lovato, M.B., 2010. Phylogeography of the endangered rosewood Dalbergia nigra (Fabaceae): insights into the evolutionary history and conservation of the Brazilian Atlantic forest. Heredity 106, 46-57.

Richards, C.L., Carstens, B.C., Knowles, L., 2007. Distribution modelling and statistical phylogeography: an integrative framework for generating and testing alternative biogeographical hypotheses. J. Biogeogr. 34, 1833-1845.

Ridgely, R.S., Tudor, G., 1996. The Birds of South America: The Oscine Passerines University of Texas Press, Austin.

Saadi, A., Machette, M.N., Haller, K.M., Dart, R.L., Bradley, L., Souza, A.M.P.D., 2002 Map and Database of Quaternary faults and Lineaments in Brazil. U.S. Geological Survey. Open-File Report 02-230, Version 1.0. <http://pubs.usgs.gov/of/2002 ofr-02-230/>.

Sambrook, J., Fritsch, E.F., Maniatis, T., 1989. Molecular Cloning: a Laboratory Manual. Cold Spring Harbor Press, Cold Spring Harbor.

Sant'Anna Neto, J.L., Nery, J.T., 2005. Variabilidade e mudanças climáticas no Brasil e seus impactos. In: Souza, G.R.G., Suguio, K., Oliveira, M.A.S., Oliveira, P.L. (Eds.), Quaternário do Brasil. Holos Editora, Ribeirão Preto, pp. 28-50.

Sick, H., 1997. Ornitologia Brasileira. Nova Fronteira, Rio de Janeiro.

Smith, T.B., Wayne, R.K., Girman, D.J., Bruford, M.W., 1997. A role for ecotones in generating rainforest biodiversity. Science 276, 1855-1857.

Smith, T.B., Schneider, C.J., Holder, K., 2001. Refugial isolation versus ecological gradients. Genetica 112, 383-398.

Sokal, R.R., Rolf, R.J., 1995. Biometry: the Principles and Practice of Statistics in Biological Research. W.H. Freeman and Company, New York.

Solomon, S.E., Bacci Jr., M., Martins Jr., J., Vinha, G.G., Mueller, U.G., 2008 Paleodistributions and comparative molecular phylogeography of leafcutter ants (Atta spp.) provide new insight into the origins of amazonian diversity. PLoS One 3, e2738.

Spellman, G.M., Klicka, J., 2006. Testing hypotheses of Pleistocene population history using coalescent simulations: phylogeography of the pygmy nuthatch (Sitta pygmaea). Proc. R. Soc. B 273, 3057-3063.

Stephens, M., Smith, N., Donnelly, P., 2001. A new statistical method for haplotype reconstruction from population data. Am. J. Hum. Genet. 68, 978-989.

Stotz, D.F., Fitzpatrick, J.W., Parker, T.A., Moskovits, D.K., 1996. Neotropical Birds: Ecology and Conservation. University of Chicago Press, Chicago.

Tajima, F., 1989. The effect of change in population size on DNA polymorphism. Genetics 123, 597-601.

Tamura, K., Dudley, J., Nei, M., Kumar, S., 2007. MEGA4: molecular evolutionary genetics analysis (MEGA) software version 4.0. Mol. Biol. Evol. 24, 1596-1599. 
Thomé, M.T.C., Zamudio, K.R., Giovanelli, J.G.R., Haddad, C.F.B., Baldissera Jr., F.A Alexandrino, J.M.B., 2010. Phylogeography of endemic toads and post-Pliocene persistence of the Brazilian Atlantic forest. Mol. Phylogenet. Evol. 55, 1018-1031.

Toon, A., Hughes, J.M., Joseph, L., 2010. Multilocus analysis of honeyeaters (Aves: Meliphagidae) highlights spatio-temporal heterogeneity in the influence of biogeographic barriers in the Australian monsoonal zone. Mol. Ecol. 19, 29802994.

Vanzolini, P.E., Williams, E.E., 1970. South American anoles: the geographic differentiation and evolution of the Anolis chrysolepis species group (Sauria: iguanidae). Arquiv. Zool. (S. Paulo) 19, 1-298.

Voight, B.F., Adams, A.M., Frisse, L.A., Qian, Y., Hudson, R.R., Di Rienzo, A., 2005 Interrogating multiple aspects of variation in a full resequencing data set to infer human population size changes. Proc. Natl. Acad. Sci. USA 102, 1850818513.

Wallace, A.R., 1852. On the monkeys of the Amazon. Proc. Zool. Soc. London 20, 107-110.

Weir, J.T., Schluter, D., 2008. Calibrating the avian molecular clock. Mol. Ecol. 17, 2321-2328

Whitlock, M.C., 2005. Combining probability from independent tests: the weighted Z-method is superior to Fisher's approach. J. Evol. Biol. 18, 1368-1373.

Whitmore, T.C., Prance, G.T., 1987. Biogeography and Quaternary History in Tropical America. Oxford University Press, New York. 


\section{Capítulo 2}

Vicariância pleistocênica e expansão depois do último máximo glacial em Myrmotherula gularis (Passeriformes: Thamnophilidae) na Mata Atlântica 


\section{Introdução}

A Mata Atlântica (MA) é bastante conhecida pelos elevados índices de biodiversidade e ameaça (Myers et al., 2000; Ribeiro et al., 2009). Embora sua biota pareça ter uma origem bastante antiga datada do Terciário médio (Fjeldså et al., 2012; Fouquet et al., 2012), vários estudos filogeográficos e de paleomodelagem (Cabanne et al., 2008; Carnaval \& Moritz, 2008; Carnaval et al., 2009; Martins et al., 2009; Ribeiro et al., 2010; d'Horta et al., 2011; Maldonado-Coelho, 2012) têm mostrado que a hipótese dos refúgios florestais (Haffer, 1969; Vanzolini \& Willians, 1970) teve um grande papel na diversificação dentro da MA, e principalmente aqueles refúgios oriundos das glaciações do final do Pleistoceno. Além disso, estudos de paleopalinologia mostraram que durante o último máximo glacial (UMG) uma longa faixa da MA que se estendeu de 27 a 20 graus de latitude foi dominada predominantemente por gramíneas (Behling and Lichte, 1997; Behling, 2002; Behling et al., 2004; Behling et al., 2005), o que indicou uma predominância significativa de áreas abertas neste bioma durante este período. Ainda, os resultados destes estudos permitiram aos autores inferir que as temperaturas durante o UMG nestas regiões foram entre 5 a $7^{\circ} \mathrm{C}$ mais frias do que o presente (Mayle et al., 2009). Entretanto, outros estudos filogeográficos mostraram diversificação anterior ao Pleistoceno (Grazziotin et al., 2006; Thomé et al., 2009; Amaro et al., 2012) e estabilidade durante o UMG (Batalha-Filho et al., 2012) dentro da MA.

Carnaval \& Moritz (2008) propuseram um modelo paleogeográfico para MA baseado em modelagem de nicho ecológico e mostraram que durante o UMG o bioma foi mais estável em sua porção central-norte, ao passo que a parte sul foi bastante instável durante este período. Assim, de acordo com este cenário seria possível predizer que a parte sul da MA manteria menos diversidade genética que a parte centro-norte, bem como teria um sinal de expansão demográfica mais acentuado ao sul do que no restante do bioma resultante da posterior expansão da área florestada. Enquanto alguns estudos corroboraram esta hipótese (Cabanne et al., 2008; Carnaval et al., 2009; Martins et al., 2009; Ribeiro et al., 2010; d'Horta et al., 2011; Martins, 2011; Maldonado-Coelho, 2012), outros mostraram que a porção sul da MA também possui elevada diversidade genética e possivelmente abrigou refúgios 
durante o UMG (Thomé et al., 2010; Álvarez-Presas et al., 2011; Batalha-Filho et al., 2012). Estes resultados mostraram que embora alguns organismos compartilhem uma história em comum, parece haver uma gama de padrões e processos de diversificação dentro da MA que possivelmente estão relacionados às dependências ecológicas e requerimento de habitats inerentes às idiossincrasias de cada organismo (Batalha-Filho et al., 2012). Desta forma, só com o acúmulo de vários estudos microevolutivos de organismos endêmicos deste bioma será possível chegar a um panorama sobre quais padrões e processos de diversificação moldaram a biodiversidade da MA que observamos atualmente.

No presente estudo nós analisamos o padrão filogeográfico e a demografia histórica da ave Myrmotherula gularis. Este pássaro é endêmico do Brasil e restrito à porção centro-sul da MA, ocorrendo desde o extremo sul de Santa Catarina até Minas Gerais e Espírito Santo (Ridgely \& Tudor, 1994; Sick, 1997) e com populações disjuntas no sul da Bahia (Fig. 1a). Habita a floresta ombrófila densa e úmida ocorrendo frequentemente à beira de córregos e rios no interior das matas. Filogenias moleculares recentes têm mostrado que o gênero Myrmotherula é polifilético (Irestedt et al., 2004; Belmonte-Lopes et al., 2012; Bravo et al., 2012), e M. gularis foi sugerida como pertencente a um gênero monotípico denominado Rophias (Belmonte-Lopes et al., 2012).

Com o intuito de contribuir para o entendimento da história evolutiva da MA nós geramos sequências de DNA de locos mitocondriais e nucleares para amostras de M. gularis distribuídas ao longo da porção centro-sul do bioma. Nós investigamos a estrutura genética e a história demográfica desta espécie e comparamos nossos resultados com estudos prévios de outros organismos endêmicos da MA. Para isto nós direcionamos algumas questões do estudo: i) M. gularis exibe um padrão diversidade genética concordante com o modelo proposto por Carnaval \& Moritz (2008)? ii) M. gularis apresenta estrutura genética congruente com aquelas observadas para outros organismos da MA? iii) Quais eventos históricos foram responsáveis pela diversificação desta espécie dentro da MA? 

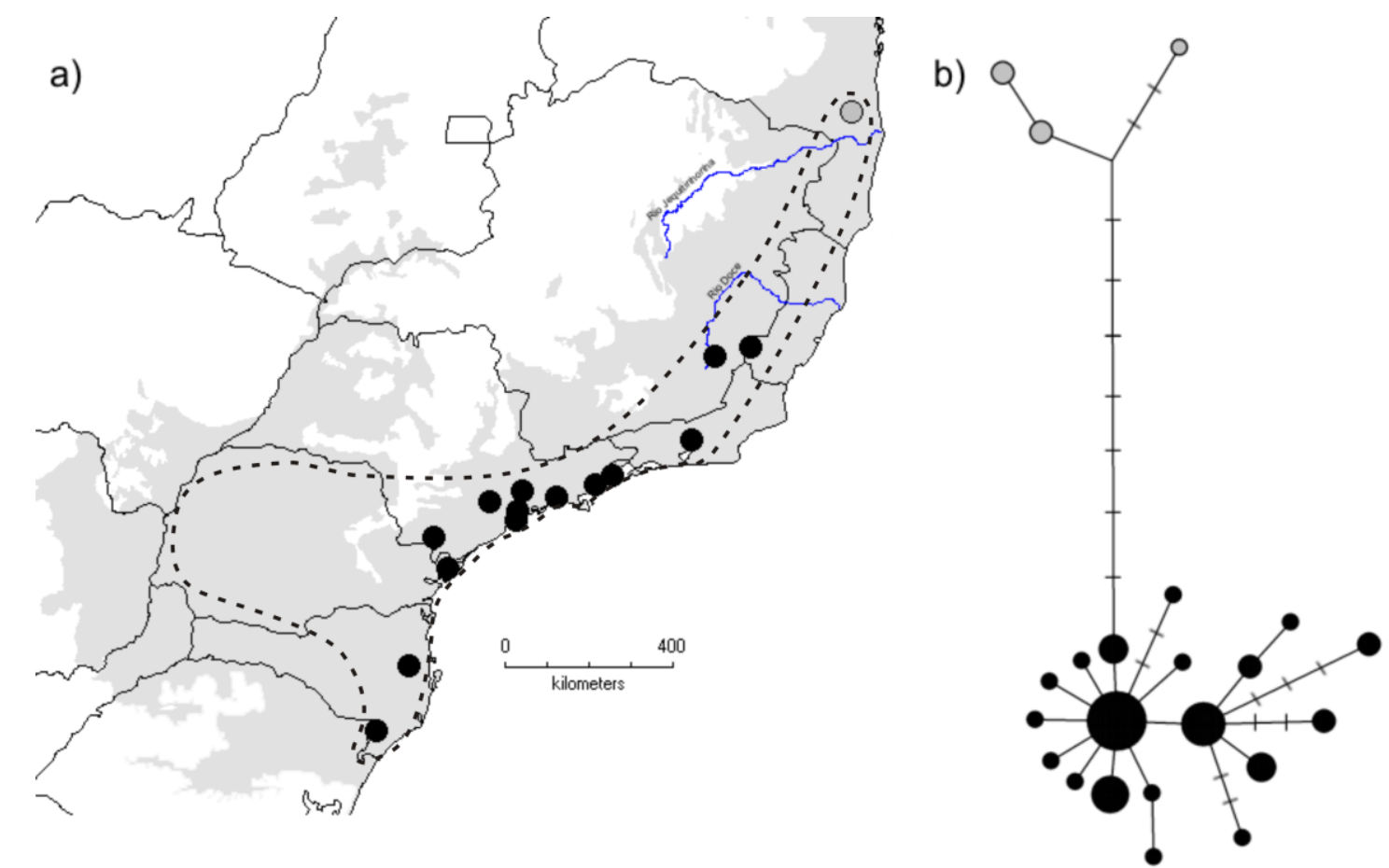

c)

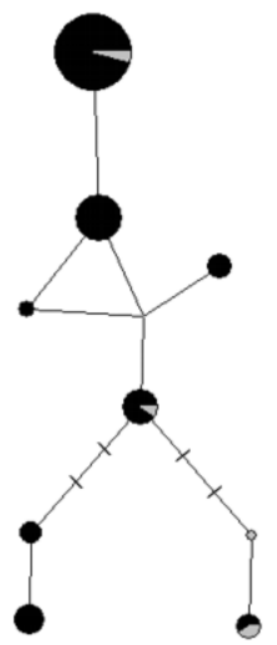

d)

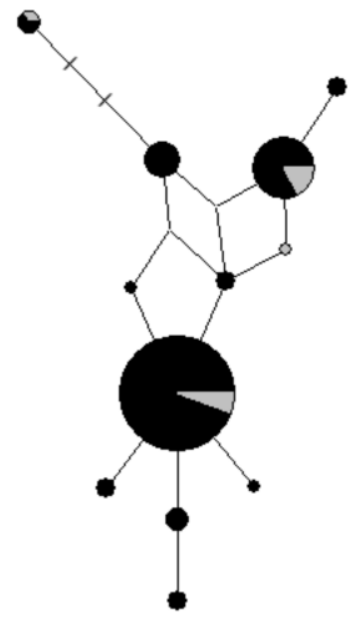

e)

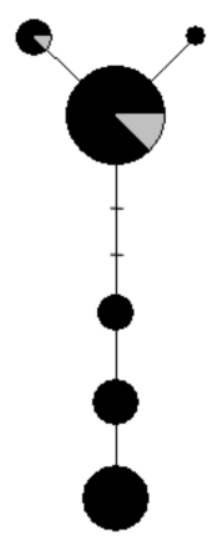

Figura 1. Localidades amostradas de $M$. gularis e rede de haplótipos para os genes mitocondriais e nucleares. a) Mapa com os pontos amostrais. Os círculos representam os pontos amostrados e suas cores são correspondentes aos filogrupos mitocondriais observados. A área em cinza no mapa representa os limites da MA e a linha pontilhada os limites de distribuição da espécie (adaptado de Ridgely \& Tudor [1994]). b) Rede de haplótipos baseada em 2025 pb dos cytb e ND2 concatenados. c) Rede de haplótipos baseada em 335 pb do íntron nuclear LRPP40. d) Rede de haplótipos baseada em $389 \mathrm{pb}$ do íntron nuclear G3PDH. e) Rede de haplótipos baseada em 576 pb do íntron nuclear TGFB. Nas redes, cada círculo representa um haplótipo e seu tamanho representa sua frequência. As linhas representam as relações entre os haplótipos que diferem em uma mutação. Traços nas linhas representam mutações adicionais. As cores representam os filogrupos observados na rede mitocondrial. 


\section{Materiais e Métodos}

\subsection{Amostragem e métodos moleculares}

Amostras de tecidos (sangue ou músculo) de 64 espécimes de M. gularis provenientes de 15 localidades ao longo da distribuição da espécie foram coletadas no período entre 2008 e 2012 (Fig. 1a, Tab. 1). Os procedimentos laboratoriais para extração e amplificação do DNA seguiram Batalha-Filho et al. (2012). Foram obtidas sequências de dois genes mitocondriais: citocromo oxidase b (cytb) com os primers L-14841 e H-16065 (Lougheed et al., 2000), e NADH desidrogenase subunidade 2 (ND2) com os primers Lmet (Hackett, 1996) e H6313 (Johnson \& Sorenson, 1998). Também foram sequenciados de três íntrons nucleares: o íntron 11 do gene gliceroldeído-3-fosfato desidrogenase (G3PDH) com os primers G3PL890 e G3PH950 (Friesen et al., 1997), o íntron 3 do gene Transforming growth factor beta (TGFB2) com os primers TGFB2-5F e TGFB2-6R (Primmer et al., 2002), e o íntron 5 do gene do receptor precursor da lamnina P40 (LRPP40) com os primers LRPP40-F e LRPP40-R (Primmer et al., 2002). As condições das reações de PCR seguiram Batalha-Filho et al. (2012) variando somente a temperatura de annealing dos íntrons nucelares: G3PDH $-62^{\circ} \mathrm{C}$; TGFB2 e LRPP40 $-61^{\circ} \mathrm{C}$. As condições do sequenciamento do cytb seguiram Batalha-Filho et al. (2012). O sequenciamento dos demais genes foi realizado pela empresa Macrogen Inc. com os mesmo primers utilizados na amplificação. 
Tabela 1. Amostras de Myrmotherula gularis: localidade amostrada, coordenadas geográficas, tamanho amostral (N), coleção de depósito da amostra, código na coleção.

\begin{tabular}{|c|c|c|c|c|c|}
\hline Localidade & Latitude & Longitude & $\mathbf{N}$ & Coleção* & Código dos tecidos \\
\hline Paraty, RJ & -23.2178 & $-44 \cdot 7131$ & 2 & MNRJ & MNT0291, MNT0296 \\
\hline Piedade, SP & -23.7767 & $-47 \cdot 32722$ & 1 & LGEMA & 1076 \\
\hline Juquitiba, SP & -24.1833 & -46.78333 & 3 & LGEMA & $1145,1146,2386$ \\
\hline Estação Biológica Boraceia, Salesópolis, SP & -23.6542 & -45.88963 & 8 & LGEMA & $\begin{array}{l}12044,12045,12046,12047,12051,15622,15655 \\
15666\end{array}$ \\
\hline Parque Nacional Serra dos Órgãos, Teresópolis, RJ & -22.4478 & -43.00595 & 6 & LGEMA & $12999,13001,13002,13003,13004,13005$ \\
\hline Parque Estadual Serra do Brigadeiro, Araponga, MG & -20.65 & -42.51666 & 1 & UFMG & $\mathrm{B} 1280$ \\
\hline Parque Nacional do Caparaó, Santa Marta, ES & -20.4549 & -41.74488 & 1 & LGEMA & 13532 \\
\hline Serra da Cantareira, São Paulo, SP & -23.5475 & -46.6361 & 4 & MZUSP & $75,82,144,145$ \\
\hline RPPN Serra Bonita, Camacan, BA & $-15 \cdot 3851$ & -39.56919 & 5 & LGEMA & $13716,13717,13727,13732,13733$ \\
\hline Parque Estadual Turístico Alto do Ribeira, Núcleo Caboclos, SP & -24.5333 & -48.53333 & 2 & LGEMA & 1593,1595 \\
\hline Nova Roma, Morro Grande, SC & -28.7053 & -49.76678 & 6 & LGEMA & $14524,14529,14531,14533,14534,14574$ \\
\hline Nova Trento, SC & -27.2989 & -49.07956 & 6 & LGEMA & $14581,14608,14609,14610,14611,14631$ \\
\hline Utinga, Guaraqueçaba, PR & -25.2031 & -48.23222 & 5 & LGEMA & $14656,14657,14680,14681,14698$ \\
\hline Fazenda Capricórnio, SP & -23.4 & -45.06667 & 3 & ZMUC & $137087,137115,137123$ \\
\hline Parque Estadual Serra do Mar, Núcleo Curucutu, SP & -23.9553 & -46.72083 & 11 & LGEMA & $\begin{array}{l}\text { 14715, 15097, 15137, 15138, 15140, 15142, } 15149 \\
15216,15217,15227,15243\end{array}$ \\
\hline
\end{tabular}

* MNRJ - Museu Nacional da Universidade Federal do Rio de Janeiro; LGEMA - Laboratório de Genética e Evolução Molecular de Aves, Universidade de São Paulo; UFMG - Laboratório de Biodiversidade e Evolução Molecular, Instituto de Ciências Biomédicas, Universidade Federal de Minas Gerais; MZUSP - Museu de Zoologia da Universidade São Paulo; ZMUC - Zoological Museum, University of Copenhagen. 


\subsection{Edição das sequências, reconstrução alélica nuclear e teste de recombinação}

Os eletroferogramas foram verificados e editados e sequências consenso foram obtidas utilizando o programa Codoncode Aligner v.3.7 (Codoncode Inc.). Essas sequências foram alinhadas utilizando-se o método CLUSTAL W (Higgins et al., 1994) no programa MEGA5 (Tamura et al., 2011). Todos os alinhamentos foram inspecionados e corrigidos visualmente. Pelo fato de os genes mitocondriais serem ligados, os mesmos foram concatenados e analisados como um único loco. Os sítios heterozigotos presentes nos íntrons nucleares foram inicialmente codificados com o código de nucleotídeos ambíguos da International Union of Pure and Applied Chemistry (IUPAC) onde houvesse picos duplos em ambas as fitas. As sequências nucleares de indivíduos com heterozigotos de indel foram resolvidas utilizando-se o algoritmo Process Heterozygous Indels do programa Codoncode Aligner v.3.7. Para a reconstrução dos alelos para os indivíduos heterozigotos dos íntrons nucleares foi utilizado o algoritmo PHASE (Stephens et al., 2001) no modo default no programa DnaSP 5 (Librado \& Rozas, 2009). Para as análises foram considerados somente haplótipos com alta probabilidade no PHASE $(p>0,9)$, os demais indivíduos com baixa probabilidade foram removidos das análises seguintes. O teste $\mathrm{PHI}$ foi aplicado para testar a hipótese de presença de sinal de recombinação dos íntrons nucleares no programa SPLITSTREE4 (Bruen et al., 2006; Huson \& Bryant, 2006).

\subsection{Testes de estrutura genética}

Nós geramos redes de haplótipos pelo método median-joining network (Bandelt et al., 1999) no programa NETWORK 4.6.1.0 (www.fluxusengineering.com) para os genes mitocondriais concatenados e para cada íntron nuclear individualmente com intuito de avaliar a estrutura genética das amostras analisadas, bem como sua distribuição geográfica. Foi calculada a distância p não corrigida entre os filogrupos detectados pelo MEGA5, e o erro padrão foi estimado com base em 1000 replicações de bootstrap.

Para se avaliar o nível de estrutura genética do DNA mitocondrial entre as localidades nos implementamos a análise de variância molecular espacial (SAMOVA) no programa SAMOVA 1.0 (Dupanloup et al., 2002). Este método delimita grupos genéticos entre localidades geograficamente homogêneas e maximamente 
diferenciadas entre elas. Nós rodamos as análises variando o número de grupos (k) de 2 a 5 com 1000 simulações de annealing processes cada. Em seguida, os valores dos índices de fixação ( $\phi_{C T}$ - estruturação entre grupos; $\phi_{S T}$ - estruturação entre localidades entre grupos) e o percentual de variação entre os níveis hierárquicos foram comparados e o agrupamento que indicou maior estruturação foi escolhido como o k mais provável. Para esta análise foram utilizadas somente localidades que possuíam no mínimo dois indivíduos.

Para inferir o grau de estrutura genética em $M$. gularis com base nos íntrons nucleares nós implementamos o método de agrupamento Bayesiano do programa Structure 2.3.3 (Pritchard et al., 2000). Este método utiliza inferência Bayesiana baseada nas frequências genotípicas multilocos para inferir o número mais provável de k sem assumir um número pré-determinado. Nós rodamos as análises assumindo que as frequências genotípicas entre as populações não são correlacionadas, e adotamos o modelo Admixture. As análises foram geradas testando-se o número de k variando de 1 a 5, e repetindo cada um destes 10 vezes. Cada corrida de k consistiu de 6 milhões de gerações de MCMC (Markov Chain Monte Carlo), sendo que o $1^{\circ}$ milhão foi usado como burn-in. Para se obter o número mais provável de $\mathrm{k}$ foi estimado o $\operatorname{Pr}(k)$ pela regra de Bayes conforme Pritchard et al. (2010) utilizando-se os valores médios de log-likelihood das probabilidades posteriores das dez corridas para cada k.

\subsection{Estatísticas sumárias e análises de demografia histórica}

Foi calculada a diversidade nucleotídica por sítio $(\pi)$ e o número de haplótipos (h) para cada gene no DnaSP 5. Para detectar possíveis sinais de expansão demográfica nós aplicamos o teste de neutralidade $F_{s}(F u, 1997)$ e o teste de mudança no tamanho da população $R_{2}$ (Ramos-Onsins \& Rozas, 2002) no DnaSP 5. A significância destes testes foi determinada com base em 10000 simulações coalescentes.

Nós também inferimos possíveis eventos de expansão demográfica pelo método Bayesiano coalescente Extended Bayesian Skyline Plot (EBSP; Heled \& Drummond, 2008) que é implementado no BEAST 1.6.2 (Drummond \& Rambaut, 2007). Este método reduz o efeito da estocasticidade do processo coalescente 
combinando diferentes genes em uma abordagem não-paramétrica de coalescência das diferentes árvores de genes para se estimar a variação do tamanho efetivo populacional ao longo do tempo (Ho \& Shapiro, 2011). Foram realizadas duas corridas independentes do EBSP (150 a 250 milhões de gerações de MCMC) para cada filogrupo mitocondrial (Fig. 1b) com os seguintes parâmetros: uma árvore inicial de UPGMA, modelo linear, parâmetros amostrados a cada 10000 gerações, e um burn-in de 10\% a 30\%. O teste hLRT implementado pelo MEGA5 não rejeitou a hipótese do relógio molecular $(p<0,05)$ para todos genes nos dois filogrupos, exceto para o DNA mitocondrial no filogrupo centro-sul. Assim, nós utilizamos o prior uncorrelated lognormal relaxed clock para esta partição, e o strict clock para as demais. O modelo evolutivo para cada gene foi estimado no MrModeltest 2.2 (Nylander, 2004) com o critério de informação de Akaike (AIC). Como calibração para análise nós utilizamos a taxa de mutação conhecida para o DNA mitocondrial em aves de 1,05\% ( \pm 0,05\%) por sítio por linhagem por milhão de anos (Weir \& Schluter, 2008) sob um prior com distribuição normal. Então, o BEAST estimou a taxa de mutação para cada íntron individualmente sob um prior log-normal com os parâmetros default. O desempenho da MCMC e a convergência entre as corridas foram analisados no TRACER 1.5 (http://beast.bio.ed.ac.uk/Tracer) para termos certeza de que os valores de ESS (Effective Sample Size) eram maiores que 200.

\subsection{Isolamento com migração}

As estimativas do tempo divergência e fluxo gênico entre os filogrupos de $M$. gularis baseadas em todos os locos foram obtidas pelo modelo Bayesiano coalescente de isolamento com migração (Nielsen \& Wakeley, 2001) implementado no programa IMa versão 17/12/2009 (Hey \& Nielsen, 2004). O programa estima seis parâmetros demográficos deste modelo: tamanho efetivo de cada uma das populações analisadas ( $\theta_{1}$ e $\left.\theta_{2}\right)$ e da população ancestral destas $(\theta a)$; taxas de fluxo gênico entre as populações (m1: taxa de genes que migraram do filogrupo centrosul para o norte do passado para o presente; m2: inverso da m1); e data de divergência das populações ( $\mathrm{t}$ ). Nós usamos o modelo evolutivo HKY (Hasegawa et al., 1985) para todos os locos e heranças escalares de 0.25 para o loco mitocondrial e 1.0 para os nucleares. Foi permitido ao programa estimar valores de $\theta$ e m 
independentes para cada população. Foram implementadas corridas preliminares para se ajustar os valores máximos de distribuição dos priors, e o número e o esquema de aquecimento das MCMCs. As análises foram realizadas com 50 MCMCs com aquecimento geométrico (g1=0.99 e g2=0.92) e os valores máximos dos priors para os parâmetros populacionais foram: $\theta_{1}$ e $\theta_{2}=10, \theta a=20, \mathrm{~m}_{1}=16, \mathrm{~m} 2=10, \mathrm{t}=$ 1.5. Nós implementamos 5 corridas usando diferentes random seeds com 11 milhões de gerações de MCMC cada, sendo o $1^{\circ}$ milhão utilizado como burn-in. Nós assumimos o tempo de geração de um ano conforme Cabanne et al. (2008). Os parâmetros foram escalonados em unidades demográficas utilizando a taxa de mutação para o DNA mitocondrial usada no EBSP, e a taxa de mutação para os íntrons nucleares de 0,135\% por sítio por linhagem por milhão de anos conforme Ellegren (2007). Nós assumimos a variação na estimativa das taxas de mutação mencionadas acima (Ellegren, 2007; Weir \& Schluter, 2008) como priors no cálculo da taxa de mutação escalar: mitocondrial, 0,96\% - 1,13\%; íntrons nucleares, $0.12 \%$ $0.15 \%$. Todas as corridas obtiveram valores de ESS maiores que 100.

\section{Resultados}

\subsection{Características das sequências}

Foi obtida uma matriz de dados com $3344 \mathrm{pb}$, sendo $1010 \mathrm{pb}$ do cytb $(\mathrm{N}=62)$, $1034 \mathrm{pb}$ do ND2 ( $\mathrm{N}=61), 389 \mathrm{pb}$ do G3PDH ( $\mathrm{N}=61), 576$ pb TGFB2 ( $=58)$, e 335 pb do LRPP40 ( $\mathrm{N}=56)$. Para os locos mitocondriais foram observados 13 sítios polimórficos no cytb e 15 no ND2, e estes permitiram identificar 22 haplótipos para o DNA mitocondrial. Foram observados 10 sítios variáveis no G3PDH, 9 no TGFB2 e 13 LRPP40. Não foram observados indels em nenhum dos genes sequenciados. Quando os genes mitocondriais foram traduzidos para aminoácidos não foi observado nenhum códon de parada para ambos os genes, sugerindo que são sequências mitocondriais.

A reconstrução alélica realizada pelo PHASE resolveu com alta probabilidade $(p>0,9) 122$ cromossomos amostrados para o G3PDH, 112 para o TGFB2 e 104 para o LRPP40, e nestes foi possível identificar 12, 6 e 9 alelos, respectivamente. O teste $\mathrm{PHI}$ não detectou evidências significativas de recombinação em nenhum dos íntrons 
analisados (G3PDH $p=0,122 ;$ TGFB2 $p=1,0 ;$ LRPP40 $p=0,889$ ). A diversidade nucleotídica para cada um dos locos está apresentada na figura 2.

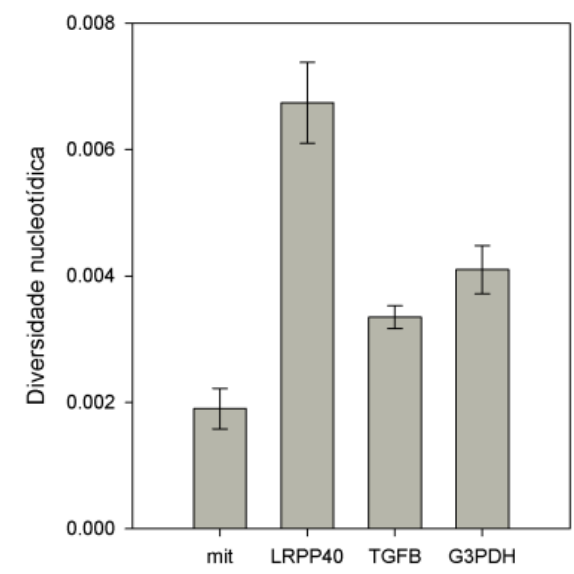

Figura 2. Estimativas e desvios padrões da diversidade nucleotídica por sítio ( $\pi$ ) para os locos analisados em Myrmotherula gularis.

\subsection{Estrutura filogeográfica}

A rede de haplótipos para o DNA mitocondrial evidenciou a presença de dois filogrupos em M. gularis (Fig. 1a e b): (i) o filogrupo centro-sul que compreende a distribuição centro-sul da espécie; (ii) e o filogrupo norte que é restrito ao limite norte da distribuição, especificamente contendo a localidade de Camacan no sul da Bahia. Estes filogrupos possuem $0,6 \%( \pm 0,1 \%)$ de divergência (distância $p$ não corrigida). A quebra filogeográfica foi observada próximo aos rios Doce e Jequitinhonha (Fig. 1a), porém existe uma ausência de amostras no interflúvio entre estes dois rios. A SAMOVA também mostrou que o agrupamento considerando 2 filogrupos é o que recupera a maior estrutura genética entre as localidades (Fig. 3). Este agrupamento indicou a mesma estruturação observada na rede haplótipos mitocondrial (Fig. 1a e b), onde 80,03\% $(p<0,05)$ da variação genética foi observada entre os grupos. 

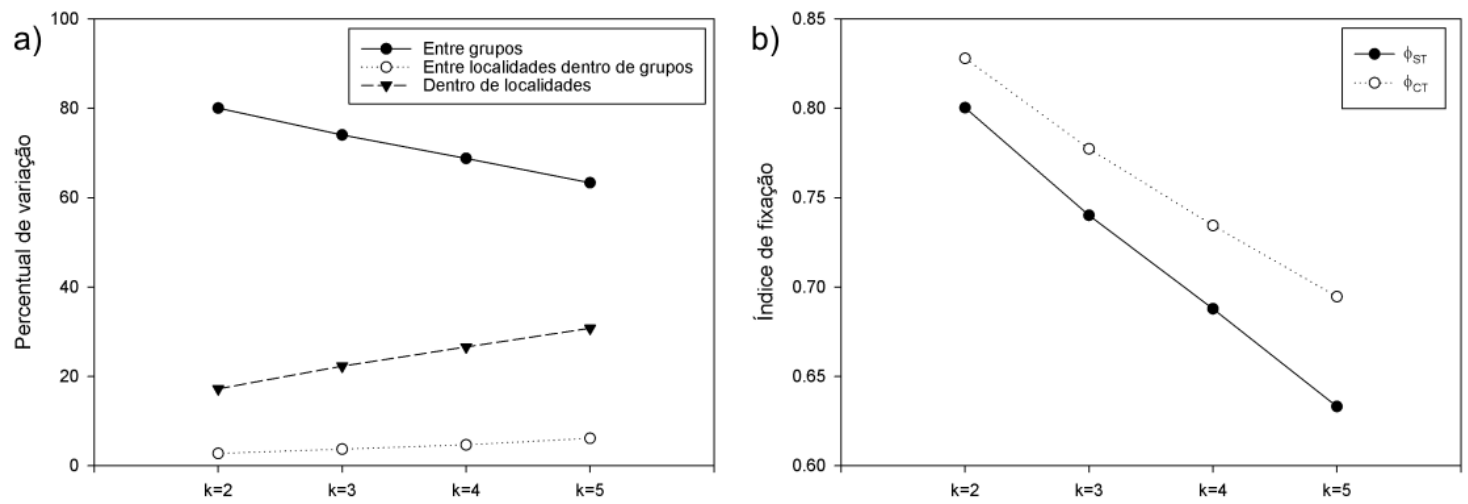

Figura 3. Análise de variância molecular espacial (SAMOVA) baseada no DNA mitocondrial de 12 localidades amostradas de Myrmotherula gularis. a) Percentual de variação genética contido nos níveis hierárquicos da SAMOVA obtidos para o melhor agrupamento em cada número k testado. b) Estimativa de valores dos índices de fixação obtidos para o melhor agrupamento em cada k testado.

Entretanto, as redes de haplótipos dos íntrons nucleares não recuperaram a mesma estrutura observada no DNA mitocondrial (Fig. 1), embora estes locos apresentem mais diversidade nucleotídica que os genes mitocondriais analisados (Fig. 2). Além disso, quando estes íntrons foram analisados em conjunto no Structure eles também falharam em recuperar estrutura genética, pois de acordo com a estimativa da regra de Bayes $[\operatorname{Pr}(k)]$ o número mais provável de k é 1 (Tab. 2).

Tabela 2. Médias $[\log L(k)]$ e desvios padrões (dp) dos valores de log-likelihood e estimativa da regra de Bayes $[\operatorname{Pr}(k)]$ para as dez corridas de cada k testado no Structure para Myrmotherula gularis.

\begin{tabular}{cccc}
\hline $\mathbf{k}$ & $\log \mathbf{L}(\mathbf{k})$ & $\mathbf{d p}$ & $\operatorname{Pr}(\mathbf{k})$ \\
\hline 1 & $-487,69$ & 0,031623 & 1 \\
2 & $-549,52$ & 10,74469 & 0 \\
3 & $-584,73$ & 29,86764 & 0 \\
4 & $-570,53$ & 27,9769 & 0 \\
5 & $-559,95$ & 19,4165 & 0 \\
\hline
\end{tabular}

\subsection{História demográfica}

Os testes $F_{S}$ e $R_{2}$ para o DNA mitocondrial evidenciaram expansão demográfica significativa somente para o filogrupo centro-sul (Tab. 3). Estes testes não evidenciaram nenhum sinal de expansão demográfica nos íntrons nucleares para ambos os filogrupos (dados não mostrados).

A estimativa da demografia histórica com base em todos os locos combinados no EBSP corroborou os resultados dos testes $F_{S}$ e $R_{2}$, evidenciando expansão demográfica somente no filogrupo centro-sul (Fig. 4). Ainda, o filogrupo 
centro-sul de M. gularis parece ter passado por uma expansão demográfica após o término do UMG, há aproximadamente 20 mil anos atrás (Fig. 4C).

Tabela 3. Estatísticas sumárias para o DNA mitocondrial em Myrmotherula gularis.

\begin{tabular}{cccccc}
\hline Filogrupo & $\mathbf{N}$ & $\mathbf{h}$ & $\boldsymbol{\pi}(\mathbf{d p})$ & $\boldsymbol{F}_{\mathbf{s}}$ & $\boldsymbol{R}_{\mathbf{2}}$ \\
\hline Norte & 5 & 3 & $0,00093(0,00037)$ & $0,469^{\text {ns }}$ & $0,3092^{\text {ns }}$ \\
Centro-sul & 59 & 20 & $0,00115(0,00013)$ & $-14,1663^{* *}$ & $0,0404^{*}$ \\
Total & 64 & 22 & $0,0019(0,00032)$ & - & - \\
\hline
\end{tabular}

N: Tamanho amostral; h: número de haplótipos; $\pi$ (dp): diversidade nucleotídica por sítio (desvio padrão); ns: não significativo; ${ }^{*} p<0,01 ; * * p<0,000001$.
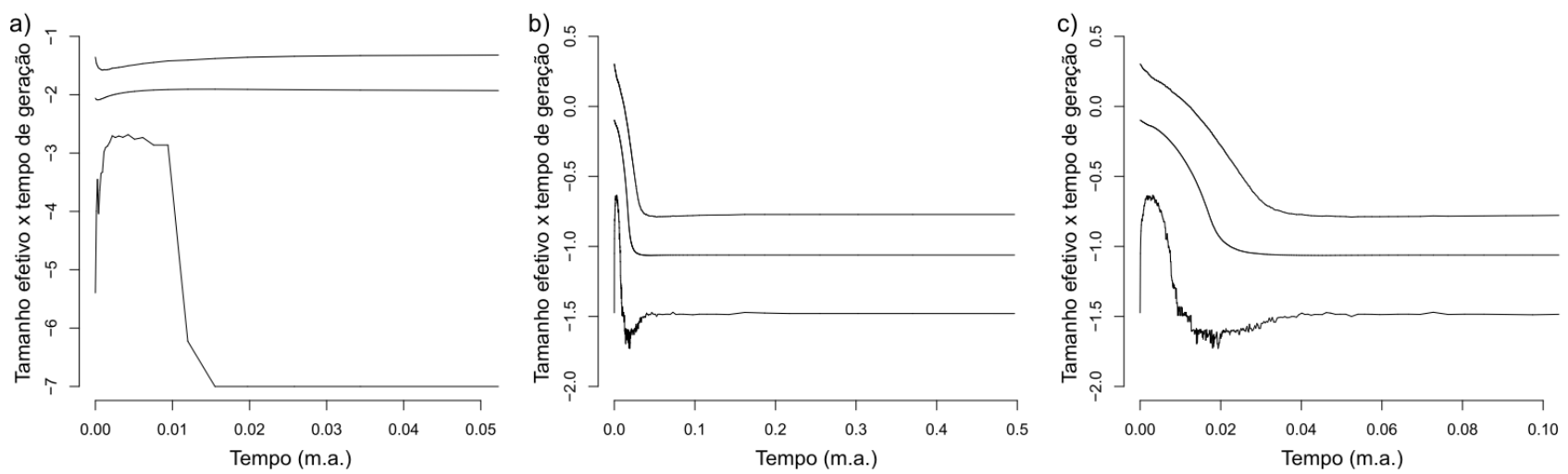

Figura 4. Estimativas do Extended Bayesian Skyline Plot (EBSP) para os filogrupos mitocondriais de Myrmotherula gularis: a) filogrupo norte; b) filogrupo centro-sul; c) detalhe dos últimos 100 mil anos do EBSP do filogrupo centro-sul. A linha do meio representa a mediana da estimativa, e as linhas superior e inferior os limites superior e inferior de $95 \%$ de HPD (Highest Posterior Density), respectivamente. $\mathrm{O}$ eixo Y está em escala logarítmica. O eixo X representa milhão de anos (m.a.).

\subsection{Tempo de divergência e fluxo gênico}

A data de divergência entre os filogrupos mitocondriais de M. gularis obtida pelo IMa (Fig. 5, Tab. 4) indicou uma separação no final do Pleistoceno há aproximadamente 304 mil anos atrás [90\% de HPD (Highest Posterior Density): 91 mil a 931 mil anos atrás). Ainda, os resultados do IMa apontaram baixas taxas de migração entre os filogrupos, com bastante sobreposição das curvas de probabilidade posterior para m1 e m2 (Fig. 5, Tab. 4). As estimativas de tamanho efetivo populacional $(\mathrm{Ne})$ mostraram que a população ancestral $(\theta a)$ possui um $\mathrm{Ne}$ maior que as populações atuais, e os valores de $\mathrm{Ne}$ dos filogrupos norte $\left(\theta_{1}\right)$ e centro-sul ( $\left.\theta_{2}\right)$ apresentaram curvas de probabilidade posterior sobrepostas (Fig. 5, Tab. 4). 

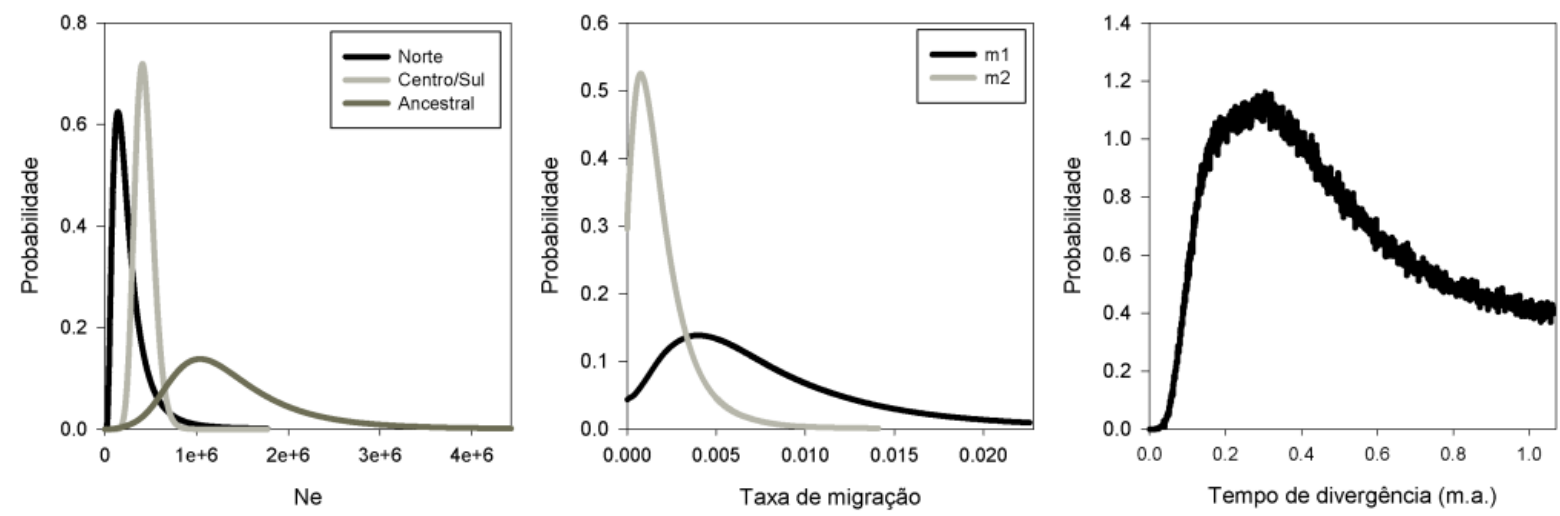

Figura 5. Distribuição das probabilidades posteriores marginais dos parâmetros populacionais estimados pelo IMa. Ne (tamanho efetivo populacional) está em número de indivíduos. Taxa de migração é a média dos eventos de migração por cópia gênica por 1000 gerações. Tempo de divergência é apresentado em milhão de anos (m.a.).

Tabela 4. Resultados das estimativas do IMa.

\begin{tabular}{lcccccc}
\hline & $\boldsymbol{\theta 1}$ & $\boldsymbol{\theta 2}$ & $\boldsymbol{\theta a}$ & $\mathbf{m 1}$ & $\mathbf{m 2}$ & $\mathbf{t}$ \\
\cline { 2 - 7 } $\begin{array}{l}\text { Estimativa pontual com maior } \\
\text { probabilidade }\end{array}$ & 144376,8 & 410101,1 & 1038539 & 0,004 & 0,0008 & 304520 \\
Limite inferior (90\% de HPD) & 39858,64 & 270153 & 409658,2 & 0 & 0 & $91940 *$ \\
Limite superior (90\% de HPD) & 528791,3 & 594336,6 & 2376018 & 0,0147 & 0,0041 & $931629 *$ \\
\hline
\end{tabular}

Ө: Tamanho efetivo populacional em número de indivíduos dos filogrupos norte $(\theta 1)$ e centro-sul $(\theta 2)$, e da população ancestral destes filogrupos $(\theta a)$.

m: média dos eventos de migração por cópia gênica por 1000 gerações do filogrupo centro-sul para o norte (m1) e vice-versa (m2).

T: Tempo de divergência em anos.

90\% de HPD: Intervalos de confiança de 90\% da distribuição posterior dos parâmetros após o burn-in. *: Valores de HPD com pouca precisão e influenciados pelos priors, pois a distribuição posterior foi plana e a curva de probabilidade não atingiu o valor zero.

\section{Discussão}

Os resultados da rede de haplótipos (Fig. 1a e b) e da SAMOVA (Fig. 3) revelaram a presença de dois filogrupos mitocondriais em $M$. gularis separados por oito passos mutacionais. O filogrupo centro-sul compreendeu quase que toda distribuição da espécie desde o extremo sul de Santa Catarina até a margem sul do Rio Doce em Minas Gerais, ao passo que o filogrupo norte foi composto apenas por amostras da localidade de Camacan no sul da Bahia. A estimativa do tempo de divergência entre os filogrupos evidenciada pelo IMa (Tab. 4, Fig. 5) mostrou uma vicariância recente datada do meio ao fim do Pleistoceno, e possivelmente pode estar associada com as mudanças climáticas ocorridas durante esta época. Contudo, devido ao fato de nossos dados apresentarem uma área sem amostras entre os rios Doce e Jequitinhonha não foi possível determinar a exata localização geográfica da descontinuidade filogeográfica observada. Entretanto, M. gularis ocorre somente 
em florestas ombrófilas acima de $700 \mathrm{~m}$ de altitude nestas latitudes, e estes habitats não são comuns nesta região atualmente. Deste modo, nós realizamos expedições de coleta para duas localidades onde estes habitats poderiam ser encontrados (Rebio Mata Escura, Jequitinhonha, MG; RPPN Fazenda Duas Barras, Santa Maria do Salto, MG) e não conseguimos detectar a presença desta espécie nestas áreas. Além disso, um estudo de levantamento de avifauna de longa duração realizado na RPPN Fazenda Duas Barras em Santa Maria do Salto-MG também não detectou a presença de $M$. gularis (R Ribon, dados não publicados). Ainda, além dos espécimes coletados por nós em Camacan-BA, só existem registros de ocorrência da espécie em outras duas localidades ao norte do Rio Jequitinhonha (Serras das Lontras e Javi; Silveira et al., 2005). Devido a estes indícios é possível que hoje as populações de $M$. gularis que ocorrem ao norte do Rio Jequitinhonha estejam isoladas das demais populações ao sul do Rio Doce.

As estimativas de estrutura genética com base nos íntrons nucleares (Fig. 1, Tab. 2) não foram congruentes com a observada baseada no DNA mitocondrial. Esta incongruência pode ser explicada pela presença de sorteamento incompleto das linhagens nos íntrons nucleares por retenção de polimorfismo ancestral devido a uma recente separação (Pinho et al., 2008), ou devido ao longo tempo de coalescência do DNA nuclear em relação ao mitocondrial (Palumbi et al., 2001; Zink \& Barrowclough, 2008). Desta forma, como os genes mitocondriais possuem Ne 4 vezes menor que os genes autossômicos, eles teriam maior capacidade de detectar eventos recentes de vicariância (Zink \& Barrowclough, 2008), pois os efeitos históricos associados à divergência das populações (e.g. deriva genética) deixariam sinais mais facilmente detectáveis nestas moléculas devido ao menor $\mathrm{Ne}$ da população ancestral.

O evento vicariante observado neste estudo apresenta congruência espacial com outros estudos filogeográficos de organismos da MA, tais como aves (Cabanne et al., 2008; d'Horta et al., 2011; Maldonado-Coelho, 2012), mamíferos (Costa, 2003), lagartos (Pellegrino et al., 2005), anfíbios (Thomé et al., 2010) e plantas (Ribeiro et al., 2010). Nestes estudos foram observadas descontinuidades filogeográficas congruentes com o Rio Doce, e este foi atribuído como uma barreira secundária (Cabanne et al., 2008; Maldonado-Coelho, 2012) entre linhagens que se divergiram 
em alopatria ao norte e ao sul do seu curso, uma vez que a formação da bacia ocorreu muito antes do Pleistoceno (Lundberg et al., 1998; Ribeiro, 2006). A datação da separação entre os filogrupos observados em $M$. gularis também apresenta congruência temporal com alguns destes estudos (Cabanne et al., 2008; d'Horta et al., 2011; Ribeiro et al., 2010), onde a vicariância concordante espacialmente com vale do Rio Doce possivelmente ocorreu no Pleistoceno tardio. Entretanto, um estudo com lagartos mostrou que o Rio Doce (além de outros rios na MA) é a possível barreira primária ao evento vicariante observado (Pellegrino et al., 2005).

Em um cenário de vicariância onde o rio seria barreira primária ao evento de separação é esperada ausência de assinaturas de expansão demográfica e congruência temporal do tempo de divergência das populações com a origem do rio (Moritz et al., 2000). No entanto, no presente estudo foi observado justamente o oposto, onde foi evidenciado um forte sinal de expansão demográfica no filogrupo centro-sul (Tab. 3, Fig. 4) e um tempo de divergência entre as populações muito mais recente que a origem do rio (Tab. 4). Assim, nós rejeitamos a hipótese dos rios Doce e Jequitinhonha terem atuado como barreira primária à vicariância observada neste estudo, e a hipótese dos refúgios florestais se sustenta como o principal processo de diversificação atuante em M. gularis dentro da MA.

Contudo, nos estudos mencionados acima e em outros estudos (Grazziotin et al., 2006; Martins et al., 2009; Batalha-Filho et al., 2010; Cabanne et al., 2011; Amaro et al., 2012) também foram observadas outras descontinuidades filogeográficas que não estão presentes em $M$. gularis, dentre elas uma no estado de São Paulo próxima aos vales dos rios Paraíba do Sul, Tietê e Ribeira do Iguape. Estas congruências e incongruências espaciais podem ser explicadas por diferenças no requerimento de habitats entre estas espécies (Batalha-Filho et al., 2012). Assim, espécies com nichos similares possivelmente responderam aos eventos históricos de fragmentação do habitat de maneira similar, ao passo que as espécies que possuem diferentes requerimentos de habitats não responderam a fragmentação da mesma maneira. Futuros estudos que analisam o componente climático do nicho poderão auxiliar no entendimento destes fatores. 
As análises de demografia histórica mostraram estabilidade no filogrupo norte e expansão demográfica no filogrupo centro-sul (Tab. 3, Fig. 4). Ainda, a expansão demográfica no clado centro-sul parece ter se iniciado há cerca de 20 mil anos atrás, o que coincide com o fim do UMG na MA (Fig. 4). Utilizando dados paleo-palinológicos, Behling \& Lichte (1997) e Behling (2002) mostraram que o UMG na MA possivelmente ocorreu entre 18 e 48 mil anos atrás. Estes resultados corroboram a hipótese de Carnaval \& Moritz (2008) em que se esperaria um pronunciado sinal de expansão demográfica após o fim do UMG na porção sul da MA por consequência de maior instabilidade do bioma nesta região durante este período. Entretanto nossa evidência de estabilidade no filogrupo norte pode estar enviesada devido ao nosso reduzido tamanho amostral desta população $(\mathrm{N}=5)$.

Em geral nossas estimativas de tempo de divergência pelo IMa (Tab. 4, Fig. 5) e de expansão demográfica pelo EBSP (Fig. 4) apontam para um cenário de vicariância recente em alopatria seguida de posterior expansão na filogrupo centrosul em M. gularis. Esta separação ocorrida no período final do Pleistoceno (Tab. 4, Fig. 5) possivelmente está relacionada com a teoria dos refúgios florestais (Haffer, 1969; Vanzolini \& Willians, 1970). Outros estudos filogeográficos de organismos da MA também mostraram que esta hipótese seria a mais plausível para explicar o padrão observado (Cabanne et al., 2008; Carnaval et al., 2009; Ribeiro et al., 2010; d'Horta et al., 2011; Maldonado-Coelho, 2012). Ainda, o possível fato do filogrupo ao norte do Rio Jequitinhonha se tratar de uma população isolada da espécie nos remete à hipótese de estas localidades serem relictos de um refúgio presente nesta parte da MA durante o fim do Pleistoceno. As estimativas de migração pelo IMa (Tab. 4, Fig. 5) mostraram que o fluxo gênico entre estes filogrupos é muito baixo, indicando assim que o contato secundário entre eles é bastante remoto. Carnaval \& Moritz (2008) mostraram que durante o UMG a porção central da MA ao norte do Rio Doce foi estável com a presença de um grande refúgio florestal denominado “Refúgio Bahia”.

Embora M. gularis não seja considerada ameaçada pelo Ministério de Meio Ambiente e pela International Union for Conservation of Nature suas populações vêm sofrendo declínio em consequência da degradação da MA (BirdLife International, 2012). Nossos resultados mostraram que as populações desta espécie isoladas ao 
norte do Rio Jequitinhonha constituem uma independente ESU (Evolutionary Significant Unity). O filogrupo norte de $M$. gularis ocorre em uma das regiões mais devastadas da MA (Ribeiro et al., 2009) e esforços para se implantar programas de conservação, bem como de restauração nestas áreas, se faz necessário, visto que várias espécies que são extremamente ameaçadas ocorrem quase que exclusivamente nestas regiões (Silveira et al., 2005).

\section{Conclusões}

Neste estudo abordagens clássicas e Bayesianas coalescentes de filogeografia permitiram fazer inferências sobre a história evolutiva de $M$. gularis, bem como contribuíram para a compreensão dos processos que atuaram na diversificação da MA. Nossos resultados mostraram a presença de dois filogrupos nesta espécie que se divergiram no final do Pleistoceno, sendo a descontinuidade filogeográfica concordante espacialmente com os rios Doce e Jequitinhonha. Também foi observada uma expansão demográfica no filogrupo centro-sul desde o fim do UMG ( 20 mil anos atrás) que corrobora as predições do modelo proposto por Carnaval \& Moritz (2008). No entanto, a quebra filogeográfica localizada no Estado de São Paulo observada para outros organismos não foi detectada em $M$. gularis.

Desta maneira, resultados deste e de outros estudos filogeográficos de organismos endêmicos da MA têm mostrado uma heterogeneidade tanto espacial quanto temporal nos padrões de estrutura genética destas espécies ao longo do bioma. Assim, é possível predizer que diferentes processos históricos ocorreram ao longo da história evolutiva da MA, e os organismos residentes nela reponderam a estes eventos de forma heterogênea conforme suas dependências ecológicas. Portanto, com o estudo filogeográfico de mais organismos outros padrões ainda não detectados devem ser revelados e, desta forma, devem reiterar a sugestão de que a diversificação dentro da MA não pode ser explicada por um única hipótese (Costa, 2003; Batalha-Filho et al., 2012). Futuros estudos que correlacionem o componente climático do nicho destas espécies com os padrões filogeográficos observados poderão ajudar a compreender o porquê desta diversidade de padrões. 


\section{Referências}

Álvarez-Presas M, Carbayo F, Rozas J, Riutort M. 2011. Land planarians (Platyhelminthes) as a model organism for fine-scale phylogeographic studies: understanding patterns of biodiversity in the Brazilian Atlantic Forest hotspot. J. Evol. Biol. 24: $887-896$.

Amaro RC, Rodrigues MT, Yonenaga-Yassuda Y, Carnaval AC. 2012. Demographic processes in the montane Atlantic rainforest: molecular and cytogenetic evidence from the endemic frog Proceratophrys boiei. Mol. Phylogenet. Evol. 62: $880-888$.

Bandelt HJ, Forster P, Röhl A. 1999. Median-joining networks for inferring intraspecific phylogenies. Mol. Biol. Evol. 16: 37-48.

Batalha-Filho H, Cabanne GS, Miyaki CY. 2012. Phylogeography of an Atlantic forest passerine reveals demographic stability through the last glacial maximum. Mol. Phylogenet. Evol. DOI: http://dx.doi.org/10.1016/j.ympev.2012.08.010.

Batalha-Filho H, Waldschmidt AM, Campos LAO, Tavares MG, Fernandes-Salomão TM. 2010. Phylogeography and historical demography of the Neotropical stingless bee Melipona quadrifasciata (Hymenoptera, Apidae): incongruence between morphology and mitochondrial DNA. Apidologie 41: 534-547.

Behling H. 2002. South and southeast Brazilian grasslands during Late Quaternary times: a synthesis. Palaeogeogr. Palaeoclimatol. Palaeoecol. 177: 19-27.

Behling H, Lichte M. 1997. Evidence of dry and cold climatic conditions at glacial times in tropical southeastern Brazil. Quatern. Res. 48: 348-358.

Behling H, Pillar VDP, Bauermann SG. 2005. Late Quaternary grassland (Campos), gallery forest, fire and climate dynamics, studied by pollen, charcoal and multivariate analysis of the São Francisco de Assis core in western Rio Grande do Sul (southern Brazil). Rev. Pal. Pal. 133: 235-248.

Behling H, Pillar VDP, Orlóci L, Bauermann SG. 2004. Late Quaternary Araucaria forest, grassland (Campos), fire and climate dynamics, studied by highresolution pollen, charcoal and multivariate analysis of the Cambara do Sul core in southern Brazil. Palaeogeog. Palaeoclim. Palaeoecol. 203: 277-297.

Belmonte-Lopes R, Bravo GA, Bornschein MR, Maurício GN, Pie MR, Brumfield RT. 2012. Genetic and morphological data support the placement of Myrmotherula 
gularis (Spix) in the monotypic genus Rhopias Cabanis and Heine (Aves: Passeriformes: Thamnophilidae). Zootaxa 3451: 1-16.

BirdLife International (2012) Species factsheet: Myrmotherula gularis. Acessado http://www.birdlife.org em 02/09/2012.

Bravo GA, Chesser RT, Brumfield RT. 2012. Isleria, a new genus of antwren (Aves: Passeriformes: Thamnophilidae). Zootaxa 3195: 61-67.

Bruen TC, Philippe H, Bryant D. 2006. A simple and robust statistical test for detecting the presence of recombination. Genetics 172: 2665-2681.

Cabanne GS, d'Horta FM, Sari EHR, Santos FR, Miyaki CY. 2008. Nuclear and mitochondrial phylogeography of the Atlantic forest endemic Xiphorhynchus fuscus (Aves: Dendrocolaptidae): Biogeography and systematic implications. Mol. Phylogenet. Evol. 49: 760-773.

Cabanne GS, d'Horta FM, Meyer D, Silva JMC, Miyaki CY. 2011. Evolution of Dendrocolaptes platyrostris (Aves: Furnariidae) between the South American open vegetation corridor and the Atlantic forest. Biol. J. Linn. Soc. 103: 801820.

Carnaval AC, Hickerson MJ, Haddad CFB, Rodrigues MT, Moritz C. 2009. Stability predicts genetic diversity in the Brazilian Atlantic forest hotspot. Science 323: 785-789.

Carnaval AC, Moritz C. 2008. Historical climate modeling predicts patterns of current biodiversity in the Brazilian Atlantic forest. J. Biogeogr. 35: 1187-1201.

Costa LP. 2003. The historical bridge between the Amazon and the Atlantic forest of Brazil: a study of molecular phylogeography with small mammals. J. Biogeogr. 30: $71-86$.

d'Horta F, Cabanne GS, Meyer D, Miyaki CY. 2011. The genetic effects of Late Quaternary climatic changes over a tropical latitudinal gradient: diversification of an Atlantic Forest passerine. Mol. Ecol. 20: 1932-1935.

Drummond AJ, Rambaut A. 2007. BEAST: Bayesian evolutionary analysis by sampling trees. BMC Evol. Biol. 7: 214.

Dupanloup I, Schneider S, Excoffier L. 2002. A simulated annealing approach to define the genetic structure of populations. Mol. Ecol. 11: 2571-2581. 
Ellegren H. 2007. Molecular evolutionary genomics of birds. Cytogenet. Genome Res. 117: 120-130.

Fjeldså J, Bowie RCK, Rahbek C. 2012. The role of mountain ranges in the diversification of birds. Annu. Rev. Ecol. Evol. Syst. DOI: http://dx.doi.org/10.1146/annurev-ecolsys-102710-145113.

Fouquet A, Recoder R, Teixeira Jr. M, Cassimiro J, Amaro RC, Camacho A, Damasceno R, Carnaval AC, Moritz C, Rodrigues MT. 2012. Molecular phylogeny and morphometric analyses reveal deep divergence between Amazonia and Atlantic Forest species of Dendrophryniscus. Mol. Phylogenet. Evol. 62: 826838.

Friesen VL, Congdon BC, Walsh HE, Birt TP. 1997. Intron variation in marbled murrelets detected using analyses of single-stranded conformational polymorphisms. Mol. Ecol. 6:1047-1058.

Fu YX. 1997. Statistical tests of neutrality of mutations against population growth, hitchhiking and background selection. Genetics 147: 915-925.

Grazziotin FG, Monzel M, Echeverrigaray S, Bonatto SL. 2006. Phylogeography of the Bothrops jararaca complex (Serpentes: Viperidae): past fragmentation and island colonization in the Brazilian Atlantic Forest. Mol. Ecol. 15: 3969-3982.

Haffer J. 1969. Speciation in Amazonian forest birds. Science 165: 131-137.

Hackett SJ. 1996. Molecular phylogenetics and biogeography of tanagers in the genus Ramphocelus (Aves). Mol. Phylogenet. Evol. 5: 368-382.

Hasegawa M, Kishino H, Yano T. 1985. Dating of the human-ape splitting by a molecular clock of mitochondrial DNA. J. Mol. Evol. 22: 160-174.

Heled J, Drummond AJ. 2008. Bayesian inference of population size history from multiple loci. BMC Evol. Biol. 8: 289.

Hey J, Nielsen R. 2004. Multilocus methods for estimating population sizes, migration rates and divergence time, with applications to the divergence of Drosophila pseudoobscura and D. persimilis. Genetics 167: 747-760.

Higgins D, Thompson J, Gibson T, Thompson JD, Higgins DG, Gibson TJ. 1994. CLUSTAL W: improving the sensitivity of progressive multiple sequence alignment through sequence weighting, position-specific gap penalties and weight matrix choice. Nucleic Acids Res. 22: 4673-4680. 
Ho SY, Shapiro B. 2011. Skyline-plot methods for estimating demographic history from nucleotide sequences. Mol. Ecol. Resour. 11: 423-434.

Huson DH, Bryant D. 2006. Application of phylogenetic networks in evolutionary studies. Mol. Biol. Evol. 23: 254-267.

Irestedt M, Fjeldså J, Nylander JAA, Ericson PGP. 2004. Phylogenetic relationships of typical antbirds (Thamnophilidae) and test of incongruence based on Bayes factors. BMC Evol. Biol. 4: 23.

Johnson KP, Sorenson MD. 1998. Comparing molecular evolution in two mitochondrial coding genes (citochrome $b$ and ND2) in the dabbling ducks (tribe: Anatini). Mol. Phylogenet. Evol. 10: 82-94.

Librado P, Rozas J. 2009. DnaSP v5: A software for comprehensive analysis of DNA polymorphism data. Bioinformatics 25: 1451-1452.

Lougheed SC, Freeland JR, Handford P, Boag PT. 2000. A molecular phylogeny of warbling-finches (Poospiza): paraphyly in a Neotropical emberizid genus. Mol. Phylogenet. Evol. 17: 367-378.

Lundberg JG, Marshall LG, Guerrero J, Horton B, Malabarba MCSL, Wesselingh F. 1998. The stage for Neotropical fish diversification: a history of tropical South American rivers. In: Malabarba LR, Reis RE, Vari RP, Lucena ZMS, Lucena CAS (eds). Phylogeny and classification of Neotropical fishes. EDIPUCRS, Porto Alegre, pp 13-48.

Maldonado-Coelho M. 2012. Climatic oscillations shape the phylogeographical structure of Atlantic Forest fire-eye antbirds (Aves: Thamnophilidae). Biol. J. Linn. Soc. 105: 900-924.

Martins FM. 2011. The Brazilian Atlantic forest historical biogeography and the Carnaval-Moritz model of Pleistocene refugia: what do the phylogeographical studies tell us? Biol. J. Linn. Soc. 104: 499-509.

Martins FM, Templeton AR, Pavan ACO, Kohlbach BC, Morgante JS. 2009. Phylogeography of the common vampire bat (Desmodus rotundus): marked population structure, Neotropical Pleistocene vicariance and incongruence between nuclear and mtDNA markers. BMC Evol. Biol. 9: 294.

Mayle FE, Burn MJ, Power M, Urrego DH. 2009. Vegetation and fire at the last Glacial Maximum in tropical South America. In Vimeux F, Sylvestre F, Khodri M 
(eds) Past Climate Variability in South America and Surrounding Regions: from the Last Glacial Maximum to the Holocene. Springer, Dordrecht, pp 89-112.

Moritz C, Patton JL, Schneider CJ, Smith TB. 2000. Diversification of rainforest faunas: An integrated molecular approach. Annu. Rev. Ecol. Syst. 31: 533-563.

Myers N, Mittermeier RA, Mittermeier CG, da Fonseca GAB, Kent J. 2000. Biodiversity hotspots for conservation priorities. Nature 403: 853-858.

Nielsen R, Wakeley J. 2001. Distinguishing migration from isolation: a Markov chain Monte Carlo approach. Genetics 158: 885-896.

Nylander JAA. 2004. MrModeltest 2.2. Program distributed by the author. Evolutionary Biology Centre, Uppsala University.

Palumbi SR, Cipriano F, Hare MP. 2001. Predicting nuclear gene coalescence from mitochondrial data: the three-times rule. Evolution 55: 859-868.

Pellegrino KCM, Rodrigues MT, Waite AN, Morando M, Yassuda YY, Sites Jr JW. 2005. Phylogeography and species limits in the Gymnodactylus darwinii complex (Gekkonidae, Squamata): genetic structure coincides with river systems in the Brazilian Atlantic Forest. Biol. J. Linn. Soc. 85: 13-26.

Pinho C, Harris DJ, Ferrand N. 2008. Non-equilibrium estimates of gene flow inferred from nuclear genealogies suggest that Iberian and North African wall lizards (Podarcis spp.) are an assemblage of incipient species. BMC Evol. Biol. 8: 63.

Primmer CR, Borge T, Lindell J, Saetre GP. 2002. Single nucleotide polymorphism characterization in species with limited available sequence information: high nucleotide diversity revealed in avian genome. Mol. Ecol. 11: 603-612.

Pritchard JK, Stephens M, Donnelly P. 2000. Inference of population structure using multilocus genotype data. Genetics 155: 945-959.

Pritchard JK, Wen X, Falush D. 2010. Documentation for Structure software: version 2.3. Disponível em: http://pritch.bsd.uchicago.edu/structure.html.

Ramos-Onsins S, Rozas J. 2002. Statistical properties of new neutrality test against population growth. Mol. Biol. Evol. 19: 2092-2100.

Ribeiro AC. 2006. Tectonic history and the biogeography of the freshwater fishes from the coastal drainages of eastern Brazil: an example of faunal evolution associated with a divergent continental margin. Neotrop. Ichthyol. 4: 225-246. 
Ribeiro CA, Metzger JP, Martensen AC, Ponzoni FJ, Hirota MM. 2009. The Brazilian Atlantic Forest: How much is left, and how is the remaining forest distributed? Implications for conservation. Biol. Cons. 142: 1141-1153.

Ribeiro RA, Lemos-Filho JP, Ramos ACS, Lovato MB. 2010. Phylogeography of the endangered rosewood Dalbergia nigra (Fabaceae): insights into the evolutionary history and conservation of the Brazilian Atlantic Forest. Heredity 106: $46-57$.

Ridgely RS, Tudor G. 1994. The birds of South America, volume II: The Suboscine Passerines. University of Texas Press, Austin.

Sick H. 1997. Ornitologia Brasileira. Nova Fronteira, Rio de Janeiro.

Silveira LF, Develey PF, Pacheco JF, Whitney BM. 2005. Avifauna of the Serra das Lontras-Javi montante complex, Bahia, Brazil. Cotinga 24: 45-54.

Stephens M, Smith N, Donnelly P. 2001. A new statistical method for haplotype reconstruction from population data. Am. J. Hum. Genet. 68: 978-989.

Tamura K, Peterson D, Peterson N, Stecher G, Nei M, Kumar S. 2011. MEGA5: Molecular Evolutionary Genetics Analysis using Maximum Likelihood, Evolutionary Distance, and Maximum Parsimony Methods. Mol. Biol. Evol. 28: 2731-2739.

Thomé MTC, Zamudio KR, Giovanelli JGR, Haddad CFB, Baldissera Jr FA, Alexandrino JMB. 2010. Phylogeography of endemic toads and post-Pliocene persistence of the Brazilian Atlantic Forest. Mol. Phylogenet. Evol. 55: 1018-1031.

Weir JT, Schluter D. 2008. Calibrating the avian molecular clock. Mol. Ecol. 17: 23212328.

Vanzolini PE, Williams EE. 1970. South American anoles: the geographic differentiation and evolution of the Anolis chrysolepis species group (Sauria: iguanidae). Arquiv. Zool. (S. Paulo) 19: 1-298.

Zink RM, Barrowclough GF. 2008. Mitochondrial DNA under siege in avian phylogeography. Mol. Ecol. 17: 2107-2121. 


\section{Capítulo 3}

Molecular systematics and evolution of the Synallaxis ruficapilla complex (Aves: Furnariidae) in the Atlantic

Forest

Manuscrito em revisão no periódico Molecular Phylogenetics and Evolution

(submetido em agosto de 2012) de autoria de Henrique Batalha-Filho, Martin Irestedt, Jon Fjeldså, Per G. P. Ericson, Luis F. Silveira e Cristina Y. Miyaki. 


\section{Abstract}

The Neotropical Synallaxis ruficapilla complex is endemic to the Atlantic Forest and is comprised of three species: S. ruficapilla, S. whitneyi, and S. infuscata. This group is closely related to the Synallaxis moesta complex that occurs in the Andes and the Amazonian Tepuis. Here we used mitochondrial and nuclear gene sequences to infer the phylogeny and the time of diversification of the S. ruficapilla and S. moesta complexes. We also included samples of an undescribed population of Synallaxis that resembles other populations of the S. ruficapilla complex. Our results showed that different geographical lineages within the S. ruficapilla complex are reciprocally monophyletic, but the northern form (S. infuscata) grouped with an Andean taxon. This suggests that at least two lineages of this group independently colonized the Atlantic Forest. Specimens of the undescribed population formed a monophyletic clade with deep divergence. Estimated diversification dates were within the late Pliocene to Pleistocene $(2.75-0.16$ million of years ago). This suggests that at this time there was a higher connectivity between habitats in the rugged landscapes of the circum-Amazonian bioregions. The observed Pleistocene diversification within the Atlantic Forest is congruent in space and time with studies of other co-distributed organisms, and may be associated with climate changes and tectonic activity during this period.

Keywords: Passeriformes, Suboscines, Neotropics, Phylogeny, Species tree, PlioPleistocene, Diversification

\section{Introduction}

Genus Synallaxis Vieillot (Spinetails) is endemic to the Neotropical region and occurs from southern Mexico to Argentina. This is the most species-rich genus in the family Furnariidae, with 33 recognized species (Remsen, 2003). Recently, an additional species of Synallaxis was described (Hilty and Ascanio, 2009). Overall, the systematics of the genus is rather obscure, as many species are similar in morphology (Ridgely and Tudor, 1996), and some species include two to ten subspecies that could represent full species themselves (Remsen, 2003). Most Synallaxis species inhabit dense understory vegetation in riparian thickets, edge 
habitat and secondary forest, with some exceptions occurring inside continuous forest (Ridgely and Tudor, 1996; Sick, 1997). Remsen (2003) suggests a close relationship between Synallaxis and the genera Certhiaxis, Schoeniophylax, Gyalophylax, and Siptornopsis. Recent phylogenetic hypotheses (Irestedt et al., 2009; Derryberry et al., 2011) confirm these relationships.

The S. ruficapilla complex (Fig. 1) comprises S. ruficapilla, S. whitneyi, and S. infuscata (Pacheco and Gonzaga, 1995) and is endemic to the highly endangered and megadiverse Atlantic Forest - AF (Myers et al., 2000; Ribeiro et al., 2009). Pacheco and Gonzaga (1995) suggested that this species complex is monophyletic based on similarities in plumage and song and notably their nearly identical scolding call. In a recent near-complete species-level phylogeny of the Furnariidae (Derryberry et al., 2011) the S. ruficapilla and S. moesta complexes are placed together as a monophyletic clade, but with low node supports for the relationships within the clade. However, this phylogeny only included one species from the $S$. ruficapilla complex (S. ruficapilla) while the S. moesta complex was represented by all three species (S. moesta, S. macconnelli, and S. cabanisi), which occur in the Andes and the Amazonian Tepuis (Fig. 1; Ridgely and Tudor, 1996; Remsen, 2003).

Recently Stopiglia et al. (2012) suggested that S. whitneyi is a junior synonym of S. ruficapilla based on plumage, morphometric and song characters. Thus, accordingly to these authors, there are only two species in the S. ruficapilla complex: S. ruficapilla and S. infuscata. They also argued that only the number of rectrices is diagnostic for both species and that other phenotypic traits show great individual variation and no constant population differences. They also included six specimens of Synallaxis sp. (vouchers in MZUSP; see Table 1) recently collected in Amazon (Vila Rica, Mato Grosso state in Brazil) and geographically disconnected from the AF. Accordingly to Stopiglia et al. (2012) these specimens overlap with S. ruficapilla in both morphology and song, suggesting that these birds, which do not occur in the AF, are S. ruficapilla. Thus, the species limits within the S. ruficapilla complex are still uncertain.

Notwithstanding, defining limits between species it is not a trivial task, mainly due to ambiguity in the species concept in biology (de Queiroz, 2007). Because of retention of ancestral polymorphism and incomplete lineage sorting it is 
particularly difficult to establish the taxonomic status of recently diverged populations (Carstens and Dewey, 2010). However, the use of molecular data as an additional means to delimitate species has become a robust tool (Carstens and Dewey, 2010; Kubatko et al., 2011), especially when a species tree is inferred based on the coalescence of multiple independent loci (Liu and Pearl, 2007; Liu, 2008; Heled and Drummond, 2010).

Here, we infer the phylogenetic relationships within the S. ruficapilla complex, as well as its relationships with the S. moesta complex, using mitochondrial and nuclear sequences. Furthermore, we investigate the taxonomic status of the putative undescribed species of Synallaxis from Vila Rica. Our results will help to trace the evolutionary history of South American forests. Yet, in the context of conservation, we add data to discuss the taxonomic status of the threatened taxa S. whitneyi and S. infuscata (Roda, 2008; Silveira, 2008).

\section{Material and Methods}

\subsection{Taxon sampling and molecular methods}

We sampled 38 individuals from all species of the S. ruficapilla and S. moesta complexes (Table 1, Fig. 2), including the putative new species of Synallaxis from Vila Rica (state of Mato Grosso, MT) in Brazil (Fig. 2). According to Stopiglia et al. (2012), the phenotypic and vocal variation in S. ruficapilla and S. whitneyi involves great individual variation with no characters that clearly distinguish these two populations. Thus, we assigned the taxonomic status of these birds according to their geographic distribution (Fig. 1; Ribon et al., 2002; Ridgely and Tudor, 1996; Vasconcelos and Silva, 2004) and assuming that the Jequitinhonha River is the northern and southern limits for S. ruficapilla and S. whitneyi, respectively (Vasconcelos and Silva, 2004). This river could be interpreted as a primary barrier for these species, but as its origin is very ancient (Gondwanic age, see Saadi, 1995), it is probably a secondary barrier or a contact zone. One specimen each from S. frontalis and S. spixi were used as outgroups, following Derryberry et al. (2011). The samples were obtained from fresh tissue (muscle or blood) and museum study skins (Table 1). 
DNA was extracted from fresh samples following Bruford et al. (1992), while the laboratory procedures for museum study skin samples followed Irestedt et al. (2006). We sequenced two mitochondrial genes - cytochrome b (cytb) and NADH dehydrogenase subunit 2 (ND2); and tree nuclear introns - $\beta$-fibrinogen intron 5 (FIB5), myoglobin intron 2 (myo2), and glyceraldehyde-3-phosphodehydrogenase intron 11 (G3PDH). For fresh samples all loci were amplified as one product each, whereas additional internal primers were designed for the study skin samples to allow the amplification of shorter fragments ( $200-250 \mathrm{bp}$ each). All primers used in this study are described in Table 2.

PCR conditions were an initial denaturation step at $94{ }^{\circ} \mathrm{C}$ for 3 minutes and 30 seconds; followed by 35 or 40 cycles at $94{ }^{\circ} \mathrm{C}$ for 35 seconds, annealing temperature for 40 seconds and $72{ }^{\circ} \mathrm{C}$ for 1 minute; plus a final extension step at 72 ${ }^{\circ} \mathrm{C}$ for 9 minutes. Annealing temperatures were: cytb and ND2 $56^{\circ} \mathrm{C}$; FIB5 and myo2 $52-58^{\circ} \mathrm{C}\left(2\right.$ cycles at $58^{\circ} \mathrm{C}, 2$ cycles at $56^{\circ} \mathrm{C}, 2$ cycles at $54^{\circ} \mathrm{C}$ and 34 cycles at $52^{\circ} \mathrm{C}$ ); $\mathrm{G} 3 \mathrm{PDH} 64^{\circ} \mathrm{C}$. PCR and sequencing protocols followed d'Horta et al. (2011) and Irestedt et al. (2006) for fresh and study skin samples, respectively.

\subsection{Sequence edition, alignment and recombination}

Electropherograms were inspected and assembled in contigs using CodonCode Aligner v. 3.7 (CodonCode Inc.). Heterozygous sites in nuclear introns were coded according to IUPAC code when double peaks were present in both strands of the same individual's electropherograms. Nuclear sequences that contained heterozygous indels were analyzed using the algorithm Process Heterozygous Indels in CodonCode Aligner v. 3.7. Sequences were aligned using the CLUSTAL W method (Higgins et al., 1994) in MEGA5 (Tamura et al., 2011). All alignments were inspected and corrected visually. We used PHI test in SPLITSTREE4 (Bruen et al., 2006; Huson and Bryant, 2006) to check for recombination in the nuclear gene sequences. This test was used due to its power to distinguish recombination events from recurrent mutation (Bruen et al., 2006). To apply the coalescent species tree analysis we resolved the gametic phase of nuclear genes using the PHASE algorithm (Stephens et al., 2001) with default settings in DnaSP 5 (Librado and Rozas, 2009) assuming a threshold of posterior probability of 0.9. 
However, we kept the unphased sequences with probabilities below this threshold in the analysis.

\subsection{Phylogenetic analyses}

The best fit model for each gene was selected using MrModeltest 2.2 (Nylander, 2004) based on the Akaike information criterion (AIC). Two partitions (cytb + ND2) were considered in the Bayesian and maximum likelihood analyses using MrBayes 3.1.2 (Huelsenbeck and Ronquist, 2001) and RAxML (Stamatakis et al., 2008), respectively. Both analyses were carried out at CIPRES Science Gateway (Miller et al., 2010). Bayesian runs consisted of 10 million generations for 2 independent runs with 4 chains of Markov chain Monte Carlo (MCMC) each. The first million generations were discarded as burn-in, after which trees were sampled every 500 generations. Chain convergence (Effective Sample Size - ESS values > 200) was checked using the likelihood plots for each run using Tracer 1.5 (http://beast.bio.ed.ac.uk/Tracer). The Potential Scale Reduction Factor was also used to check chain convergence and burn-in; values close to one indicate good convergence between runs (Gelman and Rubin, 1992). We used RAxML under the GTRAC model; invariable sites and gamma distribution were estimated for each partition during the run. Node supports of the maximum likelihood analyses were estimated by 1,000 bootstrap replications. We also obtained trees in RAxML for each nuclear gene.

\subsection{Species tree and dating}

In order to combine the information of all genes in a single tree and accommodate inconsistencies between gene and species trees (Degnan and Rosenberg, 2006; Kubatko and Degnan, 2007) we used the Bayesian coalescent method of species tree in *BEAST (Bayesian Inference of Species Trees from Multilocus Data; Heled and Drummond, 2010) in the Bioportal at University of Oslo (Kumar et al., 2009). The main mitochondrial lineages (Fig. 2) were assigned as "species" in the analysis. We also estimated the divergence times using the multispecies coalescent method of *BEAST (in BEAST 1.6.2, Drummond and Rambaut, 2007), as this method seems to be more accurate than those based on 
gene trees (McCormack et al., 2011). We generated the input file in BEAUTi considering four genes (mitochondrial + $\mathrm{FIB}_{5}+\mathrm{myO} 2+\mathrm{G}_{3} \mathrm{PDH}$ ) and the substitution models selected by MrModeltest (Table 3). We used relaxed clock with an uncorrelated lognormal distribution (Drummond et al., 2006) and Yule process for all genes. Piecewise linear and constant root were used as population size model prior. Given the very sparse fossil record of furnariids, and the general problem of correlation of furnariid splitting events to specific past events (Derryberry et al., 2011), we used the mutation rate of mitochondrial genes (under a normal distributed prior) available for birds to estimate divergence dates (Lovette, 2004; Weir and Schluter, 2008). This mutation rate of 1.05\% ( \pm 0.05$)$ per lineage per million years was estimated by Weir and Schluter (2008) based on 90 calibration points and 12 orders of birds, and included a range of 12 million years. We then used BEAST to estimate the mutation rates for the nuclear introns using a log-normal distributed prior under default settings for each partition. We did two independent runs with 100 million generations each, with parameters sampled every 10,000 steps and a burn-in of $30 \%$. We checked for convergence between runs and analysis performance using Tracer 1.5, and accepted the results if ESS values were $>200$. The resulting trees were combined in TreeAnotator and the consensus species tree with the divergence times was visualized in FigTree 1.3 .1 (http://tree.bio.ed.ac.uk/software/figtree/).

\section{Results}

\subsection{Phylogenetic inferences}

\subsubsection{Mitochondrial dataset}

Our mitochondrial dataset comprised 2043 characters for 40 individuals, including outgroups: 1002 of cytb and 1041 of ND2. For the ingroup 120 and 125 sites were variable in cytb and ND2, respectively. No indels, unexpected stop codons, or ambiguous peaks in the electropherograms were found in these sequences, suggesting that they were of mitochondrial origin. The best fit model estimated for each gene is shown in Table 3.

Bayesian and maximum likelihood analyses indicated absence of monophyly of the S. ruficapilla complex, with S. infuscata being paraphyletic with other AF 
species (Fig. 2). Besides, specimens of the undescribed Synallaxis from Vila Rica-MT (hereafter unnamed Synallaxis) formed a monophyletic clade with a deep divergence from the other species (Fig. 2). Yet, unnamed Synallaxis appeared as sister to the AF species S. ruficapilla and S. whitneyi, but with moderate node support ( 0.89 of posterior probability and $82 \%$ of bootstrap; Fig. 2). The relationships between the S. ruficapilla and S. moesta complexes were recovered as a polytomy (Fig. 2). Interestingly, the results revealed that the AF S. infuscata is sister to the Andean S. moesta with moderate support ( 0.92 of posterior probability and $94 \%$ of bootstrap; Fig. 2).

Our mitochondrial trees also revealed genetic structure in S. ruficapilla. Two clades were observed: a southern clade that included almost the entire geographical distribution of species, and an unexpected northern clade with samples from the north of state of Minas Gerais (Poté and José Gonçalves de Minas) where the AF meets the Cerrado biome (Fig. 2 and Table 1).

\subsubsection{Nuclear dataset}

We obtained sequences of all three nuclear introns for all species, except G3PDH for S. moesta (Table 1). In the FIB5 ingroup alignment (546 characters) 34 sites were polymorphic, and there were five indels in eight individuals ranging in length from 1 to $29 \mathrm{bp}$. We found 16 polymorphic sites in the myoz ingroup alignment (587 characters) and one indel in 11 individuals of $1 \mathrm{bp}$ long. For the alignment of the ingroup G3PDH (323 characters) there were 26 polymorphic sites and two indels ( 1 bp and 2 bp long, respectively) in six individuals. PHI test showed that there is no significant evidence for recombination events in any of the nuclear genes $(p>0.1)$.

Gene trees of nuclear introns did not recover the same genetic structure in the ingroup as found in the mitochondrial genes. However, a poorly supported clade that includes unnamed Synallaxis, S. ruficapilla, and S. whitneyi is observed in the G3PDH tree, but the last two taxa were not reciprocally monophyletic (Fig. 3).

\subsubsection{Species tree}


The species tree generated by *BEAST was partially congruent with the mitochondrial one, but with poorly supported nodes (Fig. 4). The only exceptions were the central-southern AF clade (S. ruficapilla and S. whitneyi) that was moderately well supported, and its sister relationship with unnamed Synallaxis that was well supported.

\subsection{Divergence times}

The dated chronogram based on the coalescent multilocus analysis in *BEAST, revealed a recent diversification. The splitting events occurred from the late Pliocene to early Pleistocene (2.75 - 0.16 million of years ago [mya]; Fig. 4; Table 4). The oldest divergence event was the split between the clade including $S$. infuscata and S. moesta at 2.24 mya. (95\% of high posterior density [HPD]: $2.75-1.80$ mya). The youngest diversification event was the separation of northern and southern clades in S. ruficapilla at 0.53 mya (95\% of HPD: $0.86-0.16$ mya).

\section{Discussion}

\subsection{Systematics of the S. ruficapilla and S. moesta complexes}

The mitochondrial phylogeny revealed eight well supported lineages including all previously described species and one unnamed Synallaxis (Fig. 2). Besides, it revealed a previously undetected cryptic diversity within S. ruficapilla, where a dichotomy separating a northern clade (comprising specimens from the northern state of Minas Gerais) and a southern clade (specimens from the remaining localities sampled in this study) where observed. S. whitneyi was found to be monophyletic and appeared as sister to S. ruficapilla. Specimens of unnamed Synallaxis also formed a monophyletic clade with a deep differentiation from its sister group (S. whitneyi and S. ruficapilla). This result reinforces the hypothesis that these specimens represent an undescribed taxon. S. infuscata and S. moesta were reciprocally monophyletic and unexpectedly recovered as sister species with a moderate node support. This is not congruent with a previous suggestion that $S$. infuscata should group with the other two AF species, S. ruficapilla and S. whitneyi (Pacheco and Gonzaga, 1995). S. cabanisi and S. macconnelli were also 
monophyletic, but their relationships to the other clades could not be resolved and is best regarded as belonging to an unresolved polytomy.

Our data also suggest that the specimens from Vila Rica-MT belong to an undescribed taxon of Synallaxis. Additional specimens possibly related to this new taxon were collected in other localities in the Amazon, in Coroatá, Maranhão (Oren, 1991, specimens in Louisiana State University, Museum of Natural Science) and São Félix do Xingu (specimens in Museu Paraense Emílio Goeldi, Brazil), previously identified as S. infuscata and S. macconeli respectively. The number of rectrices of these specimens suggests that they belong to the S. ruficapilla complex (Stopiglia et al., 2012). Also, Zimmer et al. (1997) mentioned specimens of S. cabanisi in Alta Floresta in the state of Mato Grosso (approx. $550 \mathrm{~km}$ west from Vila Rica-MT), but according to Whitney (1997) these birds possibly belong to an undescribed species of the S. ruficapilla complex. Therefore, further efforts of field surveys in these regions will be important to obtain specimens of unnamed Synallaxis to determine whether all these records represent the same cryptic taxon as identified in our study, as well as determining the geographic distribution and taxonomic status of this lineage.

Overall, our mitochondrial results were incongruent with the analyses by Stopiglia et al. (2012) that used song and morphological characters. This taxonomic revision of the S. ruficapilla group concluded that only two species should be accepted within the complex: i) S. ruficapilla that includes S. whitneyi and the unnamed Synallaxis, and; ii) S. infuscata. According to Stopiglia et al. (2012), S. whitneyi is a synonym of S. ruficapilla, and, according to the same authors, the species in the complex are primarily diagnosed by their number of rectrices: $S$. ruficapilla (including S. whitneyi and unnamed Synallaxis) with eight rectrices, and S. infuscata with ten rectrices.

The absence of a clear phenotypic distinction between the lineages detected by our mitochondrial data set could be the result of retention of ancestral polymorphism, as the majority of the Synallaxis species share a very similar plumage (Remsen, 2003). This could also be due to morphological stasis and insufficient time to evolve morphological differentiation as the estimated population divergence date is relatively recent (late Pliocene to early Pleistocene). Yet, the primarily 
identified plumage differentiation (Pacheco and Gonzaga, 1995) could represent high flexibility in ecophenotypes with no bearing on the historical population structure. Another possible explanation is selection of phenotypic characters such as plumage and song in S. ruficapilla, S. whitneyi, and unnamed Synallaxis, which would make it difficult to find diagnosable states for each of these taxa.

The nuclear gene trees did not recover the same population structure as observed in the mitochondrial tree (Fig. 3). Possible explanations for the lack of reciprocal monophyly in the nuclear DNA includes incomplete lineage sorting in these genes due to a recent diversification (Pinho et al., 2008), and the longer time of coalescence of nuclear DNA compared to the mitochondrial genome (approximately 4 times longer; Palumbi et al., 2001; Zink and Barrowclough, 2008). Also, there is the possibility of gene flow between some lineages observed here, as we found a possible contact zone (data not shown) between S. ruficapilla (northern and central to southern AF) and S. whitneyi. Further analyses of gene flow modeling based on a larger dataset will help to depict this scenario.

Recent estimates (Degnan and Rosenberg, 2006; Liu and Edwards, 2009; Heled and Drummond, 2010) showed that multilocus phylogenies based on classical concatenation of genes are less accurate than inferences based on coalescent species tree approaches to recover the phylogenetic relationships among taxa. Moreover, estimates of coalescent species tree are efficient to accommodate inconsistencies between gene trees due to incomplete lineage sorting in recently diversified populations (Heled and Drummond, 2010). Therefore, in this study we implemented the Bayesian coalescent species tree by *BEAST to depict the systematic relationships between S. ruficapilla and S. moesta complexes. Our species tree was similar to the mitochondrial tree revealing the same clades with good node support values. Although all species showed long terminal branchlengths, they were poorly supported for some species (S. macconnelli, S. cabanisi, S. moesta, and S. infuscata) and failed to resolve the polytomies observed in the mitochondrial tree (Fig. 4). 


\subsection{Biogeography}

The majority of the species $(\sim 17)$ of genus Synallaxis occurs in the Andes and Amazon, and just five are endemic to the AF (the three species from this study plus S. spixi and S. cinerascens; Remsen, 2003). Thus, assuming that the Andes and the Amazon is the possible center of origin of the genus, the AF species seem to have originated from at least three independent lineages as observed in a recent phylogeny of the Furnariidae family (Derryberry et al., 2011). Interestingly, our study showed that the S. ruficapilla complex endemic to the AF is not monophyletic, which suggests that there were additional colonization events and subsequently isolation of geographical lineages in this biome (Figs. 2 and 3). Similar patterns of non-monophyly of AF taxa have been observed in small mammals (Costa, 2003) and birds (Pessoa, 2007; Maldonado-Coelho, 2010; but see Weir and Price, 2011). Furthermore, the S. ruficapilla and S. moesta complexes together exhibit a circumAmazonian pattern as described by Remsen et al. (1991).

The dating of our phylogeny suggests a recent diversification events (late Pliocene to early Pleistocene), with the two populations of S. ruficapilla separated during the climatically most unstable part of the late Pleistocene (Fig. 4). Recently, multi-taxon analysis in conjunction with fossil data have suggested an ancient biota diversification in South America (mainly before the Pleistocene) with the uplift of the Andes and marine incursions as the driving forces of diversification in the continent, instead of Pleistocene glacial cycles (Hoorn et al., 2010; Hoorn and Wesselingh, 2010). However, other studies argued that although the uplift of the Andes and marine incursions were important in the diversification of South American organisms, Pleistocene climate changes also played a key role in the diversification process (Rull, 2008, 2011), and also documented a continuous diversification from the Neogene until the Pleistocene (Rull, 2011). Despite the controversies about the tempo of diversification in South America, our data suggest a Plio-Pleistocene diversification for this group, supporting a higher connectivity between thicket and forest habitats in the rugged landscapes in the circumAmazonian bioregions at this time.

The phylogenetic reconstructions suggest that at least two distinct lineages in the S. ruficapilla and S. moesta groups originated independently in the AF (Figs. 2 
and 4): one was the S. ruficapilla and S. whitneyi clade in central-southern AF, and another was S. infuscata in northern AF. As S. infuscata is not the sister species of the other AF species and groups as sister of the Andean species S. moesta (even though with moderate node support), its origin seems to reflect a historical connection between the Andes and the AF (Silva, 1994; Percequillo et al., 2011). Yet, our observation that the unnamed Synallaxis is sister of the S. ruficapilla/whitneyi clade raises the possibility that this is a relictual population from the time when the Andean and south-east Brazilian upland habitats were connected (Silva, 1995). This lineage could then have survived in the western Amazon after the end of historical connections between these two biomes. This result may support previously proposed historical routes during the Pleistocene connecting South American forests through the dry diagonal (Auler et al., 2004; Auler and Smart, 2001; BatalhaFilho et al., 2012; Behling et al., 2000; Costa, 2003; Oliveira et al., 1999; Por, 1992; Wang et al., 2004; Willis, 1992), specially the Amazon and the AF.

In addition, our results show a Pleistocene diversification within the AF with two vicariant events that lead to separation of three lineages (Figs. 2 and 4): an older split between S. ruficapilla and S. whitneyi at 1.17 mya (95\% of HPD: $1.58-0.74$ mya) and a more recent event separating the two groups of populations of $S$. ruficapilla at 0.53 mya (95\% of HPD: $0.86-0.16$ mya). While the AF holds lineages of ancient (mid-Tertiary) taxa (Fjeldså et al., 2012; Fouquet et al., 2012), the regional biota also underwent significant diversification during the Pleistocene, reflecting climatic-vegetational changes during the Quaternary (Cabanne et al., 2008; Carnaval and Moritz, 2008; Carnaval et al., 2009; d'Horta et al., 2011; Martins, 2011; Maldonado-Coelho, 2012). The cladogenetic events observed here show spatial and temporal congruence with previous studies of AF organisms (Cabanne et al., 2008; Carnaval et. al., 2009; Ribeiro et al., 2010; Thomé et al., 2010). These studies evoked the refuge hypothesis (Haffer, 1969; Vanzolini and Williams, 1970) or tectonical activities (Silva and Straube, 1996; Thomé et al., 2010) as main causes of vicariance. Both these hypotheses may be relevant for the speciation events observed here, and phylogeographic studies are being conducted to help to outline the evolutionary history of this group within the AF. 


\subsection{Implication to conservation}

Data from the present study provided significant arguments for the conservation of the threatened species S. whitneyi and S. infuscata (Roda, 2008; Silveira, 2008). The phylogenetic results confirmed that these are independent evolutionary units, which are reciprocally monophyletic (Fig. 2). Stopiglia et al. (2012) suggested that morphology and songs provide no clear diagnostic differences between S. ruficapilla and S. whitneyi, but our results favor the hypothesis of that each of them is a distinct evolutionary significant unit (ESU). S. ruficapilla and S. whitneyi lineages at least represent phylogenetic species, but extra efforts are needed to find out what happens in potential zones of contact, and to investigate if phenotypic or vocal differences can be detected, that can provide reliable practical diagnosis.

\section{Acknowledgments}

We thank Alexandre Aleixo (MPEG), Fabrício R. Santos (UFMG), and Marcos Raposo (MNRJ) for providing some of the tissues used in this study. We are grateful to Santiago Claramunt who sequenced samples housed in LSU. We thank Fábio S.R. Amaral, Claydson P. Assis, Luciano M. Lima, Marcos M. Coelho, Ana C. Fazza, Tiago S. Ribeiro for their help in field work. We thank Renata Stopiglia for insightful discussions about Synallaxis systematics. Luiz P. Gonzaga gently authorized the use of the illustrations of the S. ruficapilla complex. This study is part of a PhD dissertation by HBF. This work was supported by Fundação de Amparo à Pesquisa do Estado de São Paulo (FAPESP), Coordenação de Aperfeiçoamento de Pessoal de Nível Superior (CAPES), Conselho Nacional de Desenvolvimento Científico e Tecnológico (CNPq), Danish National Research Foundation (support for the Center for Macroecology, Evolution and Climate, Denmark) and the Swedish Research Council (grant numbers 621-2010-5321 to PE). Instituto Brasileiro do Meio Ambiente e dos Recursos Naturais Renováveis (IBAMA) and Instituto Chico Mendes de Conservação da Biodiversidade (ICMBio) provided permits to collect the samples. This work was developed in the Research Center on Biodiversity and Computing (BioComp) of the Universidade de São Paulo (USP), supported by the USP Provost's Office for Research. 


\section{References}

Auler, A.S., Smart, P.L. 2001., Late Quaternary Paleoclimate in semiarid northeastern Brazil from U-series dating of travertine and water-table speleothems. Quat. Res. 55, 159-167.

Auler, A.S., Wang, A., Edwards, R.L., Cheng, H., Cristalli, P.S., Smart, M.L., Richards, D.A., 2004. Quaternary ecological and geomorphic changes associated with rainfall events in presently semi-arid northeastern Brazil. J. Quaternary Sci. 19, 693-701.

Batalha-Filho, H., Fjeldså, J., Fabre, P.H., Miyaki, C.Y., 2012. Connections between the Atlantic and the Amazonian forest avifaunas represent distinct historical events. J. Ornithol. DOI: 10.1007/s10336-012-0866-7.

Behling, H., Arz, H.W., Patzold, J., Wefer, G., 2000. Late Quaternary vegetational and climate dynamics in northeastern Brazil, inferences from marine core GeoB3104-1. Quat. Sci. Rev. 19, 981-994.

Bruen, T.C., Philippe, H., Bryant, D., 2006. A simple and robust statistical test for detecting the presence of recombination. Genetics 172, 2665-2681.

Bruford, M.W., Hanotte, O., Brookfield, J.F.Y., Burke, T., 1992. Single-locus and multilocus DNA fingerprinting. In: Hoelzel, A.R. (Ed.), Molecular Genetic Analysis of Populations-A Practical Approach. IRL Press, New York, pp. 287-336.

Cabanne, G.S., d'Horta, F.M., Sari, E.H.R., Santos, F.R., Miyaki, C.Y., 2008. Nuclear and mitochondrial phylogeography of the Atlantic forest endemic Xiphorhynchus fuscus (Aves: Dendrocolaptidae): Biogeography and systematic implications. Mol. Phylogenet. Evol. 49, 760-773.

Carnaval, A.C., Moritz, C., 2008. Historical climate modeling predicts patterns of current biodiversity in the Brazilian Atlantic forest. J. Biogeogr. 35, 1187-1201.

Carnaval, A.C., Hickerson, M.J., Haddad, C.F.B., Rodrigues, M.T., Moritz, C., 2009. Stability predicts genetic diversity in the Brazilian Atlantic forest hotspot. Science $323,785-789$.

Carstens, B.C., Dewey, T.A., 2010. Species delimitation using a combined coalescent and information-theoretic approach: an example from North American Myotis bats. Syst. Biol. 59, 400-414. 
Cicero, C., Johnson, N.K., 2001. Higher level phylogeny of vireos (Aves: Vireonidae) based on sequences of multiple mtDNA genes. Mol. Phylogenet. Evol. 20, 2740.

Costa, L.P., 2003. The historical bridge between the Amazon and the Atlantic forest of Brazil: a study of molecular phylogeography with small mammals. J. Biogeogr. 30, 71-86.

de Queiroz, K., 2007. Species concepts and species delimitation. Syst. Biol. 56, 879886.

Degnan, J.H., Rosenberg, N.A., 2006. Discordance of species trees with their most likely gene trees. PLoS Genet. 2, 762-768.

Derryberry, E.P., Claramunt, S., Derryberry, G., Chesser, R.T., Cracraft, J., Aleixo, A., Pérez-Emán, J., Remsen, J.V., Brumfield, R.T., 2011. Lineage diversification and morphological evolution in a large-scale continental radiation: the Neotropical ovenbirds and woodcreepers (Aves: Furnariidae). Evolution 65, 2973-2986.

d'Horta, F., Cabanne, G.S., Meyer, D., Miyaki, C.Y., 2011. The genetic effects of Late Quaternary climatic changes over a tropical latitudinal gradient: diversification of an Atlantic Forest passerine. Mol. Ecol. 20, 1932-1935.

Drummond, A.J., Ho, S.Y.W., Phillips, M.J., Rambaut, A., 2006. Relaxed phylogenetics and dating with confidence. PLoS Biol. 4, e88.

Drummond, A.J., Rambaut, A., 2007. BEAST: Bayesian evolutionary analysis by sampling trees. BMC Evol. Biol. 7, 214.

Fjeldså, J., Irestedt, M., Jønsson, K.A., Ohlson, J.I., Ericson, P.G.P., 2007. Phylogeny of the ovenbird genus Upucerthia: a case of independent adaptations for terrestrial life. Zool. Scripta 36, 133-141.

Fjeldså, J., Bowie, R.C.K., Rahbek, C., 2012. The role of mountain ranges in the diversification of birds. Annu. Rev. Ecol. Evol. Syst. DOI: 10.1146/annurev-ecolsys$102710-145113$.

Fouquet, A., Recoder, R., Teixeira Jr., M., Cassimiro, J., Amaro, R.C., Camacho, A., Damasceno, R., Carnaval, A.C., Moritz, C., Rodrigues, M.T., 2012. Molecular phylogeny and morphometric analyses reveal deep divergence between Amazonia and Atlantic Forest species of Dendrophryniscus. Mol. Phylogenet. Evol. 62, 826-838. 
Friesen, V.L., Congdon, B.C., Walsh, H.E., Birt, T.P., 1997. Intron variation in marbled murrelets detected using analyses of single-stranded conformational polymorphisms. Mol. Ecol. 6, 1047-1058.

Gelman, A., Rubin, D., 1992. Inference from iterative simulation using multiple sequences. Stat. Sci. 7, 457-511.

Hackett, S.J., 1996. Molecular phylogenetics and biogeography of tanagers in the genus Ramphocelus (Aves). Mol. Phylogenet. Evol. 5, 368-382.

Haffer, J., 1969. Speciation in Amazonian forest birds. Science 165, 131-137.

Heled, J., Drummond, A.J., 2010. Bayesian inference of species trees from multilocus data. Mol. Biol. Evol. 27, 570-580.

Heslewood, M.M., Elphinstone, M.S., Tidemann, S.C., Baverstock, P.R., 1998. Myoglobin intron variation in the Gouldian finch Erythrura gouldiae assessed by temperature gradient gel electrophoresis. Electrophoresis 19, 142-151.

Higgins, D., Thompson, J., Gibson, T., Thompson, J.D., Higgins, D.G., Gibson, T.J., 1994. CLUSTAL W: improving the sensitivity of progressive multiple sequence alignment through sequence weighting, position-specific gap penalties and weight matrix choice. Nucleic Acids Res. 22, 4673-4680.

Hilty, S.L., Ascanio, D., 2009. A new species of spinetail (Furnariidae: Synallaxis) from the río Orinoco of Venezuela. Auk 126, 485-492.

Hoorn, C., Wesselingh, F.P., ter Steege, H., Bermudez, M.A., Mora, A., Sevink, J., Sanmartín, I., Sanchez-Meseguer, A., Anderson, C.L., Figueiredo, Jaramillo, C., Riff, D., Negri, F.R., Hooghiemstra, H., Lundberg, J., Stadler, T., Särkinen, T., Antonelli, A., 2010. Amazonia through time: Andean uplift, climate change, landscape evolution, and biodiversity. Science 330, 927-931.

Hoorn, C., Wesselingh, F., 2010. Amazonia: Landscape and Species Evolution: a Look into the Past. Blackwell, London.

Huelsenbeck, J.P., Ronquist, F., 2001. MrBayes: Bayesian inference of phylogenetic tree. Bioinformatics 17, 754-755.

Huson, D.H., Bryant, D., 2006. Application of phylogenetic networks in evolutionary studies. Mol. Biol. Evol. 23, 254-267. 
Irestedt, M., Ohlson, J.I., Zuccon, D., Källersjö, M., Ericson, P.G.P., 2006. Nuclear DNA from old collections of avian study skins reveals the evolutionary history of the Old World suboscines (Aves: Passeriformes). Zool. Scripta 35, 567-580.

Irestedt, M., Fjeldså, J., Dalén, L., Ericson, P.G.P., 2009. Convergent evolution, habitat shifts and variable diversification rates in the ovenbird-woodcreeper family (Furnariidae). BMC Evol. Biol. 9, 268.

Kumar, S., Skjæveland, Å., Orr, R.J.S., Enger, P., Ruden, T., Mevik, B.-H., Burki, F., Botnen, A., Shalchian-Tabrizi, K., 2009. AIR: A batch-oriented web program package for construction of supermatrices ready for phylogenomic analyses. BMC Bioinformatics, 10: 357.

Kubatko, L., Degnan, J.H., 2007. Inconsistency of phylogenetic estimates from concatenated data under coalescence. Syst. Biol. 56, 17-24.

Kubatko, L.S., Gibbs, H.L., Bloomquist, E.W., 2011. Inferring species-level phylogenies and taxonomic distinctiveness using multilocus data in Sistrurus rattlesnakes. Syst. Biol. 60, 393-409.

Librado, P., Rozas, J., 2009. DnaSP v5: A software for comprehensive analysis of DNA polymorphism data. Bioinformatics 25, 1451-1452.

Liu, L., 2008. BEST: Bayesian estimation of species trees under the coalescent model. Bioinformatics 24, 2542-2543.

Liu, L., Edwards, S.V., 2009. Phylogenetic analysis in the anomaly zone. Syst. Biol. 58, $452-460$.

Liu, L., Pearl, D.K., 2007. Species trees from gene trees: reconstructing Bayesian posterior distributions of a species phylogeny using estimated gene tree distributions. Syst. Biol. 56, 504-514.

Lougheed, S.C., Freeland, J.R., Handford, P., Boag, P.T., 2000. A molecular phylogeny of warbling-finches (Poospiza): paraphyly in a Neotropical emberizid genus. Mol. Phylogenet. Evol. 17, 367-378.

Lovette, I.J., 2004. Mitochondrial dating and mixed support for the " $2 \%$ rule" in birds. Auk 121, 1-6.

Maldonado-Coelho, M., 2010. Evolution and biogeography of South American fireeyes (genus Pyriglena): insights from molecules and songs. PhD Dissertation. University of Missouri, St Louis. 
Maldonado-Coelho, M., 2012. Climatic oscillations shape the phylogeographical structure of Atlantic Forest fire-eye antbirds (Aves: Thamnophilidae). Biol. J. Linn. Soc. 105: 900-924.

Marini, M.A., Hackett, S.J., 2002. A multifaceted approach to the characterization of an intergeneric hybrid manakin (Pipridae) from Brazil. Auk 119, 1114-1120.

Martins, F.M., 2011. The Brazilian Atlantic forest historical biogeography and the Carnaval-Moritz model of Pleistocene refugia: what do the phylogeographical studies tell us? Biol. J. Linn. Soc. 104: 499-509.

McCormack, J.E., Heled, J., Delaney, K.S., Peterson, A.T., Knowles, L.L., 2011. Calibrating divergence times on species trees versus gene trees: implications for speciation history of Aphelocoma jays. Evolution 65, 184-202.

Miller, M.A., Pfeiffer, W., Schwartz, T., 2010. Creating the CIPRES science gateway for inference of large phylogenetic trees. In: Proceedings of the Gateway Computing Environments Workshop (GCE), 14 Nov. 2010, New Orleans, 1-8.

Myers, N., Mittermeier, R.A., Mittermeier, C.G., da Fonseca, G.A.B., Kent, J., 2000. Biodiversity hotspots for conservation priorities. Nature 403, 853-858.

Nylander, J.A.A., 2004. MrModeltest 2.2. Program distributed by the author. Evolutionary Biology Centre, Uppsala University.

Oliveira, P.E., Barreto, A.M.F., Suguio, K., 1999. Late Pleistocene/Holocene climatic and vegetational history of the Brazilian caatinga: the fossil dunes of the middle São Francisco River. Palaeogeogr. Palaeoclimatol. Palaeoecol. 152, 319-337.

Oren, D.C., 1991. Aves do estado do Maranhão, Brasil. Goeldiana Zool. 9, 1-55.

Pacheco, J.F., Gonzaga, L.P., 1995. A new species of Synallaxis of the ruficapilla/infuscata complex form eastern Brazil (Passeriformes: Funariidae). Ararajuba 3, 3-11.

Palumbi, S.R., Cipriano, F., Hare, M.P., 2001. Predicting nuclear gene coalescence from mitochondrial data: the three-times rule. Evolution 55, 859-868.

Percequillo, A.R., Weksler, M., Costa, L.P., 2011. A new genus and species of rodent from the Brazilian Atlantic Forest (Rodentia: Cricetidae: Sigmodontinae: Oryzomyini), with comments on oryzomyine biogeography. Zool. J. Linn. Soc. $161,357-390$. 
Pessoa, R.O., 2007. Sistemática e Biogeografia Histórica da Família Conopophagidae (Aves: Passeriformes): Especiação nas Florestas da América do Sul. PhD Dissertation. Universidade de São Paulo, São Paulo.

Pinho, C., Harris, D.J., Ferrand, N., 2008. Non-equilibrium estimates of gene flow inferred from nuclear genealogies suggest that Iberian and North African wall lizards (Podarcis spp.) are an assemblage of incipient species. BMC Evol. Biol. 8, 63.

Por, F.D., 1992. Sooretama: the Atlantic rain forest of Brazil. SPB Academic Publishing, The Hague.

Remsen, J.V., 2003. Family Furnariidae (ovenbirds). In: del Hoyo, J., Elliott, A., Christie, D.A. (Eds), Handbook of the Birds of the World, vol. 8. Lynx Edicions, Barcelona, pp. 162-357.

Remsen, J.V., Rocha, O.O., Schmitt, C.G., Schmitt, D.C., 1991. Zoogeography and geographic variation of Phatyrinchus mystaceus in Bolivia and Peru, and the circum-Amazonian distribution pattern. Ornitol. Neotrop. 2, 77-83.

Ribeiro, C.A., Metzger, J.P., Martensen, A.C., Ponzoni, F.J., Hirota, M.M., 2009. The Brazilian Atlantic Forest: How much is left, and how is the remaining forest distributed? Implications for conservation. Biol. Cons. 142, 1141-1153.

Ribeiro, R.A., Lemos-Filho, J.P., Ramos, A.C.S., Lovato, M.B., 2010. Phylogeography of the endangered rosewood Dalbergia nigra (Fabaceae): insights into the evolutionary history and conservation of the Brazilian Atlantic Forest. Heredity 106, 46-57.

Ribon, R., Whitney, B.M., Pacheco, J.F., 2002. Discovery of Bahia spinetail Synallaxys cinerea in north-east Minas Gerais, Brasil, with additional records of some rare and threatened montane Atlantic forest birds. Cotinga, 17, 46-50.

Ridgely, R.S., Tudor, G., 1996. The birds of South America: The Suboscine Passerines. University of Texas Press, Austin.

Roda, S.A., 2008. Synallaxis infuscata Pinto, 1950. In: Machado, A.B.M., Drummond, G.M., Paglia, A.P. (Eds), Livro Vermelho da Fauna Brasileira Ameaçada de Extinção, volume 1. Fundação Biodiversitas, Belo Horizonte, pp. 580-581. 
Rull, V., 2008. Speciation timing and neotropical biodiversity: the TertiaryQuaternary debate in the light of molecular phylogenetic evidence. Mol. Ecol. $17,2722-2729$.

Rull, V., 2011. Neotropical biodiversity: timing and potential drivers. Trends Ecol. Evol. 26, 508-513.

Saadi, A., 1995. A geomorfologia da Serra do Espinhaço em Minas Gerais e suas margens. Geonomos 3, 41-63.

Sick, H., 1997. Ornitologia Brasileira. Nova Fronteira, Rio de Janeiro.

Silva, J.M.C., 1994. Can avian distribution patterns in northern Argentina be related to gallery-forest expansion-retraction caused by the Quaternary climatic changes? Auk 111, 495-499.

Silva, J.M.C., 1995. Biogeographic analysis of the South American Cerrado avifauna. Steenstrupia 21, 49-67.

Silva, J.M.C., Straube, F.C., 1996. Systematics and biogeography of scaled woodcreepers (Aves: Dendrocolaptidae). Stud. Neotrop. Fauna \& Environm. 31, $3-10$.

Silveira, L.F., 2008. Synallaxis cinerea Wied, 1831. In: Machado, A.B.M., Drummond, G.M., Paglia, A.P. (Eds), Livro Vermelho da Fauna Brasileira Ameaçada de Extinção, volume 1. Fundação Biodiversitas, Belo Horizonte, pp. 578-579.

Slade, R.W., Moritz, C., Heideman, A., Hale, P.T., 1993. Rapid assessment of singlecopy nuclear DNA variation in diverse species. Mol. Ecol. 2, 359-373.

Stamatakis, A., Hoover, P., Rougemont, J., 2008. A fast bootstrapping algorithm for the RAxML web-servers. Syst. Biol. 57, 758-771.

Stephens, M., Smith, N., Donnelly, P., 2001. A new statistical method for haplotype reconstruction from population data. Am. J. Hum. Genet. 68, 978-989.

Stopiglia, R., Raposo, M.A., Teixeira, D.M., 2012. Taxonomy and geographic variation of the Synallaxis ruficapilla Vieillot, 1819 species-complex (Aves: Passeriformes: Furnariidae). J. Ornithol. DOI: 10.1007/s10336-012-0886-3.

Tamura, K., Peterson, D., Peterson, N., Stecher, G., Nei, M., Kumar, S., 2011. MEGA5: Molecular Evolutionary Genetics Analysis using Maximum Likelihood, Evolutionary Distance, and Maximum Parsimony Methods. Mol. Biol. Evol. 28, $2731-2739$ 
Thomé, M.T.C., Zamudio, K.R., Giovanelli, J.G.R., Haddad, C.F.B., Baldissera Jr, F.A., Alexandrino, J.M.B., 2010. Phylogeography of endemic toads and post-Pliocene persistence of the Brazilian Atlantic Forest. Mol. Phylogenet. Evol. 55, 1018-1031. Vasconcelos, M.F., Silva, J.F., 2004. Limite norte da distribuição do pichororé Synallaxis ruficapilla (Aves, Furnariidae). Bol. Mus. Biol. Mello Leitão 17, 65-68.

Vanzolini, P.E., Williams, E.E., 1970. South American anoles: the geographic differentiation and evolution of the Anolis chrysolepis species group (Sauria: iguanidae). Arquiv. Zool. (S. Paulo) 19, 1-298.

Wang, X.F., Auler, A.S., Edwards, R.L., Cheng, H., Cristalli, P.S., Smart, P.L., Richards, D.A., Shen, C.C., 2004. Wet periods in northeastern Brazil over the past $210 \mathrm{kyr}$ linked to distant climate anomalies. Nature 432, 740-743.

Weir, J.T., Schluter, D., 2008. Calibrating the avian molecular clock. Mol. Ecol. 17, $2321-2328$.

Weir, J.T., Price, M., 2011. Andean uplift promotes lowland speciation through vicariance and dispersal in Dendrocincla woodcreepers. Mol. Ecol. 20, 45504563.

Whitney, B.M., 1997. Birding the Alta Floresta region, northern Mato Grosso, Brazil. Cotinga 7, 64-68.

Willis, E.O., 1992. Zoogeographical origins of eastern Brazilian birds. Ornit. Neotrop. $3,1-15$.

Zimmer, K.J., Parker, T.A., Isler, M.L., Isler, P.R., 1997. Survey of a southern Amazonian avifauna: the Alta Floresta region, Mato Grosso, Brazil. Ornithol. Monogr. 48, 887-918.

Zink, R.M., Barrowclough, G.F., 2008. Mitochondrial DNA under siege in avian phylogeography. Mol. Ecol. 17, 2107-2121. 
Table 1. Samples of Synallaxis spp.: species, sampling locality, collection, tissue code, voucher number, and GenBank accession numbers for each marker.

\begin{tabular}{|c|c|c|c|c|c|c|c|c|c|c|}
\hline Species & & Locality & Collection* & Tissue code & Voucher & cytb & ND2 & FIB5 & myo2 & $\mathrm{G}_{3} \mathrm{PDH}$ \\
\hline Synallaxis & cabanisi & 1. Depto. Pasco, Cacazú, Peru & MZUSPa & - & MZUSP73261 & $?$ & $?$ & $?$ & $?$ & $?$ \\
\hline Synallaxis & cabanisi & 2. Depto. Pasco, Km 41 on Villa Rica - Puerto Bermudez highway, Peru & $\mathrm{LSU}^{\mathrm{b}}$ & B2013 & B2013 & $?$ & $\mathrm{HM} 449848^{*}$ & $?$ & $?$ & - \\
\hline Synallaxis & infuscata & 3. Usina Serra Grande, São José da Lage, Alagoas, Brazil & LGEMA $^{\mathrm{b}}$ & LGEMA13568 & MZUSP88696 & $?$ & $?$ & $?$ & $?$ & $?$ \\
\hline Synallaxis & infuscata & 3. Usina Serra Grande, São José da Lage, Alagoas, Brazil & LGEMA $^{\text {b }}$ & LGEMA13573 & MZUSP88694 & $?$ & $?$ & $?$ & $?$ & $?$ \\
\hline Synallaxis & infuscata & 3. Usina Serra Grande, São José da Lage, Alagoas, Brazil & LGEMA $^{\mathrm{b}}$ & LGEMA13574 & MZUSP88695 & ? & ? & ? & ? & $?$ \\
\hline Synallaxis & infuscata & 4. Rebio Pedra Talhada, Quebrangulo, Alagoas, Brazil & LGEMA $^{\mathrm{b}}$ & LGEMA13575 & MZUSP88699 & ? & ? & ? & ? & ? \\
\hline Synallaxis & infuscata & 4. Rebio Pedra Talhada, Quebrangulo, Alagoas, Brazil & LGEMA $^{\mathrm{b}}$ & LGEMA13576 & MZUSP88698 & ? & $?$ & - & $?$ & $?$ \\
\hline Synallaxis & infuscata & 4. Rebio Pedra Talhada, Quebrangulo, Alagoas, Brazil & LGEMA $^{\mathrm{b}}$ & LGEMA13577 & MZUSP88697 & ? & ? & $?$ & ? & $?$ \\
\hline Synallaxis & macconnelli & 5. Rebio Maicuru, Almeirim, Pará, Brazil & MPEG $^{\mathrm{b}}$ & CN855 & 66294 & ? & ? & ? & ? & - \\
\hline Synallaxis & macconnelli & 5. Rebio Maicuru, Almeirim, Pará, Brazil & $M \mathrm{PEG}^{\mathrm{b}}$ & $\mathrm{CN} 928$ & 66295 & $?$ & $?$ & $?$ & $?$ & $?$ \\
\hline Synallaxis & macconnelli & 5. Rebio Maicuru, Almeirim, Pará, Brazil & $M \mathrm{MEG}^{\mathrm{b}}$ & $\mathrm{CN} 993$ & 66293 & $?$ & ? & $?$ & $?$ & $?$ \\
\hline Synallaxis & macconnelli & 6. Sipaliwini, Balchuis Gebergte, $\sim 78$ km S Apura on Nickene River, Suriname & $\mathrm{LSU}^{\mathrm{b}}$ & B55261 & B55261 & $?$ & JF975204 & $?$ & $?$ & - \\
\hline Synallaxis & moesta & 7. Rio Napo, Ecuador & $\mathrm{NRM}^{\mathrm{a}}$ & - & NRM 552855 & ? & ? & - & - & - \\
\hline Synallaxis & moesta & 8. San José, Ecuador & $\mathrm{NRM}^{\mathrm{a}}$ & - & NRM552854 & $?$ & $?$ & - & - & - \\
\hline Synallaxis & moesta & 9. Depto. San Martín; 33 km NE Florida, Peru & $\mathrm{LSU}^{\mathrm{b}}$ & B44663 & B44663 & $?$ & JF975205* & $?$ & $?$ & - \\
\hline Synallaxis & ruficapilla & 10. Juquitiba, São Paulo, Brazil & LGEMA $^{\mathrm{b}}$ & LGEMA1182 & ITA211† & $?$ & $?$ & $?$ & $?$ & ? \\
\hline Synallaxis & ruficapilla & 11. Wencenslau Braz, Paraná, Brazil & LGEMA $^{\mathrm{b}}$ & LGEMA1367 & ITA288† & $?$ & $?$ & $?$ & $?$ & $?$ \\
\hline Synallaxis & ruficapilla & 12. Parque Nacional Serra dos Órgãos, Teresópolis, Rio de Janeiro, Brazil & LGEMA $^{\mathrm{b}}$ & LGEMA13015 & MZUSP82584 & ? & ? & ? & ? & ? \\
\hline Synallaxis & ruficapilla & 13. Estação Biológica Santa Lucia, Santa Teresa, Espírito Santo, Brazil & $M N R J^{b}$ & 229 & MNA4873 & ? & $?$ & $?$ & ? & ? \\
\hline Synallaxis & ruficapilla & 14. José Gonçalves de Minas, Minas Gerais, Brazil & UFMG ${ }^{\mathrm{b} 1}$ & B2414 & - & ? & - & ? & - & - \\
\hline Synallaxis & ruficapilla & 15. RPPN Serra do Caraça, Minas Gerais, Brazil & $M N R J^{b}$ & LGEMA15756 & CPA365§ & $?$ & $?$ & $?$ & $?$ & $?$ \\
\hline Synallaxis & ruficapilla & 16. Parque Nacional do Caparaó, Alto Caparaó, Minas Gerais, Brazil & LGEMA $^{\mathrm{b}}$ & LGEMA13530 & MZUSP87024 & $?$ & $?$ & $?$ & $?$ & $?$ \\
\hline Synallaxis & ruficapilla & 17. Poté, Minas Gerais, Brazil & LGEMA $^{\mathrm{b}}$ & LGEMA13536 & MZUSP87020 & ? & ? & ? & ? & ? \\
\hline Synallaxis & ruficapilla & 17. Poté, Minas Gerais, Brazil & LGEMA $^{\text {b }}$ & LGEMA13545 & MZUSP87019 & $?$ & $?$ & $?$ & $?$ & $?$ \\
\hline Synallaxis & ruficapilla & 17. Poté, Minas Gerais, Brazil & LGEMA $^{\mathrm{b}}$ & LGEMA13549 & MZUSP87017 & $?$ & $?$ & $?$ & $?$ & $?$ \\
\hline Synallaxis & ruficapilla & 18. Nova Trento, Santa Catarina, Brazil & LGEMA $^{\mathrm{b}}$ & LGEMA14592 & MZUSP91242 & ? & ? & ? & ? & $?$ \\
\hline unnamed & Synallaxis & 19. Fazenda Ipê, Vila Rica, Mato Grosso, Brazil & LGEMA $^{\mathrm{b}}$ & LGEMA416 & MZUSP78834 & $?$ & $?$ & $?$ & $?$ & $?$ \\
\hline unnamed & Synallaxis & 19. Fazenda Ipê, Vila Rica, Mato Grosso, Brazil & MZUSPa & - & MZUSP78833 & $?$ & ? & ? & ? & $?$ \\
\hline
\end{tabular}




$\begin{array}{lcclllll}\text { MZUSP }^{a} & - & \text { MZUSP78830 } & ? & ? & ? & ? & ? \\ \text { MZUSP }^{a} & - & \text { MZUSP78835 } & ? & ? & ? & ? & ? \\ \text { MZUSP }^{a} & - & \text { MZUSP78832 } & ? & ? & ? & ? & ? \\ \text { MZUSP }^{a} & - & \text { MZUSP78831 } & ? & ? & ? & ? & ? \\ \text { LGEMA }^{\text {b }} & \text { LGEMA13401 } & \text { DZUFMG6009 } & ? & ? & ? & ? & ? \\ \text { LGEMA }^{\text {b }} & \text { LGEMA13711 } & \text { MZUSP86006 } & ? & ? & ? & ? & ? \\ \text { LGEMA }^{\text {b }} & \text { LGEMA13720 } & \text { MZUSP86015 } & ? & ? & ? & ? & ? \\ \text { LGEMA }^{\text {b }} & \text { LGEMA13736 } & \text { MZUSP86031 } & ? & ? & - & ? & ? \\ \text { LGEMA }^{\text {b }} & \text { LGEMA13763 } & \text { MZUSP86057 } & ? & ? & ? & ? & ? \\ \text { LGEMA }^{\text {b }} & \text { LGEMA13764 } & \text { MZUSP86058 } & ? & ? & ? & ? & ? \\ \text { MNRJ }^{\text {b }} & 32 & \text { MNA2246 } & ? & ? & ? & ? & ? \\ \text { MNRJ }^{\text {b }} & 155 & \text { MNA4799 } & ? & ? & ? & ? & ?\end{array}$

Locality numbers follow map in Figure 1.

*LGEMA - Laboratório de Genética e Evolução Molecular de Aves, Instituto de Biociências, Universidade de São Paulo, Brazil; MzUSP - Museu de Zoologia, Universidade de São Paulo, Brazil; UFMG - Laboratório de Biodiversidade e Evolução Molecular, Instituto de Ciências Biomédicas, Universidade Federal de Minas Gerais, Brazil; DZUFMG - Departamento de Zoologia, Universidade Federal de Minas Gerais, Brazil; MNRJ - Museu Nacional, Universidade Federal do Rio de Janeiro, Brazil; MPEG - Museu Paraense Emílio Goeldi, Brazil; NRM - Swedish Museum of Natural History, Sweden; and LSU - Museum of Natural Science, Louisiana State University, USA.

a: study skin samples; b: chest tissue sample with specimen's voucher; b1: blood sample without specimen's voucher.

† Field numbers, MZUSP pending numbers; § Field number, MNRJ pending number.

${ }^{*}$ Sequences from Derryberry et al. (2011). 
Table 2. Primers used in this study. Primers used with fresh samples are in italics.

\begin{tabular}{|c|c|c|c|}
\hline Primer name & Gene & Sequence $5^{\prime} \rightarrow 3^{\prime}$ & Reference \\
\hline Cytb-SynR1 & cytb & GTATTTCATGTCTCTTTGAATAGGTA & this study \\
\hline Cytb-SynR1b & cytb & GTCTCTTTGAATAGGTAAGAGCC & this study \\
\hline Cytb-SynF2 & cytb & ACATCGGACGAGGCTTCTACTA & this study \\
\hline Cytb-SynR2 & cytb & TGTCAACTGAAAАTССТССТСАТG & this study \\
\hline Cytb-SynF3 & cytb & CCTATATCGGACAAACACTCGT & this study \\
\hline Cytb-SynR3 & cytb & GAATGTCTTTGGTTGAGAAGTAAG & this study \\
\hline Cytb-SynF4 & cytb & TCTCATCAAACTGCGATAAAATCC & this study \\
\hline Cytb-SynR4 & cytb & TTTATTTGGAATTGATCGTAGAATGG & this study \\
\hline Cytb-SynF5 & cytb & СCTGAATGATACTTCCTATTTGCAT & this study \\
\hline Cytb-SynR5 & cytb & TCTACTGGTTGGCTGCCTACT & this study \\
\hline Cytb-SynF6 & cytb & ATATTCTGAATCCTAGTTACAAACCTT & this study \\
\hline L14841 & cytb & ССАТССААСАТСТСАGСАТGATGAAА & Lougheed et al. (2000) \\
\hline H16065 & cytb & GTCTTCAGTTTTTGGTTTACAAGAC & Lougheed et al. (2000) \\
\hline ND2-synR1 & ND2 & TAGAAAGTATTTGGTTGTGGCTTCA & this study \\
\hline ND2-synF2 & ND2 & ATCCTTCCССТAATCTCAAAACC & this study \\
\hline ND2-synR2 & ND2 & AATCAGAAGTGGAATGGGACTAG & this study \\
\hline ND2-synF3 & ND2 & TAACAACAGCCATTTCAATCAAACT & this study \\
\hline ND2-synR3 & ND2 & TTTTCGGATTTGGGTTTGGTTTAG & this study \\
\hline ND2-synF4 & ND2 & CTGCCTTAGGAGGATGAATAGG & this study \\
\hline ND2-synR4 & ND2 & TTAGTGAAGGGATTTTTGTTCATGC & this study \\
\hline ND2-synF5 & ND2 & ACСАAААТТСТТАААСТАТССТСААТАА & this study \\
\hline ND2-synR5 & ND2 & ATCGGAGGTAGAAGAAAAGTCCT & this study \\
\hline ND2-synF6 & ND2 & CAACAATCATTGCССТССТСТC & this study \\
\hline Lmet & ND2 & TATCGGGCCCATACCCCGAAAAT & Hackett (1996) \\
\hline H6312 & ND2 & CTTATTTAAGGCTTTGAAGGCC & Cicero and Johnson (2001) \\
\hline FIB5 & FIB5 & CGCCATACAGAGTATACTGTGACAT & Marini and Hackett (2002) \\
\hline FIB6 & FIB5 & GCCATCCTGGCGATTCTGAA & Marini and Hackett (2002) \\
\hline FIB-FurnL & FIB5 & AAGGAGAGCCTGGCTCATTCCTTA & Fjeldså et al. (2007) \\
\hline FIB-FurnH & FIB5 & GAAGTTGAAGGAATGCCCTGGTCT T & Fjeldså et al. (2007) \\
\hline MyO2 & myo2 & GCCACCAAGCACAAGATCCC & Slade et al. (1993) \\
\hline Myo3F & myo2 & TTCAGCAAGGACCTTGATAATGACTT & Heslewood et al. (1998) \\
\hline Myo309L & myo2 & CATAAGACCTGTCAGTGGCTGGA & Irestedt et al. (2006) \\
\hline Myo345H & myo2 & TCCTCCAGGGTTTGCTCTAAAATTGT & Fjeldså et al. (2007) \\
\hline G3PL890 & G3PDH & ACCTTTAATGCGGGTGCTGGCATTGC & Friensen et al. (1997) \\
\hline $\mathrm{G}_{3} \mathrm{PH} 950$ & G3PDH & CATCAAGTCCACAACACGGTTGCTGTA & Friensen et al. (1997) \\
\hline
\end{tabular}


Table 3. Best fit models for S. ruficapilla and S. moesta groups and outgroups estimated for each partiton.

\begin{tabular}{lc}
\hline Partition (genes) & Model of evolution \\
\hline cytb & $\mathrm{HKY}+\mathrm{I}$ \\
$\mathrm{ND2}$ & $\mathrm{HKY}+\Gamma$ \\
Mitochondrial (cytb + ND2) & $\mathrm{GTR}+\Gamma$ \\
FIB5 & $\mathrm{HKY}+\mathrm{I}$ \\
myO2 & $\mathrm{GTR}+\mathrm{I}+\Gamma$ \\
G3PDH & $\mathrm{HKY}+\mathrm{I}+\Gamma$ \\
\hline
\end{tabular}

Table 4. Divergence times and confidence intervals [ $95 \%$ of high posterior density (HPD)] between major mitochondrial lineages of S. ruficapilla and S. moesta groups estimated by *BEAST. Node numbers follow figure 4.

\begin{tabular}{cc}
\hline Node & Time mya (95\% of HPD) \\
\hline 1 & $2.24(2.75-1.80)$ \\
2 & $2.02(2.40-1.61)$ \\
3 & $1.91(2.33-1.49)$ \\
4 & $1.85(2.33-1.33)$ \\
5 & $1.56(2.04-1.03)$ \\
6 & $1.17(1.58-0.74)$ \\
7 & $0.53(0.86-0.16)$ \\
\hline
\end{tabular}

Figure captions

Figure 1. Map illustrating geographic distributions of species from the S. ruficapilla and S. moesta complexes. Distributions follow Ribon et al. (2002), Ridgely and Tudor (1996), and Vasconcelos and Silva (2004). Illustrations of S. ruficapilla complex are from Pacheco and Gonzaga (1995).

Figure 2. Map showing localities sampled for species of the S. ruficapilla and S. moesta complexes, and mitochondrial tree obtained by Bayesian inference. Circles and triangles on the map indicate collecting sites and their colors follow the legend. Locality numbers in the map follows table 1 . The gradient of gray colour in the map represents the elevation gradient (the darker the higher is the altitude). The topology was obtained by Bayesian inference based on 2043 bp of cytb and ND2. 
Node supports are posterior probabilities and bootstrap values for Bayesian inference and maximum likelihood, respectively. The colors and symbols in the tree refer to the map and legend. Bird illustrations show the three species of the $S$. ruficapilla complex (source: Pacheco and Gonzaga, 1995).

Figure 3. Nuclear gene trees generated by RAxML. Node supports are bootstrap values. Tip labels at branches follow map in figure 2 .

Figure 4. Chronogram of species tree with divergence times generated by *BEAST. Number at the nodes are clade posterior probabilities. White circles with numbers at nodes are divergence times between clades according to table 4 . Bars on the nodes represent $95 \%$ of high posterior density of divergence times. Branch colors follow figure 1. 
Figures

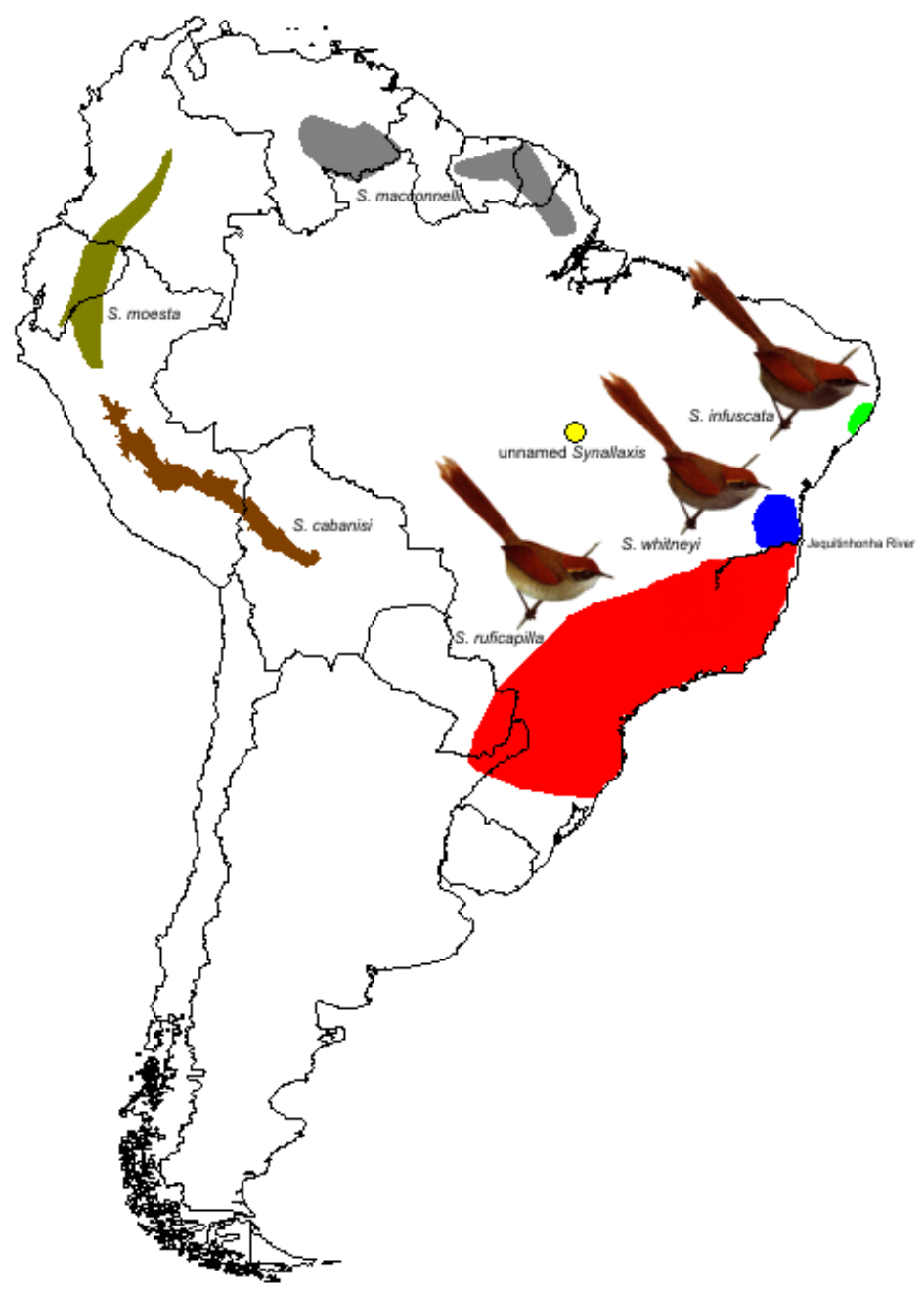

Fig. 1 


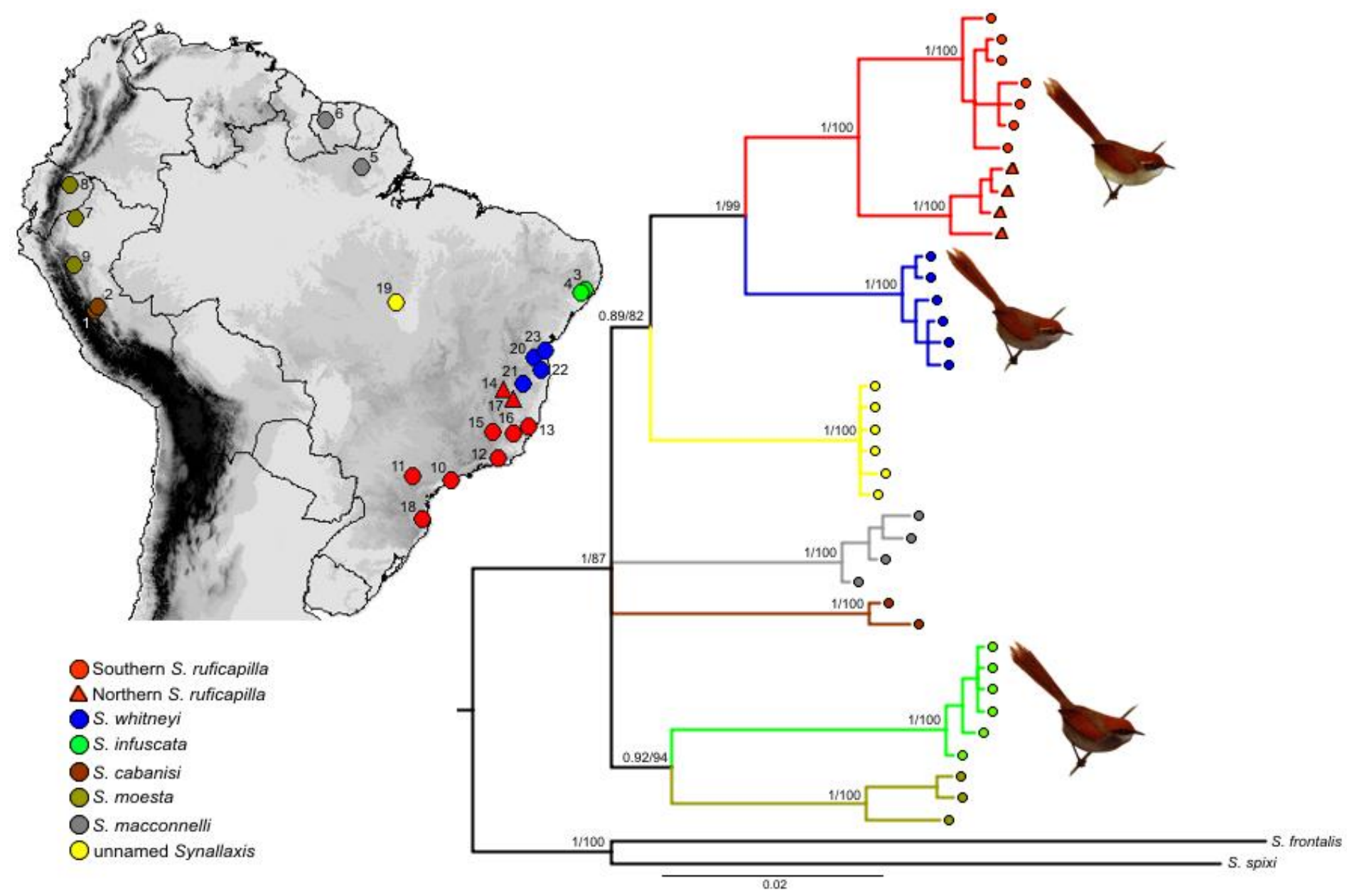

Fig. 2 

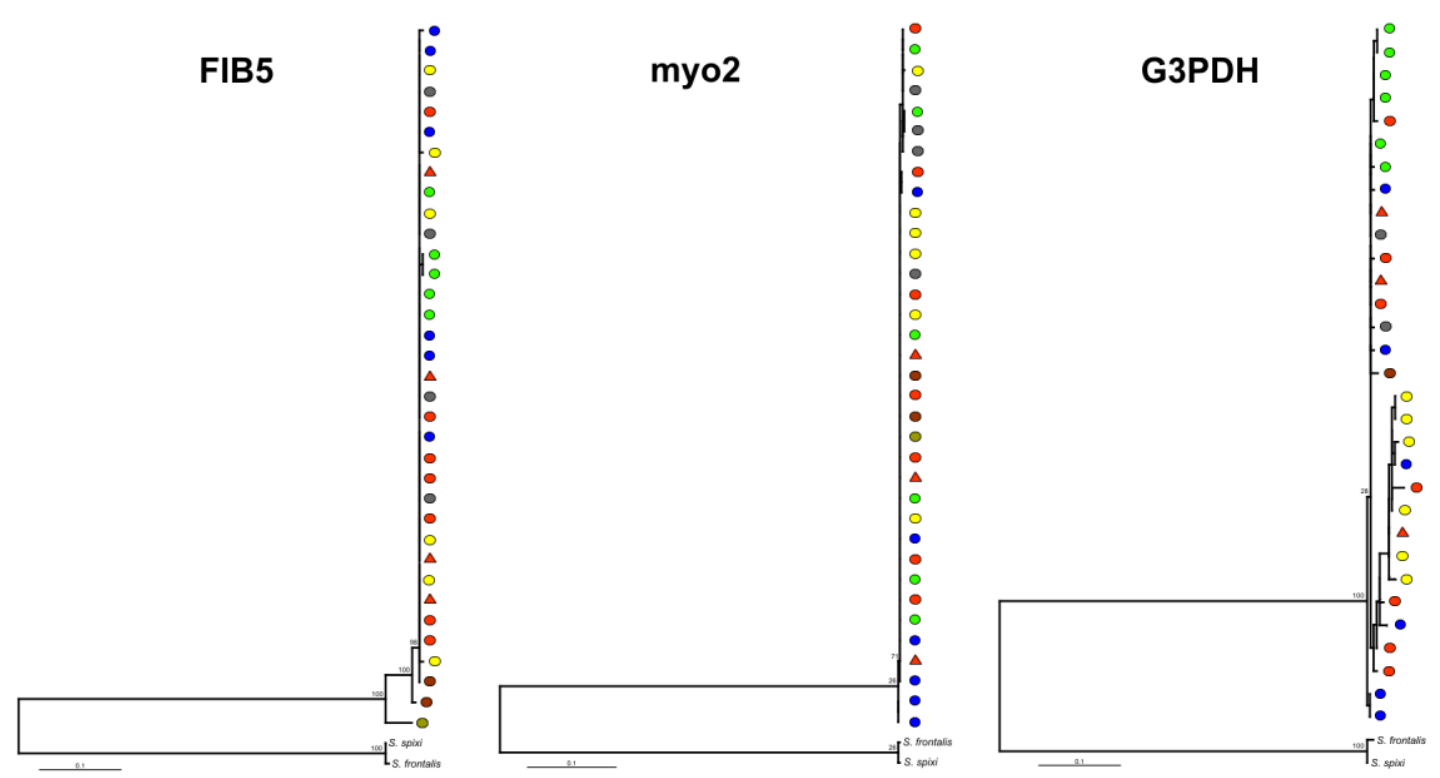

Fig. 3

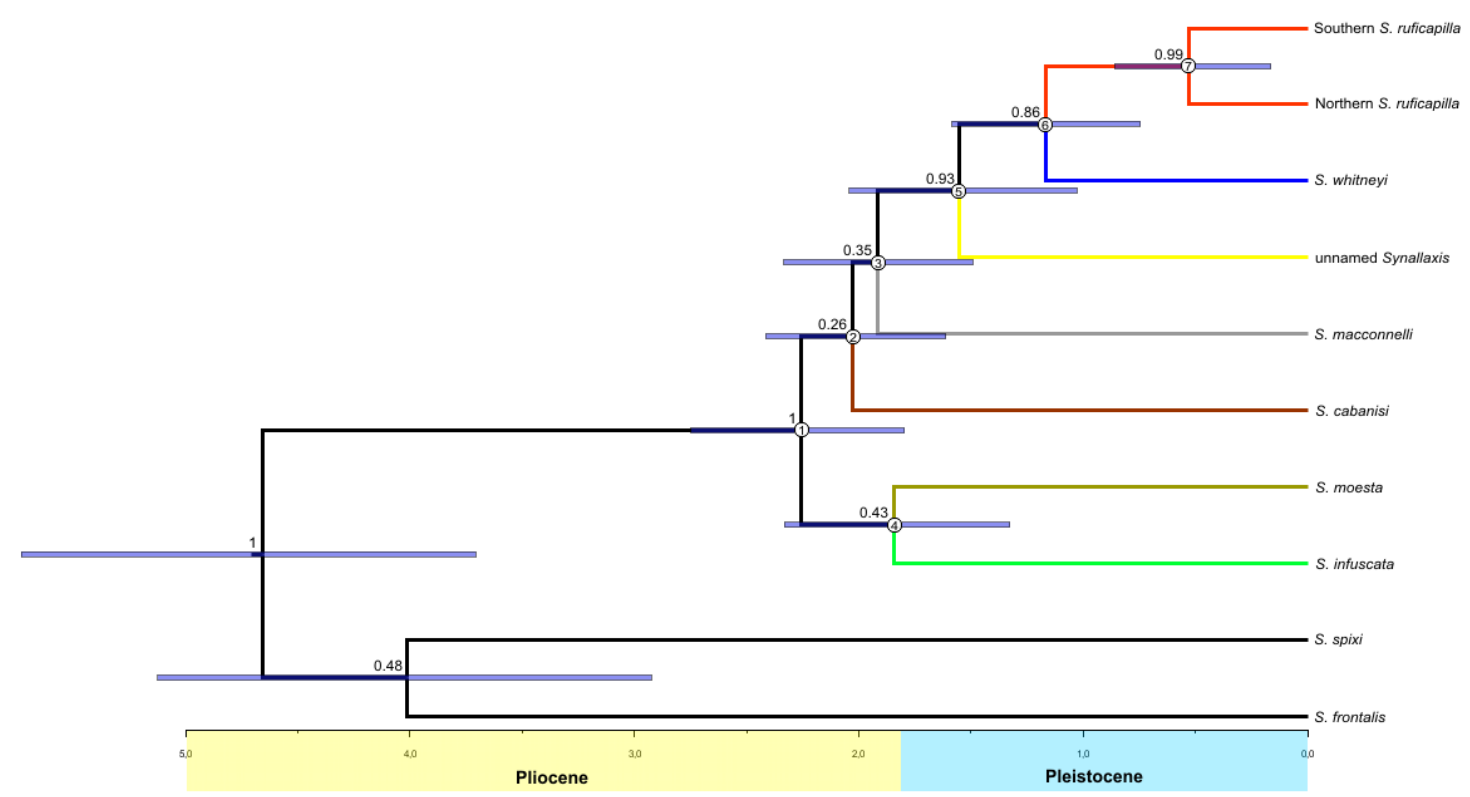

Fig. 4 


\section{Capítulo 4}

Filogeografia e história demográfica do complexo Synallaxis ruficapilla/S. whitneyi (Passeriformes, Furnariidae) revelam diversidade críptica e contato secundário na Mata Atlântica 


\section{Introdução}

Nos últimos anos estudos filogeográficos (Cabanne et al., 2008; Carnaval \& Moritz, 2008; Carnaval et al., 2009; Martins et al., 2009; Ribeiro et al., 2010; d'Horta et al., 2011; Maldonado-Coelho, 2012) têm mostrado que a hipótese dos refúgios florestais (Haffer, 1969; Vanzolini \& Willians, 1970) foi a principal força responsável pela diversificação dentro da Mata Atlântica (MA) durante o Pleistoceno. Entretanto outros estudos têm mostrado que hipóteses alternativas à teoria dos refúgios também podem ter contribuído para a diversificação do bioma. A hipótese de rios como barreira foi utilizada por Pellegrino et al. (2005) para explicar vicariâncias observadas em lagartos ao longo da MA (mas veja Cabanne et al., 2007; MaldonadoCoelho, 2012). Além disso, outros estudos mostraram que atividades tectônicas foram responsáveis pelos eventos vicariantes observados (Silva \& Straube, 1996; Batalha-Filho et al., 2010; Thomé et al., 2010; Amaro et al., 2012). Esta riqueza de padrões pode ser fruto de uma topografia bastante complexa do bioma com grandes amplitudes latitudinais, longitudinais e altitudinais (Silva \& Casteleti, 2005), e a combinação destes fatores consequentemente proporciona uma grande possibilidade para existência de vários macro e micro-habitats ao longo do bioma. Além disso, diferentes características ecológicas das espécies que ocorrem na MA podem também contribuir para existência de diferentes padrões de diversificação, uma vez que elas responderiam aos eventos históricos de forma heterogênea.

O grupo Synallaxis ruficapilla (Fig. 1) foi descrito por Pacheco \& Gonzaga (1995) como uma superespécie endêmica da MA formada pelas espécies S. ruficapilla, S. whitneyi e S. infuscata. Entretanto, Stopiglia et al. (2012) em uma revisão taxonômica do complexo S. ruficapilla utilizando dados de morfometria, plumagem e voz, sugeriram que S. whitneyi seja sinônimo de S. ruficapilla, e que S. infuscata seria um táxon válido, incluindo S. whitneyi como parte da variação geográfica de S. ruficapilla. No entanto, um estudo de sistemática molecular do grupo (Capítulo 3 desta tese) revelou que S. ruficapilla e S. whitneyi constituem linhagens genéticas distintas com elevada divergência genética ( $3 \%$ de divergência no DNA mitocondrial). Este estudo ainda mostrou que o grupo não é reciprocamente monofilético, sendo S. infuscata mais próximo do grupo S. moesta 
(que ocorre nos Andes e nos Tepuis Amazônicos) do que do complexo da MA. Contudo as análises confirmaram que S. ruficapilla e S. whitneyi são espécies irmãs.

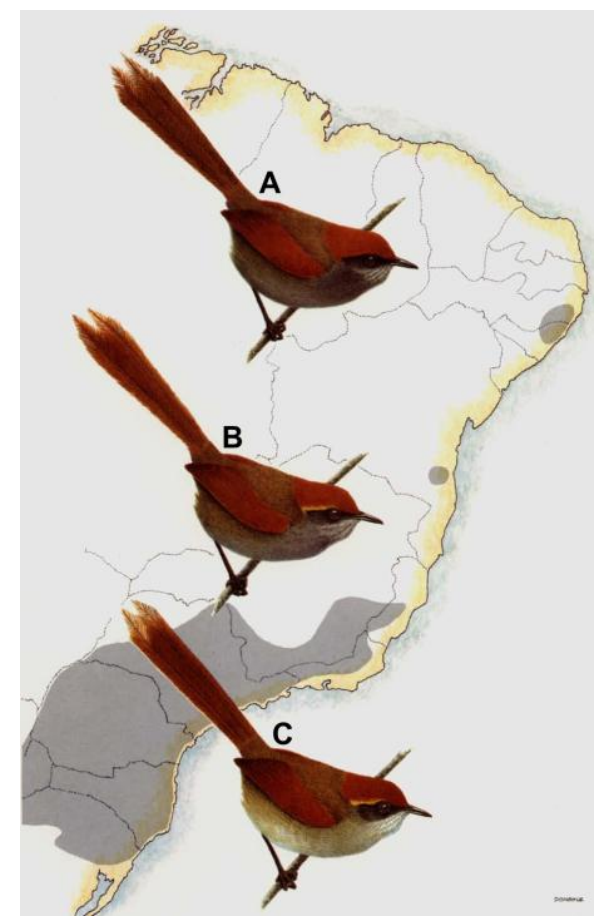

Figura 1. Distribuição geográfica do complexo Synallaxis ruficapilla. A: S. infuscata. B: S. whitneyi. C: S. ruficapilla. As áreas em cinza representam as distribuições das respectivas espécies (Fonte: Pacheco \& Gonzaga, 1995).

S. ruficapilla é conhecido popularmente como pichororé e distribui-se do norte de Minas Gerais ao Rio Grande do Sul, estendendo-se até o Paraguai e Misiones na Argentina. Na região sudeste encontra-se restrito as regiões de altitude (> 600 m; Ridgely \& Tudor, 1994). S. whitneyi ocorre em uma estreita faixa entre o centro-sul da Bahia e o nordeste de Minas Gerais. É conhecido popularmente como joão-baiano, é mais comumente observado entre 700 e 1.200 m de altitude (Silveira, 2008), entretanto a espécie ocorre ao nível do mar em Ituberá-BA. Esta espécie é considerada ameaçada de extinção pelo Livro Vermelho da Fauna Brasileira Ameaçada de Extinção (Silveira, 2008). Estas espécies habitam as brenhas e capoeiras tanto no interior quanto nas bordas das matas e também são comumente encontrados em bambuzais, e são dependentes de ambientes florestados (Sick, 1997; Silveira, 2008).

A recente descoberta de S. ruficapilla (Vasconcelos \& Silva, 2004) e S. whitneyi (Ribon et al., 2002) no norte de Minas Gerais, em áreas próximas, mas em 
margens distintas do rio Jequitinhonha, reforçou a hipótese da estreita relação entre essas espécies e o possível papel do rio do Jequitinhonha como barreira geográfica entre elas (Vasconcelos \& Silva, 2004). Estas espécies são modelos interessantes para se estudar a diversificação da MA, pois apresentam limites geográficos das espécies concordantes com as margens norte e sul do Rio Jequitinhonha, o que permite testar de maneira direta a hipótese de rios como barreiras primárias de vicariância na MA (Pellegrino et al., 2005).

No presente estudo nós analisamos o padrão filogeográfico e a história demográfica das espécies endêmicas da MA, S. ruficapilla e S. whitneyi, por meio de sequências dos DNAs mitocondrial e nuclear com o objetivo de realizar inferências sobre a história evolutiva do bioma MA. Nesse contexto, foram levantadas algumas questões: i) o grupo S. ruficapilla e S. whitneyi apresentam estrutura genética congruente com a observada em outros táxons da MA? ii) quais eventos demográficos históricos originaram o padrão filogeográfico observado neste complexo? iii) o Rio Jequitinhonha foi uma barreira histórica para as duas espécies? Os resultados deste estudo contribuirão para o entendimento da complexa história evolutiva da MA.

\section{Materiais e métodos}

\subsection{Estratégias de amostragem e métodos moleculares}

A amostragem foi realizada entre os anos de 1998 a 2012 ao longo da MA (Fig. 2a). Foram obtidas de 87 amostras de S. ruficapilla e 13 de S. whitneyi provenientes de 33 localidades (Tab. 1, Fig. 2a), cobrindo assim a maioria da distribuição geográfica das duas espécies. Todas as amostras, com exceção de duas, possuem espécimes depositados em museus. As coleções e os códigos das amostras são apresentados na tabela 1. 


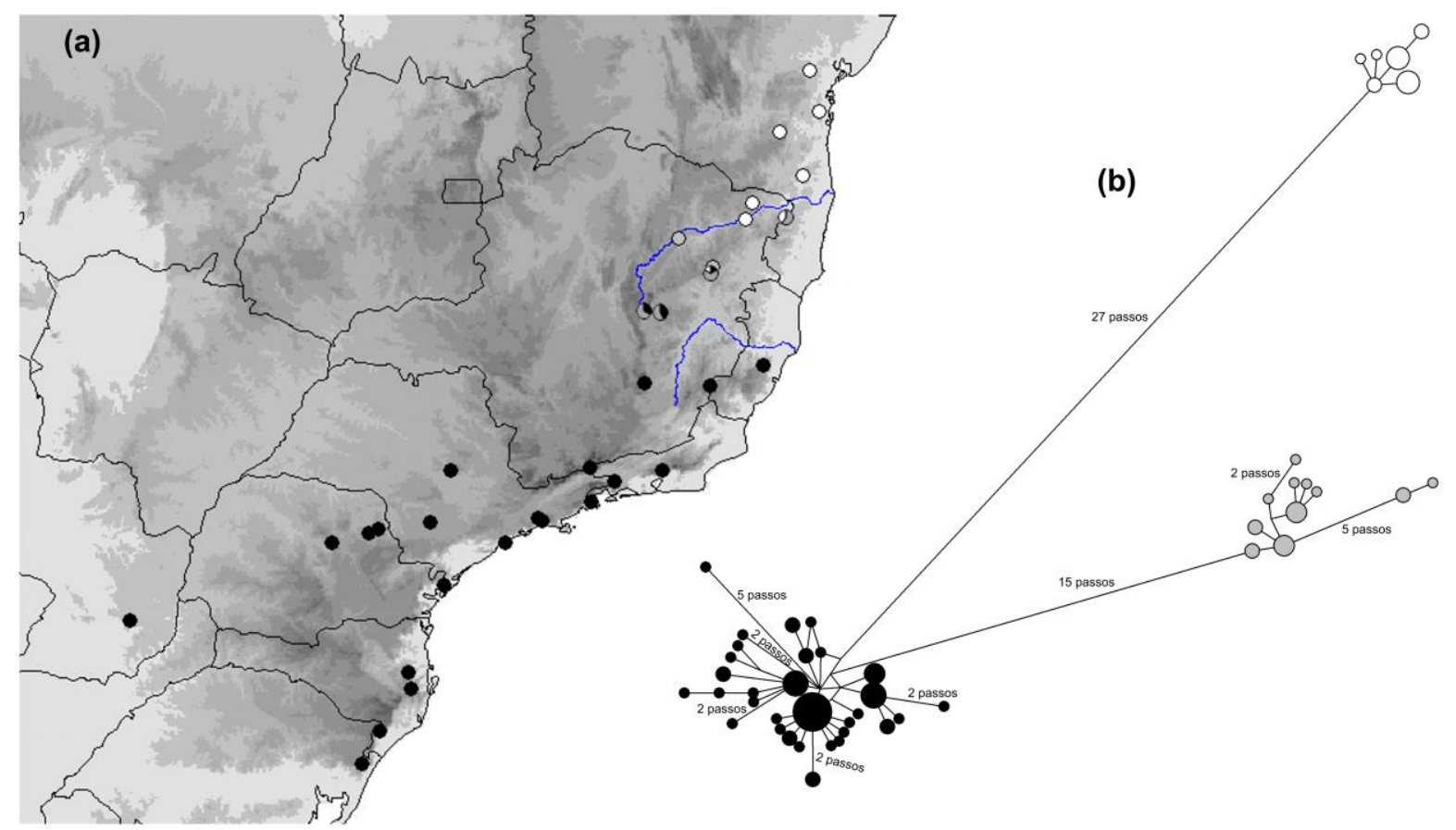

(c)

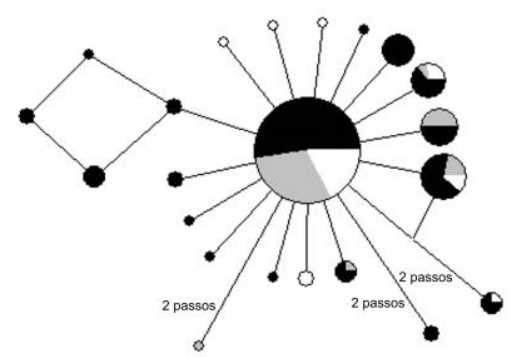

(d)

Figura 2. Distribuição geográfica das amostras das espécies Synallaxis ruficapilla e S. whitneyi e redes de haplótipos. (a): Mapa com a distribuição geográfica das amostras. Os tons de cinza representam o gradiente altitudinal (quanto mais escuro, maior altitude). Os círculos representam as localidades amostradas. As cores dos círculos representam os filogrupos mitocondriais (Figura 2b). (b): Rede de haplótipos baseada em 1001 pb do cytb. (c): Rede de haplótipos baseada em 525 pb do FIB5. (d): Rede de haplótipos baseada em 601 pb do myo2. Nas redes, cada círculo representa um haplótipo e seu tamanho representa sua frequência. As linhas representam as relações entre os haplótipos que diferem em uma mutação. Traços nas linhas representam mutações adicionais. As cores representam os clados mitocondriais das amostras conforme figura $2 a$. 
Tabela 1. Amostras de Synallaxis ruficapilla e S. whitneyi: espécie, localidade amostrada, coordenadas geográficas, tamanho da amostra (N), coleção de depósito da amostra, código na coleção.

\begin{tabular}{|c|c|c|c|c|c|c|}
\hline Espécie & Localidade, estado, país & Latitude & Longitude & $\mathbf{N}$ & Coleção* & $\mathbf{N}^{\circ}$ Coleção \\
\hline \multirow[t]{25}{*}{ Synallaxis ruficapilla } & Juquitiba, SP, BRA & -24.18333333 & -46.78333333 & 4 & LGEMA $^{a}$ & $1170,1177,1181,1182$ \\
\hline & Buri, SP, BRA & -23.71666667 & -48.56666667 & 1 & LGEMA $^{a}$ & 2988 \\
\hline & Pinhalão, PR, BRA & -23.96666667 & -50.05 & 1 & $\operatorname{LGEMA}^{\mathrm{a}}$ & 1285 \\
\hline & Wenceslau Braz, PR, BRA & -23.85 & -49.8 & 2 & LGEMA $^{a}$ & 1367,1368 \\
\hline & Fazenda Barreiro Rico, Anhembi, SP, BRA & -22.45 & -48.09 & 4 & LGEMA $^{a}$ & $2054,2067,2068,2087$ \\
\hline & Rancho Queimado, SC, BRA & -27.6833333 & -49.0333333 & 1 & LGEMA $^{a}$ & 2187 \\
\hline & Ortigueira, PR, BRA & -24.2 & -50.91666667 & 1 & LGEMA $^{\mathrm{a}}$ & 11419 \\
\hline & Resende, RJ, BRA & -22.38333333 & -44.75 & 1 & $\operatorname{LGEMA}^{\mathrm{a}}$ & 12022 \\
\hline & Estação Biológica Boracéia, Salesópolis, SP, BRA & -23.6542 & -45.889633 & 3 & LGEMA $^{a}$ & $12036,12037,15591$ \\
\hline & Biritiba Mirim, SP, BRA & -23.61666667 & $-45 \cdot 98333333$ & 2 & LGEMA $^{a}$ & 12048,12056 \\
\hline & Parque Nacional Serra dos Órgãos, Teresópolis, RJ, BRA & -22.4478 & -43.00595 & 5 & LGEMA $^{a}$ & $13011,13013,13015,13018,13021$ \\
\hline & Estação Biológica Santa Lucia, Santa Teresa, ES, BRA & -19.9356 & -40.6003 & 2 & MNRJ & 79,229 \\
\hline & Rio Claro, RJ, BRA & -22.7231 & -44.1356 & 4 & MNRJ & $254,255,256,257$ \\
\hline & Paraty, RJ, BRA & -23.2178 & -44.7131 & 2 & MNRJ & DHFo95, DHFo97 \\
\hline & Nova Roma, Morro Grande, SC, BRA & -28.70533333 & -49.76677778 & 4 & LGEMA $^{a}$ & $14527,14530,14537,14545$ \\
\hline & Nova Trento, SC, BRA & -27.29888889 & -49.07955556 & 5 & LGEMA $^{a}$ & $14580,14587,14589,14592,14612$ \\
\hline & Utinga, Guaraquecaba, PR, BRA & -25.20311111 & -48.23222222 & 4 & LGEMA $^{\mathrm{a}}$ & $14651,14655,14688,14689$ \\
\hline & José Gonçalves de Minas, MG, BRA & -16.9069 & -42.6036 & 1 & $\mathrm{UFMG}^{\dagger}$ & B2414 \\
\hline & RPPN Serra do Caraça, Catas Altas, MG, BRA & -20.375 & -43.4181 & 6 & $\operatorname{LGEMA}^{\mathrm{b}}$ & $15751,15752,15756,15758,15764,15765$ \\
\hline & CPCN Pró-Mata, São Francisco de Paula, RS, BRA & -29.49055556 & -50.18694444 & 1 & MCP & MCP3088 \\
\hline & Reserva Ecol. Caaguazú, Caazapá, PAR & -26.06667 & $-55 \cdot 75$ & 1 & ZMUC & 144765 \\
\hline & Serro, MG, BRA & -18.58722222 & -43.43516667 & 3 & $\operatorname{LGEMA}^{\mathrm{a}}$ & $15394,15395,15397$ \\
\hline & RPPN Fazenda Duas Barras, Santa Maria do Salto, MG, BRA & -16.41205556 & -40.05552778 & 5 & LGEMA $^{a}$ & $15449,15467,15469,15489,15494$ \\
\hline & Ladainha, MG, BRA & -17.57208333 & -41.80191667 & 6 & $\operatorname{LGEMA}^{\mathrm{a}}$ & $15400,15404,15405,14437,15439,15440$ \\
\hline & Parque Nacional do Caparaó, Alto Caparaó, MG, BRA & -20.42138 & -41.8534 & 5 & LGEMA $^{a}$ & $13527,13528,13529,13530,13531$ \\
\hline
\end{tabular}


Sabinópolis, MG, BRA

Poté, MG, BRA

Synallaxis whitneyi Fazenda Limoeiro, Almenara, MG, BRA

Mata Escura, Jequitinhonha, MG, BRA

Serra da Ouricana, Boa Nova, BA, BRA

RPPN Serra Bonita, Camacan, BA, BRA

Plantações da Michelin, Igrapiúna, BA, BRA

Serra da Jibóia, Elísio Medrado, BA, BRA

$\begin{array}{lllll}-18.69597222 & -43.03911111 & 7 & \text { LGEMA }^{a} & 15366,15372,15377,15381,15388,15389,15393 \\ -17.73031666 & -41.82093333 & 6 & \text { LGEMA }^{\text {a }} & 13536,13538,13541,13545,13549,15417 \\ -16.0355 & -40.85680556 & 1 & \text { LGEMA }^{\text {a }} & 13711 \\ -16.43333 & -41 & 1 & \text { UFMG }^{\dagger} & \text { B1090 } \\ -14.3625 & -40.2075 & 1 & \text { LGEMA }^{c} & 13401 \\ -15.38591667 & -39.65225 & 3 & \text { LGEMA }^{\text {a }} & 13718,13720,13736 \\ -13.86147222 & -39.23380556 & 6 & \text { LGEMA }^{\text {a }} & 13762,13763,13764,13765,13766,13767 \\ -12.87041667 & -39.47808333 & 1 & \text { LGEMA }^{\text {a }} & 14956\end{array}$

*LGEMA - Laboratório de Genética e Evolução Molecular de Aves, Instituto de Biociências da Universidade de São Paulo; MNRJ -Museu Nacional da Universidade Federal do Rio de Janeiro; UFMG - Laboratório de Biodiversidade e Evolução Molecular, Instituto de Ciências Biomédicas da Universidade Federal de Minas Gerais; ZMUC - Zoological Museum, University of Copenhagen; MCP - Coleção de Ornitologia do Museu de Ciências e Tecnologia da Pontifícia Universidade Católica do Rio Grande do Sul.

${ }^{\dagger}$ Amostra de sangue sem espécime associado.

${ }^{a}$ Espécime no MZUSP - Museu de Zoologia, Universidade de São Paulo; ${ }^{b}$ espécime no MNRJ; ${ }^{c}$ espécime no DZUFMG - Coleção Ornitológica do Departamento de Zoologia, UFMG. 
Os procedimentos laboratoriais para extração, amplificação e sequenciamento do DNA seguiram Batalha-Filho et al. (2012). Foram amplificados os genes: citocromo oxidase b mitocondrial (cytb) com os primers L-14841 e H-16065 (Lougheed et al., 2000), subunidade 2 do NADH desidrogenase mitocondrial (ND2) com primers Lmet e H6313 (Hackett, 1996; Johnson \& Sorenson, 1998; respectivamente), íntron 5 do gene nuclear beta-fibrinogênio (FIB5) com os primers FIB5 e FIB6 (Marini \& Hackett, 2002), íntron 2 do gene nuclear mioglobina (myo2) com os primers Myoz e Myo3F (Slade et al., 1993; Heslewood et al., 1998; respectivamente). As condições das amplificações para cada loco foram: 1) cytb e ND2 - um passo inicial de desnaturação a $94^{\circ} \mathrm{C}$ por $3 \mathrm{~min}$. 30 seg.; seguido de 35 ciclos a $94^{\circ} \mathrm{C}$ por 35 seg., $56^{\circ} \mathrm{C}$ por 40 seg. e $72^{\circ} \mathrm{C}$ por 1 min.; e um passo final de extensão a $72^{\circ} \mathrm{C}$ por 9 min.; 2) $\mathrm{FIB}_{5}$ - um passo inicial de desnaturação a $94^{\circ} \mathrm{C}$ por 3 min. 30 seg.; seguido de 35 ciclos a $94^{\circ} \mathrm{C}$ por 35 seg., $51-56^{\circ} \mathrm{C}\left(10\right.$ ciclos a $56^{\circ} \mathrm{C}, 10$ ciclos a $53^{\circ} \mathrm{C}$ e 15 ciclos a $51^{\circ} \mathrm{C}$ ) por $40 \mathrm{seg}$. e $72^{\circ} \mathrm{C}$ por 1 min.; e um passo final de extensão a $72^{\circ} \mathrm{C}$ por 9 min.; 3) myor - um passo inicial de desnaturação de $95^{\circ} \mathrm{C}$ por 5 min.; seguido de 10 ciclos a $95^{\circ} \mathrm{C}$ por 30 seg., $60^{\circ} \mathrm{C}$ decrescendo $1^{\circ} \mathrm{C}$ por ciclo por 30 seg. e $72^{\circ} \mathrm{C} 40$ seg.; seguidos de 30 ciclos com $95^{\circ} \mathrm{C}$ por 30 seg., $50^{\circ} \mathrm{C}$ por 30 seg. e $72^{\circ} \mathrm{C} 40$ seg.; e um passo final de extensão por 9 min.

\subsection{Edição das sequências, alinhamento, fase gamética e recombinação}

Os eletroferogramas foram verificados e editados e sequências consenso foram obtidas utilizando o programa Codoncode Aligner v.3.7 (Codoncode Inc.). Essas sequências foram alinhadas utilizando-se o método CLUSTAL W (Higgins et al., 1994) no programa MEGA5 (Tamura et al., 2011). Todos os alinhamentos foram inspecionados e corrigidos visualmente.

As sequências de indivíduos heterozigotos para os locos FIB5 e myoz foram inicialmente codificadas com o código de nucleotídeos ambíguos da IUPAC onde houvesse picos duplos em ambas as fitas. As sequências nucleares de indivíduos heterozigotos para inserção ou deleção (indel) foram resolvidas utilizando-se o algoritmo Process Heterozigous Indels do programa Codoncode Aligner v.3.7. Para a reconstrução dos alelos dos indivíduos heterozigotos para íntrons nucleares foi utilizado o algoritmo PHASE (Stephens et al., 2001) no modo default no programa 
DnaSP 5 (Librado \& Rozas, 2009). Para as análises foram considerados somente haplótipos com alta probabilidade no PHASE $(p>0,6)$, e os demais indivíduos com baixa probabilidade foram removidos das análises seguintes. $\mathrm{O}$ teste $\mathrm{PHI}$ foi aplicado para testar a hipótese de presença de sinal de recombinação dos íntrons nucleares no programa SPLITSTREE4 (Bruen et al., 2006; Huson \& Bryant, 2006).

\subsection{Estimativas de estrutura genética}

As relações entre os haplótipos do gene mitocondrial cytb e dos íntrons nucleares, bem como sua distribuição geográfica, foram construídas utilizando-se redes de haplótipos pelo método median-joining network (Bandelt et al., 1999) no programa NETWORK 4.6.1.0 (www.fluxus-engineering.com). A rede de haplótipos foi estimada apenas para o gene cytb pelo fato deste ter sido sequenciado para todas as amostras. Além disso, a rede de haplótipos do ND2 foi idêntica à obtida com o cytb (dados não mostrados). Nas demais análises os genes mitocondriais foram concatenados e analisados como um único loco devido ao fato de eles serem ligados. Também foi implementada uma reconstrução filogenética por máxima verossimilhança para os genes mitocondriais concatenados (partições: cytb e ND2) pelo algoritmo RAxML-HPC 7.3.0 (Stamatakis et al., 2008) com 1000 replicações de bootstrap, utilizando com grupo externo Synallaxis sp. de Vila Rica-MT conforme capítulo 3 desta tese. A análise foi implementada no portal CIPRES Science Gateway (Miller et al., 2010) com o modelo de substituição GTR (Tavaré, 1986), onde o percentual de sítios invariáveis (I) e a distribuição gama (G) foram otimizados para cada partição durante a análise (cytb: I = 0,717247, G = 1,266860; ND2: I = 0,593002, $G=1,285384$ ).

Com o intuito de se medir a variação genética entre as localidades analisadas, bem como entre os filogrupos observados, nós implementamos uma análise de variância molecular (AMOVA; Excoffier et al., 1992) com três níveis hierárquicos para cada um dos locos no programa Arlequim 3.5.1.2 (Excoffier \& Lischer, 2010). Também foram estimados os índices de fixação $\phi_{C T}$ (estruturação entre grupos) e $\phi_{\text {ST }}$ (estruturação entre localidades entre grupos). Como grupos no terceiro nível hierárquico da AMOVA nós assumimos os filogrupos mitocondriais observados (Fig. 
2b). A significância dos testes foi obtida com 1000 permutações. Para esta análise foram utilizadas somente localidades que possuíam no mínimo dois indivíduos.

\subsection{História demográfica}

Foi calculada a diversidade nucleotídica por sítio $(\pi)$ e o número de haplótipos (h) para cada loco no DnaSP 5. Para detectar possíveis sinais de expansão demográfica nós aplicamos o teste de neutralidade $F_{s}(F u, 1997)$ e o teste de mudança no tamanho da população $R_{2}$ (Ramos-Onsins \& Rozas, 2002) no DnaSP 5. A significância destes testes foi determinada com base em 10000 simulações coalescentes.

Nós também inferimos possíveis eventos de expansão demográfica pelo método Bayesiano coalescente Extended Bayesian Skyline Plot (EBSP; Heled \& Drummond, 2008) que é implementado no BEAST 1.6.2 (Drummond \& Rambaut, 2007). Este método reduz o efeito da estocasticidade do processo coalescente combinando diferentes genes em uma abordagem não-paramétrica de coalescência das diferentes árvores de genes para se estimar a variação do tamanho efetivo populacional ao longo do tempo (Ho \& Shapiro, 2011). Foram realizadas duas corridas independentes do EBSP (100 a 250 milhões de gerações de MCMC - Monte Carlo Markov chain) para cada filogrupo mitocondrial (Fig. 2b e 4) com os seguintes parâmetros: uma árvore inicial de UPGMA, modelo linear, parâmetros amostrados a cada 10000 gerações, e um burn-in de $10 \%$ a 30\%. O teste hLRT implementado pelo MEGA5 não rejeitou a hipótese do relógio molecular $(p<0,05)$ para todos genes nos dois filogrupos, exceto para o DNA mitocondrial no clado centro-sul e myo2 para clado norte. Assim, nós utilizamos o prior uncorrelated lognormal relaxed clock para estas partições e o strict clock para as demais. O modelo evolutivo para cada gene foi estimado pelo MrModeltest 2.2 (Nylander, 2004) com o critério de informação de Akaike (AIC). Como calibração para análise nós utilizamos a taxa de mutação conhecida para o DNA mitocondrial em aves de 1,05\% ( \pm 0,05\%) por sítio por linhagem por milhão de anos (Weir \& Schluter, 2008) sob um prior com distribuição normal. Em seguida o BEAST foi utilizado para estimar a taxa de mutação para cada íntron individualmente sob um prior log-normal com os parâmetros default. O desempenho da MCMC e a convergência entre as corridas foram analisados no 
TRACER 1.5 (http://beast.bio.ed.ac.uk/Tracer), e verificamos que os valores de ESS (Effective Sample Size) foram maiores que 200.

\subsection{Isolamento com migração}

As estimativas do tempo de divergência e do nível de fluxo gênico entre os filogrupos observados com base em todos os locos foram obtidas pelo modelo Bayesiano coalescente de isolamento com migração (Nielsen \& Wakeley, 2001) implementado no programa IMa2 versão 27/08/2012 (Hey, 2010). Este programa implementa o modelo de isolamento com migração para mais de duas populações na mesma análise. Em uma análise com três populações o programa estima 13 parâmetros demográficos sobre este modelo (Fig. 3): tamanho efetivo de cada uma das populações analisadas $\left(\theta_{1}, \theta_{2}\right.$ e $\left.\theta_{3}\right)$ e das populações ancestrais destas $\left(\theta_{4}\right.$ e $\left.\theta_{5}\right)$; taxas de fluxo gênico entre as populações atuais $\left(\mathrm{m}_{1} \rightarrow 2, \mathrm{~m}_{2} \rightarrow 1, \mathrm{~m}_{1} \rightarrow 3, \mathrm{~m}_{3} \rightarrow 1\right.$, $\mathrm{m}_{2} \rightarrow 3$ e $\mathrm{m} 3 \rightarrow 2$ ); e tempo divergência das populações (to e t1). Nós usamos o modelo evolutivo HKY (Hasegawa et al., 1985) para todos os locos e heranças escalares de 0.25 para o loco mitocondrial e 1.0 para os nucleares. As taxas de migração foram estimadas somente entre as populações atuais, e assumindo que as populações ancestrais possuem taxa zero de migração. A topologia de relação entre as populações foi assumida conforme os resultados da análise de verossimilhança (Fig. 4) e do capítulo 3 desta tese: ((centro-sul,norte),whitneyi). Foram implementadas corridas preliminares para se ajustar os valores máximos de distribuição dos priors, e o número e o esquema de aquecimento das MCMCs. As análises foram realizadas com 80 MCMCs com aquecimento geométrico (ha=0.999 e $\mathrm{hb}=0.3$ ) e os valores máximos dos priors para os parâmetros populacionais foram: $\theta=25, m=10, t=8$. Nós implementamos 4 corridas usando diferentes random seeds com 5 milhões de gerações de MCMC cada, sendo o $1^{\circ}$ milhão utilizado como burnin. Nós assumimos o tempo de geração de um ano conforme Cabanne et al. (2008). Os parâmetros foram escalonados em unidades demográficas utilizando a taxa de mutação para o DNA mitocondrial usada no EBSP, e a taxa de mutação para os íntrons nucleares de 0,135\% por sítio por linhagem por milhão de anos conforme Ellegren (2007). Nós assumimos a variação na estimativa das taxas de mutação mencionadas acima (Ellegren, 2007; Weir \& Schluter, 2008) como priors no cálculo 
da taxa de mutação escalar: mitocondrial, 0,96\% - 1,13\%; íntrons nucleares, $0.12 \%$ $0.15 \%$. Todas as corridas obtiveram valores de ESS maiores que 50.

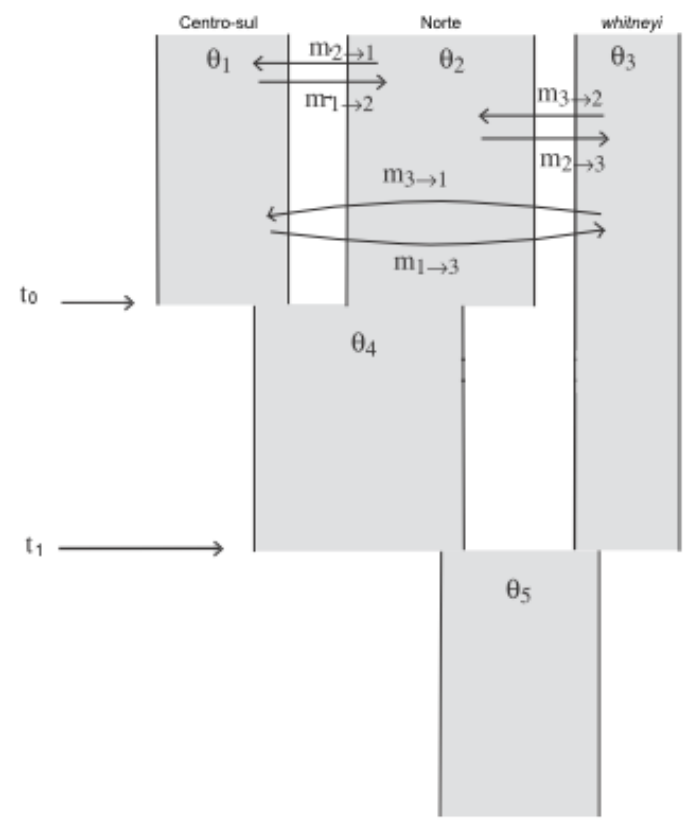

Figura 3. Esquema dos parâmetros estimados pelo IMaz para os três clados mitocondriais do complexo S. ruficapilla/S. whitneyi (modificado de Hey, 2010). Para detalhes dos parâmetros veja texto em materiais e métodos.

\section{Resultados}

\subsection{Características das sequências, PHASE e teste de recombinação}

Obtivemos uma matriz com total de 3168 caracteres, sendo 1001 pb do cytb $(\mathrm{N}=99), 1041 \mathrm{pb}$ do ND2 (N=93), 525 pb do FIB5 $(\mathrm{N}=97)$, e $601 \mathrm{pb}$ do myo2 $(\mathrm{N}=89)$. Foram observados 66 sítios variáveis no cytb e 50 no ND2, e estes resultaram em 57 haplótipos para o DNA mitocondrial. Nos íntrons nucleares foram observados 29 e 28 sítios polimórficos no FIB5 e myo2, respectivamente. Não foram observados indels nas sequências mitocondriais e na tradução para aminoácidos de ambos os genes não foi observado nenhum códon de parada, sugerindo que são sequências mitocondriais. No FIB5 foi detectado um indel de $7 \mathrm{pb}$ em 5 indivíduos de $\mathrm{S}$. whitneyi, e no myoz nenhum indel foi encontrado.

A reconstrução alélica pelo PHASE resolveu com alta probabilidade $(p>0,6)$ 178 cromossomos amostrados para o FIB5 e 154 para o myo2. Estes deram origem a 22 e 25 haplótipos no $\mathrm{FIB5}$ e myo2, respectivamente. O teste $\mathrm{PHI}$ não encontrou evidência significativa de recombinação tanto para o $\operatorname{FIB}_{5}(p=0,939)$ quanto para o myo2 $(p=0,221)$. 


\subsection{Estrutura filogeográfica}

A reconstrução filogenética pelo RAxML para o DNA mitocondrial indicou a presença de três clados bem suportados (Fig. 2a e 4): (1) o clado centro-sul de S. ruficapilla incluindo amostras oriundas desde a porção central até ao extremo sul da ocorrência da espécie (preto); (2) o clado norte de S. ruficapilla com uma estruturação críptica no nordeste de Minas Gerais, e ocorrendo especificamente no interflúvio entre os rios Doce e Jequitinhonha (cinza); (3) o clado S. whitneyi com amostras desde Vale do Rio Jequitinhonha em Minas Gerais até o Vale do Rio Jiquiriçá na Bahia (branco).

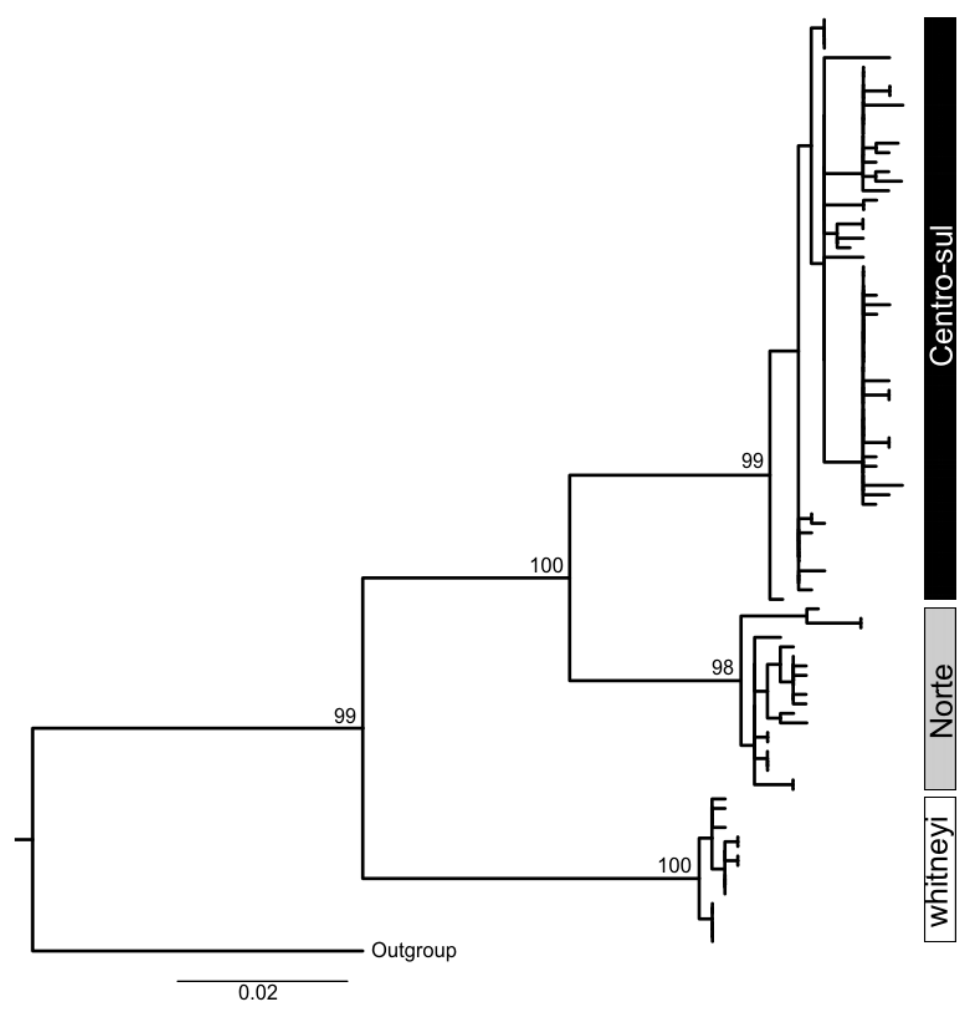

Figura 4. Topologia obtida por máxima verossimilhança pelo RAxML baseada em 2042 pb dos genes mitocondriais cytb e ND2 concatenados do complexo S. ruficapilla e S. whitneyi, e grupo externo. Os suportes dos ramos mostram valores de bootstrap. As barras coloridas representam os filogrupos observados (ver texto e figura $2 a$ ).

A rede de haplótipos para o cytb (Fig. 2b) também recuperou a mesma estrutura observada na árvore de verossimilhança (Fig. 4). Entretanto, as redes de haplótipos dos íntrons nucleares não recuperaram esta estrutura genética (Fig. 2). Contudo, na rede de haplótipos do cytb foi observada uma subestruturação genética dentro do clado centro-sul com dois grupos separados por dois passos 
mutacionais (Fig. 5): (1a) subclado sul com amostras dos estados do Paraná, Santa Catarina e Rio Grande do Sul, e do Paraguai (amarelo); (1b) subclado central com amostras desde o norte do Paraná e sul de São Paulo até o Vale do Rio Doce em Minas Gerais (preto). Ainda na localidade de Wenceslau Braz-PR foi observada a presença de haplótipos destes dois grupos, mostrado assim uma possível zona de contato entre eles (Fig. 5).

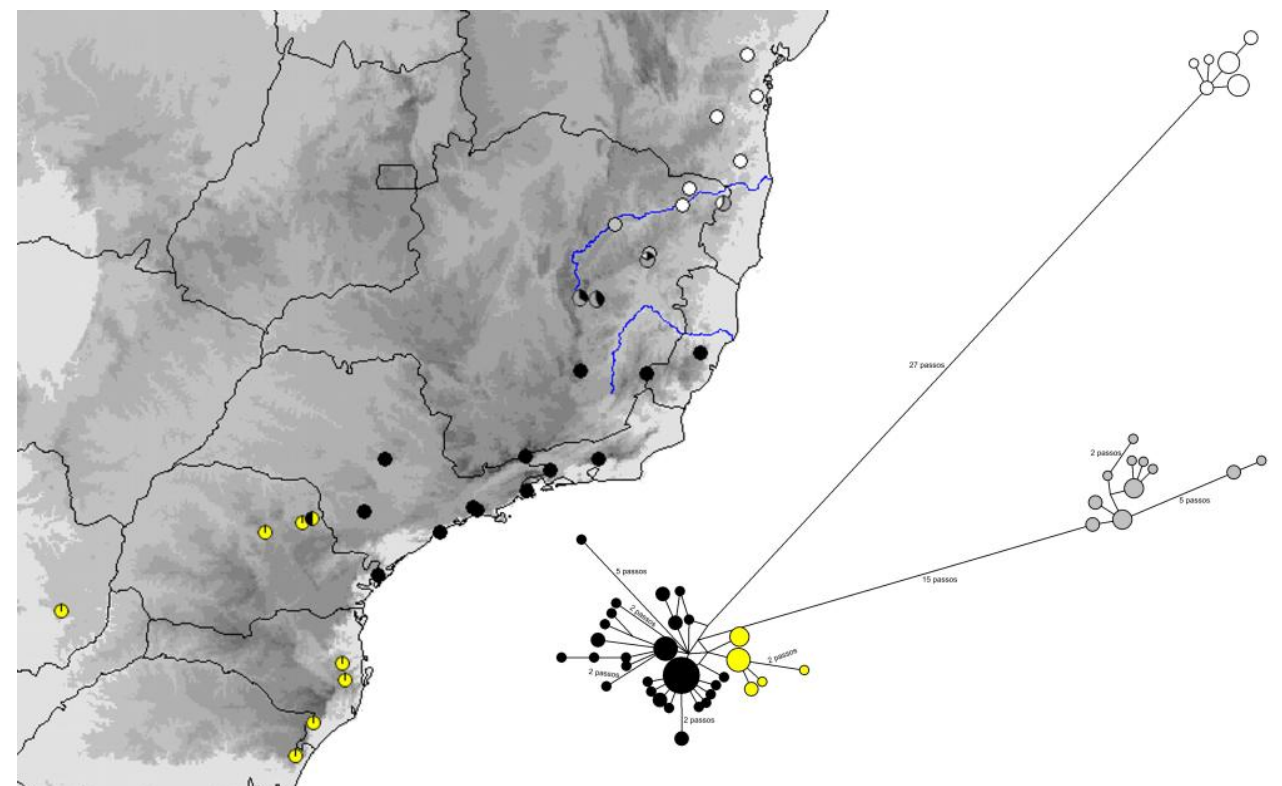

Figura 5. Mapa com a distribuição geográfica das amostras e rede de haplótipos para 1001 pb do cytb de Synallaxis ruficapilla e $S$. whitneyi. Os detalhes desta figura seguem figura 1.

Inesperadamente nós também detectamos uma zona de contato entras as 3 linhagens mitocondriais no interflúvio entre os rios Doce e Jequitinhonha (Fig. 2a e b). Nesta zona de contato entre linhagens mitocondriais de S. ruficapilla e S. whitneyi foram observadas quatro localidades onde estas linhagens estão ocorrendo em simpatria (Fig. 6). Além disso, em uma delas (Pote-MG) foi observada a co-ocorrência das três linhagens mitocondriais do complexo S. ruficapilla, enquanto que nas demais foi observada ou a co-ocorrência da linhagem norte de $S$. ruficapilla e a de S. whitneyi, ou das duas linhagens de S. ruficapilla (Fig. 6). Interessante ressaltar aqui que este deve ser $01^{\circ}$ caso descrito de zona de contato na MA envolvendo três linhagens divergentes em uma mesma localidade. 


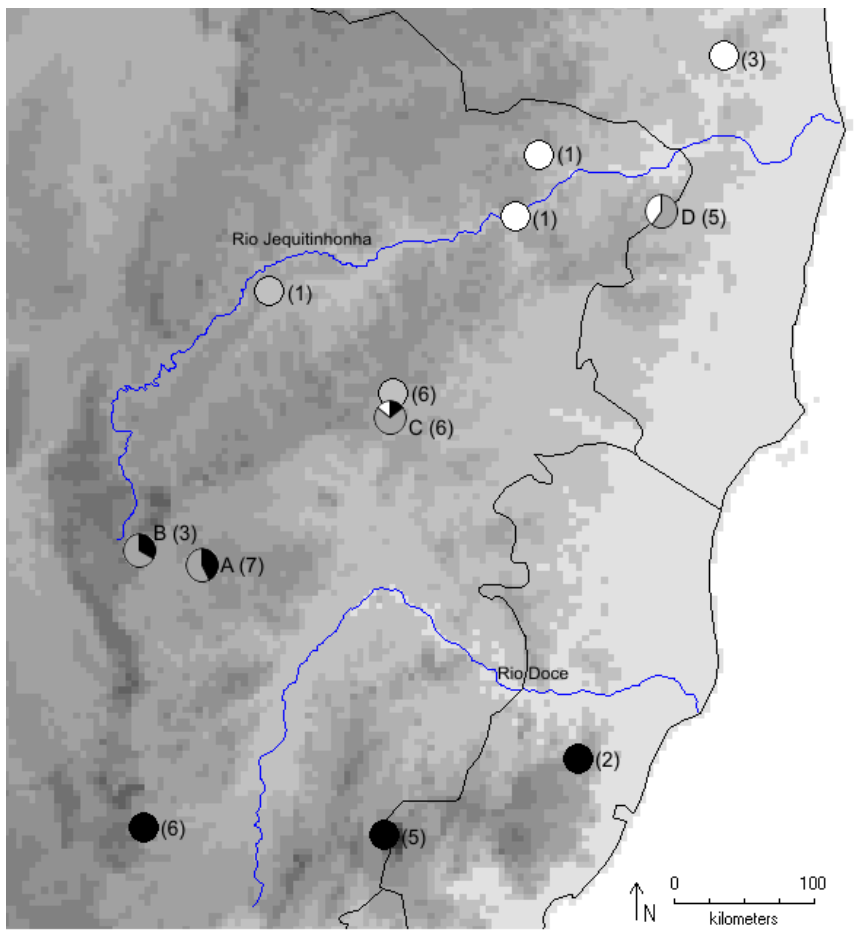

Figura 6. Mapa detalhando a zona de contato entre linhagens mitocondriais de S. ruficapilla e S. whitneyi. Os tons de cinza representam o gradiente altitudinal (quanto mais escuro, maior altitude). Os círculos representam as localidades amostradas e suas cores representam as linhagens mitocondriais conforme figura $2 \mathrm{~b}$. As localidades com letras indicam onde foram detectados contatos entre as linhagens: A-Sabinópolis-MG; B-Serro-MG; C-Poté-MG; D-Santa Maria do Salto-MG (Tab. 1). Os números entre parênteses próximos às localidades indicam seu tamanho amostral.

As estimativas da AMOVA considerando-se 3 grupos (centro-sul, norte e whitneyi) no terceiro nível hierárquico (Tab. 2) corroboram as evidências de estrutura genética observada no DNA mitocondrial (Fig. 2b e 4) e ausência de estrutura nos íntrons nucleares (Fig. 2c e d). Porém, quando se considerou 4 grupos (sul, centro, norte e whitneyi) no terceiro nível hierárquico da AMOVA para o DNA mitocondrial, conforme figura 5, esta mostrou menos estrutura genética do que a análise com 3 grupos (Tab. 2). Desta forma, nas análises seguintes o clado centro-sul foi analisado como uma linhagem única, uma vez que a AMOVA recuperou menos estruturação no DNA mitocondrial quando considerada estrutura dentro deste clado (Tab. 2). 
Tabela 2. Análises de variância molecular (AMOVA) do complexo S. ruficapilla/S. whitneyi.

\begin{tabular}{|c|c|c|c|c|}
\hline Loco $^{\dagger}$ & Fonte de variação & GL & Percentual de Variação & Índice de Fixação \\
\hline \multirow{4}{*}{$\mathrm{a} 1$} & Entre clados & 2 & 73,57 & $\phi_{\mathrm{CT}}=0,7357^{* *}$ \\
\hline & Entre localidades dentro de clados & 18 & 4,55 & $\phi_{\mathrm{ST}}=0,7812^{* *}$ \\
\hline & Dentro de localidades & 71 & 21,88 & \\
\hline & Total & 91 & & \\
\hline \multirow{4}{*}{ a2 } & Entre clados & 3 & 70,72 & $\phi_{\mathrm{CT}}=0,7072^{* *}$ \\
\hline & Entre localidades dentro de clados & 17 & 4,45 & $\phi_{\mathrm{ST}}=0,7517^{* *}$ \\
\hline & Dentro de localidades & 71 & 24,83 & \\
\hline & Total & 91 & & \\
\hline \multirow{4}{*}{$\mathrm{b}$} & Entre clados & 2 & 16,62 & $\phi_{\mathrm{CT}}=0,1662^{*}$ \\
\hline & Entre localidades dentro de clados & 20 & 23,51 & $\phi_{\mathrm{ST}}=0,4012^{* *}$ \\
\hline & Dentro de localidades & 155 & 59,87 & \\
\hline & Total & 177 & & \\
\hline \multirow{4}{*}{ C } & Entre clados & 2 & 5,49 & $\phi_{\mathrm{CT}}=0,0549^{* *}$ \\
\hline & Entre localidades dentro de clados & 20 & $-11,97$ & $\phi_{\mathrm{ST}}=-0,0648^{\mathrm{ns}}$ \\
\hline & Dentro de localidades & 131 & 106,48 & \\
\hline & Total & 153 & & \\
\hline
\end{tabular}

\subsection{Demografia histórica}

As estatísticas sumárias para todos os marcadores analisados são mostradas na tabela 3. O teste $R_{2}$ evidenciou expansão demográfica no clado centro-sul nos locos mitocondrial e FIB5, e no clado whitneyi para o FIB5 (Tab. 3). O teste $F_{s}$ mostrou expansão demográfica em todos os clados para os locos mitocondrial e FIB5 (Tab. 3). Entretanto, no íntron myo2 foi observado nenhum sinal de expansão demográfica (Tab. 3).

As estimativas de demografia histórica com base em todos os locos combinados pelo EBSP evidenciaram expansão demográfica nos clados centro-sul e whitneyi (Fig. 7), a despeito dos intervalos de confiança no clado whitneyi. Entretanto, no clado norte o ESBP não evidenciou mudanças aparentes no $\mathrm{Ne}$ ao longo to tempo (Fig. $7 \mathrm{c}$ ), e embora pareça haver uma mudança na mediana por volta dos 100 mil anos atrás (ka) uma análise mais cuidadosa do ESBP deste clado não mostra isso. Com base no ESBP do clado centro-sul (Fig. 7b) a expansão demográfica parece ter iniciado há aproximadamente 50 ka. Contudo o clado 
whitneyi parece ter experienciado uma expansão demográfica após o término do UMG, há aproximadamente $20 \mathrm{ka}$ (Fig. 7d).

Tabela 3. Estatísticas sumárias para o complexo S. ruficapilla/S. whitneyi.

\begin{tabular}{lcccccc}
\hline Clado & Loco & $\mathbf{N}$ & $\mathbf{h}$ & $\pi / \mathbf{d p}$ & $\boldsymbol{R}_{\mathbf{2}}$ & $\boldsymbol{F}_{\mathbf{s}}$ \\
\hline Centro-sul & mit & 57 & 34 & $0,00252 / 0,00018$ & $0,0355^{* * *}$ & $-26,3685^{* * *}$ \\
& FIB5 & 108 & 17 & $0,00236 / 0,00023$ & $0,0382^{* *}$ & $-11,2400^{* * *}$ \\
& myO2 & 98 & 16 & $0,00687 / 0,00020$ & $0,1351^{\text {ns }}$ & $-0,9707^{\text {ns }}$ \\
Norte & mit & 20 & 15 & $0,00397 / 0,00119$ & $0,1262^{\text {ns }}$ & $-3,8942^{* *}$ \\
& FIB5 & 42 & 6 & $0,00118 / 0,00023$ & $0,0706^{\text {ns }}$ & $-2,7487^{* *}$ \\
\multirow{5}{*}{ S. whitneyi } & myO2 & 32 & 12 & $0,00914 / 0,00043$ & $0,1926^{\text {ns }}$ & $-0,3702^{\text {ns }}$ \\
& mit & 16 & 8 & $0,00123 / 0,00011$ & $0,1289^{\text {ns }}$ & $-2,3834^{*}$ \\
& FIB5 & 28 & 8 & $0,00159 / 0,00036$ & $0,0746^{* *}$ & $-5,0094^{* *}$ \\
Total & myO2 & 24 & 11 & $0,00887 / 0,00054$ & $0,1983^{\text {ns }}$ & $-0,7640^{\text {ns }}$ \\
& mit & 93 & 57 & $0,01332 / 0,00105$ & - & - \\
& FIB5 & 178 & 22 & $0,00200 / 0,00018$ & - & - \\
& myO2 & 154 & 25 & $0,00781 / 0,00018$ & - & - \\
\hline
\end{tabular}

$\mathrm{N}$ - tamanho da amostra; $\mathrm{h}$ - número de haplótipos; $\pi$ - diversidade nucleotídica por sítio; $\mathrm{dp}$ desvio padrão; $* * * p<0,0001 ; * * p<0,05 ;{ }^{*} 0.10>p>0.05 ;^{\text {ns }}$ não significativo.
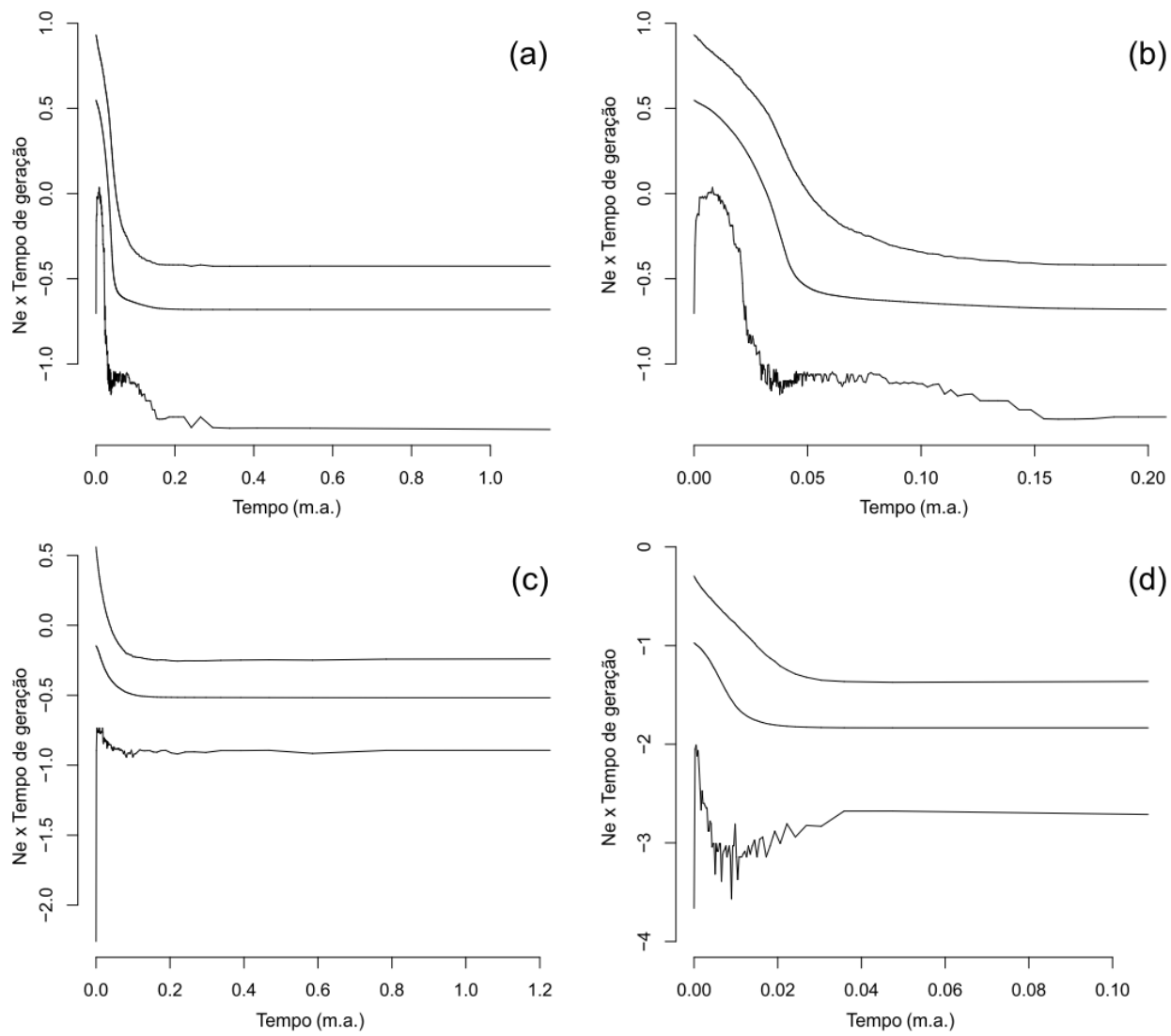

(d)

Figura 7. Estimativas do Extended Bayesian Skyline Plot (EBSP) para os filogrupos mitocondriais do complexo S. ruficapilla/S. whitneyi: (a) clado centro-sul; (b) detalhamento para os últimos 200 mil anos do EBSP do clado centro-sul; (c) clado norte; (d) clado whitneyi. A linha do meio representa a mediana da estimativa, e as linhas superior e inferior os limites superior e inferior de $95 \%$ de HPD (Highest Posterior Density), respectivamente. O eixo $\mathrm{Y}$ está em escala logarítmica. $\mathrm{O}$ eixo $\mathrm{X}$ está milhão de anos (m.a.). 


\subsection{Divergência com fluxo gênico}

As estimativas dos tempos de divergência entre os clados mitocondriais de $S$. ruficapilla/S. whitneyi obtidas pelo IMa2 (Fig. 8, Tab. 4) indicaram uma diversificação durante o fim do Plioceno ao Pleistoceno, sendo que os clados centro-sul e norte divergiram há aproximadamente 721 mil anos atrás [95\% de HPD (Highest Posterior Density): 0,077 a 1,885 milhões de anos atrás). Ao passo que o ancestral destes dois clados divergiu do clado whitneyi há aproximadamente 902 mil anos atrás [95\% de HPD: 0,541 a 3,461 milhões de anos atrás). As estimativas de migração mostraram um fluxo gênico mais acentuado entre os clados centro-sul e norte, e entre os clados norte e whitneyi, sendo que neste último a migração ocorre com mais intesidade de whitneyi para o clado norte (Fig. 9, Tab. 5). Ainda, as estimativas de tamanho efetivo populacional $(\mathrm{Ne})$ mostraram que o clado centro-sul possui um $\mathrm{Ne}$ maior que o Ne dos clados norte e whitneyi (Fig. 8, Tab. 4). Contudo, os valores de Ne dos clados norte e whitneyi apresentaram curvas de probabilidade posterior das estimativas com bastante sobreposição (Fig. 8, Tab. 4).
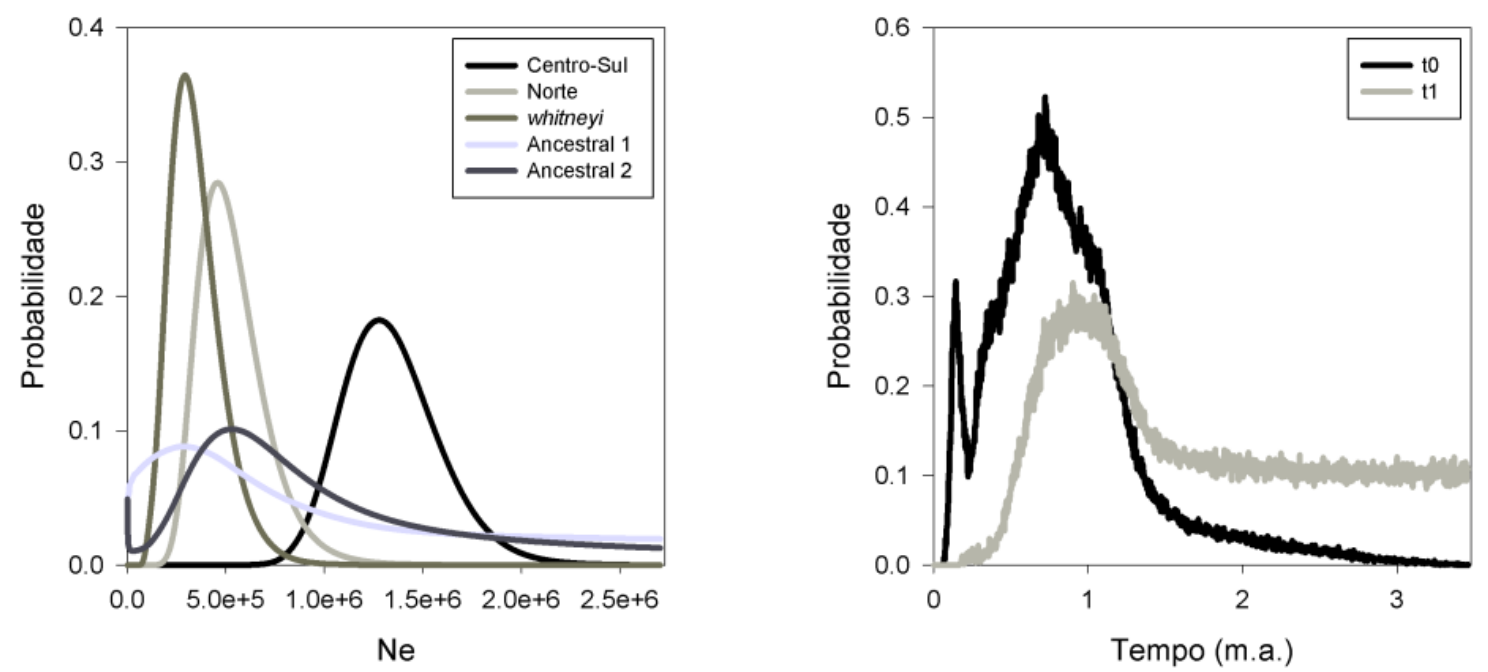

Figura 8. Distribuição das probabilidades posteriores marginais dos tamanhos efetivos populacionais $(\mathrm{Ne})$ e tempos de divergência estimados pelo IMa2. O Ne está em número de indivíduos. Tempo de divergência é apresentado em milhão de anos (m.a.). Os parâmetros estimados são conforme figura 3 . 
Tabela 4. Resultados das estimativas de tamanho efetivo populacional (em número de indivíduos) e tempo de divergência (em anos) pelo IMa2. Os parâmetros estimados são conforme figura 3.

\begin{tabular}{lccccccc}
\hline & $\boldsymbol{\theta 1}_{1}$ & $\boldsymbol{\theta} \mathbf{2}$ & $\boldsymbol{\theta}_{\mathbf{3}}$ & $\boldsymbol{\theta} \mathbf{4}$ & $\boldsymbol{\theta} \mathbf{5}$ & to & t1 \\
\cline { 2 - 8 } $\begin{array}{l}\text { Estimativa pontual com } \\
\text { maior probabilidade }\end{array}$ & 1275539 & 455840 & 293523 & 279996 & 523472 & 721985 & 902048 \\
Limite inferior (95\% de HPD) & 885979 & 244828 & 131206 & $0 *$ & $0 *$ & 77912 & $521145^{*}$ \\
Limite superior (95\% de HPD) & 1819300 & 875158 & 623567 & $2427988 *$ & $2395525^{*}$ & 1885471 & $3461026 *$ \\
\hline
\end{tabular}

95\% de HPD: Intervalos de confiança de 95\% da distribuição posterior dos parâmetros após o burn-in. *: Valores de HPD com pouca precisão e influenciados pelos priors, pois a distribuição posterior foi plana e a curva de probabilidade não atingiu o valor zero.

(a)

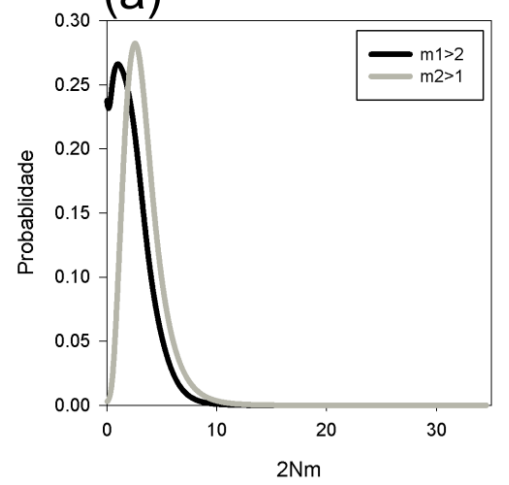

(b)

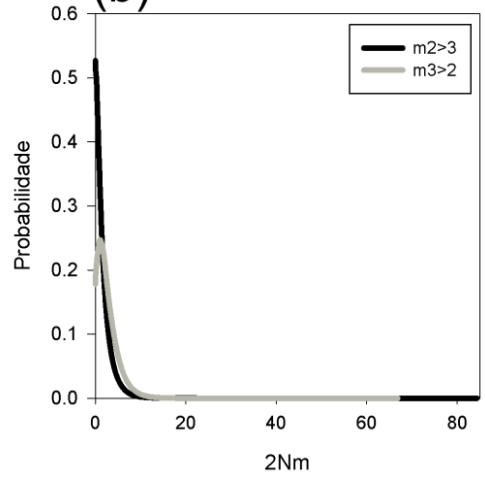

(c)

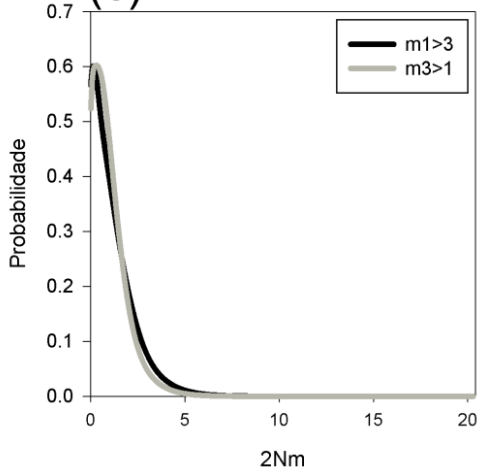

Figura 9. Distribuição das probabilidades posteriores marginais das taxas de migração (2Nm: número de migrantes por geração): (a) entre os clados centro-sul e norte; (b) entre os clados centro-sul e whitneyi; (c) entre os clados norte e whitneyi. Os parâmetros estimados são conforme figura 3 .

Tabela 5. Resultados das taxas migração (em $2 \mathrm{Nm}$ : número de migrantes por geração) estimadas pelo IMa2. Os parâmetros estimados são conforme figura 3.

\begin{tabular}{lcccccc}
\hline & $\mathbf{m 1} \rightarrow \mathbf{2}$ & $\mathbf{m} \mathbf{2} \rightarrow \mathbf{1}$ & $\mathbf{m 1} \rightarrow \mathbf{3}$ & $\mathbf{m} \mathbf{3} \rightarrow \mathbf{1}$ & $\mathbf{m} \mathbf{2} \rightarrow \mathbf{3}$ & $\mathbf{m 3} \rightarrow \mathbf{2}$ \\
\cline { 2 - 7 } Estimativa pontual com & 0,9978 & 2,575 & 0,1408 & 0,2945 & 0,04222 & 1,104 \\
maior probabilidade & 0 & 0,5703 & 0 & 0 & 0 & 0 \\
Limite inferior (95\% de HPD) & 5,739 & 6,792 & 3,420 & 2,813 & 5,362 & 7,196 \\
\hline Limite superior (95\% de HPD) & 5
\end{tabular}

As setas indicam o sentido da migração (por exemplo, $\mathrm{m} 1 \rightarrow 2$ significa a taxa na qual a população 2 recebeu migrantes da população 1).

95\% de HPD: Intervalos de confiança de 95\% da distribuição posterior dos parâmetros após o burn-in. *: Valores de HPD com pouca precisão e influenciados pelos priors, pois a distribuição posterior foi plana e a curva de probabilidade não atingiu o valor zero.

\section{Discussão}

\subsection{Diversificação do complexo S. ruficapilla/S. whitneyi}

A análise filogenética, a rede de haplótipos e a AMOVA baseadas no DNA mitocondrial para o complexo S. ruficapilla/S. whitneyi revelaram a presença de três clados com profunda divergência genética (Fig. 2b e 4, Tab. 2). A despeito das inconsistências taxonômicas das espécies analisadas neste estudo (Stopiglia et al., 2012) os clados centro-sul e norte correspondem a S. ruficapilla, com uma 
estruturação inesperada no norte do Estado de Minas Gerais, ao passo que o terceiro clado observado foi formado por espécimes de S. whitneyi. Além disso, o clado centro-sul mostrou subestruturação dando origem aos subclados sul e central (Fig. 5).

Entretanto, as análises por meio do DNA nuclear não corroboraram a presença de estrutura genética populacional observada no DNA mitocondrial (Fig. 2, Tab. 2). Essa ausência de monofilia recíproca no DNA nuclear possivelmente está relacionada à presença de sorteamento incompleto das linhagens nos íntrons nucleares por retenção de polimorfismo ancestral devido a uma recente separação (Pinho et al., 2008), ou devido ao longo tempo de coalescência do DNA nuclear em relação ao mitocondrial (aproximadamente quatro vezes maior; Palumbi et al., 2001; Zink \& Barrowclough, 2008). Outra justificativa para esta incongruência seria a taxa de substituição mais lenta dos genes autossômicos quando comparada com a dos genes mitocondriais (Avise, 2000). Cabanne et al. (2008) estudando uma espécie de pássaro endêmica da MA encontraram um padrão similar ao apresentado aqui, com profunda divergência no DNA mitocondrial e ausência de monofilia recíproca no FIB5. Ainda, o fluxo gênico entre estas linhagens pode ter levado a esta ausência de estrutura nesses locos autossômicos, uma vez que foi observada uma possível zona de contato secundário (Fig. 6) e evidências de migração entre os clados do complexo S. ruficapilla/S. whitneyi (Fig. 9, Tab. 5).

A distribuição geográfica das linhagens concorda em parte com os dados prévios da literatura para S. ruficapilla e S. whitneyi (Fig. 2; Pacheco \& Gonzaga, 1995; Ribon et al., 2002; Vasconcelos \& Silva, 2004). No entanto, a linhagem críptica referente ao clado norte não corresponde a nenhuma variação fenotípica previamente descrita. Este clado parece ter sua distribuição restrita ao norte do Estado de Minas Gerais, mais precisamente próximo à Cadeia do Espinhaço no médio Jequitinhonha (Fig. 6). Entretanto, serão necessárias mais amostragens nessa região para se determinar a extensão da distribuição geográfica do clado norte, pois a maioria das localidades onde esta linhagem foi amostrada apresenta contato secundário com as outras linhagens observadas neste estudo (Fig. 6).

Outro resultado interessante deste presente estudo foi a não confirmação da hipótese levantada por Vasconcelos \& Silva (2004) de existência de uma possível 
barreira geográfica formada pelo Rio Jequitinhonha separando as espécies $S$. ruficapilla e S. whitneyi. Nossas análises mostraram presença de linhagens de $S$. whitneyi ao sul do Jequitinhonha (Fig. 2 e 6), mostrando assim que o rio não seria barreira ao fluxo gênico entre essas linhagens. Nossos resultados mostram ainda uma zona de contato secundário ao sul do Rio Jequitinhonha com três ou dois dos clados observados ocorrendo em simpatria (Fig. 6). Nós mostramos que diferente de outras estimativas (Pellegrino et al., 2005), os rios provavelmente não foram as principais barreiras ao fluxo gênico na MA. Estudos recentes mostraram que a origem dos rios da bacia Amazônica tiveram um importante papel na diversificação da biota presente naquela região (Ribas et al., 2012; Fernandes et al., 2012), contudo na MA eles possivelmente não foram responsáveis pela diversificação da biota (Cabanne et al., 2007; Maldonado-Coelho, 2012). Além disso, no cenário de vicariância onde o rio seria a barreira primária ao evento de vicariância é esperado ausência de assinaturas de expansão demográfica e congruência temporal do tempo de divergência das populações com a origem do rio (Moritz et al., 2000). Entretanto, nossas análises recuperam sinais de expansão demográfica nas duas margens do Rio Jequitinhonha (Tab. 2, Fig. 7), e a origem Gondwânica do rio (Saadi, 1995) é muito mais antiga que os eventos vicariantes datados neste estudo (Fig. 8, Tab. 4).

A existência de uma zona de contato secundário entre os rios Doce e Jequitinhonha (Fig. 6), bem como as evidências de expansão demográfica (Tab. 3. Fig. 7), remete à hipótese da existência de uma barreira histórica ao fluxo gênico possivelmente associada com a teoria dos refúgios florestais (Haffer, 1969; Vanzolini \& Willians, 1970; Carnaval \& Moritz, 2008) que teria originado essas linhagens. E uma vez que a barreira ao fluxo gênico deixou de existir essas linhagens teriam expandido suas distribuições geográficas e teriam se encontrado dando origem a essa zona de contato secundário. Os indícios de expansão demográfica baseados nos testes $F_{\mathrm{s}}$ e $R_{2}$ e no EBSP mostram assinaturas demográficas de um possível efeito de fragmentação de habitats associada com refúgios florestais durante o Pleistoceno. Além disso, as estimativas do IMa2 mostraram que a separação dos clados observados ocorreu durante o Plioceno final até o Pleistoceno (Fig. 8, Tab. 4). Entretanto, embora as divergências tenham sido datadas para antes 
do último máximo glacial (UMG), os intervalos de confiança das estimativas se sobrepõem com outras glaciações anteriores ao UMG (Petit et al., 1999).

\subsection{Biogeografia histórica da Mata Atlântica}

Datações do tempo de divergência entre os clados aqui observados apontam para uma diversificação durante o Plioceno final até o Pleistoceno (Fig. 8, Tab. 4). Interessantemente, estas estimativas do tempo de divergência e a localização geográfica das quebras apresentam congurência espacial e temporal com atividades neotectônicas ocorridas durante o Quaternário (Saadi et al., 2002). Saadi et al. (2002) mostram diversas falhas neotectônicas presentes no Brasil que tiveram movimentação durante o Pleistoceno (<1,6 milhões de anos). Dentre elas a falha do rio Araçuaí (Saadi et al., 2002) possui bastante concordância tanto em espaço quanto em tempo com os dois eventos vicariantes observados no presente estudo. De acordo com Saadi et al. (2002) essa falha se estendeu por cerca de $639 \mathrm{~km}$ e sua porção norte teria controlado a confluência dos rios Araçuaí e Jequitinhonha. O real efeito destas atividades neotectônicas sobre as biotas florestais ainda é bastante obscuro, no entanto dadas suas concordâncias espaço-temporais com os eventos vicariantes observados, sua importância como força atuante na diversificação dos organismos não pode ser descartada. Além disso, estudos filogeográficos para organismos da MA também têm mostrado que atividades tectônicas possivelmente tiveram algum papel no processo de diversificação das linhagens residentes no bioma (Batalha-Filho et al., 2010; Thomé et al., 2010; Amaro et al., 2012). Porém, em um cenário onde atividades tectônicas deram origem aos eventos vicariantes

observados seria esperado ausência de sinais de expansão demográfica, e no complexo S. ruficapilla/S. whitneyi foi observado justamente o oposto (Tab. 3, Fig. 7).

As quebras filogeográficas observadas no presente estudo são congruentes com estudos filogeográficos prévios para organismos da MA (Fig. 2, 4 e 5): 1) a quebra localizada no estado de São Paulo bastante recorrente em vários estudos filogeográficos (Grazziotin et al., 2006; Cabanne et al., 2007, 2008; Carnaval et al., 2009; Martins et al., 2009; Batalha-Filho et al., 2010; Thomé et al., 2010; d'Horta et al., 2011; Amaro et al., 2012) é congruente com a subestruturação dentro do clado centro-sul; 2) a quebra localizada aproximadamente entre os rios Doce e 
Jequitinhonha observada em aves (Cabanne et al., 2008; d'Horta et al., 2011), sapos (Carnaval et al., 2009; Thomé et al., 2010) e plantas (Ribeiro et al., 2010) é congruente com as separações dos clados centro-sul, norte e whitneyi. Porém estes estudos mencionados acima concordam com a estruturação aqui observada quando se considera somente a vicariância entre S. ruficapilla (clado centro-sul + clado norte) e S. whitneyi. O padrão de estrutura genética entre os clados centro-sul e norte não foi observado para outro organismo da MA até o momento.

Na maioria destes estudos (Cabanne et al., 2007, 2008; Carnaval et al., 2009; Martins et al., 2009; Ribeiro et al., 2010; d'Horta et al., 2011) a hipótese dos refúgios (Haffer, 1969; Vanzolini \& Williams, 1970) foi invocada para explicar os padrões vicariantes observados, e concordando assim com o padrão observado neste presente estudo.

Os eventos vicariantes aqui observados, embora mais antigos que o último máximo glacial, poderiam também estar relacionados com a hipótese de refúgios florestais. Segundo Haffer (1997) os ciclos de Milankovitch que proporcionaram os eventos glaciais no planeta afetando a dinâmica das áreas florestadas nos biomas do mundo todo não ocorreram somente durante o Pleistoceno, mas também durante períodos mais antigos na história da Terra, como o Terciário. Outra evidência do efeito dos ciclos glaciais na história demográfica do complexo $\mathrm{S}$. ruficapilla e S. whitneyi são os sinais de expansão demográfica (Fig. 8, Tab. 4).

O modelo paleogeográfico da MA proposto por Carnaval \& Moritz (2008) com base em modelagem ecológica de nicho prediz que durante o UMG o bioma foi mais estável em sua porção central-norte, ao passo que a parte sul foi bastante instável durante este período. Assim, de acordo com este cenário seria possível predizer que a parte sul da MA manteria menos diversidade genética que a parte centro-norte, e bem como um sinal de expansão demográfica mais acentuado ao sul do que no restante do bioma devido à maior expansão da área florestada. Nossos resultados (Fig. 8, Tab. 4) corroboram parcialmente esta hipótese onde foi observado sinal de expansão na parte sul da MA (clado cetro-sul), porém nós também detectamos expansão demográfica na porção norte do bioma (clado whitneyi). Embora alguns estudos tenham corroborado o modelo proposto por Carnaval \& Moritz (2008) (Cabanne et al., 2008; Carnaval et al., 2009; Martins et al., 
2009; Ribeiro et al., 2010; d'Horta et al., 2011; Martins, 2011; Maldonado-Coelho, 2012), outros mostraram que a porção sul da MA também possui elevada diversidade genética e possivelmente abrigou refúgios durante o UMG (Thomé et al., 2010; Álvarez-Presas et al., 2011; Batalha-Filho et al., 2012). Mostrado assim uma complexidade na história evolutiva da MA e que possivelmente não exista uma única hipótese evolutiva que explique a diversificação da biota residente neste bioma extremamente biodiverso.

Nossos resultados mostram concordância espacial com algumas quebras filogeográficas previamente observadas para organismos da MA. Além disso, evidenciamos uma quebra filogeográfica no norte de Minas Gerais que não havia sido observada na MA (clado norte), e ainda mostramos que a hipótese do rio Jequitinhonha como barreira ao fluxo não é congruente com nossos dados. Nós inferimos que os principais eventos históricos responsáveis pela diversificação do complexo S. ruficapilla e S. whitneyi na MA foram possivelmente atividades neotectônicas e mudanças climáticas ocorridas no Pleistoceno, ou a ação conjunta das duas hipóteses. Ainda, nós observamos uma possível zona de contato secundária entre os rios Doce e Jequitinhonha onde, interessantemente, as três linhagens aqui observadas ocorrem em simpatria. Dessa maneira, é necessária a realização de mais estudos filogeográficos de táxons endêmicos da MA com o intuito de contribuir para o entendimento da complexa história evolutiva deste bioma, pois ainda estão sendo encontrados padrões filogeográficos inéditos e o papel das oscilações climáticas e atividades neo-tectônicas ocorridas no Quaternário ainda é pouco conhecido.

\section{Referências}

Álvarez-Presas M, Carbayo F, Rozas J, Riutort M. 2011. Land planarians (Platyhelminthes) as a model organism for fine-scale phylogeographic studies: understanding patterns of biodiversity in the Brazilian Atlantic Forest hotspot. J. Evol. Biol. 24: $887-896$.

Amaro RC, Rodrigues MT, Yonenaga-Yassuda Y, Carnaval AC. 2012. Demographic processes in the montane Atlantic rainforest: molecular and cytogenetic 
evidence from the endemic frog Proceratophrys boiei. Mol. Phylogenet. Evol. 62: 880-888.

Avise JC. 2000. Phylogeography: The history and formation of species. Harvard University Press, Cambridge.

Bandelt HJ, Forster P, Röhl A. 1999. Median-joining networks for inferring intraspecific phylogenies. Mol. Biol. Evol. 16: 37-48.

Batalha-Filho H, Cabanne GS, Miyaki CY. 2012. Phylogeography of an Atlantic forest passerine reveals demographic stability through the last glacial maximum. Mol. Phylogenet. Evol. DOI: http://dx.doi.org/10.1016/j.ympev.2012.08.010.

Batalha-Filho H, Waldschmidt AM, Campos LAO, Tavares MG, Fernandes-Salomão TM. 2010. Phylogeography and historical demography of the Neotropical stingless bee Melipona quadrifasciata (Hymenoptera, Apidae): incongruence between morphology and mitochondrial DNA. Apidologie 41: 534-547.

Bruen TC, Philippe H, Bryant D. 2006. A simple and robust statistical test for detecting the presence of recombination. Genetics 172: 2665-2681.

Cabanne GS, Santos FR, Miyaki CY. 2007. Phylogeography of Xiphorhynchus fuscus (Passeriformes, Dendrocolaptidae): vicariance and recent demographic expansion in southern Atlantic forest. Biol. J. Linn. Soc. 91: 73-84.

Cabanne GS, d'Horta FM, Sari EHR, Santos FR, Miyaki CY. 2008. Nuclear and mitochondrial phylogeography of the Atlantic forest endemic Xiphorhynchus fuscus (Aves: Dendrocolaptidae): biogeography and systematic implications. Mol. Phylogenet. Evol. 49: 760-773.

Carnaval AC, Moritz C. 2008. Historical climate modelling predicts patterns of current biodiversity in the Brazilian Atlantic forest. J. Biogeogr. 35: 1187-1201.

Carnaval AC, Hickerson MJ, Haddad CFB, Rodrigues MT, Moritz C. 2009. Stability predicts genetic diversity in the Brazilian Atlantic forest hotspot. Science 323: 785-789.

d'Horta F, Cabanne GS, Meyer D, Miyaki CY. 2011. The genetic effects of Late Quaternary climatic changes over a tropical latitudinal gradient: diversification of an Atlantic Forest passerine. Mol. Ecol. 20: 1932-1935.

Drummond AJ, Rambaut A. 2007. BEAST: Bayesian evolutionary analysis by sampling trees. BMC Evol. Biol. 7: 214. 
Ellegren H. 2007. Molecular evolutionary genomics of birds. Cytogenet. Genome Res. 117: 120-130.

Excoffier L, Lischer HEL. 2010. Arlequin suite ver 3.5: A new series of programs to perform population genetics analyses under Linux and Windows. Mol. Ecol. Resour. 10: 564-567.

Excoffier L, Smouse PE, Quattro JM. 1992. Analyses of molecular variance inferred from metric distances among DNA haplotypes: application to human mitochondrial DNA restriction data. Genetics 131, 479-491.

Fernandes AM, Wink M. Aleixo A. 2012. Phylogeography of the chestnut-tailed antbird (Myrmeciza hemimelaena) clarifies the role of rivers in Amazonian biogeography. J. Biogeogr. 39: 1524-1535.

Fu YX. 1997. Statistical tests of neutrality of mutations against population growth, hitchhiking and background selection. Genetics 147: 915-925.

Grazziotin FG, Monzel M, Echeverrigaray S, Bonatto SL. 2006. Phylogeography of the Bothrops jararaca complex (Serpentes: Viperidae): past fragmentation and island colonization in the Brazilian Atlantic Forest. Mol. Ecol. 15: 3969-3982.

Hackett SJ. 1996. Molecular phylogenetics and biogeography of tanagers in the genus Ramphocelus (Aves). Mol. Phylogenet. Evol. 5: 368-382.

Haffer J. 1969. Speciation in Amazonian forest birds. Science 165: 131-137.

Haffer J. 1997. Alternative models of vertebrate speciation in Amazonia: an overview. Biodivers. Conserv. 6: 451-476.

Hasegawa M, Kishino H, Yano T. 1985. Dating of the human-ape splitting by a molecular clock of mitochondrial DNA. J. Mol. Evol. 22: 160-174.

Heled J, Drummond AJ. 2008. Bayesian inference of population size history from multiple loci. BMC Evol. Biol. 8: 289.

Heslewood MM, Elphinstone MS, Tidemann SC, Baverstock PR. 1998. Myoglobin intron variation in the Gouldian finch Erythrura gouldiae assessed by temperature gradient gel electrophoresis. Electrophoresis 19: 142-151.

Hey J. 2010. Isolation with migration models for more than two populations. Mol. Biol. Evol. 27: 905-920.

Higgins D, Thompson J, Gibson T, Thompson JD, Higgins DG, Gibson TJ. 1994. CLUSTAL W: improving the sensitivity of progressive multiple sequence 
alignment through sequence weighting, position-specific gap penalties and weight matrix choice. Nucleic Acids Res. 22: 4673-4680.

Ho SY, Shapiro B. 2011. Skyline-plot methods for estimating demographic history from nucleotide sequences. Mol. Ecol. Resour. 11: 423-434.

Huson DH, Bryant D. 2006. Application of phylogenetic networks in evolutionary studies. Mol. Biol. Evol. 23: 254-267.

Johnson KP, Sorenson MD. 1998. Comparing molecular evolution in two mitochondrial coding genes (cytochrome $b$ and ND2) in the dabbling ducks (tribe: Anatini). Mol. Phylogenet. Evol. 10: 82-94.

Librado P, Rozas J. 2009. DnaSP v5: A software for comprehensive analysis of DNA polymorphism data. Bioinformatics 25: 1451-1452.

Lougheed SC, Freeland JR, Handford P, Boag PT. 2000. A molecular phylogeny of warbling-finches (Poospiza): paraphyly in a Neotropical emberizid genus. Mol. Phylogenet. Evol. 17: 367-378.

Maldonado-Coelho M. 2012. Climatic oscillations shape the phylogeographical structure of Atlantic Forest fire-eye antbirds (Aves: Thamnophilidae). Biol. J. Linn. Soc. 105: 900-924.

Marini MA, Hackett SJ. 2002. A multifaceted approach to the characterization of an intergeneric hybrid manakin (Pipridae) from Brazil. Auk 119: 1114-1120.

Martins FM, Templeton AR, Pavan ACO, Kohlbach BC, Morgante JS. 2009. Phylogeography of the common vampire bat (Desmodus rotundus): marked population structure, Neotropical Pleistocene vicariance and incongruence between nuclear and mtDNA markers. BMC Evol. Biol. 9: 294.

Miller MA, Pfeiffer W, Schwartz T. 2010. Creating the CIPRES science gateway for inference of large phylogenetic trees. In: Proceedings of the Gateway Computing Environments Workshop (GCE), 14 Nov. 2010, New Orleans, 1-8.

Moritz C, Patton JL, Schneider CJ, Smith TB. 2000. Diversification of rainforest faunas: An integrated molecular approach. Annu. Rev. Ecol. Syst. 31: 533-563.

Nielsen R, Wakeley J. 2001. Distinguishing migration from isolation: a Markov chain Monte Carlo approach. Genetics 158: 885-896.

Nylander JAA. 2004. MrModeltest 2.2. Program distributed by the author. Evolutionary Biology Centre, Uppsala University. 
Palumbi SR, Cipriano F, Hare MP. 2001. Predicting nuclear gene coalescence from mitochondrial data: the three-times rule. Evolution 55: 859-868.

Pacheco JF, Gonzaga LP. 1995. A new species of Synallaxis of the ruficapila/infuscata complex form eastern Brazil (Passeriformes: Funariidae). Ararajuba 3: 3-11.

Pellegrino KCM, Rodrigues MT, Waite AN, Morando M, Yassuda YY, Sites Jr JW. 2005. Phylogeography and species limits in the Gymnodactylus darwinii complex (Gekkonidae, Squamata): genetic structure coincides with river systems in the Brazilian Atlantic Forest. Biol. J. Linn. Soc. 85: 13-26.

Petit JR, Jouzel J, Raynaud D, Barkov NI, Barnola JM, Basile I, Bender M, Chappellaz J, Davis M, Delaygue G, Delmotte M, Kotlyakov VM, Legrand M, Lipenkov VY, Lorius C, Pepin L, Ritz C, Saltzman E, Stievenard M. 1999. Climate and atmospheric history of the past 420,000 years from the Vostok ice core, Antarctica. Nature 399: 429-436.

Pinho C, Harris DJ, Ferrand N. 2008. Non-equilibrium estimates of gene flow inferred from nuclear genealogies suggest that Iberian and North African wall lizards (Podarcis spp.) are an assemblage of incipient species. BMC Evol. Biol. 8: 63.

Ramos-Onsins S, Rozas J. 2002. Statistical properties of new neutrality test against population growth. BMC Evol. Biol. 19: 2092-2100.

Ribas CC, Aleixo A, Nogueira ACR, Miyaki CY, Cracraft J. 2012. A palaeobiogeographic model for biotic diversification within Amazonia over the past three million years. Proc. Roy. Soc. B 279, 681-689.

Ribeiro RA, Lemos-Filho JP, Ramos ACS, Lovato MB. 2010. Phylogeography of the endangered rosewood Dalbergia nigra (Fabaceae): insights into the evolutionary history and conservation of the Brazilian Atlantic Forest. Heredity 106: 46-57.

Ribon R, Whitney BM, Pacheco JF. 2002. Discovery of Bahia spinetail Synallaxis cinerea in north-east Minas Gerais, Brasil, with additional records of some rare and threatened montane Atlantic forest birds. Cotinga 17: 46-50.

Ridgely R, Tudor G. 1994. The birds of South America, volume II: the suboscine passerines. University of Texas Press, Austin.

Saadi A. 1995. A geomorfologia da Serra do Espinhaço em Minas Gerais e suas margens. Geonomos 3, 41-63. 
Saadi A, Machette MN, Haller KM, Dart RL, Bradley L, Souza AMPD. 2002. Map and Database of Quaternary Faults and Lineaments in Brazil. U.S. Geological Survey Open-File Report 02-230, Version 1.0. Disponível em: http://pubs.usgs.gov/of/2002/ofr-02-230/.

Sick H. 1997. Ornitologia Brasileira. Nova Fronteira, Rio de Janeiro.

Silva JMC, Straube FC. 1996. Systematics and biogeography of Scaled Woodcreepers (Aves: Dendrocolaptidae). Stud. Neotrop. Fauna E. 31: 3-10.

Silva JMC, Casteleti CHM. 2005. Estado da biodiversidade da Mata Atlântica brasileira. In: Galindo-Leal C, Câmara IG (Eds). Mata Atlântica: Biodiversidade, Ameaças e Perspectivas. Belo Horizonte: Conservação Internacional, 43-59 pp. Silveira LF. 2008. Synallaxis cinerea Wied, 1831. In: Machado ABM, Drummond GM, Paglia AP (Eds). Livro Vermelho da Fauna Brasileira Ameaçada de Extinção. Volume 1. Fundação Biodiversitas, Belo Horizonte, 578-579 pp.

Slade RW, Moritz C, Heideman A, Hale PT. 1993. Rapid assessment of single-copy nuclear DNA variation in diverse species. Mol. Ecol. 2: 359-373.

Stamatakis A, Hoover P, Rougemont J. 2008. A fast bootstrapping algorithm for the RAxML web-servers. Syst. Biol. 57: 758-771.

Stephens M, Smith N, Donnelly P. 2001. A new statistical method for haplotype reconstruction from population data. Am. J. Hum. Genet. 68: 978-989.

Stopiglia R, Raposo MA, Teixeira DM. 2012. Taxonomy and geographic variation of the Synallaxis ruficapilla Vieillot, 1819 species-complex (Aves: Passeriformes: Furnariidae). J. Ornithol. DOI: http://dx.doi.org/10.1007/s10336-012-0886-3.

Tamura K, Peterson D, Peterson N, Stecher G, Nei M, Kumar S. 2011. MEGA5: Molecular Evolutionary Genetics Analysis using Maximum Likelihood, Evolutionary Distance, and Maximum Parsimony Methods. Mol. Biol. Evol. 28: $2731-2739$

Tavaré S. 1986. Some probabilistic and statistical problems in the analysis of DNA sequences. Lect. Math. Life Sci. 17: 57-86.

Thomé MTC, Zamudio KR, Giovanelli JGR, Haddad CFB, Baldissera Jr FA, Alexandrino JMB. 2010. Phylogeography of endemic toads and post-Pliocene persistence of the Brazilian Atlantic Forest. Mol. Phylogenet. Evol. 55: 1018-1031. 
Vanzolini PE, Williams EE. 1970. South American anoles: the geographic differentiation and evolution of the Anolis chrysolepis species group (Sauria: iguanidae). Arquiv. Zool. (S. Paulo) 19: 1-298.

Vasconcelos MF, Silva JF. 2004. Limite norte da distribuição do pichororé Synallaxis ruficapilla (Aves, Furnariidae). Bol. Mus. Biol. Mello Leitão 17: 65-68.

Weir JT, Schluter D. 2008. Calibrating the avian molecular clock. Mol. Ecol. 17: 23212328.

Zink RM, Barrowclough GF. 2008. Mitochondrial DNA under siege in avian phylogeography. Mol. Ecol. 17: 2107-2121. 


\section{Capítulo 5}

Filogeografia multilocos de Thamnomanes caesius

(Passeriformes, Thamnophilidae) revela diversificação

Plio-Pleistocênica na Amazônia 


\section{Introdução}

A Amazônia (AM) e a Mata Atlântica (MA) estão entre os biomas com os maiores índices de biodiversidade do mundo, e estão separadas pela diagonal seca da América do Sul, que é formada pelos biomas Chaco, Cerrado e Caatinga (Ab’Saber, 1977). A origem desta biodiversidade intriga os naturalistas desde a época de Alfred Russel Wallace (1852), que observou padrões de distribuição de espécies de primatas concordantes com os grandes rios amazônicos. Durante muitos anos a origem da biodiversidade na região Neotropical foi atribuída às mudanças climáticas cíclicas ocorridas no Pleistoceno (Whitmore \& Prance, 1987). A principal hipótese invocada para explicar esta grande biodiversidade do continente sul americano foi a teoria dos refúgios florestais (Haffer, 1969; Vanzolini \& Williams, 1970; Brown \& Ab’Saber, 1979). Segundo esta hipótese as áreas florestadas teriam sido ciclicamente fragmentadas durante períodos de máximo glacial (mais secos) e expandido durante os períodos interglaciais (mais úmidos). Nesses períodos glaciais, populações de espécies florestais poderiam ter ficado isoladas nos refúgios florestais por tempo suficiente para originar espécies plenas.

Entretanto, outros autores têm questionado o papel da teoria dos refúgios como principal hipótese para explicar a diversificação nos neotrópicos (Bush, 1994; Nelson et al., 1990), e com isto outras teorias foram invocadas para explicar esta complexa dinâmica de diversificação (Marroig \& Cerqueira, 1997; Patton et al., 1994; Smith et al., 1997). Recentemente uma nova perspectiva sobre a diversificação dos Andes e Amazônia tem emergido (Antonelli \& Sanmartín, 2011; Hoorn et al., 2010). De acordo com este novo paradigma o soerguimento dos Andes juntamente com as incursões marinhas durante o Mioceno superior teriam desempenhado papel crucial na diversificação do norte da América do Sul (Hoorn et al., 2010). Ainda segundo Hoorn et al. (2010) o soerguimento dos Andes influenciaram o curso de todo o sistema fluvial do norte da América do Sul, e também alteraram o clima do continente, o que possivelmente desencadeou mudanças significativas em outros biomas sul americanos. Entretanto, ainda existem controvérsias em relação a esta hipótese, ao passo que vários grupos se diversificaram durante o Quaternário (Rull, 2008; Rull, 2011b) e uma diversificação contínua ao longo do tempo seria a hipótese mais plausível para a origem da biota Neotropical (Rull, 2011a). 
Ainda mais recentemente alguns estudos têm mostrado que a hipótese dos rios como barreira ao fluxo gênico para animais terrestres (Wallace, 1852) foi responsável por eventos de especiação recentes de aves na bacia Amazônica (Fernandes et al., 2012; Ribas et al., 2012). Ribas et al. (2012) estudando a diversificação do gênero Psophia (jacamins) na Amazônia mostrou que a hipótese do estabelecimento recente da drenagem moderna da bacia Amazônica nos últimos 3 milhões de anos deu origem às espécies do gênero presentes nos grandes interflúvios da bacia.

Outro aspecto bastante intrigante são os contatos históricos entre AM e MA (Andrade-Lima, 1982; Batalha-Filho et al., 2012b; Por, 1992; Silva, 1994; Willis, 1992). Existe uma série de evidências que suportam inúmeros contatos históricos entre estas duas florestas (Auler et al., 2004; Auler \& Smart, 2001; Batalha-Filho et al., 2012b; Behling et al., 2000; Costa, 2003; Oliveira et al., 1999; Wang et al., 2004). Porém, poucos estudos moleculares têm dado enfoque sobre a dinâmica destes contatos históricos (Batalha-Filho et al., 2012b; Costa, 2003; Cabanne et al., 2008; Fouquet et al., 2012; Martins et al., 2009). Além disso, embora algumas rotas históricas destes contatos tenham sido propostas (Andrade-Lima, 1982; Por, 1992; Willis, 1992), um estudo recente mostrou diferenças espaço-temporais na dinâmica destas conexões (Capítulo 6 da presente Tese).

No presente estudo nós realizamos uma análise filogeográfica multilocos de um pássaro (Thamnomanes caesius) que se distribui de maneira disjunta na AM e MA (Fig. 1). T. caesius ocorre por quase toda AM nas florestas de várzea e de terra firme, e na MA pelas florestas de baixada (até 80om) desde o Pernambuco até o norte do Rio de Janeiro (Ridgely \& Tudor, 1994; Zimmer \& Isler, 2003). Atualmente, cinco subespécies são reconhecidas com base em variação de plumagem e canto [Zimmer \& Isler (2003): T. c. ceasius, T. c. glaucus, T. c. persimilis, T. c. simillimus e T. c. hoffmannsi]. Além disso, a espécie possivelmente forma uma superespécie com $T$. schistogynus, que se distribui no leste do Peru, norte da Bolívia e oeste do Brasil (Ridgely \& Tudor, 1994; Zimmer \& Isler, 2003), ou seja, associado à área de endemismo Amazônica Inambari (Fig. 1).

Nas duas últimas décadas a filogeografia contribuiu de maneira significativa para o entendimento dos processos de diversificação da vida na terra (Beheregaray, 
2008; Hickerson et al., 2010), e criou uma ponte entre disciplinas até então divergentes, a macro e a microevolução (Avise, 2008). Também nos últimos anos, com a diminuição dos custos e facilitação do processo de sequenciamento, a filogeografia multilocos vem se tornando uma ferramenta robusta para inferir histórias evolutivas das espécies, pois o uso de vários locos tende a reduzir os ruídos associados à estocasticidade das genealogias gênicas em diferentes regiões do genoma (Brito \& Edwards, 2009). Ainda, a filogeografia de aves tem contribuído significativamente para a elucidação da história de diversificação da AM e MA, bem como testado hipóteses concorrentes de diversificação destes biomas (Aleixo, 2004; Aleixo \& Rosseti, 2007; Batalha-Filho et al., 2012a; Cabanne et al., 2007, 2008, 2011; d'Horta et al., 2011; Fernandes et al., 2012; Maldonado-Coelho, 2012; Ribas et al., 2012).

O presente estudo teve como objetivo analisar a filogeografia e a demografia histórica de T. caesius e T. schistogynus ao longo da bacia amazônica e do norte da MA utilizando-se genes mitocondriais e nucleares. Nossos resultados permitiram testar hipóteses de diversificação na $A M$ e revelaram diversificação recente no bioma. Ainda, nós inferimos sobre a dinâmica de conexões históricas entre a MA e a AM durante o Pleistoceno.

\section{Material e métodos}

\subsection{Amostragem e métodos moleculares}

Nossa amostragem de T. caesius consistiu de 70 amostras frescas (músculo e sangue) e 14 de peles de museu, em um total de 84 amostras, cobrindo a maioria da distribuição geográfica da espécie (Tab. 1, Fig. 1). A amostragem de T. schistogynus compreendeu 7 indivíduos, sendo duas amostras frescas e cinco de peles de museu (Tab. 1, Fig. 1). Amostras das outras duas espécies do gênero Thamnomanes foram sequenciadas para testar a monofilia do complexo T. caesius/T. schistogynus: quatro amostras de $T$. saturninus e seis de $T$. ardesiacus (Tab. 1). Nós também incluímos sequências do GenBank para o gene ND2 das espécies de Thamnomanes: T. caesius (Northwest District, Baramita, Guiana: EF030288), T. schistogynus (La Paz, Bolívia: HM637243), T. saturninus (EF640057) e T. ardesiacus (HM637242). Como grupo externo (Irestedt et al., 2004) utilizamos sequências de ND2 do GenBank das 
espécies Dichrozona cincta (EF640010), Dysithamnus mentalis (EF640012) e Hypocnemis cantator (EF640021).

O DNA total das amostras frescas foi extraído seguindo o protocolo de Bruford et al. (1992) e também com o kit Dneasy Extraction (Qiagen, CA). Nós sequenciamos o gene mitocondrial da subunidade 2 do NADH desidrogenase (ND2) e quatro íntrons nucleares: o íntron 2 do gene mioglobina (myo2), o íntron 11 do gene gliceroldeído-3-fosfato desidrogenase (G3PDH), o íntron 6 do gene tropomiosina (TPM1), e o íntron 3 do gene Transforming growth factor beta (TGFB2).

Para as amostras frescas nós usamos os seguintes primers: ND2 - Lmet e H6312 (Hackett, 1996; Cicero \& Johnson, 2001; respectivamente), myo2 - Myo2 e Myo3F (Slade et al., 1993; Heslewood et al., 1998; respectivamente), G3PDH G3PL890 e G3PH950 (Friesen et al., 1997), TPM1 - TPM1F e TPM1R (Primmer et al., 2002), e TGFB2 - TGFB2-5F e TGFB2-6R (Primmer et al., 2002). As amplificações foram conduzidas em termociclador GeneAmp Thermal Cycler 9700 (Applied Biosystems) em um mix de reação de $25 \mu \mathrm{L}$ com 50 ng de DNA total, $1 \mathrm{X}$ do tampão (Invitrogen), 0,32 $\mu \mathrm{M}$ de dNTPs, $1,6 \mathrm{mg} / \mathrm{mL}$ de albumina de soro bovino (BSA), 0,5 $\mu \mathrm{M}$ de cada primer e $1 \mathrm{U}$ de Taq polimerase (Invitrogen). As condições das amplificações foram as mesmas para todos os locos, variando somente a temperatura de hibridação dos primers (TH): um passo inicial de desnaturação a $94^{\circ} \mathrm{C}$ por 4 min.; seguido de 40 ciclos com $94^{\circ} \mathrm{C}$ por 40 seg., TH por 40 seg. e $72^{\circ} \mathrm{C}$ por 1 min.; e um passo final de extensão a $72^{\circ} \mathrm{C}$ por $9 \mathrm{~min}$. As THs foram: ND2 e myo2 $-58-52^{\circ} \mathrm{C}\left(2\right.$ ciclos a $58^{\circ} \mathrm{C}, 2$ ciclos a $56^{\circ} \mathrm{C}, 2$ ciclos a $54^{\circ} \mathrm{C}$ e 34 ciclos a $52^{\circ} \mathrm{C}$ ), G3PDH $63^{\circ} \mathrm{C}$, TPM1 $-62^{\circ} \mathrm{C}$ e TGFB2 $-57^{\circ} \mathrm{C}$. A purificação dos produtos de PCR e 0 sequenciamento utilizando os mesmos primers da amplificação das amostras frescas foram realizados pela Macrogen Inc. 
Tabela 1. Amostras de Thamnomanes spp.: espécie, localidade amostrada, tamanho amostral (N), coordenadas, coleção de depósito da amostra, código na coleção.

\begin{tabular}{|c|c|c|c|c|c|c|}
\hline Espécie & Localidade & $\mathbf{N}$ & Latitude & Longitude & Coleção & $\mathrm{N}^{\circ}$ tombo \\
\hline \multirow[t]{26}{*}{ Thamnomanes caesius } & Aripuanã, MT, BRA & 1 & -10.1667 & -59.4594 & LGEMA $^{a}$ & 456 \\
\hline & Juruena, MT, BRA & 1 & -10.3181 & -58.3589 & LGEMA $^{a}$ & 583 \\
\hline & Estrada Manacapuru-Novo Airão Km75, AM, BRA & 5 & -2.85 & -60.86666667 & LGEMA $^{\mathrm{a}}$ & $9576,9702,9652,9685,9709$ \\
\hline & Rio Quiuini, Barcelos, AM, BRA & 5 & -0.78333333 & -63.16666667 & LGEMA $^{a}$ & $9854,9855,9867,9869,9868$ \\
\hline & Rio Araca, Barcelos, AM, BRA & 6 & -0.41666667 & -62.93333333 & $\operatorname{LGEMA}^{\mathrm{a}}$ & $9959,9960,10018,10083,10084,10086$ \\
\hline & Vilhena, RO, BRA & 3 & -12.8336 & -60.1596 & LGEMA $^{a}$ & $12074,12079,12117$ \\
\hline & Jacareacanga, PA, BRA & 4 & -9.2262 & -56.99845 & LGEMA $^{a}$ & $12479,12539,13980,14038$ \\
\hline & Paranaita, MT, BRA & 5 & -9.32166667 & -56.78194444 & LGEMA $^{a}$ & $12735,12737,12739,13791,13834$ \\
\hline & Fazenda Geripá, Nova Bandeirantes, MT, BRA & 2 & -9.8497 & -57.8106 & $\operatorname{LGEMA}^{\mathrm{a}}$ & 12922,12923 \\
\hline & Aveiro, PA, BRA & 5 & -3.05 & -55.1833 & LGEMA $^{a}$ & $13075,13081,13143,13204,13250$ \\
\hline & Parna Pau Brasil, Porto Seguro, BA, BRA & 1 & -16.4497 & -39.0647 & LGEMA $^{\mathrm{a}}$ & 13400 \\
\hline & REBIO Sooretama, Sooretama, ES, BRA & 1 & -19.1969 & -40.0978 & LGEMA $^{a}$ & 13407 \\
\hline & Fazenda Maracau, Sinop, MT, BRA & 1 & -11.8642 & -55.5025 & LGEMA $^{\mathrm{a}}$ & MMC MT 08 \\
\hline & Pacangê, Plantações Michelin, Igrapiúna, BA, BRA & 4 & -13.86147222 & -39.23380556 & LGEMA $^{a}$ & $14786,14791,14908,14936$ \\
\hline & Rio Teles Pires, MT, BRA & 1 & -9.6 & $-55 \cdot 9$ & $\mathrm{ZMUC}^{\mathrm{a}}$ & 125863 \\
\hline & Pompeya, PN Yasuní, Napo, ECU & 6 & -0.63333 & -76.43333 & $\mathrm{ZMUC}^{\mathrm{a}}$ & $126328,126350,126356,126391,126407,126437$ \\
\hline & Melgaço, PA, BRA & 2 & -1.71667 & -50.75 & $Z_{M U C^{a}}$ & 128190,128211 \\
\hline & N Canelos, Pastaza, ECU & 1 & -1.53333 & -77.75 & $Z_{M U C}$ & 144088 \\
\hline & Margem esquerda do Rio Aripuanã, Rio Arauazinho, AM, BRA & 3 & -6.31666667 & -60.3 & INPA $^{a}$ & A481, A490, A497 \\
\hline & ESEC Juami-Japurá; margem direita do Rio Japurá, AM, BRA & 3 & -1.8261 & -66.5989 & $\mathrm{INPA}^{\mathrm{a}}$ & $A 642, A 705, A 713$ \\
\hline & São Gabriel da Cachoeira, AM, BRA & 2 & 0.13333333 & -67.08333333 & $\mathrm{INPA}^{\mathrm{a}}$ & A1131, A1195 \\
\hline & Margem esquerda do Rio Demini, Comunidade Samaúma, AM, BRA & 1 & -0.9747 & -62.9242 & INPA $^{a}$ & $\mathrm{~A} 1268$ \\
\hline & RDS Amanã, Igarapé do Baré, AM, BRA & 1 & -1.59527778 & -62.73611111 & INPA $^{a}$ & A1313 \\
\hline & Santa Isabel do Rio Negro, margem esquerda do Rio Preto, AM, BRA & 1 & 0.4 & -65.03333333 & INPA $^{a}$ & A 1633 \\
\hline & Caracarai, margem direita do Rio Branco, Vicinal Aporui, RR, BRA & 1 & 1.8161 & -61.1281 & $\mathrm{INPA}^{\mathrm{a}}$ & A1704 \\
\hline & Resex Baixo Juruá, margem direita do baixo Rio Juruá, AM, BRA & 1 & -3.6 & -66.06666667 & $I_{N P A}{ }^{a}$ & A80o \\
\hline
\end{tabular}


Parque Nacional do Jaú, margem esquerda Rio Jaú, AM, BRA Rio Purus, Labrea, AM, BRA

Rio Solimões, Codajas, AM, BRA

Rio Amazonas, Igarapé Aniba, BRA

Rio Tapajós, Marai, PA, BRA

Rio Purus, Redempção, AM, BRA

Rio Purus, Itaboca, AM, BRA

Thamnomanes schistogynus Rio Eiru, Santo Antonio, AM, BRA

Rio Madre de Dios, Beni, Victoria, BOL

Rio Moaco, margem direita, AM, BRA

Sajta, Cochabamba, ECU

Thamnomanes saturinus

Fazenda Geripá, Nova Bandeirantes, MT

Paranaíta, MT

Thamnomanes ardesiacus
$3 \quad-1.95$

$4-7.26666667$

$4-3.13333333$

$-2.91666667$

$-2.73333333$

$-4.96666667$

$1-4.88333333$

$2-6.7$

$-10.98333333$

$-8.36979167$

$-17.1$
$-61.8167$

$-60.01666667$

$-58.55$

$-54.68333333$

$-62.58333333$

$-62.68333333$

$-66.16666667 N R M^{b}$

$-69.44242778$

$-64.75$

INPA $^{a}$

$N R M^{b}$

$R M^{b}$

$N R M^{b}$

b

26/11/1935

26/9/1936, 29/9/1936

13/10/1937, 1/11/1937, 2/11/1937

INPA $^{\mathrm{b}} \quad \mathrm{A} 1413$

ZMUC $^{\mathrm{b}} \quad 126220$

LGEMA $^{\text {a }} \quad 12897,12939$

LGEMA $^{\text {a }} \quad 13880,1440$

ZMUC $^{\mathrm{a}} \quad 126428$

ZMUC $^{\mathrm{a}} \quad 127992$

ZMUC $^{\mathrm{a}} \quad 126451,126340$

INPA $^{\mathrm{a}} \quad \mathrm{A} 181$

INPA $^{\text {a }} \quad$ A1181

Margem direita do Rio Negro, São Gabriel da Cachoeira, AM, BRA

37 rd km SE Pompeya, PN Yasuní, Napo, ECU

a amostra fresca; ${ }^{b}$ amostra de museu; LGEMA - Laboratório de Genética e Evolução Molecular de Aves, Instituto de Biociências, Universidade de São
Paulo; INPA - Instituto Nacional de Pesquisas da Amazônia; ZMUC - Zoological Museum, University of Copenhagen; NRM - Swedish Museum of Natural
History.

History. 


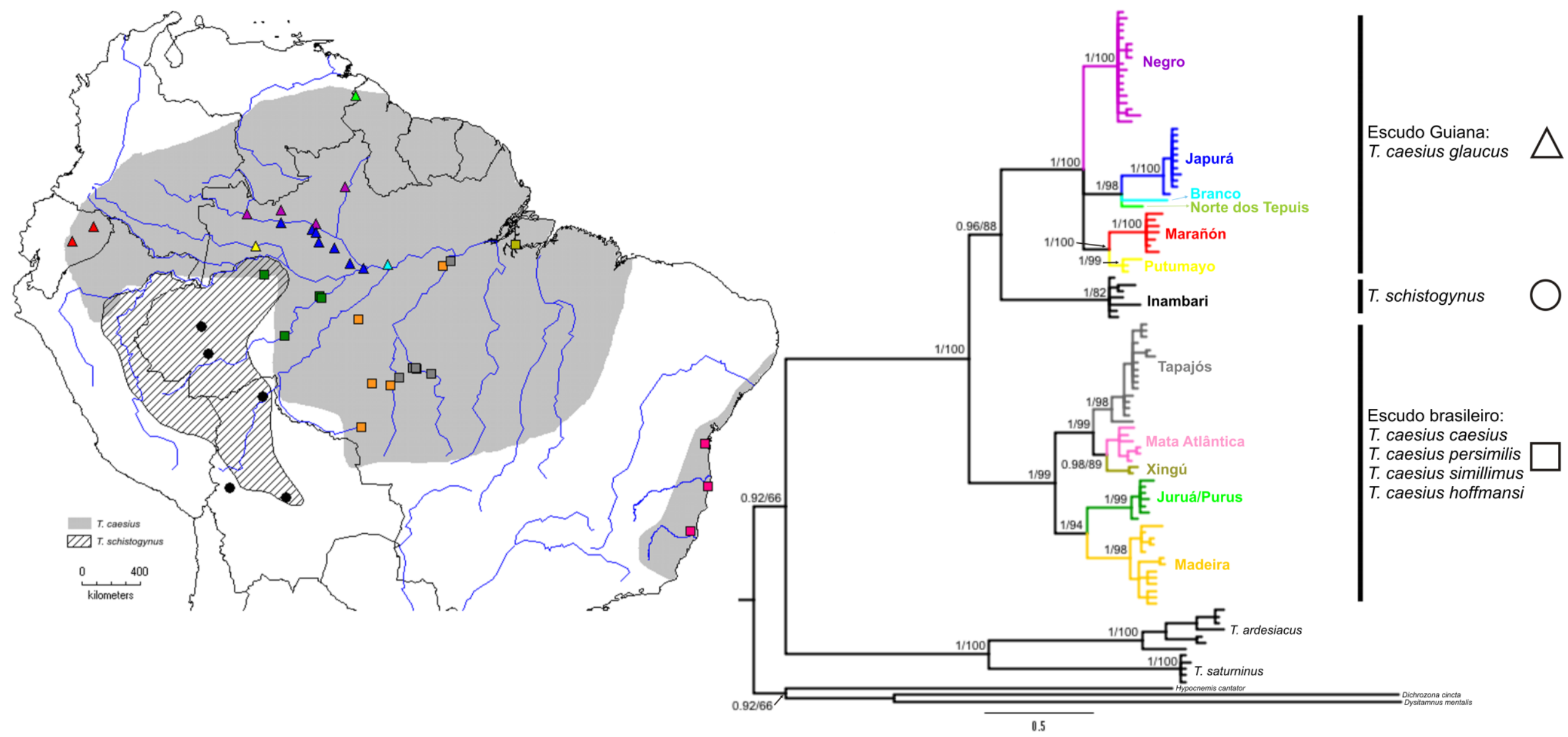

Figura 1. Mapa com distribuição geográfica das amostras e topologia da inferência Bayesiana para 1030 pb do ND2 de T. caesius e T. schistogynus mais grupos externos. No mapa os símbolos representam os pontos amostrados. Os símbolos e suas cores estão de acordo com a árvore. As distribuições geográficas das espécies são baseadas em Ridgely \& Tudor (1994). Os suportes dos ramos mostram valores de probabilidade posterior do MrBayes e valores de bootstrap do RAxML, respectivamente. 
Os procedimentos laboratoriais para extração, amplificação e sequenciamento do DNA das amostras de pele de museu seguiram Irestedt et al. (2006). Para o G3PDH foram utilizados os mesmos primers das amostras frescas. Para as amplificações dos demais genes foram desenhados primers internos específicos, sendo o ND2 divido em seis fragmentos, o TGFB2 em dois, e o TPM1 e myoz em três (Tab. 2).

Tabela 2. Primers utilizados no presente estudo e suas sequências e referências.

\begin{tabular}{|c|c|c|c|}
\hline Nome do primer & Gene & Sequencia 5' $\rightarrow$ 3' & Referência \\
\hline ND2-ThamnF2 & ND2 & ACCACCCACGAGCTATTGAAG & Presente estudo \\
\hline ND2-ThamR1 & ND2 & CTGAGGCAGTTGCTTGGACTA & Presente estudo \\
\hline ND2-ThamR2 & ND2 & ATGTGCCTTGGAGGACTTCTG & Presente estudo \\
\hline ND2-ThamnF3 & ND2 & GGATTAGTCCCATTTCACTTTTGAT & Presente estudo \\
\hline ND2-ThamR3 & ND2 & GCTAGGATCTTACGGGTTTG & Presente estudo \\
\hline ND2-ThamnF4 & ND2 & CTGAGCCGGACTAAACCAAAC & Presente estudo \\
\hline ND2-ThamR4 & ND2 & TGCAGTTAATGAGGGGATTTTTGT & Presente estudo \\
\hline ND2-ThamnF5 & ND2 & 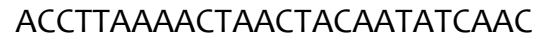 & Presente estudo \\
\hline ND2-ThamR5 & ND2 & TAGGCAAGGCGGAGGTAAAAG & Presente estudo \\
\hline ND2-ThamF6 & ND2 & САТАСТАТСССТАСТСGGACTT & Presente estudo \\
\hline Lmet & ND2 & TATCGGGCCCATACCCCGAAAAT & Hackett (1996) \\
\hline $\mathrm{H} 6312$ & ND2 & CTTATTTAAGGCTTTGAAGGCC & Cicero \& Johnson (2001) \\
\hline Myo-ThamnF1 & myo2 & GAGGTATGGAAAAGGACAAGGA & Presente estudo \\
\hline Myo-ThamnF2 & myo2 & TTTCCСАTTCCAAACACCACACA & Presente estudo \\
\hline Myo-ThamnF2b & myo2 & AAGTCCAAGGTCTCTGTGTACA & Presente estudo \\
\hline Myo-ThamnF3 & myo2 & TGAGGAAGACAAAAAGTGGACAG & Presente estudo \\
\hline Myo-ThamnR1 & myo2 & TTGTTGTCAAGGGTTAGTCAGAC & Presente estudo \\
\hline Myo-ThamnR2 & myo2 & СТTCATGACСTTGCAAAGACCAT & Presente estudo \\
\hline Myo-ThamnR3 & myo2 & GAAATGAACTGTGAGGAAGGAAAG & Presente estudo \\
\hline TPM-ThamnF1 & TPM1 & GATAAGGTACTGAGACTAATGAAC & Presente estudo \\
\hline TPM-ThamnF2 & TPM1 & АССТССТGTGCAGCCAAAAGA & Presente estudo \\
\hline TPM-ThamnF3 & TPM1 & TTGCTTTGAATCTGTGATGGATCA & Presente estudo \\
\hline TPM-ThamnR1 & TPM1 & AGCTTTTACACGTGAGACAGTTC & Presente estudo \\
\hline TPM-ThamnR2 & TPM1 & GAAAATAGAGGGAAGAGATAGAGA & Presente estudo \\
\hline TPM1R & TPM1 & TCCTCTTCAAGCTCAGCACA & Primmer et al. (2002) \\
\hline TGFB2-5F & TGFB2 & GAAGCGTGCTCTAGATGCTG & Primmer et al. (2002) \\
\hline TGFB2-6R & TGFB2 & AGGCAGCAATTATCCTGCAC & Primmer et al. (2002) \\
\hline TGFB2-ThamnF1 & TGFB2 & AGATGCTGCCTATTGTTTTAGGT & Presente estudo \\
\hline TGFB2-ThamnR1 & TGFB2 & CCAGGTCCTACAGAGAAGACT & Presente estudo \\
\hline
\end{tabular}

\subsection{Edição das sequências, reconstrução alélica nuclear e teste de recombinação}

Os eletroferogramas foram verificados e editados e sequências consenso foram obtidas utilizando o programa Codoncode Aligner v.3.7 (Codoncode Inc.). 
Essas sequências foram alinhadas utilizando-se o método CLUSTAL W (Higgins et al., 1994) no programa MEGA5 (Tamura et al., 2011). Todos os alinhamentos foram inspecionados e corrigidos visualmente.

As sequências de indivíduos heterozigotos para os locos FIB5 e myo2 foram inicialmente codificadas com o código de nucleotídeos ambíguos da IUPAC onde houvesse picos duplos em ambas as fitas. As sequências nucleares de indivíduos heterozigotos de inserção ou deleção (indel) para ambos os locos foram resolvidas utilizando-se o algoritmo Process Heterozigous Indels do programa Codoncode Aligner v.3.7. Para a reconstrução dos alelos para os indivíduos heterozigotos dos íntrons nucleares foi utilizado o algoritmo PHASE (Stephens et al., 2001) no modo default no programa DnaSP 5 (Librado \& Rozas, 2009). Para as análises foram considerados somente haplótipos com alta probabilidade no PHASE $(p>0,6)$, e os demais indivíduos com baixa probabilidade foram removidos das análises seguintes. O teste PHI foi aplicado para testar a hipótese de presença de sinal de recombinação dos íntrons nucleares no programa SPLITSTREE4 (Bruen et al., 2006; Huson \& Bryant, 2006).

\subsection{Estrutura genética}

Para inferir o grau de estrutura genética em T. caesius e T. schistogynus com base no gene mitocondrial ND2 nós estimamos as relações filogenéticas por inferência Bayesiana e máxima verossimilhança nos programas MrBayes 3.1.2 (Huelsenbech \& Ronquist, 2001) e RAxML-HPC 7.3.0 (Stamatakis et al., 2008), respectivamente. O modelo de substituição GTR + G (Tavaré, 1986) foi usado para o ND2, conforme estimado pelo MrModeltest (Nylander, 2004) com o critério de informação de Akaike (AIC). As inferências Bayesianas consistiram de duas corridas com 10 milhões de gerações cada, sendo cada uma com quatro Monte Carlo Markov chains (MCMC). Foram excluídas 500.000 gerações iniciais como período de burn in, e as árvores foram amostradas a cada 500 gerações após este período. O diagnóstico de convergência entre as cadeias foi verificado no PSRF (Potential scale reduction factor), onde valores próximos de 1 indicaram bom desempenho da análise. A análise máxima verossimilhança foi implementada com o modelo de substituição GTR (Tavaré, 1986), onde o percentual de sítios invariáveis (I) e a 
distribuição gama (G) foram otimizados durante a análise. As topologias Bayesiana e de máxima verossimilhança foram visualizadas no programa FigTree 1.3.1 (http://tree.bio.ed.ac.uk/software/figtree/). As análises filogenéticas foram implementadas no portal CIPRES Science Gateway (Miller et al., 2010).

As relações entre os haplótipos para cada íntron nuclear foram inferidas por meio de redes de haplótipos pelo método median-joining network (Bandelt et al., 1999) no programa NETWORK 4.6.1.0 (www.fluxus-engineering.com). Para inferir o grau de estrutura genética com base nos íntrons nucleares combinados nós implementamos o método de agrupamento Bayesiano do programa Structure 2.3.3 (Pritchard et al., 2000, 2010). Este método utiliza inferência Bayesiana baseada nas frequências genotípicas multilocos para inferir o número mais provável de grupos (k) sem assumir um número pré-determinado. Nós rodamos as análises assumindo que as frequências genotípicas entre as populações não são correlacionadas, e o modelo Admixture. As análises foram geradas testando-se o número de $\mathrm{k}$ variando de 1 a 10, e repetindo cada um destes 10 vezes. Cada corrida de k consistiu de 6 milhões de gerações de $M C M C$, sendo que $01^{\circ}$ milhão foi usado como burn-in. Para se obter o número mais provável de $k$ foi estimado o $\operatorname{Pr}(k)$ pela regra de Bayes conforme Pritchard et al. (2010) utilizando-se os valores médios de log-likelihood das probabilidades posteriores das dez corridas para cada k. Nós então combinamos as 10 corridas do $\mathrm{k}$ mais provável pelo programa CLUMPP 1.1.2 (Jakobsson \& Rosenberg, 2007) com o algoritmo Greedy com 1000 permutações.

\subsection{Estatísticas sumárias e análises de demografia histórica}

Foram estimadas as seguintes estatísticas sumárias para cada gene no DnaSP 5: diversidade nucleotídica por sítio $(\pi)$ e o número de haplótipos (h). Nós também inferimos possíveis eventos de expansão demográfica pelo método Bayesiano coalescente Extended Bayesian Skyline Plot (EBSP; Heled \& Drummond, 2008) que é implementado no BEAST 1.6.2 (Drummond \& Rambaut, 2007). Este método reduz o efeito da estocasticidade do processo coalescente combinando diferentes genes em uma abordagem não-paramétrica de coalescência das diferentes árvores de genes para se estimar a variação do tamanho efetivo populacional ao longo do tempo (Ho \& Shapiro, 2011). Foram realizadas duas corridas independentes do EBSP 
com 150 milhões de gerações de MCMC para cada filogrupo mitocondrial com 6 ou mais indivíduos amostrados. Essas corridas seguiram os seguintes parâmetros: uma árvore inicial de UPGMA, modelo linear, parâmetros amostrados a cada 10000 gerações, e burn-in de 10\%. O teste hLRT implementado pelo MEGA5 não rejeitou a hipótese do relógio molecular $(p<0,05)$ para todos os genes em todos os filogrupos. Assim, nós utilizamos o prior strict clock. O modelo evolutivo para cada gene em cada filogrupo foi estimado pelo MrModeltest 2.2 com AIC. Como calibração para a análise nós utilizamos a taxa de mutação conhecida para o DNA mitocondrial em aves de 1,05\% ( \pm 0,05\%) por sítio por linhagem por milhão de anos (Weir \& Schluter, 2008) sob um prior com distribuição normal. Então o BEAST estimou a taxa de mutação para cada íntron individualmente sob um prior lognormal com os parâmetros default. O desempenho da MCMC e a convergência entre as corridas foram analisados no TRACER 1.5 (http://beast.bio.ed.ac.uk/Tracer) para verificar que os valores de ESS (Effective Sample Size) eram maiores que 200.

\section{4 Árvore de espécies (Species Tree) e tempos de divergências}

Com o intuito de combinar todos os genes analisados em uma única árvore e acomodar as inconsistências entre árvore genes e árvore de espécies (Degnan \& Rosenberg, 2006; Kubatko \& Degnan, 2007), nós usamos o método Bayesiano coalescente do *BEAST (Bayesian Inference of Species Trees from Multilocus Data; Heled \& Drummond, 2010) no programa BEAST 1.6.2 (Drummond \& Rambaut, 2007) no Bioportal da University of Oslo (Kumar et al., 2009). Nós atribuímos os filogrupos mitocondriais observados em T. caesius e T. schistogynus (Fig. 1) como "espécies" na estimativa. O clado do Norte dos Tepuis não foi incluído nesta análise pelo fato de possuir somente a sequência do gene ND2, e somente para uma amostra. Nós incluímos as outras espécies de Thamnomanes (T. ardesiacus e T. saturninus) como grupos externos. Nós também estimamos o tempo de divergência entre os filogrupos utilizando o método de coalescência multiespécies do *BEAST, uma vez que um estudo recente mostrou que este método é mais acurado que aqueles baseados somente em árvores de genes (McCormack et al., 2011). O arquivo de entrada do programa foi gerado pelo BEAUTi considerando-se cinco partições (ND2, G3PDH, myo2, TGFB2 e TPM) e os modelos de substituição foram estimados para 
cada partição pelo MrModeltest 2.2 com o AIC. Como o teste hLRT implementado pelo MEGA5 rejeitou a hipótese do relógio molecular $(p<0,05)$ para todos locos nós utilizamos o prior uncorrelated lognormal relaxed clock. Nós usamos os priors Yule process e Piecewise linear and constant root. A calibração da análise foi feita da mesma maneira que na estimativa do EBSP. Foram realizadas duas corridas independentes cada uma com 100 milhões de gerações de MCMC com os parâmetros sendo amostrados a cada 10000 gerações, e um burn-in de 10\%. O desempenho da MCMC e a convergência entre as corridas foram analisados no TRACER 1.5 para verificar que os valores de ESS foram maiores que 200. As árvores resultantes da análise foram combinadas pelo TreeAnotator e a árvore de espécies com os tempos de divergência foi visualizada no programa FigTree 1.3.1.

\section{Resultados}

\subsection{Características das sequências}

Foi obtida uma matriz de dados com 3182 pb para o grupo interno, sendo $1030 \mathrm{pb}$ do ND2 (N=90), 640 pb do myo2 ( $=67), 396$ pb do G3PDH ( $=77), 608$ pb do TGFB2 (N=79), e 508 pb do TPM1 ( $=81)$. No ND2 foram observados 178 sítios polimórficos que resultaram em 54 haplótipos. Foram observados 37 sítios variáveis no myo2, 46 no G3PDH, 43 no TGFB2 e 37 TPM1. Não foram observados indels nas sequências mitocondriais e na tradução para aminoácidos não foi observado nenhum códon de parada, sugerindo que são sequências mitocondriais. Porém em 3 íntrons nucleares foram observados indels: myoz - 1 indel de $61 \mathrm{pb}$ (somente em T. schistogynus), 1 de 3 pb, e 2 de 1 pb; G3PDH - 2 indels de 3 pb, 1 de 4 pb, e 1 de 1 pb; TPM1 - 1 indel de 2 pb, e 1 de 1 pb.

A reconstrução alélica pelo PHASE resolveu com alta probabilidade $(p>0,6)$ 120 cromossomos amostrados para o my02, 130 para o G3PDH, 138 para o TGFB2 e 136 para o TPM1. Estes deram origem a 28, 28, 32 e 33 haplótipos no myo2, G3PDH, TGFB2 e TPM1, respectivamente. O teste PHI não encontrou evidências significativas de recombinação nos íntrons analisados (myo2 p=0,317; G3PDH p=0,873; TGFB2 $p=0,253 ;$ TPM1 $p=0,118)$. A diversidade nucleotídica para cada um dos locos está apresentada na figura 2. 


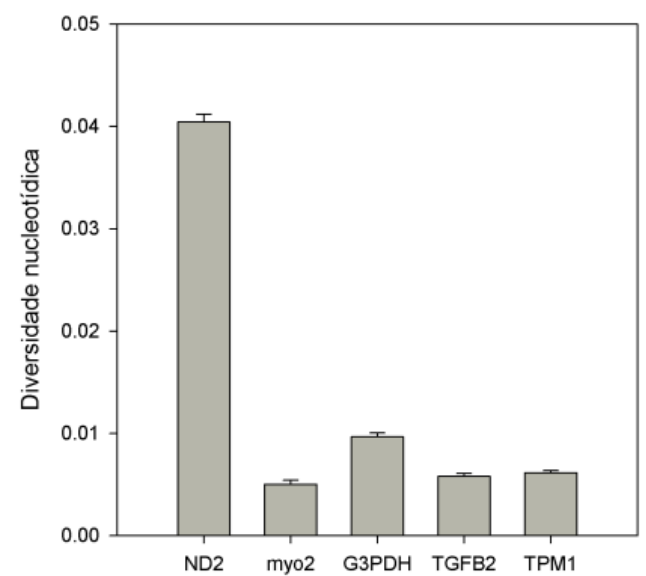

Figura 2. Estimativas e desvios padrões da diversidade nucleotídica por sítio $(\pi)$ para os locos analisados.

\subsection{Estrutura filogeográfica}

As reconstruções filogenéticas para o gene mitocondrial ND2 mostraram que a superespécie T. caesius/schistogynus é reciprocamente monofilética (Fig. 1). Além disso, a topologia recuperou 12 clados bem suportados em $T$. caesius e $T$. schistogynus referente a MA e a cada grande interflúvio da bacia Amazônica (Fig. 1):

1. Negro - clado do interflúvio entre os rios Negro e Branco;

2. Japurá - clado do interflúvio entre os rios Japurá e Negro;

3. Branco - clado do interflúvio à margem esquerda do Rio Branco;

4. Norte dos Tepuis - clado das amostras ao norte do Tepuis Amazônicos;

5. Marañón - clado do interflúvio entre os rios Marañón e Putumayo;

6. Putumayo - clado do interflúvio entre os rios Putumayo e Japurá;

7. Inambari - clado da espécie T. schistogynus concordante espacialmente com a área de endemismo Inambari;

8. Tapajós - clado do interflúvio entre os rios Tapajós/Juruena e Madeira;

9. Xingú - clado do interflúvio entre os rios Xingú e Tocantins/Araguaia;

10. Juruá/Purus - clado dos interflúvios entre os rios Juruá e Amazonas, Juruá e Purus, e Purus e Madeira;

11. Madeira - clado do interflúvio entre os Madeira e Tapajós/Juruena;

12. Mata Atlântica - clado das amostras da Mata Atlântica;

Outro aspecto interessante revelado pela topologia do ND2 (Fig. 1) foi a existência de estrutura genética concordante com as clássicas áreas de endemismo propostas para a Amazônia (Cracraft, 1985; Silva et al., 2005). Sendo que os clados 
referidos acima correspondem às seguintes áreas: clados 1, 3 e 4 área de endemismo Guiana; clado 2 área de endemismo Imeri; clados 5 e 6 área de endemismo Napo; clados 7 e 10 área de endemismo Inambari; clado 11 área de endemismo Rondônia; clado 8 área de endemismo Tapajós; clado 9 área de endemismo Xingú; clado 12 área de endemismo Mata Atlântica. Entretanto, algumas destas áreas não se apresentaram como reciprocamente monofiléticas, como por exemplo, a área Guiana foi recuperada em três clados, sendo um à margem esquerda ("Branco"; Fig.1) e outro à margem direita do rio Branco ("Negro"; Fig.1) e o terceiro com amostras do norte dos Andes venezuelanos ("Norte dos Tepuis"; Fig. 1). Ainda, a área de endemismo Inambari foi parafilética, com um clado mais basal ( $T$. schistogynus) e um clado mais recente (Juruá/Purus). Este resultado aponta para uma possível dispersão seguida de vicariância que deu origem ao clado Juruá/Purus, pois quando da origem deste clado o Rio Madeira já havia se estabelecido (Fig. 1).

Nas divergências mais basais foi observada a presença de três grupos: um correspondente a T. schistogynus, e dois compreendendo amostras de T. caesius, sendo um referente aos espécimes do norte do rio Amazonas, e o outro aos espécimes do sul do rio Amazonas juntamente com os da Mata Atlântica. Interessantemente, T. caesius não foi monofilético na topologia do ND2 (embora com suportes de ramo moderados), ao passo que o grupo do norte amazônico, referente à subespécie $T$. caesius glaucus, foi irmão de $T$. schistogynus, e ficando o grupo do sul do Rio Amazonas junto com a MA (Fig. 1). Na distribuição do clado sul amazônico 4 subespécies são reconhecidas (Zimmer \& Isler, 2003), contudo a estrutura genética detectada não foi totalmente congruente com estas subespécies.

As redes de haplótipos dos quatro genes nucleares (Fig. 3) recuperam as divergências mais basais obsevadas no DNA mitocondrial (Fig. 1) referente aos clados de T. caesius ao norte e ao sul do rio Amazonas e T. schistogynus. Todos os íntrons, com exceção do myo2, mostraram compartilhamento de haplótipos entre estes clados (Fig. 3). Surpreendentemente, os íntrons G3PDH e myo2 recuperaram uma estrutura genética considerável para as amostras provenientes da MA (Fig. 3), 
uma vez que estes marcadores apresentam taxas de evolução muito mais lentas que o DNA mitocondrial, e esta divergência parace ter sido recente.

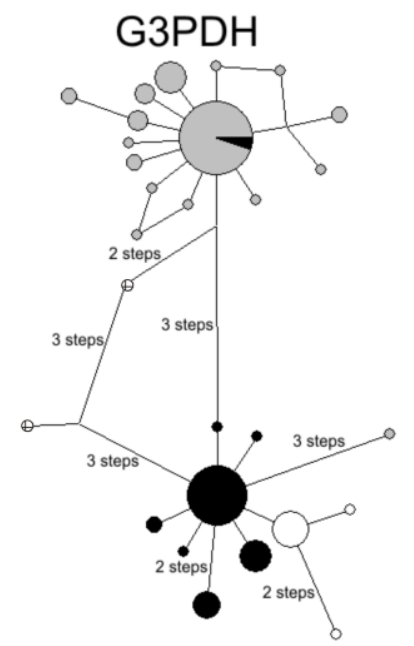

TGFB2

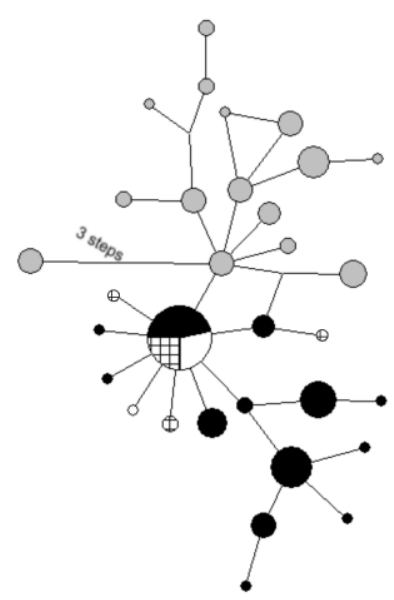

myo2

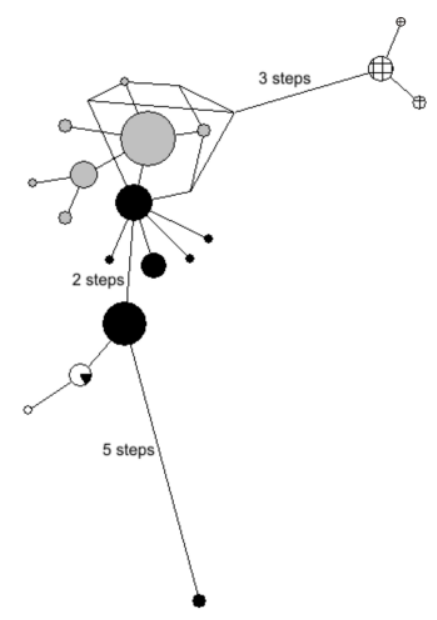

TPM1

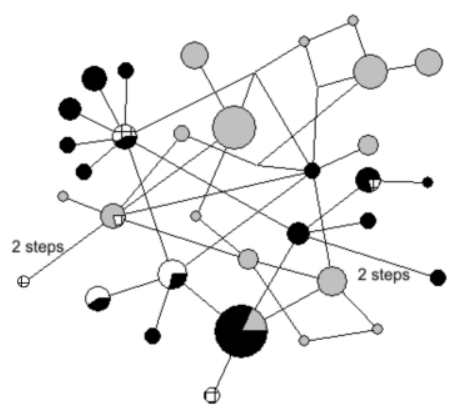

Sul do Rio Amazonas

Norte do Rio Amazonas

$\square$ Mata Atlântica

Figura 3. Redes de haplótipos para os íntrons nucleares. Nas redes de haplótipos cada círculo representa um haplótipo e seu tamanho representa sua frequência. Nas redes, cada círculo representa um haplótipo e seu tamanho representa sua frequência. As linhas representam as relações entre os haplótipos que diferem em uma mutação. Números nas linhas representam mutações adicionais. As cores representam os clados mitocondriais conforme legenda na figura.

A análise de todos os íntrons nucleares em conjunto pelo Structure mostrou com base na estimativa da regra de Bayes $[\operatorname{Pr}(k)]$ que o número mais provável de $\mathrm{k}$ é 4, embora k=5 não possa ser descartado, pois este apresentou um valor médio de log-likelihood muito próximo do estimado para $k=4$ (Tab. 2). Além disso, quando k=4 T. schistogynus não é recuperado como uma população independente, ao contrário se $k=5$. Assim, nós apresentamos os gráficos dos coeficientes de ancestralidade ( $q$ ) para estas duas estimativas de k (Fig. 4). Ambos os gráficos de q (Fig. 4) recuperam as divergências mais basais observadas na filogenia mitocondrial (Fig. 1), porém com 
mais resolução que as redes de haplótipos baseadas nos íntrons individuais (Fig. 3). A única diferença entre os gráficos do $k=4$ e $k=5$ é a inclusão de $T$. schistogynus em um grupo único com k=5. Ainda, alguns indivíduos apresentaram altas taxas de Admixture, o que pode ser devido a fluxo gênico ou retenção de polimorfismo ancestral.

Tabela 2. Médias $[\log L(k)]$ e desvios padrões (dp) dos valores de log-likelihood e estimativa da regra de Bayes $[\operatorname{Pr}(k)]$ para as dez corridas de cada $k$ testado no Structure para T. caesius e T. schistogynus.

\begin{tabular}{cccc}
\hline $\mathbf{k}$ & $\log \mathrm{L}(\mathbf{k})$ & $\mathbf{d p}$ & $\operatorname{Pr}(\mathbf{k})$ \\
\hline 1 & $-1629,3$ & 0 & 0 \\
2 & $-1428,68$ & 0,078881 & 0 \\
3 & $-1375,63$ & 0,133749 & 0 \\
4 & $-1357,75$ & 0,164992 & 1 \\
5 & $-1357,89$ & 0,228279 & 0 \\
6 & $-1376,79$ & 0,264365 & 0 \\
7 & $-1393,31$ & 0,166333 & 0 \\
8 & $-1409,02$ & 0,297396 & 0 \\
9 & $-1424,14$ & 0,245855 & 0 \\
10 & $-1439,47$ & 0,279086 & 0 \\
\hline
\end{tabular}

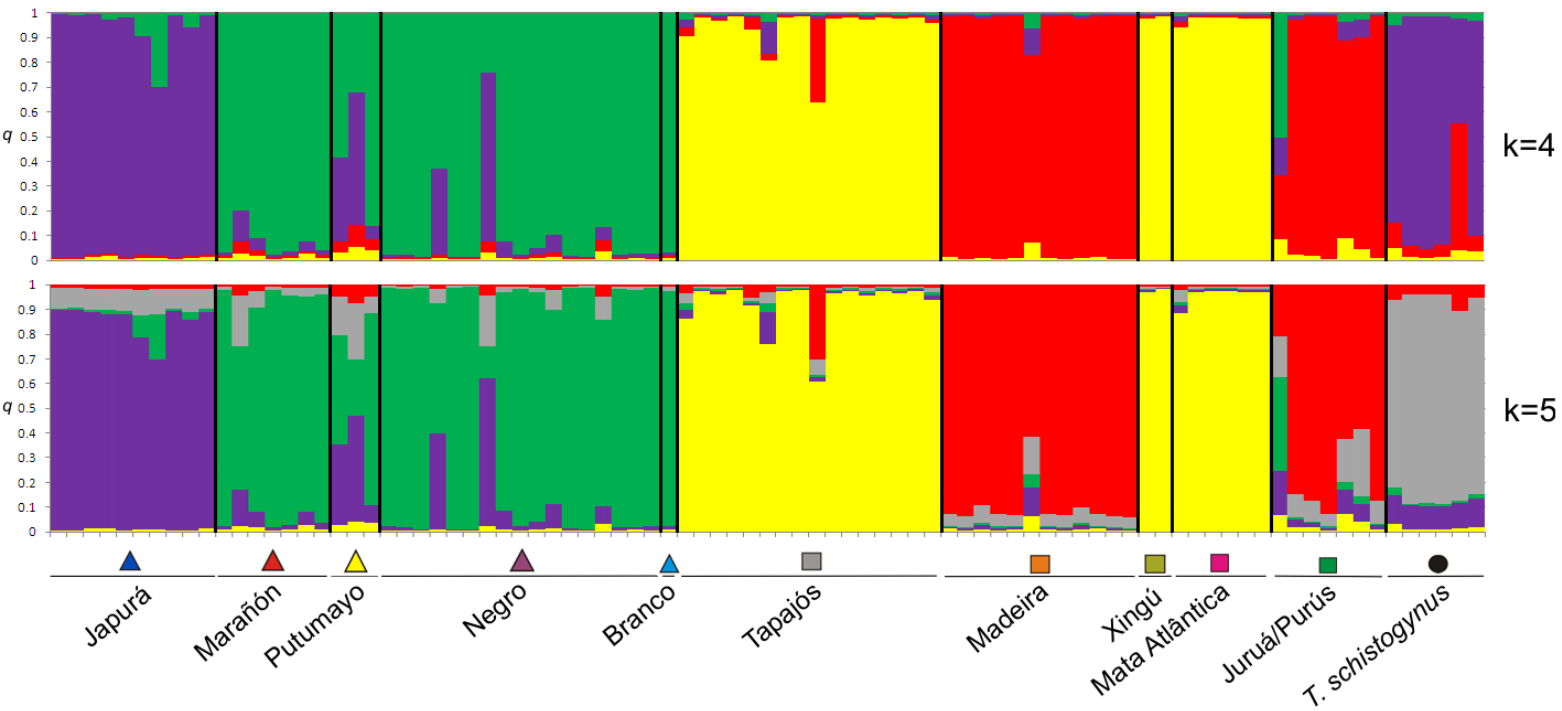

Figura 4. Gráficos com os coeficientes de ancestralidade (q: probabilidade de cada indivíduo pertencer a uma das populações estimadas) das amostras de $T$. caesius e $T$. schistoynus estimados pelo Structure. As cores representam os grupos estimados para cada um dos valores de k. Cada coluna representa um indivíduo e as legendas do eixo $\mathrm{X}$ seguem os clados mitocondriais conforme figura 1.

\subsection{Demografia histórica}

As estimativas da variação do tamanho efetivo populacional $(\mathrm{Ne})$ ao longo do tempo com base em todos os locos combinados pelo EBSP evidenciaram expansão 
demográfica nos clados Negro e Tapajós (Fig. 5). Contudo se considerarmos somente as medianas, a despeito dos largos intervalos de confiança, também é possível notar sinais de expansão demográfica nos clados Mata Atlântica, Marañón, Juruá/Purus e Madeira (Fig. 5). Ainda em todos os EBSP que detectaram expansão demográfica esta foi datada tendo início por volta de 10 mil anos atrás (Fig. 5).
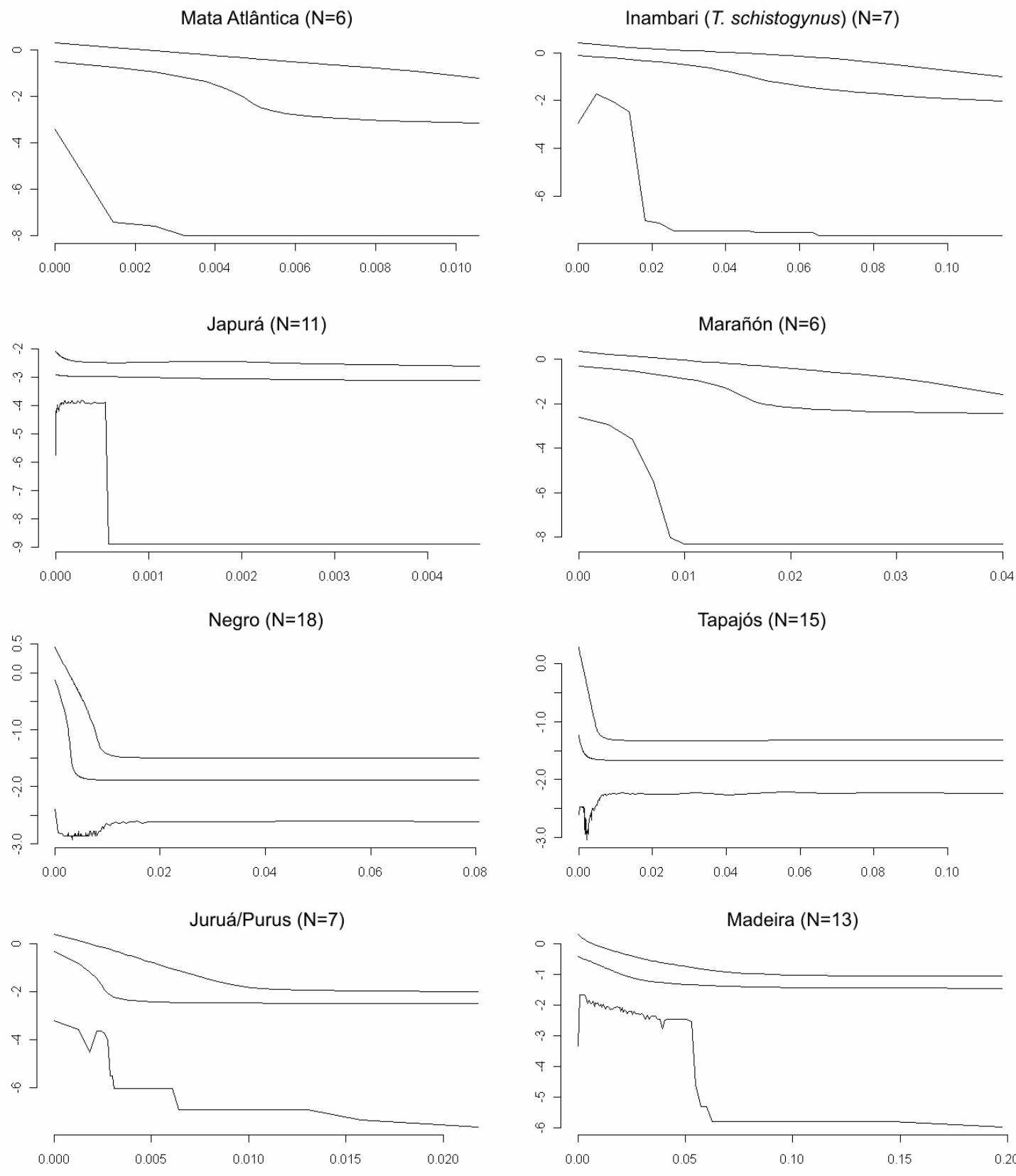

Figura 5. Estimativas do Extended Bayesian Skyline Plot (EBSP) para os filogrupos mitocondriais (Fig. 1) de $T$. caesius e T. schistogynus. A linha do meio representa a mediana da estimativa, e as linhas superior e inferior os limites superior e inferior de $95 \%$ de HPD (highest posterior density), respectivamente. $\mathrm{O}$ eixo $\mathrm{Y}$ está em escala logarítmica e representa o tamanho efetivo populacional $\mathrm{x}$ o tempo de geração. $O$ eixo $X$ representa o tempo em milhão de anos. 


\section{4 Árvore de espécies e tempos de divergência}

A árvore de espécies gerada pelo *BEAST (Fig. 6) foi parcialmente congruente com as reconstruções filogenéticas com base no ND2 (Fig. 1). Uma das incongruências foi a posição de T. schistogynus em relação aos dois clados mais profundos de T. caesius, pois na árvore de espécies T. schistogynus agrupou como basal aos dois clados de T. caesius, ao passo que na topologia do ND2 ele foi irmão do clado norte do Rio Amazonas. Porém nestas duas análises os ramos referentes a estes agrupamentos não apresentaram suporte máximo (Fig. 1 e Fig. 6). A outra incongruência foi a relação entre os clados Negro, Marañón e Putumayo, pois na árvore de espécies os dois últimos agruparam como irmãos e Negro como irmão deste agrupamento, ao passo a filogenia do ND2 só recuperou Marañón e Putumayo como e irmãos (Fig. 1 e 6). Contudo, a maioria dos ramos na árvore de espécies apresentou alto suporte, sendo que o menor valor de probabilidade posterior foi 0,73 (Fig. 6).

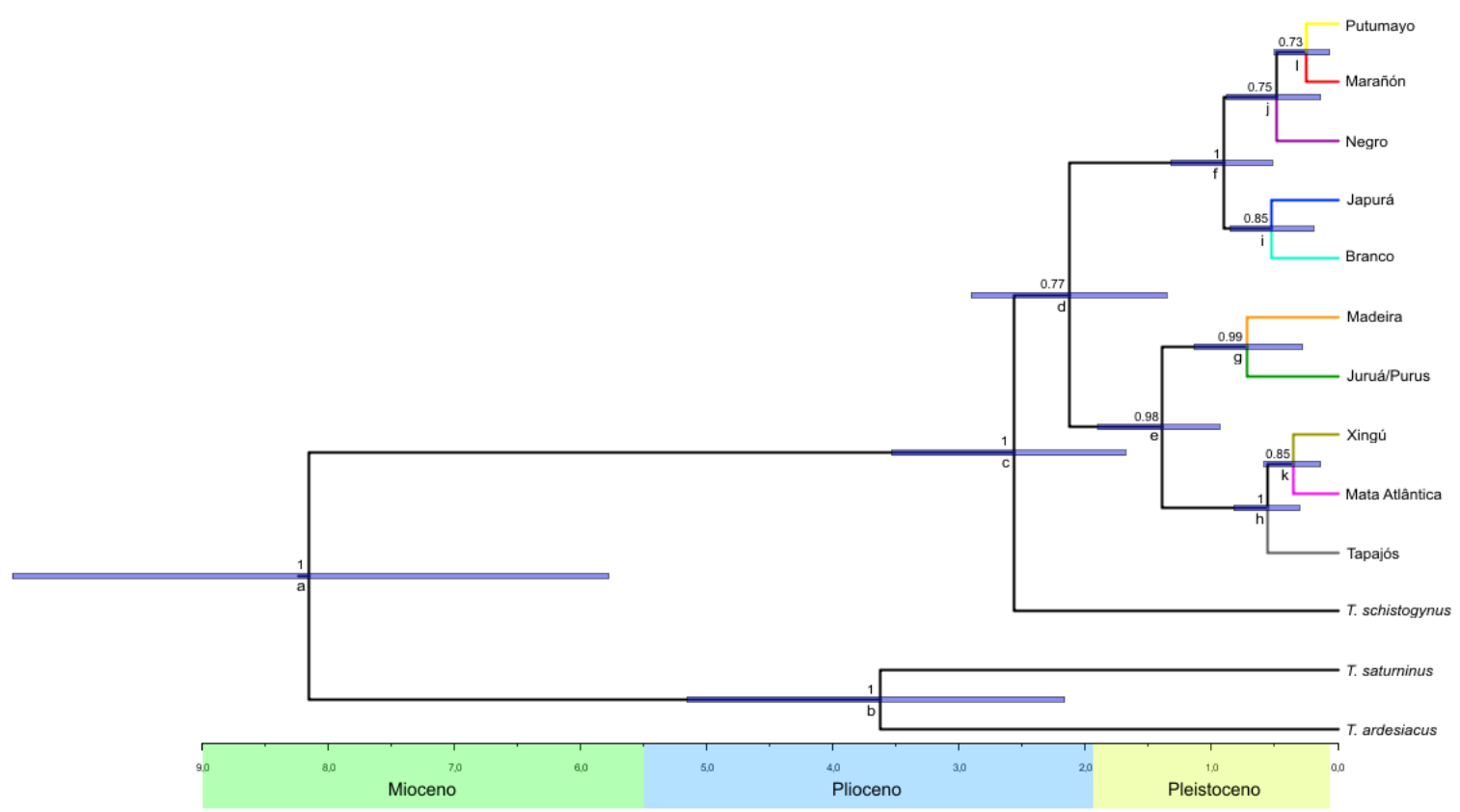

Figura 6. Topologia da árvore de espécies com os tempos de divergência dos clados mitocondriais de T. caesius e T. schistogynus gerada pelo *BEAST. Números presentes em cada nó são valores de probabilidade posterior do agrupamento. As letras presentes em cada nó são os tempos de divergência conforme tabela 3. As barras presentes em cada nó representam intervalos de confiança de $95 \%$ de HPD (highest posterior density) dos tempos de divergência. O eixo X representa o tempo em milhões de anos. As cores dos ramos seguem a figura 1.

A datação dos tempos de divergência pela coalescência multiespécies estimada pelo *BEAST revelou uma diversificação do fim do Plioceno ao Pleistoceno (Fig. 6, Tab. 3), desde os últimos 3,53 milhões de anos atrás (ma). A divergência mais antiga 
foi entre T. schistogynus e os dois clados mais profundos de T. caesius há 2,56 ma [95\% de HPD (highest posterior density): 3,53-1,68 ma]. A divergência mais recente foi entre os clados Marañón e Putumayo há 0,24 ma [95\% de HPD (highest posterior density): 0,50-0,06 ma].

Tabela 3. Tempo de divergência e intervalos de confiança [95\% de HPD (highest posterior density)] em milhão de anos (ma) dos clados mitocondriais de T. caesius e T. schistogynus. Letras referentes a cada nó são conforme figura 6.

\begin{tabular}{cc}
\hline Nó & Tempo (95\% of HPD) \\
\hline a & $8,15(10,50-5,77)$ \\
b & $3,62(5,15-2,16)$ \\
c & $2,56(3,53-1,68)$ \\
d & $2,12(2,90-1,35)$ \\
e & $1,39(1,89-0,93)$ \\
f & $0,90(1,32-0,51)$ \\
g & $0,71(1,13-0,28)$ \\
h & $0,55(0,82-0,30)$ \\
i & $0,52(0,85-0,19)$ \\
j & $0,48(0,87-0,13)$ \\
k & $0,35(0,58-0,13)$ \\
I & $0,24(0,50-0,06)$ \\
\hline
\end{tabular}

\section{Discussão}

\subsection{Sistemática molecular}

Nossas análises filogenéticas (Fig. 1 e 6) mostraram que o complexo de espécies T. caesius/T. schistogynus é monofilético e irmão do clado que contém as outras duas espécies do gênero ( $T$. saturninus e $T$. ardesiacus). Estes resultados corroboram um estudo recente que também mostra o gênero Thamnomanes como irmão do gênero Isleria que foi recentemente proposto (Bravo et al., 2012). Nós observamos três clados profundos dentro deste complexo (Fig. 1 e 6): um referente à T. schistogynus, o outro correspondendo às amostras de T. caesius do norte do Rio Amazonas, e o terceiro composto pelas amostras de T. caesius do sul do Rio Amazonas e da Mata Atlântica. Entretanto, os dados indicam que T. caesius possivelmente não seja reciprocamente monofilético, uma vez que na reconstrução filogenética para o ND2 T. schistogynus foi irmão do clado norte amazônico de T. caesius. Porém na estimativa da árvore de espécies T. caesius foi recuperado como monofilético, embora com suporte de ramo moderado (0,77 de probabilidade posterior). 
A maior diferença entre a filogenia do ND2 (Fig. 1) e a árvore de espécies (Fig. 6) foi a resolução da politomia basal da filogenia do ND2 pela árvore de espécies que resultou no posicionamento de T. schistogynus como basal aos dois clados mais profundos de T. caesius (mas com baixo valor de suporte). Estudos recentes têm mostrado que as reconstruções filogenéticas que se baseiam nos métodos de árvore de espécies são mais acuradas que aquelas baseadas somente em árvore de genes únicos ou de vários genes concatenados (Kubatko \& Degnan, 2007; Heled \& Drummond, 2010), pois elas reduzem os problemas associados à estocasticidade do processo coalescente em divergências recentes, como por exemplo, o sorteamento incompleto das linhagens em alguns genes.

As redes de haplótipos dos íntrons nucleares (Fig. 3) mostraram somente as estruturas mais profundas observadas no DNA mitocondrial, o que é esperado devido aos tempos de coalescência mais profundos do DNA nuclear (Zink \& Barrowclough, 2008). Contudo, a análise do Structure recuperou mais estrutura que as redes de haplótipos indicando até cinco grupos congruentes com a filogenia do DNA mitocondrial (Fig. 4).

Com relação às subespécies de T. caesius nossos dados indicam T. c. glaucus (clado norte Amazônico) como uma linhagem independente e bastante diferenciada no complexo de espécies T. caesius/T. schistogynus. Contudo, nós não detectamos estruturação concordante com as demais subespécies que pertencem ao clado sul Amazônico, exceto pela subespécie T. c. caesius que é restrita à Mata Atlântica. Entretanto será necessária a confirmação das subespécies com base na análise de espécimes de museus, uma vez que as distribuições geográficas das subespécies não são precisas (Zimmer \& Isler, 2003). Futuras análises que incluam caracteres de plumagem e voz poderão confirmar se alguns destes táxons devem ou não ser elevados ao nível de espécie, ou até mesmo sinonimizados.

\subsection{Diversificação da Amazônia}

Em geral nossos dados apontam para uma origem do complexo de espécies T. caesius/T. schistogynus entre 3,53 e 1,68 ma. Esta estimativa concorda com outros estudos de aves amazônicas onde a origem dos grupos foi datada no fim do Plioceno por volta de 4 a 3 ma (Patel et al., 2011; Fernandes et al., 2012; Ribas et al., 
2012). Os dois clados mais basais de T. caesius concordam com as áreas mais estáveis da bacia amazônica, os escudos das Guianas (norte do rio Amazonas) e Brasileiro (sul do rio Amazonas) (Aleixo \& Rosseti, 2007), e conforme a datação pelo *BEAST se divergiram há aproximadamente 2,12 (95\% de HPD: 2,90-1,35). Ainda, o clado basal referente à $T$. schistogynus está relacionado à formação mais antiga da drenagem do rio Madeira, que deu origem à área de endemismo Inambari (Ribas et al., 2012).

A origem da biodiversidade Amazônica vem sendo tema de discussão entre os biólogos evolutivos nas últimas décadas (Antonelli \& Sanmartín, 2011), e um consenso geral sobre a dinâmica de diversificação deste bioma ainda não foi estabelecido. Nossos dados mostram um padrão de estrutura genética concordante com os grandes rios Amazônicos (Fig. 1 e 6). Existem duas hipóteses sobre a origem dos rios Amazônicos: a primeira delas afirma que a drenagem atual dos principais rios teria sido estabelecida com a fase final do soerguimento dos Andes no final do Mioceno entre 11,8 e 10 ma (Figueiredo et al., 2009; Hoorn et al., 2010); ao passo que a outra argumenta que a drenagem atual bacia teria se estabelecido mais recentemente entre 6 e 2,5 ma (Campbell et al., 2006; Latrubesse et al., 2010; Ribas et al., 2012). Nossa estimativa de tempo de divergência suporta a hipótese do estabelecimento mais recente da drenagem atual da bacia Amazônica (Fig. 6).

De acordo com a hipótese paleogeográfica da Amazônia proposta por Ribas et al. (2012) com base na diversificação do gênero Psophia a vicariância primária no bioma teria ocorrido com o estabelecimento do baixo Amazonas em função da drenagem das regiões alagadas a oeste da Amazônia durante o fim do Plioceno (2,7 - 2,0 ma). Em sequência teria ocorrido outra vicariância pela formação do Rio Madeira, e esta separação teria dado origem a área de endemismo Inambari (2,0 1,0 ma; Ribas et al., 2012). Então, nos últimos 1,8 ma os demais rios dos escudos Guiana e Brasileiro teriam se estabelecido, e consequentemente dado origem às demais vicariâncias (Ribas et al., 2012). O padrão de diversificação em T. caesius/T. schistogynus revelado neste estudo exibe parcial concordância com a hipótese proposta por Ribas et al. (2012): (i) as duas vicariâncias mais basais que teriam dado origem às três linhagens mais antigas em Psophia apresentam concordância espaçotemporal com os clados basais de T. caesius/T. schistogynus, contudo a relação entre 
os clados observada no presente estudo não foi congruente com aquela observada em Psophia (Ribas et al. 2012) cujo clado do sul do rio Amazonas é irmão do clado Inambari; (ii) as demais relações dentro dos clados basais do norte e sul do Rio Amazonas foram similares, contudo foi observado mais estruturação em $T$. caesius/T. schistogynus do que em Psophia, sendo que no presente estudo foram evidenciados clados concordantes com rios dentro das áreas de endemismo Napo e Guiana (Fig. 1); (iii) a área de endemismo Inambari foi parafilética em nossas análises (Fig. 1 e 6) com uma linhagem antiga (entre 3,53 e 1,68 ma) que deu origem a $T$. schistogynus e outra mais recente (entre 1,13 e 0,28 ma) que corresponde ao clado Juruá/Purus. Este último resultado aponta para uma possível dispersão através do rio Madeira após seu estabelecimento.

A clássica hipótese dos refúgios florestais como força motriz que originou a biodiversidade da Amazônia (Haffer, 1969; Vanzolini \& Williams, 1970) vem sendo refutada por vários estudos nos últimos anos (Bush, 1994; Nelson et al., 1990; Hoorn et al., 2010; Ribas et al., 2012). Nossos resultados não suportaram esta teoria como o único processo que teria promovido à diversificação em T. caesius/T. schistogynus: (1) nossa estimativa dos tempos de divergência dos clados observados sugere que a diversificação em T. caesius/T. schistogynus antecedeu o último máximo glacial (UMG), embora algumas vicariâncias (Fig. 6, Tab. 3) sejam congruentes com três glaciações anteriores ao UMG (Petit et al., 1999); (2) as análises do EBSP evidenciaram expansão demográfica somente em dois clados (Fig. 5), e nestes a expansão teve início muito depois do fim do UMG há aproximadamente 0,01 ma.

Nossas análises também evidenciaram uma possível dispersão recente para a MA, sendo que o clado referente ao bioma foi recuperado como irmão do clado Xingú, e a divergência entre eles ocorreu entre 0,58 e 0,13 ma (Fig. 1 e 6, Tab. 3). Este padrão de relacionamento da população da MA com a população amazônica mais ocidental já foi reportado em outros estudos (Marks et al., 2002; Nyari, 2007; Solomon et al., 2008), contudo ainda se faz necessário incluir amostras do interflúvio a oeste dos rios Tocantins e Araguaia para se confirmar qual o clado mais próximo da MA. Além disso, os resultados do presente estudo corroboram a hipótese de Batalha-Filho et al. (2012b) que as espécies ou populações aves que ocorrem na porção centro-norte da MA e que possuem linhagens irmãs e disjuntas 
na $A M$ seriam produto de uma conexão recente durante o Plio-Pleistoceno entre estes dois bioma. Desta forma, com base nos nossos dados o cenário mais plausível da origem do clado da MA é de uma dispersão oriunda da $A M$, neste caso da região mais ocidental do clado basal do sul do Rio Amazonas.

\subsection{Relações entre as áreas de endemismo}

Desde os estudos de Wallace (1852) a AM não é considerada uma única província biogeográfica, mas um mosaico de áreas de endemismo. Cracraft (1985), com base em padrões de distribuição de espécies de aves dividiu a AM em sete áreas de endemismo, e posteriormente Silva et al. (2002, 2005) encontrou evidências que uma delas poderia ser dividida em duas. Desta forma, com base nestes estudos a hipótese mais aceita sobre as áreas de endemismo na AM é aquela que considera oito áreas (Fig. 7): Guiana, Imeri, Napo, Inambari, Rondônia, Tapajós, Xingú e Belém (não mostrada na figura 7).

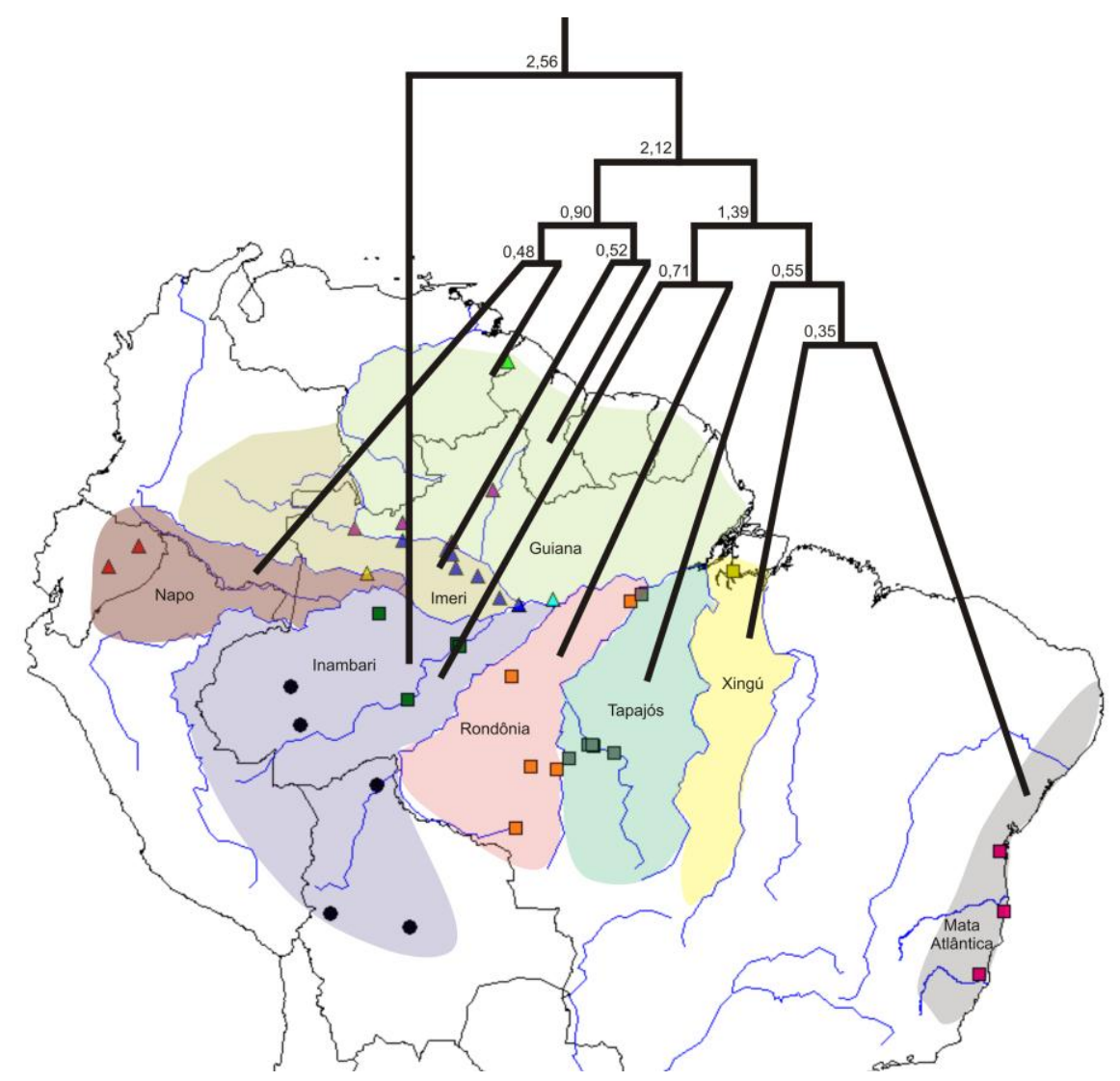

Figura 7. Representação das áreas de endemismo da Amazônia e relação entre elas com base na árvore de espécies (Fig. 6) de T. caesius/T. schistogynus. As áreas de endemismo seguem Cracraft (1985) e Silva et al. (2005). Os valores representados nos nós da árvore são os tempos de divergência em milhão de anos estimado pelo *BEAST (Tab. 3). 
Nossas reconstruções filogenéticas nos permitiu fazer inferências sobre o relacionamento entre as áreas de endemismo, bem como do tempo de separação entre elas (Fig. 7). De acordo com a árvore de espécies pelo *BEAST a área Inambari seria basal, e posteriormente uma dicotomia dividiu as áreas do sul e do norte do Rio Amazonas (Fig. 7). No clado que compreende as áreas do norte do Rio Amazonas foram observados dois clados: um com Napo e Guiana como irmãos e o outro agrupando Guiana e Imeri, indicando que a área Guiana seja parafilética. No clado correspondente ao sul do Rio Amazonas e a MA uma dicotomia separa as áreas Rondônia e Inambari de Tapajós, Xingú e MA, agrupando assim Rondônia como irmã de Inambari. E no outro clado Tapajós é irmão do clado que agrupa Xingú como irmão da MA. Inesperadamente Inambari apresentou duas linhagens parafiléticas nas reconstruções filogenéticas, sendo que uma linhagem apareceu como basal nas filogenias, ao passo que a outra divergiu mais recentemente.

As relações entre as áreas de endemismo observadas neste estudo (Fig. 7) concordam parcialmente com outros que tentaram propor este relacionamento (Cracraft \& Prum, 1988; Bates et al., 1998; Marks et al., 2002; Eberhard \& Bermingham, 2005), e as principais diferenças foram: (1) Inambari é basal a todas as áreas [embora a filogenia do ND2 (Fig. 1) coloque ela como irmã do norte da AM]; (2) as áreas Guiana e Inambari são parafiléticas, embora isto também tenha sido observado por Marks et al. (2002); (3) Inambari como irmão de Rondônia no clado do sul da AM.

\section{Conclusões}

O presente estudo mostrou que a hipótese de estabelecimento mais recente (últimos $3 \mathrm{ma}$ ) da drenagem dos rios Amazônicos (Ribas et al., 2012) é congruente com a diversificação de T. caesius/T. schistogynus. No entanto nós mostramos evidências de uma possível dispersão através do Rio Madeira que teria dado origem à vicariância entre os clados Madeira e Juruá/Purus, uma vez que existe uma origem mais antiga do clado de Inambari (T. schistogynus) restrito ao interflúvio à esquerda do Rio Madeira. Nossos dados também não excluem totalmente a hipótese dos refúgios para a origem de alguns clados observados neste estudo que coincidem com ciclos glaciais do fim do Pleistoceno. Desta forma, devido à ambiguidade dos 
padrões observados em T. caesius e T. schistogynus não é possível assumir uma destas hipóteses em detrimento à outra como principal fator de levou à diversificação neste grupo. Talvez um cenário mais plausível seja a combinação de rios e refúgios levando à diversificação neste complexo de espécies.

Outros estudos suportaram uma diversificação antiga da biota Amazônica (Hoorn et al., 2010) associada com soerguimento dos Andes no fim do Mioceno. Deste modo, o cenário mais plausível é aquele reconhecido por Rull $(2008,2011 a)$ e corroborado por Derryberry et al. (2011) em que é mostrada uma diversificação constante desde o Mioceno para a região neotropical.

Assim é ingênuo atribuir a diversificação da $A M$ a somente a um único evento histórico, uma vez que uma complexa história evolutiva que envolve desde eventos tectônicos ocorridos durante o Neogeno, passando pelo estabelecimento da drenagem atual dos rios Amazônicos durante o Plio-Pleistoceno, e até mesmo eventos recentes de oscilações climáticas ocorridas durante o final do Quaternário possivelmente estiveram envolvidos na evolução da biota residente no bioma (Rull, 2011a). A realização de mais estudos de organismos distribuídos ao longo da bacia Amazônica é necessária para se confirmar os padrões observados neste e em outros trabalhos, e reforçar assim a hipótese de um processo evolutivo contínuo na AM.

\section{Referências}

Ab’Saber NA. 1977. Os domínios morfoclimáticos da América do Sul. Primeira Aproximação. Geomorfologia 53:1-23.

Aleixo A. 2004. Historical diversification of a "terra-firme" forest bird superspecies: a phylogeographic perspective on the role of different hypotheses of Amazonian diversification. Evolution 58: 1303-1317.

Aleixo A, Rosseti DF. 2007. Avian gene trees, landscape evolution, and geology: towards a modern synthesis of Amazonian historical biogeography? J. Ornithol. 148 (Suppl 2): S443-S453.

Andrade-Lima D. 1982. Present day forest refuges in Northeastern Brazil. In: Prance GT (Ed). Biological diversification in the Tropics. Columbia University Press, New York, pp 245-254. 
Antonelli A, Sanmartín I. 2011. Why are there so many plant species in the Neotropics? Taxon 60: 403-414.

Auler AS, Smart PL. 2001. Late Quaternary paleoclimate in semiarid northeastern Brazil from u-series dating of travertine and water-table speleothems. Quat. Res. 55: 159-167.

Auler AS, Wang A, Edwards RL, Cheng H, Cristalli PS, Smart ML, Richards DA. 2004. Quaternary ecological and geomorphic changes associated with rainfall events in presently semi-arid northeastern Brazil. J. Quat. Sci. 19: 693-701.

Avise JC. 2008. Phylogeography: retrospect and prospect. J. Biogeogr. 36: 3-15.

Bandelt HJ, Forster P, Röhl A. 1999. Median-joining networks for inferring intraspecific phylogenies. Mol. Biol. Evol. 16: 37-48.

Batalha-Filho H, Cabanne GS, Miyaki CY. 2012a. Phylogeography of an Atlantic forest passerine reveals demographic stability through the last glacial maximum.

Mol. Phylogenet. Evol. DOI: http://dx.doi.org/10.1016/j.ympev.2012.08.010.

Batalha-Filho H, Fjeldså J, Fabre P-H, Miyaki, CY. 2012b. Connections between the Atlantic and the Amazonian forest avifaunas represent distinct historical events. J. Ornithol. DOI: http://dx.doi.org/10.1007/s10336-012-0866-7.

Bates JM, Hackett SJ, Cracraft J. 1998. Area-relationships in the Neotropical lowlands: an hypothesis based on raw distributions of passerine birds. J. Biogeogr. 25, 783-793.

Beheregaray LB. 2008. Twenty years of phylogeography: the state of the field and the challenges for the Southern Hemisphere. Mol. Ecol. 17: 3754-3774.

Behling H, Arz HW, Patzold J, Wefer G. 2000. Late Quaternary vegetational and climate dynamics in northeastern Brazil, inferences from marine core GeoB3104-1. Quat. Sci. Rev. 19: 981-994.

Bravo GA, Chesser RT, Brumfield RT. 2012. Isleria, a new genus of antwren (Aves:

Passeriformes: Thamnophilidae). Zootaxa 3195: 61-67.

Brito PH, Edwards SV. 2009. Multilocus phylogeography and phylogenetics using sequence-based markers. Genetica 135: 439-455.

Brown KS, Ab'Saber AN. 1979. Ice - ages forest refuges and evolution in the Neotropics: correlation of paleoclimatological, geomorphological, and pedological data with modern biological endemism. Paleoclimas 5: 1-30. 
Bruen TC, Philippe H, Bryant D. 2006. A simple and robust statistical test for detecting the presence of recombination. Genetics 172: 2665-2681.

Bruford MW, Hanotte O, Brookfield JFY, Burke T. 1992. Single-locus and multilocus DNA fingerprinting. In: Hoelzel AR (Ed). Molecular Genetic Analysis of Populations - a Practical Approach. IRL Press, New York, pp 287-336.

Bush MB. 1994. Amazonian speciation: a necessarily complex model. J. Biogeogr. 21: $5-17$.

Cabanne GS, Santos FR, Miyaki CY. 2007. Phylogeography of Xiphorhynchus fuscus (Passeriformes, Dendrocolaptidae): vicariance and recent demographic expansion in southern Atlantic forest. Biol. J. Linn. Soc. 91: 73-84.

Cabanne GS, d'Horta FM, Sari EHR, Santos FR, Miyaki CY. 2008. Nuclear and mitochondrial phylogeography of the Atlantic forest endemic Xiphorhynchus fuscus (Aves: Dendrocolaptidae): biogeography and systematic implications. Mol. Phylogenet. Evol. 49: 760-773.

Cabanne GS, d'Horta FM, Meyer D, Silva JMC, Miyaki CY. 2011. Evolution of Dendrocolaptes platyrostris (Aves: Furnariidae) between the South American open vegetation corridor and the Atlantic forest. Biol. J. Linn. Soc. 103: 801820.

Campbell Jr KE, Frailey CD, Romero-Pittman L. 2006 The Pan-Amazonian Ucayali Peneplain, late Neogene sedimentation in Amazonia, and the birth of the modern Amazon River system. Palaeogeogr. Palaeoclimatol. Palaeoecol. 239, 166-219.

Cicero C, Johnson NK. 2001. Higher level phylogeny of vireos (Aves: Vireonidae) based on sequences of multiple mtDNA genes. Mol. Phylogenet. Evol. 20: 2740.

Costa LP. 2003. The historical bridge between the Amazon and the Atlantic forest of Brazil: a study of molecular phylogeography with small mammals. J. Biogeogr. 30: 71-86.

Cracraft J. 1985. Historical biogeography and patterns of differentiation within the South American avifauna: areas of endemism. Ornithol. Monogr. 36: 49-84.

Cracraft J, Prum RO. 1988. Patterns and processes of diversifcation: speciation and historical congruence in some Neotropical birds. Evolution 42, 603-620. 
Degnan JH, Rosenberg NA. 2006. Discordance of species trees with their most likely gene trees. PLoS Genet. 2: 762-768.

Derryberry EP, Claramunt S, Derryberry G, Chesser RT, Cracraft J, Aleixo A, PérezEmán J, Remsen JV, Brumfield RT. 2011. Lineage diversification and morphological evolution in a large-scale continental radiation: the Neotropical ovenbirds and woodcreepers (Aves: Furnariidae). Evolution 65: 2973-2986.

d'Horta F, Cabanne GS, Meyer D, Miyaki CY. 2011. The genetic effects of Late Quaternary climatic changes over a tropical latitudinal gradient: diversification of an Atlantic Forest passerine. Mol. Ecol. 20: 1932-1935.

Drummond AJ, Rambaut A. 2007. BEAST: Bayesian evolutionary analysis by sampling trees. BMC Evol. Biol. 7: 214.

Eberhard JR, Bermingham E. 2005. Phylogeny and comparative biogeography of Pionopsitta parrots and Pteroglossus toucans. Mol. Phylogenet. Evol. 36: 288304.

Fernandes AM, Wink M. Aleixo A. 2012. Phylogeography of the chestnut-tailed antbird (Myrmeciza hemimelaena) clarifies the role of rivers in Amazonian biogeography. J. Biogeogr. 39: 1524-1535.

Figueiredo J, Hoorn C, van der Ven P, Soares E. 2009. Late Miocene onset of the Amazon River and the Amazon deep-sea fan: evidence from the Foz do Amazonas Basin. Geology 37: 619-622.

Fouquet A, Recoder R, Teixeira Jr M, Cassimiro J, Amaro RC, Camacho A, Damasceno R, Carnaval AC, Moritz C, Rodrigues MT. 2012. Molecular phylogeny and morphometric analyses reveal deep divergence between Amazonia and Atlantic Forest species of Dendrophryniscus. Mol. Phylogenet. Evol. 62: 826838.

Friesen VL, Congdon BC, Walsh HE, Birt TP. 1997. Intron variation in marbled murrelets detected using analyses of single-stranded conformational polymorphisms. Mol. Ecol. 6: 1047-1058.

Hackett SJ. 1996. Molecular phylogenetics and biogeography of tanagers in the genus Ramphocelus (Aves). Mol. Phylogenet. Evol. 5: 368-382.

Haffer J. 1969. Speciation in Amazonian forest birds. Science 165: 131-137. 
Heled J, Drummond AJ. 2008. Bayesian inference of population size history from multiple loci. BMC Evol. Biol. 8: 289.

Heled J, Drummond AJ. 2010. Bayesian inference of species trees from multilocus data. Mol. Biol. Evol. 27: 570-580.

Heslewood MM, Elphinstone MS, Tidemann SC, Baverstock PR. 1998. Myoglobin intron variation in the gouldian finch Erythrura gouldiae assessed by temperature gradient gel electrophoresis. Electrophoresis 19: 142-151.

Hickerson MJ, Carstens BC, Cavender-Bares J, Crandall KA, Graham CH, Johnson JB, Rissler L, Victoriano PF, Yoder AD. 2010. Phylogeography's past, present, and future: 10 years after Avise, 2000. Mol. Phylogenet. Evol. 54: 291-301.

Higgins D, Thompson J, Gibson T, Thompson JD, Higgins DG, Gibson TJ. 1994. CLUSTAL W: improving the sensitivity of progressive multiple sequence alignment through sequence weighting, position-specific gap penalties and weight matrix choice. Nucleic Acids Res. 22: 4673-4680.

Ho SY, Shapiro B. 2011. Skyline-plot methods for estimating demographic history from nucleotide sequences. Mol. Ecol. Resour. 11: 423-434.

Hoorn C, Wesselingh FP, ter Steege H, Bermudez MA, Mora A, Sevink J, Sanmartín I, Sanchez-Meseguer A, Anderson CL, Figueiredo, Jaramillo C, Riff D, Negri FR, Hooghiemstra H, Lundberg J, Stadler T, Särkinen T, Antonelli A. 2010. Amazonia through time: Andean uplift, climate change, landscape evolution, and biodiversity. Science 330: 927-931.

Huelsenbech JP, Ronquist F. 2001. MrBayes: Bayesian inference of phylogenetic tree. Bioinformatics 17: 754-755.

Huson DH, Bryant D. 2006. Application of phylogenetic networks in evolutionary studies. Mol. Biol. Evol. 23: 254-267.

Irestedt M, Fjeldså J, Nylander JAA, Ericson PGP. 2004. Phylogenetic relationships of typical antbirds (Thamnophilidae) and test of incongruence based on Bayes factors. BMC Evol. Biol. 4: 23.

Irestedt M, Ohlson Jl, Zuccon D, Källersjö M, Ericson PGP. 2006. Nuclear DNA from old collections of avian study skins reveals the evolutionary history of the Old World suboscines (Aves: Passeriformes). Zool. Scripta 35: 567-580. 
Jakobsson M, Rosenberg NA. 2007. CLUMPP: a cluster matching and permutation program for dealing with label switching and multimodality in analysis of population structure. Bioinformatics 23: 1801-1806.

Kubatko L, Degnan JH. 2007. Inconsistency of phylogenetic estimates from concatenated data under coalescence. Syst. Biol. 56: 17-24.

Kumar S, Skjæveland Å, Orr RJS, Enger P, Ruden T, Mevik B-H, Burki F, Botnen A, Shalchian-Tabrizi K. 2009. AIR: A batch-oriented web program package for construction of supermatrices ready for phylogenomic analyses. BMC Bioinformatics, 10: 357 .

Latrubesse EM, Cozzuol M, Silva-Caminha SAF, Rigsby CA, Absy MA, Jaramillo C. 2010. The late Miocene paleogeography of the Amazon Basin and the evolution of the Amazon River system. Earth Sci. Rev. 99: 99-124.

Librado P, Rozas J. 2009. DnaSP v5: A software for comprehensive analysis of DNA polymorphism data. Bioinformatics 25: 1451-1452.

McCormack JE, Heled J, Delaney KS, Peterson AT, Knowles LL. 2011. Calibrating divergence times on species trees versus gene trees: implications for speciation history of Aphelocoma jays. Evolution 65: 184-202.

Maldonado-Coelho M. 2012. Climatic oscillations shape the phylogeographical structure of Atlantic Forest fire-eye antbirds (Aves: Thamnophilidae). Biol. J. Linn. Soc. 105: 900-924.

Marks BD, Hackett SJ, Capparella AP. 2002. Historical relationships among Neotropical lowland forest areas of endemism as determined by mitochondrial DNA sequence variation within the wedge-billed woodcreeper (Aves: Dendrocolaptidae: Glyphorhynchus spirurus). Mol. Phylogenet. Evol. 24: 153-167. Marroig G, Cerqueira R. 1997. Plio-Pleistocene South American history and the Amazon lagoon hypothesis: a piece of the puzzle of Amazonian diversification. J. Comp. Biol. 2: 103-119.

Martins FM, Templeton AR, Pavan ACO, Kohlbach BC, Morgante JS. 2009. Phylogeography of the common vampire bat (Desmodus rotundus): marked population structure, Neotropical Pleistocene vicariance and incongruence between nuclear and mtDNA markers. BMC Evol. Biol. 9: 294. 
Miller MA, Pfeiffer W, Schwartz T. 2010. Creating the CIPRES science gateway for inference of large phylogenetic trees. In: Proceedings of the Gateway Computing Environments Workshop (GCE), 14 Nov. 2010, New Orleans, 1-8.

Nelson BW, Ferreira CAC, Da Silva MF, Kawasaki ML. 1990. Endemism centres, refugia and botanical collection density in Brazilian Amazonia. Nature 345: 714716.

Nyari ÁS. 2007. Phylogeographic patterns, molecular and vocal differentiation, and species limits in Schiffornis turdina (Aves). Mol. Phylogenet. Evol. 44: 154-164.

Nylander JAA. 2004. MrModeltest 2.2. Program distributed by the author.

Evolutionary Biology Centre, Uppsala University.

Oliveira PE, Barreto AMF, Suguio K. 1999. Late Pleistocene/Holocene climatic and vegetational history of the Brazilian caatinga: the fossil dunes of the middle São Francisco River. Palaeogeogr. Palaeoclimatol. Palaeoecol. 152: 319-337.

Patel S, Weckstein JD, Patané JSL, Bates JM, Aleixo A. 2011. Temporal and spatial diversification of Pteroglossus araçaris (Aves: Ramphastidae) in the Neotropics: constant rate of diversification does not support an increase in radiation during the Pleistocene. Mol. Phylogenet. Evol. 58: 105-115.

Patton JL, Dasilva MNF, Malcolm JR. 1994. Gene genealogy and differentiation among arboreal spiny rats (Rodentia, Echimyidae) of the Amazon basin - a test of the riverine barrier hypothesis. Evolution 48: 1314-1323.

Petit JR, Jouzel J, Raynaud D, Barkov NI, Barnola JM, Basile I, Bender M, Chappellaz J, Davis M, Delaygue G, Delmotte M, Kotlyakov VM, Legrand M, Lipenkov VY, Lorius C, Pepin L, Ritz C, Saltzman E, Stievenard M. 1999. Climate and atmospheric history of the past 420,000 years from the Vostok ice core, Antarctica. Nature 399: 429-436.

Por FD. 1992. Sooretama: the Atlantic Rain Forest of Brazil. SPB Academic Publishing, The Haugue.

Primmer CR, Borge T, Lindell J, Saetre GP. 2002. Single nucleotide polymorphism characterization in species with limited available sequence information: high nucleotide diversity revealed in avian genome. Mol. Ecol. 11: 603-612.

Pritchard JK, Stephens M, Donnelly P. 2000. Inference of population structure using multilocus genotype data. Genetics 155: 945-959. 
Pritchard JK, Wen X, Falush D. 2010. Documentation for Structure software: version 2.3. Disponível em: http://pritch.bsd.uchicago.edu/structure.html.

Ribas CC, Aleixo A, Nogueira ACR, Miyaki CY, Cracraft J. 2012. A palaeobiogeographic model for biotic diversification within Amazonia over the past three million years. Proc. Roy. Soc. B 279, 681-689.

Ridgely R, Tudor G. 1994. The birds of South America, volume II: the suboscine passerines. Austin, University of Texas Press.

Rull V. 2008. Speciation timing and neotropical biodiversity: the Tertiary-Quaternary debate in the light of molecular phylogenetic evidence. Mol. Ecol. 17: 2722-2729. Rull, V., 2011a. Neotropical biodiversity: timing and potential drivers. Trends Ecol. Evol. 26: 508-513.

Rull V. 2011b. Origins of biodiversity. Science 331: 398-399.

Silva JMC. 1994. Can avian distribution patterns in northern Argentina be related to gallery-forest expansion-retraction caused by the Quaternary climatic changes? Auk 111: 495-499.

Silva JMC, Novaes FC, Oren DC. 2002. Differentiation of Xiphocolaptes (Dendrocolaptidae) across the river Xingu, Brazilian Amazonia: recognition of a new phylogenetic species and biogeographic implications. Bull. Br. Ornithol. Club. 122: 185-194.

Silva JMC, Rylands AB, Fonseca GAB. 2005. The fate of Amazonian areas of endemism. Conserv. Biol. 19: 689-694.

Slade RW, Moritz C, Heideman A, Hale PT. 1993. Rapid assessment of single-copy nuclear DNA variation in diverse species. Mol. Ecol. 2: 359-373.

Smith TB, Wayne RK, Girman DJ, Bruford MW. 1997. A role for ecotones in generating rainforest biodiversity. Science 276: 1855-1857.

Solomon SE, Bacci MJr, Martins JJr, Vinha GG, Mueller UG. 2008. Paleodistributions and comparative molecular phylogeography of leafcutter ants (Atta spp.) provide new insight into the origins of amazonian diversity. PLoS One 3: e2738.

Stamatakis A, Hoover P, Rougemont J. 2008. A fast bootstrapping algorithm for the RAxML web-servers. Syst. Biol. 57: 758-771.

Stephens M, Smith N, Donnelly P. 2001. A new statistical method for haplotype reconstruction from population data. Am. J. Hum. Genet. 68: 978-989. 
Tamura K, Peterson D, Peterson N, Stecher G, Nei M, Kumar S. 2011. MEGA5: Molecular Evolutionary Genetics Analysis using Maximum Likelihood, Evolutionary Distance, and Maximum Parsimony Methods. Mol. Biol. Evol. 28: $2731-2739$.

Tavaré S. 1986. Some probabilistic and statistical problems in the analysis of DNA sequences. Lect. Math. Life Sci. 17: 57-86.

Vanzolini PE, Williams EE. 1970. South American anoles: the geographic differentiation and evolution of the Anolis chrysolepis species group (Sauria: iguanidae). Arquiv. Zool. (S. Paulo) 19: 1-298.

Wallace AR. 1852. On the monkeys of the Amazon. Proc. Zool. Soc. London 20: 107110.

Wang XF, Auler AS, Edwards RL, Cheng H, Cristalli PS, Smart PL, Richards DA, Shen CC. 2004. Wet periods in northeastern Brazil over the past 210 kyr linked to distant climate anomalies. Nature 432: 740-743.

Weir JT, Schluter D. 2008. Calibrating the avian molecular clock. Mol. Ecol. 17: 23212328.

Whitmore TC, Prance GT. 1987. Biogeography and Quaternary History in Tropical America. Oxford University Press, Oxford.

Willis EO. 1992. Zoogeographical origins of eastern Brazilian birds. Ornit. Netrop. 3: $1-15$.

Zimmer KJ, Isler ML. 2003. Family Thamnophilidae (typical antbirds). In: del Hoyo J, Elliott A, Sargatal J (eds.). Handbook of the Birds of the World, 8. Lynx Edicions, Barcelona, pp 448-681.

Zink RM, Barrowclough GF. 2008. Mitochondrial DNA under siege in avian phylogeography. Mol. Ecol. 17: 2107-2121. 


\section{Capítulo 6}

Connections between the Atlantic and the Amazonian forest avifaunas represent distinct historical events

Artigo aceito para publicação no periódico Journal of Ornithology de autoria de Henrique Batalha-Filho, Jon Fjeldså, Pierre-Henri Fabre e Cristina Yumi Miyaki com previsão para publicação em 2012 sob DOI: http://dx.doi.org/10.1007/s10336-0120866-7. 


\title{
Connections between the Atlantic and the Amazonian forest avifaunas represent distinct historical events
}

\author{
Henrique Batalha-Filho $\cdot$ Jon Fjeldså • \\ Pierre-Henri Fabre $\cdot$ Cristina Yumi Miyaki
}

Received: 4 October 2011/Revised: 20 March 2012/ Accepted: 25 May 2012

(C) Dt. Ornithologen-Gesellschaft e.V. 2012

\begin{abstract}
There is much evidence to support past contact between the Atlantic and the Amazon forests through the South American dry vegetation diagonal, but the spatiotemporal dynamics of this contact still need to be investigated to allow a better understanding of its biogeographic implications for birds. Here, we combined phylogenetic data with distributional data using a supermatrix approach in order to depict the historical connection dynamics between these biomes for New World suboscines. We examined the variation in divergence time and then compared the spatial distributions of taxon pairs representing old and recent divergences. Our results pointed to two distinct spatiotemporal pathways connecting the Atlantic and the Amazonian forests in the past: (1) old connections (middle to late Miocene) through the current southern Cerrado and Mato Grosso and the transition towards the Chaco and palm savannas of Bolivia and Paraguay; (2) young connections (Pliocene to Pleistocene) that possibly occurred through the Cerrado and Caatinga in northeastern Brazil. We suggest that the main events that played
\end{abstract}

Communicated by T. Gottschalk.

Electronic supplementary material The online version of this article (doi:10.1007/s10336-012-0866-7) contains supplementary material, which is available to authorized users.

H. Batalha-Filho $(\bowtie) \cdot$ C. Y. Miyaki

Laboratório de Genética e Evolução Molecular de Aves,

Departamento de Genética e Biologia Evolutiva, Instituto de

Biociências, Universidade de São Paulo, Rua do Matão 277,

Cidade Universitária, São Paulo, SP 05508-090, Brazil

e-mail: henrique.batalha@usp.br; rickbio@hotmail.com

J. Fjeldså · P.-H. Fabre

Center for Macroecology, Evolution and Climate at the Natural

History Museum of Denmark, University of Copenhagen,

Copenhagen, Denmark important roles in these connections were geotectonic events during the late Tertiary associated with the uplift of the Andes (old connections) and Quaternary climate changes that promoted the expansion of gallery forest through the Cerrado and Caatinga in northeastern Brazil (young connections). Our results provide the first general temporal and spatial model of how the Atlantic and Amazonian forests were connected in the past, which was derived using bird data.

Keywords Neotropical region - New World suboscines · Supermatrix · Worldmap · Biogeography · Miocene · Quaternary

\section{Zusammenfassung}

Verbindungen zwischen atlantischen und amazonischen Waldvogelfaunen spiegeln distinkte historische Ereignisse wider

Zahlreiche Hinweise belegen ehemalige Kontakte zwischen atlantischen und amazonischen Wäldern über die diagonal durch Südamerika verlaufende Trockenvegetationszone hinweg, allerdings bedarf die raumzeitliche Dynamik dieser Kontakte noch näherer Untersuchung, um deren biogeografische Auswirkungen auf Vögel besser verstehen zu können. Hier fassten wir phylogenetische Daten mit Verbreitungsdaten in einer Supermatrix-Analyse zusammen, um so die Dynamik der historischen Verbindungen zwischen diesen Biomen für Neuwelt-Suboscine abzubilden. Wir untersuchten die Variation im Zeitpunkt der Artentrennung und verglichen dann die räumliche Verteilung von Taxonpaaren, die alte und rezente Trennungsereignisse repräsentieren. Unsere Ergebnisse deuten auf zwei distinkte raumzeitliche Verbindungswege zwischen 
atlantischen und amazonischen Wäldern in der Vergangenheit hin: (1) alte Verbindungen (Mittleres bis Oberes Miozän) durch den heutigen südlichen Cerrado und Mato Grosso sowie den Übergang zum Chaco und den Palmsavannen Boliviens und Perus; (2) junge Verbindungen (Pliozän bis Pleistozän), möglicherweise durch die Cerrados und die Caatinga im nordöstlichen Brasilien. Unserer Ansicht nach spielten die folgenden Hauptereignisse eine wichtige Rolle für diese Verbindungswege: geotektonische Ereignisse während des späten Tertiärs im Zusammenhang mit der Auffaltung der Anden (alte Verbindungen) sowie Klimaänderungen im Quartär, die die Ausbreitung von Galeriewäldern durch Cerrado und Caatinga im nordöstlichen Brasilien begünstigten (junge Verbindungen). Auf der Grundlage von Vogeldaten stellen unsere Ergebnisse die erste allgemeine Näherung für Zeiträume und die Art und Weise dar, wie atlantische und amazonische Wälder in der Vergangenheit in Verbindung standen.

\section{Introduction}

It is well known that many sister species and lineages are disjunctly distributed in the Brazilian Atlantic Forest (AF) and in the Amazon Basin (AM), but this biogeographic pattern has never been explored in depth for birds. The two biomes are separated by a broad diagonal of more xeric habitats comprising the Chaco, the Cerrado uplands, and the Caatinga (Ab'Saber 1977), and together they encompass one of the most diverse tropical forests of the world. There is much evidence to support past contact between the $\mathrm{AF}$ and the $\mathrm{AM}$ through this dry vegetation diagonal (Auler et al. 2004; Auler and Smart 2001; Behling et al. 2000; Costa 2003; Oliveira et al. 1999; Patton et al. 1997; Patton and Costa 1999; Vilela et al. 2009; Por 1992; Wang et al. 2004; Willis 1992). Palynological and geological data from these studies cover the late Pleistocene (the last 0.9 mya) and indicate that there were wetter periods that allowed the expansion of gallery forest into the Cerrado and Caatinga, providing connections between the $\mathrm{AF}$ and the $\mathrm{AM}$ (Auler et al. 2004; Auler and Smart 2001; Behling et al. 2000; Oliveira et al. 1999; Wang et al. 2004). Costa (2003) compared the phylogeographic patterns of small mammals in the $\mathrm{AF}$ and the $\mathrm{AM}$ and found lineages from either the AF or the AM in the Cerrado. Costa (2003) also observed that some taxa from northern AF are more closely related to AM taxa than to southern AF forms. Silva (1996) showed that several birds from the AM and the AF show distributions that extend along the Cerrado gallery forests. However, there are several species with disjunct distributions in these forested biomes (e.g., see Ridgely and Tudor 1994 for birds; see Vivo 1997 for mammals; see Martini et al. 2007 for plants), and this reinforces the idea that the dry vegetation diagonal plays an important role in the connection of theses biomes. Similarly, there is evidence from Africa supporting episodes of faunal connection across the "arid corridor" in eastern Africa between the main rainforest tracts and those near the Indian Ocean (the African Rift; Couvreur et al. 2008; Tolley et al. 2011). However, questions concerning the timing and nature of this connection are still to be conclusively answered. Such questions include: were the AF and AM biota connected just once in the past? Was the connection related solely to Quaternary climate changes? If not, when did this (these) connection(s) occur? Were there different pathways connecting $\mathrm{AM}$ and $\mathrm{AF}$ ?

Possible explanations for the observed patterns could be extinction, dispersal, or vicariance (Crisci et al. 2003). A basic assumption of vicariance biogeography (as well as panbiogeography) is that generalized patterns can be detected by searching for concordance in area cladograms (or tracks) across multiple lineages. Although there are numerous known cases of different historical events generating similar patterns (e.g., Tuomisto 2007), there is still a widespread tendency to treat similar patterns as indications of common biogeographic events. Besides, distinct co-distributed taxa could present similar cladogenetic splits if speciation and/or diversification are driven by vicariance, as the distributions of the ancestor populations would have been affected in a similar way when the barriers to dispersal formed.

However, it is important to distinguish true congruence, where the taxa and areas share the same history (Cracraft 1985, 1988) from "pseudocongruence" (Cunningham and Collins 1994; Donoghue and Moore 2003), where cyclical processes (such as orbitally driven climatic/vegetational changes; Bennett 1990; Hooghiemstra et al. 1993) result in the repetition of historical events. This could be a repeated process of range expansion and retreat. We also need to consider whether entirely different biogeographic events, superimposed over millions of years, may in some cases result in patterns that we perceive as being congruent.

Recently, the integration of distributional and phylogenetic data has given robust insights into diversification processes and biogeographical patterns of tropical forests (Fjeldså et al. 2007; Fjeldså and Irestedt 2009; Fjeldså and Rahbek 2006; Roncal et al. 2011). This kind of approach connects ecological and historical biogeographies and gives insight into community assembly and species richness patterns by considering the biogeographical history of the species and clades that make up these patterns (Wiens and Donoghue 2004).

In the work described in this paper, we applied this approach to New World suboscine birds, a monophyletic group (Barker et al. 2004) with 1,200 extant species. This 
group evolved within South America, but some subclades recently expanded to colonize Central and North America during the great American exchange (Smith and Klicka 2010; Weir et al. 2009). Several phylogenies for this group have been published (Derryberry et al. 2011; Irestedt et al. 2002, 2004, 2009; Moyle et al. 2009; Ohlson et al. 2008; Tello et al. 2009), which provide a large data source for biogeographic inferences.

In this paper, taxa with disjunct Amazonian/Atlantic forest distributions were examined to investigate whether such disjunctions are the result of a single (or at the very least a recurrent) range fragmentation event or entirely different events. This was done in two steps: first by examining the degree of genetic divergence between them, and second by examining their geographical distributions.

Thus, we aimed to combine phylogenetic data using a dated phylogeny with distributional data in order to try to depict the historical connection dynamics between AF and AM. We examined the variation in divergence time and then compared spatial distributions of taxon pairs representing old and recent divergences. This allowed us to address two main questions. (1) When and where did this (these) connection(s) happen? (2) Which historical events were responsible for the interchange of avifauna between the $\mathrm{AF}$ and the $\mathrm{AM}$ ?

\section{Materials and methods}

Taxa selection and phylogenetic analyses

The first step was to identify sister groups (species or lineages) with disjunct distributions in the AF and the AM. This was done by performing a comprehensive search of the Handbook of the Birds of the World (del Hoyo et al. 2003, 2004), and utilizing information on species and population distributions as well as their putative evolutionary relationships with published phylogenetic information (Derryberry et al. 2011; Irestedt et al. 2002, 2004, 2009; Moyle et al. 2009; Ohlson et al. 2008; Tello et al. 2009). Thus, we selected only pairs of sister taxa with AF and AM distributions that had a well-supported phylogenetic grouping (including cases where an AF species is sister to a small group of species with an AM distribution). We also included, as recent splits, disjunctly distributed species whose populations in the $\mathrm{AF}$ and the $\mathrm{AM}$ are slightly differentiated morphologically, suggesting a recent (Plio-Pleistocene) split (see below). Unfortunately, no DNA sequence data on these populations are available, and we acknowledge that it would be desirable to use such data to estimate their divergence times. However, we decided to include these groups in our analyses with the assumption that the current species-level taxonomy reflects relationships accurately. While there may be some exceptions where subspecies in the AM and the AF are genetically more divergent than their subtle morphological differences would suggest, but we find it unlikely that such divergences would be older than the 5.5 million years (Plio-Pleistocene period) that we regarded here as a recent split.

Other New World subsoscine species were also included to help strengthen the support for some phylogenetic relationships (see Table S1 of the Electronic supplementary material, ESM). Based on Barker et al. (2004), the outgroups used were: Pitta baudii, Smithornis rufolateralis, Corvus corone, Parula americana, Menura novaehollandiae, Acanthisitta chloris, and Pterocles namaqua (Table S1 of the ESM).

The sequences of six genes for which data are available for many species of New World suboscines were downloaded from the GenBank/EMBI databases: one mitochondrial—cytb; three nuclear introns-myo2, G3PDH and FIB5; and two nuclear exons-RAG-1 and RAG-2 (Table $\mathrm{S} 1$ of the ESM). Thus, we selected 83 species (including outgroups) to reconstruct the phylogenetic relationships of New World suboscines from the AF and the AM (Table S1 of the ESM). Sequences were aligned using MUSCLE (Edgar 2004) in MEGA5 (Tamura et al. 2011). All alignments were inspected and corrected manually when necessary. The genes were concatenated using SeaView4 (Gouy et al. 2010), and this alignment contained 7,092 characters (the percentage of the data that are missing for each gene is shown in Table S2 of the ESM).

The best-fit substitution model for each partition was estimated using MrModeltest 2.2 (Nylander 2004) based on Akaike's information criterion (AIC). We used Bayesian and maximum likelihood inferences based on six partitions (Table S2 of the ESM) to reconstruct phylogenies using MrBayes 3.1.2 (Huelsenbech and Ronquist 2001) and RAxML (Stamatakis et al. 2008), respectively. Bayesian runs consisted of 17 million generations of two independent runs with four chains of Markov chain Monte Carlo (MCMC) each. The first one million generations were discarded as "burn-in," and the trees were sampled every 500 generations. The burn-in and convergence diagnostics were estimated using the PSRF (potential scale reduction factor), where values close to one indicate a good convergence between runs (Gelman and Rubin 1992). We also assessed the chain convergence by checking the posterior distribution plots of each run using Tracer 1.5 (http://beast. bio.ed.ac.uk/Tracer), verifying that the ESS values were $>200$. We carried out RAxML analysis in the CIPRES Science Gateway (Miller et al. 2010) using the same partitions of Bayesian inference under the GTRAC model; invariable sites and the gamma distribution were estimated 
for each partition during the run. Node supports for the maximum likelihood analyses were estimated by performing 100 bootstrap replications.

Date estimates were obtained by implementing a Bayesian relaxed clock model in BEAST 1.6.1 (Drummond et al. 2006; Drummond and Rambaut 2007) based on the concatenated dataset. Two independent runs with 50 millions of generations were obtained using the following parameters: the Yule prior, a random starting tree, the GTR $+\mathrm{I}+\Gamma$ model, parameters sampled every 1,000 steps, a burn-in of $10 \%$, and an assumption of an uncorrelated relaxed lognormal clock. We used the geological split between New Zealand and Antarctica as the calibration point, as this has been related to the basal separation of the Acanthisitta lineage from the other passerines (Barker et al. 2002, 2004; Ericson et al. 2002). Thus, we used a normally distributed tree prior with a mean of 78 mya and a standard deviation of 7 , as used by Irestedt et al. (2009). To check the convergence of the parameters between runs, we used Tracer 1.5, verifying that the ESS values were $>200$. The consensus topology with the divergence times was visualized in FigTree 1.3.1 (http://tree.bio.ed.ac.uk/software/figtree).

\section{Distributional analysis}

We used the bird distribution for South America that is digitalized in Worldmap (Williams 1998), which was generated from a comprehensive global distribution database developed at the Center for Macroecology, Evolution and Climate (January 2011 version). The resolution of the map used was $1^{\circ} \times 1^{\circ}$ quadrates (latitude $\times$ longitude), following the approach outlined in Brooks et al. (2001) and in Rahbek and Graves (2001). Maps represent a conservative source of extent-of-occurrence for the breeding ranges based on museum specimens, published sighting records, and spatial distribution of habitats of documented records ( $>1,000$ references used), and have been validated by many experts.

To estimate the possible different pathways of contact between the AF and the AM, we selected species from the young and old divergences based on Bayesian dating. Ranges of young and old divergences assumed here were: young-comprising divergence during the Pliocene and Pleistocene (the last 5.5 million years); old-comprising the Miocene period (ranging from 5.6 to 23 million years ago). Thus, we generated species richness maps for young and old divergences.

In order to assess the degree of co-distribution between the richness maps of young and old splits, we applied a correlation test (rho, $\rho$ ) between the maps, and this was visualized by overlaying a two-color scheme on the species distribution (Williams and Gaston 1998).

\section{Results}

Phylogenetic reconstruction and dating

Our supermatrix consisted of 7,092 characters and provided a robust dataset to estimate the phylogenetic relationships and to date New World subsoscines divergencies. The best-fit model estimated for each gene partition as well as the length of each gene are shown in Table S2 of the ESM. The phylogenetic reconstruction inferred by the Bayesian and maximum likelihood (Fig. S1 of the ESM) approaches were congruent and agreed with previous published phylogenies (Irestedt et al. 2002, 2004, 2009; Moyle et al. 2009; Ohlson et al. 2008; Tello et al. 2009). All splits between the AF and the AM identified based on the supermatrix topologies showed strong node support values.

The dated chronogram generated by BEAST revealed that the majority of the splits between pairs of sister groups investigated here occurred before the Plio-Pleistocene (Fig. S2 of the ESM). The only exceptions were the younger splits: Mionectes rufiventris versus M. oleagineus and M. macconnelli (4.85 mya); Chiroxiphia caudata versus C. boliviana (4.17 mya); and Dendrocolaptes platyrostris versus D. picumnus (4.2 mya). In addition, it was possible to identify very old splits, such as Piprites pileata versus $P$. chloris (25.76 mya) and Psilorhamphus guttatus versus Liosceles thoracicus (21.63 mya).

Species included in our Worldmap analyses that showed young divergences provided a good aid to understanding the dynamics of past connections between the AF and the $\mathrm{AM}$, since no sequences are available for most of these populations in GenBank. Furthermore, phylogeographic studies of bird species distributed disjunctly in these biomes suggested divergence in the Pleistocene (Marks et al. 2002; Miller et al. 2008; Nyári 2007).

Spatiotemporal patterns

We selected a total of 33 and 29 taxa to build the richness maps for young and old splits, respectively (Table S3 of the ESM). These taxon pairs represent 32 young and 10 old splits between the AF and the AM (Fig. S2 and Table S3 of the ESM). The few species that were used in the dating analyses but not included in richness maps exhibited uncertain sister species relationships between the $\mathrm{AF}$ and the AM or low node support in the phylogenetic reconstruction.

The overall species richness maps for old and young splits showed a disparity in the AF taxa distribution (Fig. 1). Interestingly, nearly all AF species that originated from old splits occur in central and southern AF (Fig. 1a), whereas taxa that originated from recent splits occur 


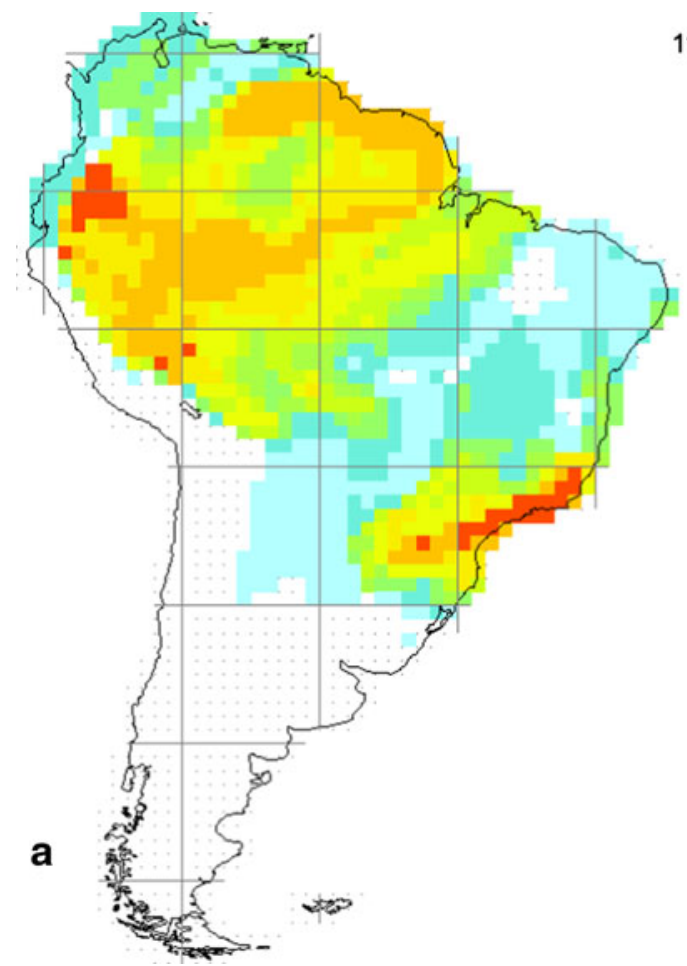

Fig. 1 Species richness variation maps of New World suboscines for disjunctions between the Atlantic Forest and the Amazon Basin. a Geographical distribution of 21 taxon pairs representing old divergences (Miocene: 5.6-23 mya) between these biomes.

predominantly in northern AF (Fig. 1b). Also, there is a contrast between the distributions of old and young taxa in the AM. Old taxa are mainly found in the western part of the basin and in the Guianas, and in a rather restricted area along the lower Amazon. In contrast, taxa representing younger splits are predominantly present in the lower AM at the north of Pará and in the eastern Amazonian states of Brazil (Fig. 1b). The correlation between maps was moderate $(\rho=0.78)$, but the two-color map shows a clear distinction in the distributions of young and old splits of AF taxa (Fig. 2). However, more green (young splits) is evident for the Caatinga and northern Cerrado, whereas there is a predominance of blue in southern Cerrado as well as in northern Chaco (Fig. 2).

A large number of old AF species, mostly from the cooler southern uplands, have corresponding sister species in the tropical Andes, mainly in Bolivia and Peru (not shown), and some species have disjunct populations in the Andes and the AF (see Ridgely and Tudor 1994). Therefore, these biomes may have been connected by two spatiotemporally distinct pathways, as observed here for the AF and the AM. Percequillo et al. (2011) also suggested a close relationship historically between the $\mathrm{AF}$ and the Andes for mammals.

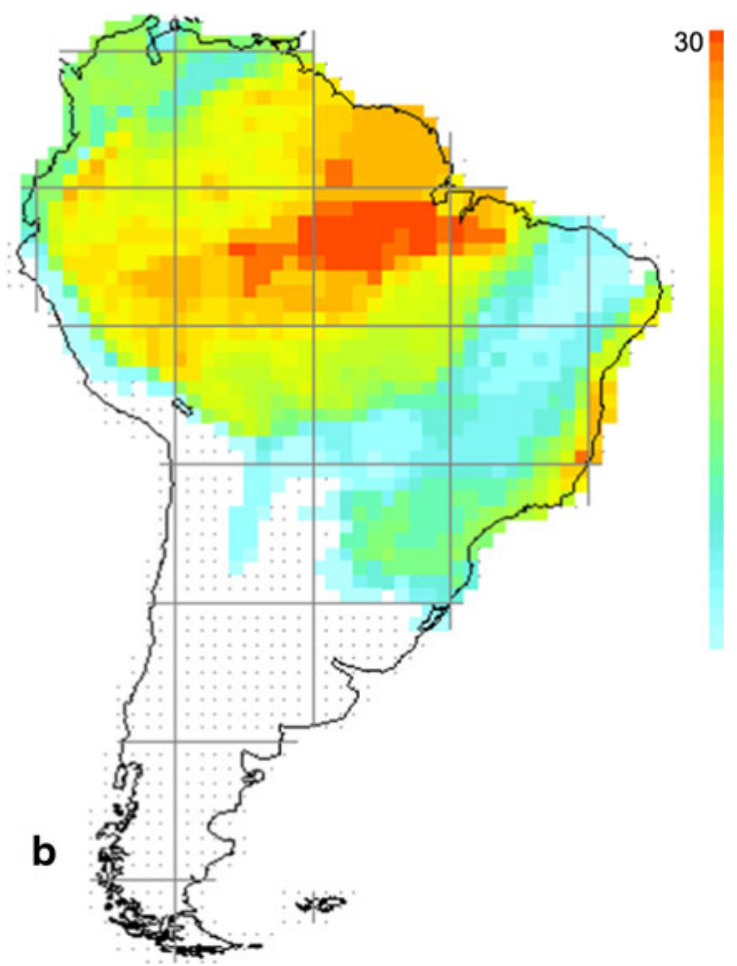

b Geographical distribution of 37 taxon pairs representing young divergences (Plio-Pleistocene: the last 5.5 mya) between these biomes. Bars in both maps indicate the species richness for each pixel

\section{Discussion}

In this study, the use of a dated avian molecular phylogeny in combination with distributional data provided an evolutionary time perspective on the dynamics of historical connections between the AF and the AM. In concordance with previous studies, we found three putative pathways connecting the AF and the AM (Auler et al. 2004; Costa 2003; Oliveira et al. 1999; Por 1992; Wang et al. 2004). To our knowledge, this is the first study to present a general spatiotemporal model for the biogeographical connections between the two forest biomes based on bird data (Figs. 2, 3).

Our data show that the Quaternary climatic changes were important in the interchange of avifauna between these two biomes, and that geological events during the Miocene, such as Andean uplift (Hoorn et al. 2010) and associated changes in the axial grove to the east-the establishment of broad foreland basins and marine incursions (Cozzuol 1996; Haq et al. 1987; Paxton and Crampton 1996; Räsänen et al. 1995; Wesselingh et al. 2006; Wesselingh and Salo 2006), may also have played significant roles (see below). Cracraft (1985), in his definition of areas of avian endemism in South America, postulated that these areas are primarily historical 


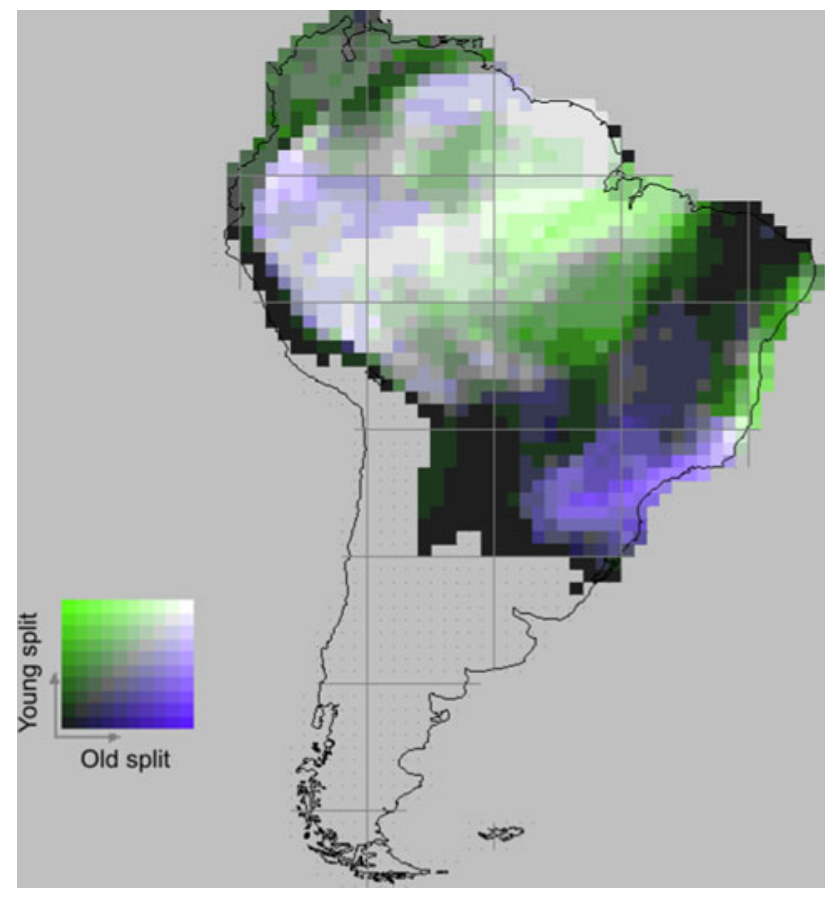

Fig. 2 Correlation map comparing geographic distributions for taxon pairs comprising old and young divergences, $\rho=0.78$. The colors show the level of overlap: green shades represent young splits, blue shades represent old splits, and white represents completely overlapping distributions (color figure online)

entities rather than simply manifestations of a single, coherent ecology or consequences of climatic-vegetational changes during the Pleistocene. Fjeldså (1994) postulated that massive radiations of South American terrestrial biota occurred during the upper Tertiary, but Rull (2008) and Derryberry et al. (2011) documented a continuous rate of diversification during the Neogene.

In our study, species richness maps show clearly early and late $\mathrm{AM} / \mathrm{AF}$ disjunctions. These events seem to represent the signatures of at least two distinct biogeographic connections (Figs. 1, 2): (1) the old connections (middle to late Miocene) between these two biomes appear to have existed along the southern margin of the modern Cerrado and in Mato Grosso, or on the transition towards the Chaco and palm savannas of Bolivia and Paraguay (Fig. 3); (2) the young connections (Pliocene to Pleistocene) possibly occurred through the Cerrado and Caatinga in northeastern Brazil (Fig. 3). Furthermore, there seem to be differences in the spatial occupations of young and old divergences within the AF, with the old ones restricted to the southern AF, upland forests at southern Bahia, Minas Gerais, Espírito Santo, Rio Janeiro, and northern São Paulo, and lowland forests in the south, while taxa representing young $\mathrm{AF} /$ AM divergences occur in lowland coastal forests from northern Rio de Janeiro to northeastern Brazil (Figs. 1, 2). This pattern also involves two climatic settings, as forests in southern Brazil are cooler than lowland forests in the northern part of the AF. However, most of the species of the upland forests of southern Brazil have their nearest relatives in the Andes, as the bending of the Bolivian orocline (Chapare Buttress) made contact with the Brazilian Shield up until the Plio-Pleistocene, when the continuous crust thickening in the Bolivian Andes caused geological subsidence and the formation of hydrologically unstable savannah plains that now form a barrier between the Andean and South Brazilian forest faunas (Hanagarth 1993; Silva 1994).

The old pathway connecting the AF and the AM

Based on the species richness map comprising old divergences between the AF and the AM (Figs. 1a, 2), we hypothesize that an old pathway connected these biomes during much of the Miocene along the western edge of the Brazilian cratonic shield, from the northern modern Chaco in the state of Mato Grosso in Brazil, west to Bolivia and Paraguay, and from the state of Rondônia southeast to the state of Paraná (Brazil) (Fig. 3). During the Miocene, the axial grove of the western Amazon Basin expanded to become broad foreland basins characterized by marine and fresh water flux (7-23 mya; see Hoorn et al. 2010; Hoorn and Wesselingh 2010; Lundberg et al. 1998; Wesselingh et al. 2006; Wesselingh and Salo 2006), and there was also a shift in the position of the watershed between the Amazon and the Paraná Sea (Lundberg et al. 1998; Marshall et al. 1993; Marshall and Lundberg 1996; Roddaz et al. 2006). Despite controversies, these paleoseas could have been connected during the late Miocene through the Bolivian/Paraguayan Chaco (Hulka et al. 2006; Roddaz et al. 2006). In these scenarios, we can hypothesize that a pathway may have connected the AF and the AM along these paleoseas and the Chapare Buttress (Lundberg et al. 1998; Roddaz et al. 2006). This pathway could have originated via elevated channel belts (late Tertiary) through flooded savannas that may have provided dispersal pathways for terrestrial organisms (Wesselingh and Salo 2006). Besides, it is well known that the Andean uplift was crucial for the evolution of Amazonian landscapes (Hoorn et al. 2010; Hoorn and Wesselingh 2010), and played a key role in the diversification of organisms in adjacent regions. Also, molecular studies on mammals (Galewski et al. 2005) and lizards (Pellegrino et al. 2011) have postulated old connections (Miocene) between the AF and the AM.

All 19 lineages of New World suboscines that diverged in the mid-Oligocene are present in the AF (data not shown). This observation raises the possibility that many New World suboscine relict lineages originated within the $\mathrm{AF}$, and that only during the Miocene did they colonize the AM. Also, Irestedt et al. (2002) suggested that tracheophone birds originated in southern AF. 


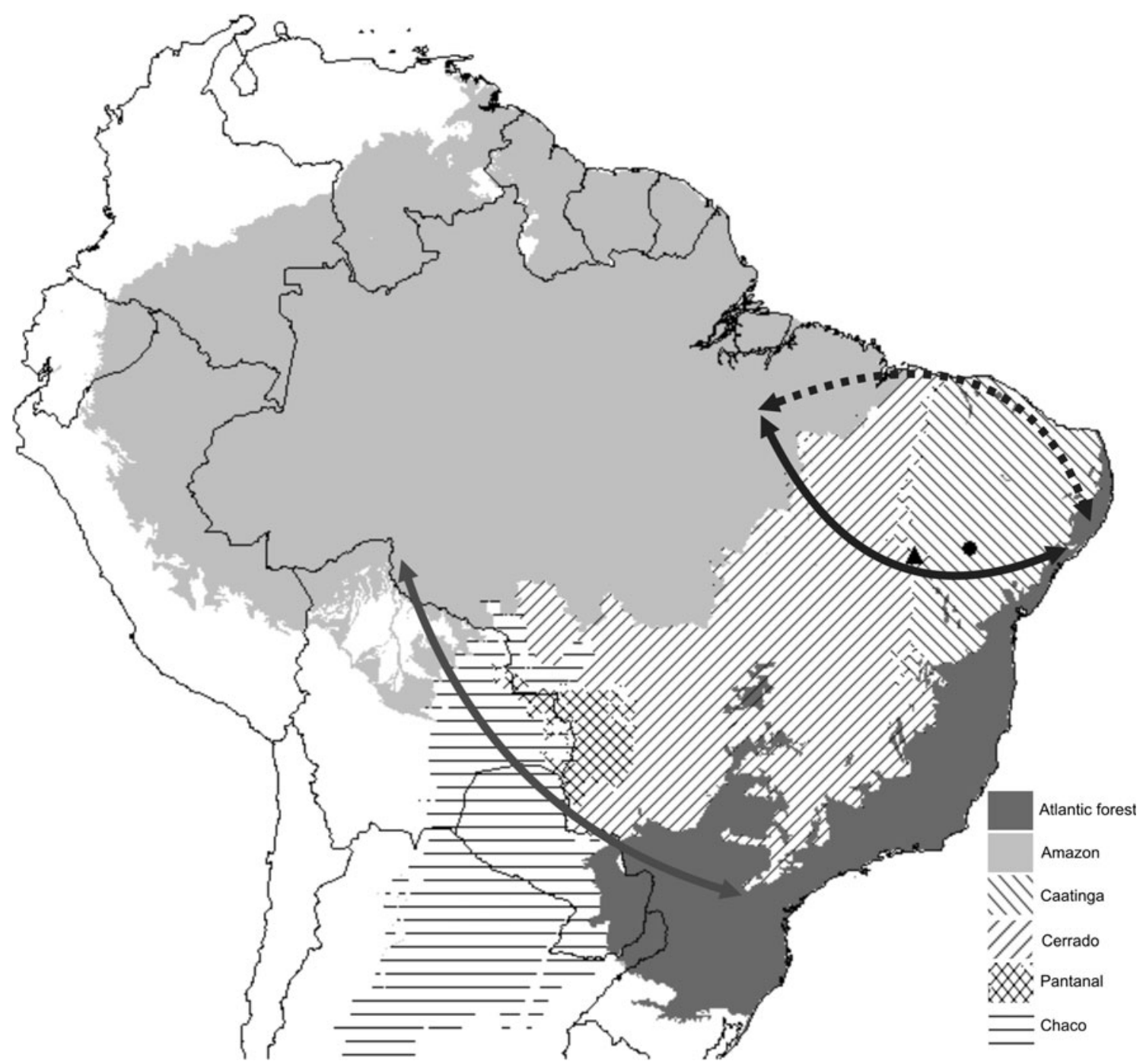

Fig. 3 Representation of the hypothetical historical pathways connecting the Atlantic Forest and the Amazon Basin. Double headed arrows represent pathways. The dark gray arrow corresponds to old contacts, whereas the black arrows correspond to young contacts. The broken black arrow shows a less commonly observed young pathway, while the continuous black arrow represents a more commonly observed young pathway (see text for more details). These pathways

Furthermore, Por (1992) suggested a pathway connecting the AF and the AM through the Paraná River basin, and this is in accordance with our hypothesis. Costa (2003) also showed that this route could have been important for small mammals.

Young pathways connecting the AF and the AM

Our analyses suggest the presence of young pathways connecting the AF and the AM through current distributions in northern Cerrado and Caatinga (Fig. 3). Based on previous evidence (Auler et al. 2004; Costa 2003; Oliveira et al. 1999; Por 1992; Wang et al. 2004), we can also are supported by other studies that are not based on bird data: Andrade-Lima (1982), Auler et al. (2004), Costa (2003), Oliveira et al. (1999), Por (1992), and Wang et al. (2004). The dots in the Caatinga are localities in which there is evidence of the presence of gallery forest during the late Pleistocene ( $>0.9$ mya), based on paleopalynological and speleothems (triangle Oliveira et al. 1999; circle Auler and Smart 2001 and Wang et al. 2004)

suggest two connection pathways in northeastern Brazil: one through the coastal zones of Maranhão, Piauí, Ceará, and Rio Grande do Norte (Brazil), and another through Tocantins and Bahia (Brazil; Fig. 3).

The most northern young pathway is congruent with the presence of the "Brejos de Altitude" in this area. These "brejos" are relict rain forests enclaved in the Caatinga, and they represent current forest refuges (Andrade-Lima 1982). However, this pathway possibly played a minor role in the young AF/AM connections, as most of the birds with disjunct distributions between the $\mathrm{AF}$ and the AM included in our study do not occur in these areas in the state of Ceará. Albano and Girão (2008) 
and Girão et al. (2007) only registered Xiphorhyncus guttatus, Dendrocolaptes platyrostris, Rhynchocyclus olivaceus, Capsiempis flaveola, Attila spadiceus, Myrmotherula axillaris, and Xenops minutus in these areas. In addition, Cavalcanti and Tabarelli (2004) showed that "brejos" and lowland Atlantic forest from northeastern Brazil are distinct phytogeographical units. Nevertheless, it is conceivable that these "brejos" intermittently constituted suitable habitats during the Plio-Pleistocene for most species with AF/AM disjunctions, which have since gone extinct in these areas.

Some Plio-Pleistocene connections may have also existed further south during contractions and retractions of gallery forests during the Quaternary climate episodes. Such pathways are supported by paleopalynological and geological studies (Auler et al. 2004; Auler and Smart 2001; Oliveira et al. 1999; Wang et al. 2004) indicating the presence of gallery forest in the Caatinga in Bahia (Brazil) during the late Pleistocene ( $>0.9$ mya; Fig. 3 ).

There are few molecular studies on the AF/AM disjunction, but their results are in accordance with the data shown here. Costa (2003) pointed out that some small mammals that occur in the AF and the AM diverged during the Pleistocene. Also, Cabanne et al. (2008) and Weir and Price (2011) suggested that woodcreepers species endemic to the AF diverged from its Amazonian sister species or group during the Pliocene ( $\cong 3$ mya), and that the connection between these biomes possibly occurred through northeastern Brazil. However, Martins et al. (2009) observed that AF/AM populations of a vampire bat diverged in the Pleistocene, following the expansion of dry habitats between these two biomes.

These results have allowed us to propose the first general temporal and spatial model of the historical connections between the AF and the AM. Future historical demographic and phylogeographic studies of organisms with disjunct distributions in these biomes would provide fine-scale tests of this model, and uncover further complexities regarding the nature of the biogeographic connections between the two biomes that are not readily apparent in our study.

Acknowledgments This study was funded by the Fundação de Amparo à Pesquisa do Estado de São Paulo (Brazil), Coordenação de Aperfeiçoamento de Pessoal de Nível Superior (Brazil), Conselho Nacional de Desenvolvimento Científico e Tecnológico (Brazil), and the Danish National Research Foundation (support for the Center for Macroecology, Evolution and Climate, Denmark). We thank Marcos $\mathrm{M}$. Coelho and two anonymous reviewers for suggestions regarding a previous version of this manuscript. BEAST and MrBayes analyses were carried out by using the resources of the Computational Biology Service Unit from Cornell University, which is partially funded by Microsoft Corporation. This study is a result of the Research Center on Biodiversity and Computer Science of the Universidade de São Paulo (NAP BioComp).

\section{References}

Ab'Saber AN (1977) Os domínios morfoclimáticos da América do Sul. Primeira Aproximação. Geomorfologia 53:1-23

Albano C, Girão W (2008) Aves das matas úmidas das serras de Aratanha, Baturité e Maranguape, Ceará. Rev Bras Ornit 16:142-154

Andrade-Lima D (1982) Present day forest refuges in Northeastern Brazil. In: Prance GT (ed) Biological diversification in the tropics. Columbia University Press, New York, pp 245-254

Auler AS, Smart PL (2001) Late Quaternary paleoclimate in semiarid northeastern Brazil from U-series dating of travertine and watertable speleothems. Quat Res 55:159-167

Auler AS, Wang A, Edwards RL, Cheng H, Cristalli PS, Smart ML, Richards DA (2004) Quaternary ecological and geomorphic changes associated with rainfall events in presently semi-arid northeastern Brazil. J Quat Sci 19:693-701

Barker KF, Barrowclough GF, Groth JG (2002) A phylogenetic hypothesis for passerine birds: taxonomic and biogeographic implications of an analysis of nuclear DNA sequence data. Proc R Soc Lond B 269:295-305

Barker FK, Cibois A, Schikler P, Feinstein J, Cracraft J (2004) Phylogeny and diversification of the largest avian radiation. Proc Natl Acad Sci USA 101:11040-11045

Behling H, Arz HW, Patzold J, Wefer G (2000) Late Quaternary vegetational and climate dynamics in northeastern Brazil, inferences from marine core GeoB3104-1. Quat Sci Rev 19:981-994

Bennett KD (1990) Milankovitch cycles and their effects on species in ecological and evolutionary time. Paleobiology 16:11-21

Brooks T, Balmford A, Burgess N, Fjeldså J, Hansen LA, Moore J, Rahbek C, Williams P (2001) Toward a blueprint for conservation in Africa. Bioscience 51:613-624

Cabanne GS, d'Horta FM, Sari EHR, Santos FR, Miyaki CY (2008) Nuclear and mitochondrial phylogeography of the Atlantic forest endemic Xiphorhynchus fuscus (Aves: Dendrocolaptidae): biogeography and systematic implications. Mol Phylogenet Evol 49:760-773

Cavalcanti D, Tabarelli M (2004) Distribuição das plantas amazônico-nordestinas no centro de endemismo Pernambuco: brejos de altitude versus florestas de terras baixas. In: Porto $\mathrm{KC}$, Cabral JJP, Tabarelli M (eds) Brejos de altitude em Pernambuco e Paraíba. Ministério do Meio Ambiente, Brasília, pp 285-296

Costa LP (2003) The historical bridge between the Amazon and the Atlantic forest of Brazil: a study of molecular phylogeography with small mammals. J Biogeogr 30:71-86

Couvreur TLP, Chatrou LW, Sosef MSM, Richardson JE (2008) Molecular phylogenetics reveal multiple tertiary vicariance origins of the African rain forest trees. BMC Biol 6:54

Cozzuol M (1996) The record of aquatic mammals in southern South America. Muench Geowiss Abh 30:321-342

Cracraft J (1985) Historical biogeography and patterns of differentiation within the South American avifauna: areas of endemism. Ornithol Monogr 36:49-84

Cracraft J (1988) Deep history biogeography: retrieving the historical pattern of evolving continental biotas. Syst Zool 37:221-236

Crisci JV, Katinas L, Posadas P (2003) Historical biogeography: an introduction. Harvard University Press, Cambridge

Cunningham CW, Collins TM (1994) Developing model systems from molecular biogeography: vicariance and interchange in marine invertebrates. In: Schierwater B, Streit B, Wagner GP, DeSalle R (eds) Molecular ecology and evolution: approaches and applications. Birkhauser, Switzerland, pp 405-433

del Hoyo J, Elliott A, Christie D (2003) Handbook of the birds of the world-broadbills to tapaculos, vol 8. Lynx Edicions, Barcelona 
del Hoyo J, Elliott A, Christie D (2004) Handbook of the birds of the world-cotingas to pipits and wagtails, vol 9. Lynx Edicions, Barcelona

Derryberry EP, Claramunt S, Derryberry R, Chesser RT, Cracraft J, Aleixo A, Pérez-Emán J, Remsen JV, Brumfield RT (2011) Lineage diversification and morphological evolution in a largescale continental radiation: the Neotropical ovenbirds and woodcreepers (Aves: Furnariidae). Evolution 65:2973-2986

Donoghue MJ, Moore BR (2003) Toward an integrative historical biogeography. Integr Comp Biol 43:261-270

Drummond AJ, Rambaut A (2007) BEAST: bayesian evolutionary analysis by sampling trees. BMC Evol Biol 7:214

Drummond AJ, Ho SYW, Phillips MJ, Rambaut A (2006) Relaxed phylogenetics and dating with confidence. PLoS Biol 4:e88

Edgar RC (2004) MUSCLE: multiple sequence alignment with high accuracy and high throughput. Nucleic Acids Res 32:1792-1797

Ericson PGP, Christidis L, Cooper A, Irestedt M, Jackson J, Johansson US, Norman JA (2002) A Gondwanan origin of passerine birds supported by DNA sequences of the endemic New Zealand wrens. Proc R Soc Lond B 269:235-241

Fjeldså J (1994) Geographical patterns for relict and young species of birds in Africa and South America and implications for conservation priorities. Biodiv Conserv 3:207-226

Fjeldså J, Irestedt M (2009) Diversification of the South American avifauna: patterns and implications for conservation in the Andes. Ann Mo Bot Gard 96:398-409

Fjeldså J, Rahbek C (2006) Diversification of tanagers, a species rich bird group, from lowlands to montane regions of South America. Integr Comp Biol 46:72-81

Fjeldså J, Johansson U, Lokugalappatti LGS, Bowie RCK (2007) Diversification of African greenbuls in space and time: linking ecological and historical processes. J Ornithol 148(Suppl. 2):359-367

Galewski T, Mauffrey JF, Leite YL, Patton JL, Douzery EJ (2005) Ecomorphological diversification among South American spiny rats (Rodentia; Echimyidae): a phylogenetic and chronological approach. Mol Phylogenet Evol 34:601-615

Gelman A, Rubin D (1992) Inference from iterative simulation using multiple sequences. Stat Sci 7:457-511

Girão W, Albano C, Pinto T, Silveira LF (2007) Avifauna da Serra de Baturité: dos naturalistas à atualidade. In: Oliveira TS, Araújo FS (eds) Biodiversidade e conservação da biota na serra de Baturité, Ceará. Edições UFC, Fortaleza

Gouy M, Guindon S, Gascuel O (2010) SeaView version 4: a multiplatform graphical user interface for sequence alignment and phylogenetic tree building. Mol Biol Evol 27:221-224

Hanagarth W (1993) Acerca de la geoecologia de las sabanas del Beni en el noreste de Bolivia. Instituto de Ecología, La Paz

Haq BU, Hardenbol J, Vail P (1987) Chronology of fluctuating sea levels since the triassic. Science 235:1156-1167

Hooghiemstra H, Melice JL, Berger A, Shackleton NJ (1993) Frequency-spectra and paleoclimatic variability of the highresolution 30-1450-Ka Funza I pollen record (Eastern Cordillera, Colombia). Quat Sci Rev 12:141-156

Hoorn C, Wesselingh F (2010) Amazonia: landscape and species evolution: a look into the past. Blackwell, London

Hoorn C, Wesselingh FP, ter Steege H, Bermudez MA, Mora A, Sevink J, Sanmartín I, Sanchez-Meseguer A, Anderson CL, Figueiredo JC, Riff D, Negri FR, Hooghiemstra H, Lundberg J, Stadler T, Särkinen T, Antonelli A (2010) Amazonia through time: andean uplift, climate change, landscape evolution, and biodiversity. Science 330:927-931

Huelsenbech JP, Ronquist F (2001) MrBayes: Bayesian inference of phylogenetic tree. Bioinformatics 17:754-755

Hulka C, Gräfe K-U, Sames B, Uba CE, Heubeck C (2006) Depositional setting of the middle to late Miocene Yecua formation of the Chaco foreland basin, southern Bolivia. J S Am Earth Sci 21:135-150

Irestedt M, Fjeldså J, Johansson US, Ericson PGP (2002) Systematic relationships and biogeography of the tracheophone suboscines (Aves: Passeriformes). Mol Phylogenet Evol 23:499-512

Irestedt M, Fjeldså J, Nylander JAA, Ericson PGP (2004) Phylogenetic relationships of typical antbirds (Thamnophilidae) and test of incongruence based on Bayes factors. BMC Evol Biol 4:23

Irestedt M, Fjeldså J, Dalén L, Ericson PGP (2009) Convergent evolution, habitat shifts and variable diversification rates in the ovenbird-woodcreeper family (Furnariidae). BMC Evol Biol 9:268

Lundberg JG, Marshall LG, Guerrero J, Horton B, Malabarba MCSL, Wesselingh F (1998) The stage for Neotropical fish diversification: a history of tropical South American rivers. In: Malabarba LR, Reis RE, Vari RP, Lucena ZMS, Lucena CAS (eds) Phylogeny and classification of Neotropical fishes. EDIPUCRS, Porto Alegre, pp 13-48

Marks BD, Hackett SJ, Capparella AP (2002) Historical relationships among Neotropical lowland forest areas of endemism as determined by mitochondrial DNA sequence variation within the wedge-billed woodcreeper (Aves: Dendrocolaptidae: Glyphorynchus spirurus). Mol Phylogenet Evol 24:153-167

Marshall LG, Lundberg JG (1996) Miocene deposits in the Amazonian Foreland Basin (technical comments). Science 273:123-124

Marshall LG, Sempere T, Gayet M (1993) The Petaca (Late Oligocene-Middle Miocene) and Yecua (Late Miocene) formations of the Subandean-Chaco basin, Bolivia, and their tectonic significance. Docum Lab Géol Lyon 125:291-301

Martini AMZ, Fiaschi P, Amorim AM, Paixão JM (2007) A hot-point within a hot-spot: a high diversity site in Brazil's Atlantic Forest. Biodivers Conserv 16:3111-3128

Martins FM, Templeton AR, Pavan ACO, Kohlbach BC, Morgante JS (2009) Phylogeography of the common vampire bat (Desmodus rotundus): marked population structure, Neotropical Pleistocene vicariance and incongruence between nuclear and mtDNA markers. BMC Evol Biol 9:294

Miller MJ, Bermingham E, Klicka J, Escalante P, Amaral FSR, Weir JT, Winker K (2008) Out of Amazonia again and again: episodic crossing of the Andes promotes diversification in a lowland forest flycatcher. Proc R Soc Lond B 275:1133-1142

Miller MA, Pfeiffer W, Schwartz T (2010) Creating the CIPRES science gateway for inference of large phylogenetic trees. In: Proc Gateway Computing Environments Workshop (GCE), New Orleans, 14 Nov 2010, pp 1-8

Moyle RG, Chesser RT, Brumfield RT, Tello JG, Marchese DJ, Cracraft J (2009) Phylogeny and phylogenetic classification of the antbirds, ovenbirds, woodcreepers, and allies (Aves: Passeriformes: infraorder Furnariides). Cladistics 25:386-405

Nyári ÁS (2007) Phylogeographic patterns, molecular and vocal differentiation, and species limits in Schiffornis turdina (Aves). Mol Phylogenet Evol 44:154-164

Ohlson J, Fjeldså J, Ericson PGP (2008) Tyrant flycatchers coming out in the open: ecological radiation in Tyrannidae (Aves, Passeriformes). Zool Scripta 37:315-335

Oliveira PE, Barreto AMF, Suguio K (1999) Late pleistocene/ holocene climatic and vegetational history of the Brazilian caatinga: the fossil dunes of the middle São Francisco River. Palaeogeogr Palaeoclimatol Palaeoecol 152:319-337

Patton JL, Costa LP (1999) Diversidade, limites geográficos e sistemáticos de marsupiais brasilieros. In: Cáceres NC, Monteiro-Filho ELA (eds) Marsupiais brasileiros. Editora da Universidade Federal do Paraná, Curitiba, pp 63-81

Patton JL, da Silva MN, Lara MC, Mustrangi MA (1997) Diversity, differentiation, and the historical biogeography of nonvolant small mammals of the neotropical forests. Tropical forest remnants. University of Chicago Press, Chicago 
Paxton CGM, Crampton WGR (1996) Miocene deposits in the Amazonian foreland basin. Science 273:123

Pellegrino KMC, Rodrigues MT, Harris DJ, Yonenaga-Yassuda Y, Sites JS Jr (2011) Molecular phylogeny, biogeography and insights into the origin of parthenogenesis in the Neotropical genus Leposoma (Squamata: Gymnophthalmidae): ancient links between the Atlantic Forest and Amazonia. Mol Phylogenet Evol 61:446-459

Percequillo AR, Weksler M, Costa LP (2011) A new genus and species of rodent from the Brazilian Atlantic Forest (Rodentia: Cricetidae: Sigmodontinae: Oryzomyini), with comments on oryzomyine biogeography. Zool J Linn Soc 161:357-390

Por FD (1992) Sooretama: the Atlantic rain forest of Brazil. SPB Academic, The Hague

Rahbek C, Graves GR (2001) Multiscale assessment of patterns of avian species richness. Proc Natl Acad Sci USA 98:4534-4539

Räsänen ME, Linna AM, Santos JCR, Negri FR (1995) Late Miocene tidal deposits in the Amazonian foreland basin. Science 269:386-390

Ridgely R, Tudor G (1994) The birds of South America, volume II: the suboscine passerines. University of Texas Press, Austin. http:// books.google.com.br/books?id=FPrCwEeHGkIC\&printsec $=$ frontcover\&dq=ridgely + and +tudor+1994\&hl=pt-BR\&sa=X\&ei $=$ IT_WT9_JMqaQ0QHUxK2SAw\&ved=0CDMQ6AEwAA\#v=one page \&q=ridgely $\% 20$ and $\% 20$ tudor $\% 201994 \& \mathrm{f}=$ false

Roddaz M, Brusset S, Boby P, Hérail G (2006) Miocene tidalinfluenced sedimentation in the forebulge-backbulge depozones of the Beni-Mamore foreland basin (northern Bolivia). J South Am Earth Sci 20:351-368

Roncal J, Blach-Overgaard A, Borchsenius F, Balslev H, Svenning J-C (2011) A dated phylogeny complements macroecological analysis to explain the diversity patterns in Geonoma (Arecaceae). Biotropica 43:324-334

Rull V (2008) Speciation timing and neotropical biodiversity: the Tertiary-Quaternary debate in the light of molecular phylogenetic evidence. Mol Ecol 17:2722-2729

Silva JMC (1994) Can avian distribution patterns in northern Argentina be related to gallery-forest expansion-retraction caused by the quaternary climatic changes? Auk 111:495-499

Silva JMC (1996) Distribution of Amazonian and Atlantic birds in gallery forests of the Cerrado region, South America. Ornit Neotrop 7:1-18

Smith BT, Klicka J (2010) The profound influence of the late Pliocene Panamanian uplift on the exchange, diversification, and distribution of New World birds. Ecography 33:333-342

Stamatakis A, Hoover P, Rougemont J (2008) A rapid bootstrap algorithm for the RAxML web-servers. Syst Biol 75:758-771

Tamura K, Peterson D, Peterson N, Stecher G, Nei M, Kumar S (2011) MEGA5: molecular evolutionary genetics analysis using likelihood, distance, and parsimony methods. Mol Biol Evol 28:2731-2739

Tello JG, Moyle RG, Marchese DJ, Cracraft J (2009) Phylogeny and phylogenetic classification of the tyrant flycatchers, cotingas, manakins, and their allies (Aves: Tyrannides). Cladistics 25:429-467

Tolley KA, Tilbury CR, Measey GJ, Menegon M, Branch WR, Matthee CA (2011) Ancient forest fragmentation or recent radiation? Testing refugial speciation models in chameleons within an African biodiversity hotspot. J Biogeogr 38:1748-1760

Tuomisto H (2007) Interpreting the biogeography of South America. J Biogeogr 34:1294-1295

Vilela RV, Machado T, Ventura K, Fagundes V, Silva MJDJ, Yonenaga-Yassuda Y (2009) The taxonomic status of the endangered thin-spined porcupine, Chaetomys subspinosus (Olfers, 1818), based on molecular and karyologic data. BMC Evol Biol 9:29

Vivo M (1997) Mammalian evidence of historical ecological change in the Caatinga semiarid vegetation of northeastern Brazil. J Comp Biol 2:65-73

Wang XF, Auler AS, Edwards RL, Cheng H, Cristalli PS, Smart PL, Richards DA, Shen CC (2004) Wet periods in northeastern Brazil over the past $210 \mathrm{kyr}$ linked to distant climate anomalies. Nature 432:740-743

Weir JT, Price M (2011) Andean uplift promotes lowland speciation through vicariance and dispersal in Dendrocincla woodcreepers. Mol Ecol 20:4550-4563

Weir JT, Bermingham E, Schluter D (2009) The Great American biotic interchange in birds. Proc Natl Acad Sci USA 106:21737-21742

Wesselingh FP, Salo JA (2006) Miocene perspective on the evolution of the Amazonian biota. Scripta Geol 133:439-458

Wesselingh FP, Kaandorp RJG, Vonhof HB, Räsänen ME, Renema W, Gingras M (2006) The nature of aquatic landscapes in the Miocene of western Amazonia: an integrated palaeontological and geochemical approach. Scripta Geol 133:363-393

Wiens JJ, Donoghue MJ (2004) Historical biogeography, ecology and species richness. Trends Ecol Evol 19:639-644

Williams PH (1998) Key sites for conservation: area-selection methods for biodiversity. In: Mace GM, Balmford A, Ginsberg JR (eds) Conservation in a changing world. Cambridge University Press, Cambridge, pp 211-249

Williams PH, Gaston KJ (1998) Biodiversity indicators: graphical techniques, smoothing and searching for what makes relationships work. Ecography 21:551-560

Willis EO (1992) Zoogeographical origins of eastern Brazilian birds. Ornit Netrop 3:1-15

Nylander JAA (2004) MrModeltest 2.2 (program distributed by the author). Evolutionary Biology Centre, Uppsala University, Uppsala 
Discussão geral e conclusões 
Nesta Tese foram descritos padrões de diversificação de pássaros que ocorrem na Amazônia (AM) e na Mata Atlântica (MA), os quais permitiram fazer inferências sobre os processos que tiveram papel na evolução das biotas residentes nestes biomas. Nos capítulos de 1 a 4 foi inferida a diversificação dentro da MA, adicionalmente, no capítulo 3 foi abordada sua relação com as florestas Andinas associada ao padrão de distribuição Circum-Amazônico. No capítulo 5 foi estudada a diversificação da $A M$, bem como sua relação com o norte da MA. No capítulo 6 foi analisada a dinâmica das conexões históricas entre AM e MA.

\section{Diversificação na Mata Atlântica}

Os padrões filogeográficos de Basileuterus leucoblepharus, Myrmotherula gularis e do complexo Synallaxis ruficapilla revelaram facetas interessantes da evolução da MA. B. leucoblepharus revelou um padrão de ausência de forte estrutura genética ao longo do sudeste da MA que é incongruente com de outros organismos do bioma, onde foram observadas descontinuidades filogeográficas nesta região. Além disso, B. leucoblepharus inesperadamente mostrou estabilidade populacional ao longo do último máximo glacial (UMG), o que é incongruente com o modelo paleogeográfico para o UMG na MA. A sistemática molecular do complexo S. ruficapilla mostrou que o mesmo não é reciprocamente monofilético, com duas linhagens independentes dando origem às espécies Atlânticas deste grupo. Os dados deste estudo também apontam para uma dinâmica de contatos históricos entre as florestas Atlântica e Andina de táxons com distribuição CircumAmazônica. Os estudos de M. gularis e do complexo S. ruficapilla revelaram estrutura filogeográfica ao longo da região centro-sul da MA. M. gularis mostrou uma descontinuidade filogeográfica localizada entre os rios Doce e Jequitinhonha datada no fim do Pleistoceno. Já no complexo S. ruficapilla foram detectadas quebras filogeográficas profundas no vale do Rio Jequitinhonha que deram origem a três filogrupos que se divergiram durante o Pleistoceno. Ainda no complexo S. ruficapilla foi observada uma extensa zona de contato secundário entre as três linhagens ao longo do no vale do Rio Jequitinhonha. Também no complexo S. ruficapilla foi detectada uma quebra filogeográfica fraca no norte do Paraná. No entanto estes padrões observados nestes táxons não foram totalmente 
concordantes com estudo prévios (veja respectivos capítulos). O papel dos rios como barreira primária aos eventos vicariantes observados foi rejeitado para MA nesta Tese. As análises mostraram que a hipótese dos refúgios florestais teve grande importância na diversificação das espécies estudadas, e isto corrobora outros estudos com organismos endêmicos da MA. Além disso, foi mostrado que atividades tectônicas ocorridas no Quaternário possivelmente atuaram na diversificação do complexo S. ruficapilla.

Os resultados desta Tese mostraram que embora alguns organismos compartilhem uma história em comum, não existe um único padrão ou processo capaz de explicar a diversificação dentro da MA. Esta gama de padrões de diversificação dentro da MA possivelmente está relacionada às dependências ecológicas e requerimento de habitats inerentes às idiossincrasias de cada organismo. Assim a presença de barreiras históricas ao fluxo não influenciaram igualmente a todos os organismos, pois aqueles com ecologias mais generalistas teriam maior capacidade de manter fluxo gênico através destas barreiras e consequentemente não sofreriam o efeito histórico das mesmas. Deste modo, é possível predizer que diferentes processos históricos ocorreram ao longo da história evolutiva da MA, e os organismos residentes nela reponderam a estes eventos de forma heterogênea conforme suas dependências ecológicas. Portanto, com o estudo filogeográfico de mais organismos outros padrões ainda não detectados devem ser revelados, desta forma reiterando a hipótese de que a diversificação dentro da MA não pode ser explicada por uma única hipótese. Futuros estudos que correlacionem o componente climático do nicho destas espécies com os padrões filogeográficos observados poderão ajudar a compreender o porquê destas congruências e incongruências de padrões.

\section{Diversificação na Amazônia}

O estudo filogeográfico do complexo Thamnomanes caesius/T. schistogynus mostrou que tanto a origem recente dos rios (do Plioceno ao Pleistoceno) Amazônicos quanto os ciclos glaciais possivelmente foram responsáveis pela diversificação que deu origem aos filogrupos observados, não permitindo assim excluir uma das duas hipóteses. Foram observados 12 clados, dos quais 10 
correspondem aos interflúvios delimitados pelos principais rios da bacia Amazônica. Os outros 2 clados correspondem à MA e ao norte dos Tepuis. As datações das divergências dos mesmos concordam com a origem recente dos rios Amazônicos e com ciclos glaciais do fim do Pleistoceno. No entanto, este estudo discorda da hipótese de origem antiga da biota da $\mathrm{AM}$, onde o soerguimento dos Andes durante o Neogeno em conjunto com incursões marinhas teriam sido responsáveis pelo estabelecimento da drenagem atual da bacia Amazônica, e consequentemente desencadeado a diversificação da biota residente no bioma.

Entretanto, análises recentes mostraram que o cenário mais plausível seria de uma diversificação constante desde o Neogeno até o Pleistoceno, e certamente ainda ocorre hoje. No caso do estudo do complexo T. caesius/T. schistogynus somente os últimos 3 milhões de anos deste processo evolutivo foram investigados, ao passo que outros grupos se diversificaram em épocas mais pretéritas.

\section{Contatos históricos entre a Amazônia e a Mata Atlântica}

Os resultados desta Tese mostraram uma perspectiva interessante sobre a dinâmica espaço-temporal das conexões históricas entre AM e MA. O fato de que padrões biogeográficos similares refletem uma história em comum nem sempre é uma regra geral, ao passo que esta concordância de padrões em alguns casos pode se tratar de uma pseudo-congruência, ou seja, padrões similares podem ter sido originados por processos distintos. No capítulo 6 desta Tese foi testado isto para a hipótese de contatos históricos entre pássaros do grupo Suboscines que ocorrem de maneira disjunta entre AM e MA. Os resultados mostraram que os contatos históricos entre estes dois biomas compreendem duas conexões espaço-temporais distintas: 1) uma mais antiga durante o Mioceno através da porção sul do Cerrado pelo Mato Grosso, e na transição do Chaco e da savana de palmeiras no Paraguai e Bolívia possivelmente associada com eventos tectônicos; 2) a outra seria mais recente durante o Plioceno e o Pleistoceno através da Caatinga e Cerrado no Nordeste do Brasil e estaria associada com as mudanças climáticas neste período que promoveram expansões das florestas de galeria para dentro da diagonal seca da América do Sul. Ainda, este cenário de conexões recentes está de acordo com os resultados do capítulo 5 desta tese, onde o clado da MA em T. caesius/T. 
schistogynus se originou de uma separação no fim do Pleistoceno do clado do interflúvio mais a leste da bacia Amazônica.

\section{Conclusões}

Os dados desta Tese permitiram testar o papel de algumas hipóteses concorrentes na diversificação da $\mathrm{AM}$ e MA. A hipótese dos rios parece ter contribuído significativamente para a diversificação da AM ocorrida durante o Plioceno e Pleistoceno, no entanto ela não se aplica na diversificação da MA, uma vez que os estudos filogeográficos desta Tese rejeitaram sua influência neste bioma. A hipótese dos refúgios florestais possivelmente teve um papel crucial da diversificação da biota da MA, embora em um dos estudos desta Tese tenha sido observada estabilidade demográfica ao longo do UMG. A hipótese dos refúgios também não pode ser rejeitada como um das forças que deu origem à biota que observamos atualmente. Na MA também foi observada uma possível influência de atividades neotectônicas na origem de algumas linhagens. Ainda, as mudanças climáticas ocorridas no Plio-Pleistoceno e as atividades tectônicas durante o Mioceno proporcionaram eventos de contatos entre a AM e MA.

De certa forma a origem da biodiversidade neotropical é produto de uma evolução bastante complexa, e assumir que esta diversificação foi originada por um ou poucos processos evolutivos é simplista demais. O que parece ter acontecido nas florestas Amazônica e Atlântica foi um processo de diversificação contínuo ao longo do tempo, e extremamente complexo com diversas forças atuantes. Porém é factível de se observar nos pássaros estudados nesta Tese dominância de alguns processos evolutivos na AM do que na MA, e vice-versa.

Os avanços nos campos da filogenética e filogeografia nos últimos anos vêm trazendo novas perspectivas sobre como os biólogos evolutivos podem olhar para o passado. Além disso, cada vez mais os filogeógrafos e filogeneticistas têm procurado associar seus resultados a dados geológicos e paleoambientais com o intuito de tornar suas discussões mais realistas. O recente surgimento da nova geração de sequenciamento de DNA é um campo extremante promissor nestas áreas, porém o modo pelo qual os dados são extraídos e analisados nas técnicas de next generation sequencing ainda está em sua "infância" e muito pouco prático para 
estes estudos. Contudo nos próximos anos estes métodos estarão completamente acessíveis e permitirão testar as hipóteses levantadas nesta Tese e em outros estudos. 